\title{
THE ADDED
}

VALUE OF EHEALTH $\mathbb{N}$

\section{TREATMENT OF OFFENDERS}

Improving the development, implementation and evaluation of technology in forensic mental healthcare
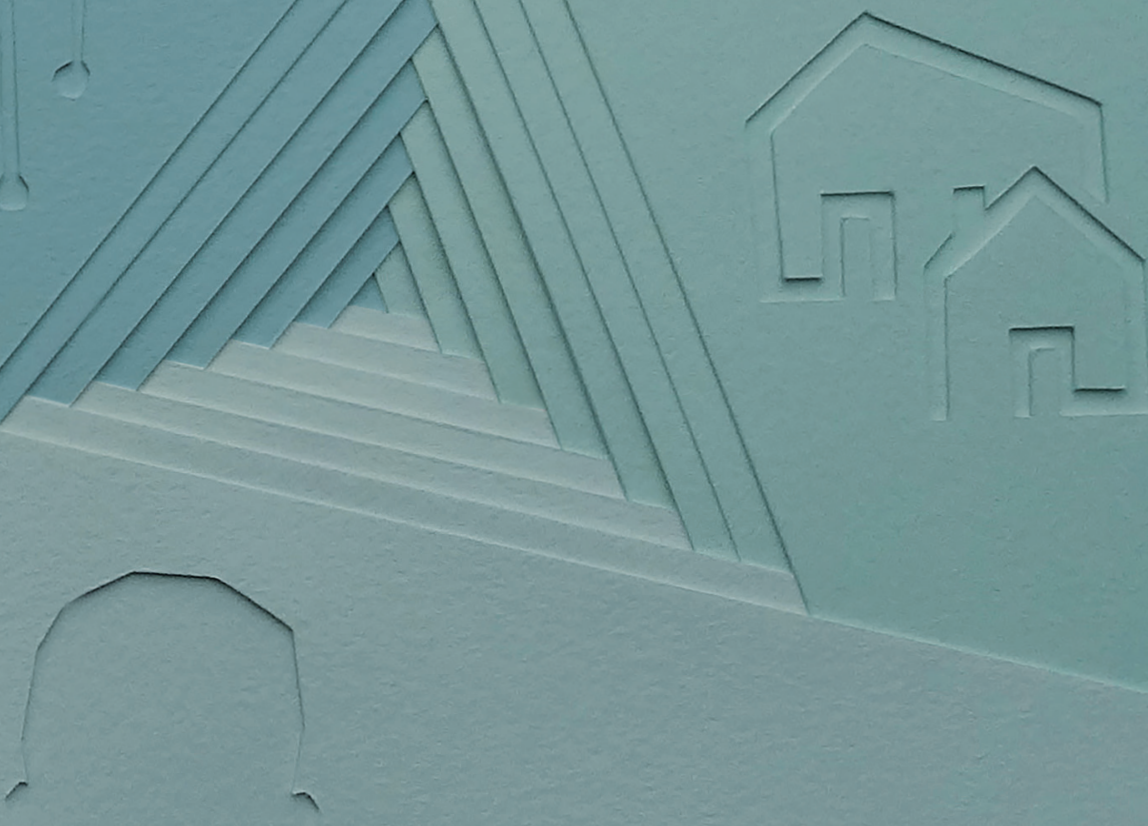


\section{THE ADDED VALUE OF EHEALTH}

IMPROVING THE DEVELOPMENT, IMPLEMENTATION AND

EVALUATION OF TECHNOLOGY IN TREATMENT OF OFFENDERS

Hanneke Kip 



\title{
THE ADDED VALUE OF EHEALTH
}

\section{IMPROVING THE DEVELOPMENT, IMPLEMENTATION AND EVALUATION OF TECHNOLOGY IN TREATMENT OF OFFENDERS}

\section{DISSERTATION}

\author{
to obtain \\ the degree of doctor at the University of Twente, \\ on the authority of the rector magnificus, \\ prof. dr. ir. A. Veldkamp, \\ on account of the decision of the Doctorate Board \\ to be publicly defended \\ on Friday 26 March 2021 at 14.45 hours
}

by

\section{Hanneke Kip}

born on the 29th of March, 1990

in Winterswijk, The Netherlands 
This dissertation has been approved by:

Supervisor

prof. dr. J.E.W.C. van Gemert - Pijnen

Co-supervisors

dr. S.M. Kelders

dr. Y.H.A. Bouman

Cover design: Esther Scheide, www.proefschriftomslag.nl Printed by: Gildeprint - The Netherlands

ISBN: 978-90-365-5131-1

DOI: $\quad 10.3990 / 1.9789036551311$

(C) 2021 Hanneke Kip, The Netherlands. All rights reserved. No parts of this thesis may be reproduced, stored in a retrieval system or transmitted in any form or by any means without permission of the author. 


\section{Graduation Committee:}

Chair / secretary: prof. dr. T.A.J. Toonen

University of Twente

Supervisor:

prof. dr. J.E.W.C. van Gemert - Pijnen

University of Twente

Co-supervisors:

dr. S.M. Kelders

University of Twente

dr. Y.H.A. Bouman

Transfore

Committee

prof. dr. ir. G.D.S. Ludden

Members:

University of Twente

prof. dr. W. Veling

University Medical Centre Groningen

prof. dr. F.F. Sniehotta

University of Twente; NIHR Policy Research

Unit Behavioural Science

prof. dr. D.C. Mohr

Northwestern University

prof. dr. S. Bogaerts

Tilburg University; Fivoor 



\section{Table of contents}

Chapter 1

Part 1

Chapter 2

Chapter 3

Part 2

Chapter 4

Chapter 5

Chapter 6

Intermezzo

Part 3

Chapter 7

Chapter 8

Samenvatting (Summary in Dutch)

Publications and other output

Dankwoord
General introduction

The current state of affairs of eHealth in forensic mental healthcare

eHealth in treatment of offenders in forensic

mental health: A review of the current state

Integrating people, context, and technology in

the implementation of a web-based

intervention in forensic mental health care:

Mixed-methods study

\section{The added value of virtual reality}

Identifying the added value of virtual reality for

treatment in forensic mental health: A scenario-based, qualitative approach

Putting the value in VR. How to systematically and iteratively develop a value-based VR application with a complex target group

The importance of systematically reporting and reflecting on eHealth development: Participatory development process of a virtual reality application for forensic mental health

VR application 'Triggers \& Helpers'

Novel methods to evaluate eHealth

Can self-control training (SCT) increase selfcontrol and decrease aggression? Two evaluation studies to optimize a SCT app

General discussion 



\section{Chapter 1}

\section{General introduction}

Partially based on:

Kip, H., \& van Gemert-Pijnen, J.E.W.C (2018). Holistic development of eHealth technology. In: eHealth Research, Theory and Development: A Multi-Disciplinary Approach

(pp. 131-166). Routledge.

Kip, H., Oberschmidt, K., Bierbooms, J., Dijkslag, D., Kelders, S., \& Roelofsen, B. (2019). Technologie in de forensische zorg - Crossing borders. Kwaliteit Forensische Zorg. 
Box 1

\section{Case - Introducing Freddy: a forensic psychiatric patient}

Freddy is a 42-year-old father of three young boys and has been married to Mary for over ten years. Ever since he was a boy, Freddy has had issues with controlling his temper. At 14, he was diagnosed with attention deficit hyperactivity disorder (ADHD) and between the age of 18 and 25 he was addicted to alcohol, which he still often struggles with. He received therapy to deal with his aggression regulation issues multiple times, but he dropped out after several sessions every time, mostly because he didn't like to talk about his feelings. Besides that, he also struggled with the homework assignments he received from his therapists: he only completed secondary education and he is ashamed to admit that he has difficulty with reading and writing. Ever since Freddy became a father, he was able to prevent most of his anger outbursts, but recently, things have been getting worse. Freddy doesn't know why, but he has been lashing out at his wife and children. A while ago it escalated: he hit his wife, was on the verge of hitting his eldest son as well and threatened a neighbour that came to take a look because of the noise. The police had to de-escalate the situation, resulting in a devastated and ashamed Freddy. A judge ordered that Freddy should receive treatment at a forensic psychiatric outpatient clinic to deal with his aggression regulation problems, alcohol abuse and ADHD. However, because of the waiting list, Freddy has been sitting at home for the last couple of weeks, clueless as to what to do next and how to make himself into a better person. 


\section{Forensic mental healthcare}

\subsection{What is forensic mental healthcare?}

In the case above, Freddy is introduced. People like Freddy are treated in forensic mental healthcare, which focuses on people who display aggressive or sexual delinquent behaviour that led or could lead to offending and simultaneously suffer from at least one psychiatric disorder, for example schizophrenia, alcohol abuse, antisocial personality disorder or post-traumatic stress-disorder [1-3]. Due to this combination of offending and psychiatric disorders, forensic mental healthcare - or forensic psychiatry - takes place at the intersect of mental healthcare and the law. Forensic mental healthcare encompasses treatment of both in- and outpatients. Inpatients reside in clinics with different levels of security, ranging from very high levels, where patients are not or almost never allowed to go on leave, to medium or low levels, where patients have more freedom and independence [4]. While relatively many forensic psychiatric patients receive treatment at inpatient clinics, a large share of the patient population comprises outpatients who live at home and receive treatment at an outpatient clinic [5]. Some patients receive treatment voluntarily and not as part of a sentence, for example when a general practitioner refers them to forensic mental healthcare because it fits their aggression regulation problems better than regular mental healthcare. Regardless of the differences between level of security, the main goal of forensic mental healthcare is always to prevent (re)offending and thus to protect society. However, treatment of forensic psychiatric patients is viewed as challenging, which can be partly explained by characteristics of the patient population.

\subsection{Forensic psychiatric patients}

When looking at the forensic psychiatric patient population in general, there are several characteristics that can help to explain why forensic mental healthcare is considered to be a complex branch of care. First, an important barrier is that most forensic psychiatric patients are not that motivated for their often obligatory treatment $[6,7]$. This lack of motivation can result in low engagement with treatment and, if possible, drop-out, which results in lower effectiveness of treatment. Furthermore, many forensic psychiatric patients experience difficulties with reflecting on their own behaviour and emotions. This implies that it is difficult for them to follow therapies and interventions underpinned by the often-used cognitive behavioural model, in which a lot of reflecting is required [8]. An explanation for these problems with reflecting can be found in some characteristics that are fairly common in the 
forensic psychiatric patient population, such as low intelligence, cognitive deficits due to mental disorders or medication, personality traits such as a lack of empathy, or a lack of experience with reflecting on their own behaviour [8-10]. Additionally, the forensic psychiatric patient population is considered to be very complex due to its heterogeneity: there is no 'typical' forensic psychiatric patient due to a large diversity in type of offense, mental disorders, socio-demographic background, and personality types. This diversity - combined with the fact that many forensic psychiatric patients display comorbidity of mental disorders [11] - indicates that treatment has to be tailored to individual patients. Since there is no one-size-fits-all approach, therapists have to look for the most optimal fit between treatment and the individual patient [12]. This makes treatment not only very complicated, but also time-consuming, which is especially problematic considering that the number of forensic psychiatric patients is increasing all over the world $[13,14]$. In order to support treatment, there are several treatment models that focus specifically on treatment of forensic psychiatric patients and thus aim to account for the complex and heterogeneous nature of this population.

\subsection{Forensic treatment models}

Forensic mental healthcare aims to provide patients with skills that can support them in successfully participating in society and prevent them from reoffending during and after treatment. To achieve this, different types of treatment models that focus specifically on treatment of offenders are used, of which the most predominant and influential ones are considered to be the Risk-Need-Responsivity (RNR) model and, more recently, the Good Lives Model $[15,16]$. The RNR model is the most well-known model and provides the foundation for assessment and treatment of offenders, based on the risk they present to society and what their needs are. It is based on three principles: risk, need and responsivity. First, according to the risk principle of this model, offenders that have a high risk of reoffending should receive more intense levels of treatment in order to reduce the risk of reoffending. Second, the need principle focuses on criminogenic needs, also known as risk factors. Research has shown that there are static risk factors such as prior offenses or job history, and dynamic risk factors, like antisocial attitudes, substance abuse, financial problems and antisocial associates $[17,18]$. These dynamic risk factors can be changed, which influences the chance on reoffending. Each forensic psychiatric patient has their own unique set of dynamic risk factors, which should be identified by means of risk assessment instruments. In these risk assessment instruments, therapist and patient 
discuss questions about evidence-based static and dynamic risk factors, after which the therapist fills out the instrument, resulting in an overview of risk factors that are relevant for that specific patient [19]. Interventions should focus on the dynamic factors in order to optimally target the criminogenic needs of individual patients [18]. A distinction can be made between stable and acute dynamic risk factors [20]. Stable dynamic risk factors are often incorporated in risk assessment instruments, while acute dynamic risk factors can rapidly change are harder to assess and thus to treat, mostly due to their temporal and contextual nature. Acute dynamic risk factors are often only relevant for short periods of time and in specific situations, for example the access an offender has to a potential victim, or a fit of rage, which makes it hard to identify and improve them [21,22]. Finally, the responsivity principle of the RNR model prescribes that interventions need to be evidence-based and that they should fit the attributes of the individual offender, such as motivation or cognitive abilities.

Research has shown that treatment conforming to the RNR principles is fairly effective in reducing reoffending. For example, a meta-analysis on RNR-guided treatment of sex offenders resulted in recidivism rates of $10.1 \%$, whereas $13.7 \%$ of untreated offenders recommitted a crime, but indicated that there was too much heterogeneity between study outcomes to draw robust conclusions [23]. These effect sizes are comparable to other studies on treatment based on RNR-principles [24, 25]. It can be concluded that while treatment guided by RNR principles is effective, there is room for improvement $[12,26]$. Amongst other things, recidivism rates in patients who receive treatment focused on risk-reduction are often very high [27]. A possible explanation for this is that the RNR model is mostly focused on deficits such as poor emotion regulation or problem solving skills, and this negative, avoidant focus is considered to be unmotivating for forensic psychiatric patients [28-30].

In order to overcome the issue of unmotivated and unengaged patients, the Good Lives Model (GLM) has been developed [16]. While this model also underlines the importance of managing risk factors, it claims that only focusing on risk factors is not enough to optimally treat offenders. The GLM emphasizes the importance of focusing on the offenders' strengths by supporting them in finding other ways than crime to reach primary life goals, also called 'primary goods'. These primary goods are related to, amongst other things, work, inner peace and community. Because of this strength-based approach, in which attention is not only paid to risk factors, but also to offenders' interests, abilities and aspirations, this model is in line with principles from positive psychology [31]. While response from clinical practice has been positive and there is some evidence that approach-goals lead to more engagement $[32,33]$, it 
is not yet clear whether the GLM actually results in decreased recidivism rates. Additionally, there is some debate about the added value of GLM compared to RNR and the extent to which they are mutually exclusive: some literature suggests that the models can complement each other. Those areas where RNR lacks specificity, for example a focus on positive, approach-oriented goals, can be enriched by the GLM model $[34,35]$. Overall, while the GLM offers a more positive approach towards treatment of offenders, there are many similarities with the RNR model. However, there are multiple points of improvements for treatment guided by either model.

\subsection{Points of improvement for current treatment of forensic psychiatric patients}

Models such as the RNR and GLM serve as broad "templates" which need to be filled in by means of specific interventions. In forensic mental healthcare, behavioural or cognitive-behavioural interventions are often used to target thoughts, feelings, and behaviours associated with crime, such as antisocial attitudes, impulse control problems and emotion regulation strategies [12, 24, 36]. A recent meta-analysis on the efficacy of different types of psychological treatment in violent offenders showed that treatment significantly reduced violent recidivism by $10.2 \%$, which means that $50 \%$ of offenders who did not receive treatment would reoffend, as opposed to $38.8 \%$ of offenders who received psychological treatment [24]. Furthermore, although it has been helpful in reducing aggression - for which it is often used in forensic mental health [24], cognitive behavioural therapy appears to be more effective for treatment of specific disorders such as anxiety or depression [37, 38]. All of this shows that psychological treatment is effective, but that there is room for improvement to ensure that recidivism is further decreased. Another type of treatment used in forensic mental healthcare is vocational therapy, such as job training, social skill training, art therapy, or psychomotor therapy [39,40]. While multiple types of advantages of these more creative and functional therapies are experienced in practice, such as a focus on doing instead of talking, there is hardly any evidence for their impact on recidivism rates [40].

Because psychological and vocational therapies mostly take place inside treatment rooms or secured inpatient clinics, it is difficult to target undesired behaviour in a realistic context $[39,40]$. Often, therapists are dependent on the quality, clarity and validity of the answers of the patient to questions about their behaviour outside treatment, but these answers are often influenced by memory or social desirability biases $[39,41]$. Also, patients might not be completely honest about 
undesired behaviour during their leave from a clinic or daily lives, since they might fear repercussions. This illustrates a challenging paradox in treatment of forensic psychiatric patients. While borderline delinquent or risky behaviour - such as drinking too much by patients with aggression regulation problems or paedophiliacs being in the proximity of children - is often punished in order to protect society, these are exactly the situations in which a patient can learn more about their triggers or apply newly learned skills. Consequently, in order to ensure the transfer of skills that are acquired in treatment, patients should be able to apply them in risky situations. Because those are often avoided to decrease risk, there is no room for a patient to learn from their mistakes. It can be concluded that despite the fact that treatment of offenders does result in less recidivism than not receiving any treatment [5, 24, 42], there is opportunity for improvement in the current intervention base and predominant treatment approaches. An approach that seems to be especially promising in addressing these points of improvement can be found in technology: eHealth interventions have the potential to further increase the quality of forensic mental healthcare.

\section{The potential of technology for forensic mental healthcare}

eHealth refers to technology, mostly information and communication technologies, to support health, wellbeing and healthcare [43]. eHealth technologies can be used as a way to increase the effectiveness or efficiency of existing treatment, but they can also serve as entirely new types of interventions for healthcare. Even though technology is central in eHealth, it is much more than a technical development. According to the much-used definition of Eysenbach, "eHealth characterizes not only a technical development, but also a state-of-mind, a way of thinking, an attitude, and a commitment for networked, global thinking, to improve healthcare locally, regionally and worldwide" [44]. This implies that eHealth interventions should not be seen as a tool or a separate addition to healthcare: they can change the way healthcare is delivered and organized, and requires and causes changes in the role of healthcare professionals and patients. In mental healthcare, eHealth is often used in a blended way. Blended care refers to the combination of 'offline', in-person treatment with 'online' technologies [45]. By integrating offline and online care, it is possible to have the best of both worlds: offering treatment independent of place and time to increase a patients' sense of ownership for their treatment, while maintaining the advantages of a strong therapeutic alliance of in-person treatment [46-48]. In order to unravel why and how eHealth, especially in a blended form, can improve 
forensic mental healthcare, it is important to discuss two important and interrelated concepts: technology and psychology.

\section{1 eHealth, technology and psychology}

eHealth and technology are inseparable, since the first is not possible without the second. While the first eHealth interventions were mostly websites with plain text, there currently are many different types of technologies that can be used to support behaviour change and improve healthcare. When looking at eMental health, which specifically focuses on the use of technology to prevent and treat mental disorders [49], different types of goals and accompanying technologies can be identified [41].

First, technology can be used to facilitate communication between patients and therapists who do not reside at the same location. Communication can be either synchronously via for example videoconferencing, or a-synchronously via for example e-mail. If implemented well, the use of these types of technologies might save time and costs [50]. Second, technologies such as websites or mobile apps can be used to offer (parts of) treatment to a patient, enabling them to work independently on for example psycho-education or assignments from cognitive behavioural therapy. These types of interventions have the potential to not only facilitate ownership and empowerment in patients, but can also result in a decrease in therapists' time investment, while maintaining outcomes that are comparable to face-to-face treatment $[49,51,52]$. While randomized controlled trials (RCTs) have consistently demonstrated the effectiveness of web-based interventions, especially when combined with low-intensity support, much remains unclear about whether these results hold up in practice - outside of experimental settings [53]. Third, technology can be used to continuously collect unique information from patients that cannot be retrieved by a therapist and/or in a regular treatment setting. Examples are wearables that continuously collect data on physiological signals such as heartrate variability or skin conductance to get a better understanding of stress throughout the day, or neurofeedback to gain insight into the neurological responses to relaxation exercises $[54,55]$. These data can be used to optimally tailor face-to-face treatment to an individual patient, but can also enable just-in-time coaching by means of technology. To illustrate, smartphones or smartwatches can send tips to decrease arousal to patients when physiological values exceed a predetermined threshold [56, 57]. However, not much is known yet about how these types of interventions should be designed and implemented. Fourth, immersive technologies such as virtual reality (VR) can transport a patient to a digital yet realistic environment. Because of the sense 
of presence in these virtual environments, patients can be exposed to difficult situations or stimuli in a realistic way - for example drugs in case of addiction or high buildings in case of fear of heights - in order to effectively decrease negative emotional responses [58]. Patients can also practice with behaviour such as emotion regulation exercises or social skills in a realistic, virtual environment $[59,60]$. A metaanalysis on VR in psychological interventions found an overall moderate effect size for VR interventions with an active control group, and an overall large effect size of VR compared to waiting list control groups that didn't receive an intervention, highlighting the large potential of VR for mental healthcare [58]. Fifth, technology can be placed in a specific environment to account for the contextual aspects of behaviour. Examples are robots to support patients in remembering their daily routines, or domotics to create calming environments by means of light and sound [61]. In the case in Box 2, a (very) fictional example is provided to illustrate the potential of these types of eHealth interventions. However, at this point in time, not much is known yet about the usefulness of these types of technologies for clinical practice since most data are collected in experimental settings. While all the aforementioned technologies are accompanied by multiple potential and observed advantages, they are not used much in forensic mental healthcare, and not much is known about their effectiveness and efficiency in this specific branch of healthcare.

While technology is a necessary precondition for eHealth interventions, they encompass more than only technology: psychology plays an important role as well. eHealth targets behaviours or attitudes related to health, wellbeing or healthcare, which underlines the interrelationship between psychology, technology and eHealth. When aiming to do this, using a well-functioning technology does not suffice: theories and models from psychology can be integrated within technology to increase the chances on behaviour change $[62,63]$. One possible way to achieve this is by adding elements from the Persuasive System Design (PSD) model to an eHealth technology, such as rewards, reminders or personalization. These types of elements can support users in using a technology in the intended way, which increases adherence, and can also facilitate a change in health-related attitudes and behaviours $[64,65]$. In line with this, approaches such as gamification - in which elements from game-design are added to an eHealth intervention - can be used to increase engagement with a technology, which might in turn positively impact its effectiveness [66, 67]. Additionally, theory-based behaviour change techniques (BCTs) such as goal setting, fear appeal and social comparison can be incorporated in the design of a technology to increase the chance on behaviour change [68]. These BCTs are derived from 
behaviour change theories and influence or create changes in predictors of behaviour, which in turn also influences the (un)desired behaviour itself. Furthermore, domain-specific theories, models and frameworks can also be used to get insight into the undesired behaviour and can be used to facilitate the integration of eHealth interventions in existing treatment models. A general example is the use of cognitive behavioural therapy in web-based interventions. While the relevance of incorporating theory in eHealth design seems to be clear, there often is no good fit between psychology and technology, highlighting the importance of an interdisciplinary approach towards eHealth. In general, more insight is required into how to integrate behaviour change theory within eHealth, and how to embed eHealth interventions within domain-specific theoretical frameworks. 


\section{Box 2}

\section{Case - Supporting Freddy with eHealth interventions?}

After waiting to start treatment for a few weeks, a therapist reached out to Freddy and offered him the possibility to work on a web-based module on treatment in forensic mental healthcare which contained written explanations, videos and assignments. When working on this module, Freddy got to know more about what to expect from his treatment. By means of short assignments he also started thinking about what went wrong and what he wanted to improve in himself. While Freddy did not fully understand the entire module because of his struggles with reading and writing, he was still able to put some things on paper and gained several new insights. Because of this, his first appointment with his therapist went very well: they could get to the point very quickly and were on the same page regarding their expectations of treatment. After several meetings during which they talked about how to control Freddy's aggressive impulses during conflict situations, they decided to put his new skills to the test in virtual reality. By re-enacting situations during which Freddy became aggressive, they figured out that he was especially triggered by the feeling that his partner and children look down on him. In virtual environments, they started practicing with alternative behaviour and relaxation exercises when such a situation occurred. However, despite Freddy's best efforts, there were still multiple incidents at home. 


\section{Box 2 - Continued}

To gain more insight into the causes of Freddy's outbursts, the therapist gave him a mobile app which was connected to a smartwatch that monitored his heartrate variability, skin conductance, physical activity and sleep. When Freddy's heartrate rose, he was asked what was going on at that point in time and, if he indicated that he experienced negative emotions, what possible causes might be. Freddy and his therapist analysed the data that were collected and concluded that most incidents at home occurred on days when he slept less than 7 hours, had some drinks and felt generally tired and overwhelmed. Based on these new insights, Freddy practiced again in VR. He learned that it was best to walk away from difficult situations when he was feeling tired, while when he was feeling better, it was better to directly explain what was bothering him. By means of another online module, Freddy was able to learn about other types of coping strategies and after a while he was able to select the most effective strategy for different types of difficult situations. Soon, it wasn't necessary anymore for Freddy and this therapist to meet, but they still sporadically have contact via e-mail. Also, if Freddy really feels lost, they sometimes have short consults via video-conferencing and the therapist recommends some modules or useful apps that Freddy might use to better manage his anger. Ever since his final in-person appointment with his therapist, Freddy hasn't been in contact with the police and, while he does sometimes still get angry, he hasn't lashed out against his family anymore. 


\section{2 eHealth and forensic mental healthcare}

As described in the fictional case on Freddy, eHealth can offer a broad range of benefits and improve forensic mental healthcare. However, in practice, there is a major gap between the expected potential of eHealth and the actual situation [41, 69]. When looking at the use of eHealth within forensic mental healthcare, one of the main issues is that eHealth interventions are often not used at all, and if they are used, their uptake isn't as high as would be desirable [41]. While implementation is considered to be essential for the success of any eHealth intervention [70], it has not received much attention within forensic mental healthcare [41, 69]. Additionally, there is a lack of knowledge about the possibilities of different types of eHealth for forensic mental healthcare. While, as described in the previous paragraph, there are many different technologies that can be used, web-based modules and videoconferencing are the most pre-dominant interventions [41]. Furthermore, not much is known about how to combine theories on aggressive and sexual criminal behaviour with eHealth interventions. For example, it is not clear how eHealth interventions can be embedded within the previously described RNR model, or how they can be of added value for the GLM. Another example is the $\mathrm{I}^{3}$ theory, which aims to explain and predict aggressive behaviour by mapping and influencing instigating triggers (for example a fight with one's partner), impelling forces (for example being intoxicated) and inhibiting forces (for example self-control) [71, 72]. While it might be a valuable theory to inspire the content of interventions on aggression regulation, not much is known yet about how this could be done. Finally, while there is evidence for the effectiveness and added value of some types of eHealth, such as VR and web-based interventions $[51,52,58]$, these findings cannot simply be generalized to forensic mental healthcare due to its unique and complex nature. Consequently, there is a need for more knowledge about the added value of eHealth in treatment of offenders [41].

In order to bridge the gap between the potential and current situation regarding eHealth in forensic mental healthcare, in which there is much unchartered territory, more attention needs to be paid to their development, implementation and evaluation. When looking at development, there is a need for thorough development processes that account for the needs and wishes of the patients and therapists and the characteristics of treatment. This should result in eHealth interventions that seamlessly fit these needs and can be fully embedded in forensic mental healthcare. However, not much is known about how to shape such a development process within complex settings such as forensic mental healthcare, and how to include challenging 
patient populations such as forensic psychiatric patients. Furthermore, because implementation of eHealth interventions in forensic mental healthcare has not received much attention, there is a need for more information about how to approach this from multiple perspectives and on different levels, accounting for the patients, therapists, organizations and the technology. Finally, more insight into effectiveness of eHealth interventions is required, which is accompanied by a need for suitable and robust methods and evaluation approaches that do justice to the complex nature of eHealth in forensic mental healthcare.

\section{3. eHealth development, implementation and evaluation}

Ideally, the development, implementation and evaluation process of eHealth are guided by models and frameworks [73]. These types of models can support interdisciplinary teams in accounting for all relevant aspects of development, implementation and evaluation. There are multiple approaches that can be used for eHealth. A first example is the CeHRes Roadmap (the Centre for eHealth Research Roadmap); an interdisciplinary framework to plan, coordinate and execute the holistic and iterative research and development processes of eHealth [74]. Another model that focuses on digital behaviour change interventions is the Accelerated Creation-toSustainment (ACTS) model. In this iterative model, design and evaluation cycles are used in three phases - create, trial and sustain - resulting in sustainable digital mental health interventions that can be used in real-world settings [75]. A third example is intervention mapping, which is a planning approach that mostly relies on theory and evidence as foundations for an ecological approach of creating interventions for health problems [76]. Even though this approach wasn't specifically developed for eHealth interventions, it can be used to plan its development, implementation and evaluation [77]. A final example is the Person-Based Approach (PBA), which provides participatory methods for planning, optimizing, evaluating and implementing behavioural health interventions in which the perspective of people is central [78]. While these models all have their unique elements, there are multiple principles that can be derived from most of these models and frameworks: the importance of participatory development, the use of agile, iterative development with formative evaluation cycles, the added value of using a holistic approach in which people, technology and context are intertwined, and the necessity of an interdisciplinary approach in which methods and principles from multiple disciplines are combined [79]. 


\subsection{Participatory development}

In order to create eHealth that meets the needs and wishes of users and other stakeholders, a participatory development approach is recommended, in which stakeholders are actively involved throughout the entire process [80, 81]. Participatory development goes beyond merely involving end-users because this might cause a dominance of the user perspective and might lead to overlooking the needs of other stakeholders [82]. In participatory development, the roles of a stakeholder can range from an informant that mostly provides input on products when asked, to a co-creator that is actively involved in creating ideas and products $[83,84]$. Amongst other things, stakeholders can provide input when identifying problems where technology can be of added value, improving the design of a technology, or identifying critical issues for implementation. Participatory development can be shaped by means of methods from human-centred design (HCD), such as usability testing, prototyping and qualitative data collection by means of interviews or focus groups [85].

\subsection{Agile, iterative development with formative evaluation cycles}

In order to justice to the dynamic nature of technology, eHealth development should not be viewed as a linear process with consecutive steps: it is iterative, flexible and dynamic, with constant changes to the process and products [86,87]. Consequently, all products of the development process have to be critically analysed, evaluated and adapted based on formative evaluations with stakeholders and based on outcomes of earlier development activities [73]. This is in line with an agile approach, which currently is common practice in software development. Such an approach is characterized by the division of large tasks into rapid, shorter phases and constant adaptations of plans based on the outcomes of evaluations $[86,87]$. Core values are close collaboration, a 'lean' mentality to minimize unnecessary work, active stakeholder involvement, and the acceptance of uncertainty. This results in a dynamic process that is able to deal with changes and new insights $[88,89]$.

\subsection{The holistic approach}

Regardless of the type or goal of an eHealth intervention, there are interrelationships between the design of a technology, the needs and preferences of the people involved, and the context in which it is used. While more research is necessary, it seems that this fit between technology, people and context increases the chances of successful adoption and sustained use [90-93]. These interrelationships refer to a 
holistic approach, in which different concepts are all interdependent and part of one whole instead of separate elements [43]. This implies that eHealth should not be viewed as a separate thing or tool, but has to be integrated within a larger system. A holistic approach towards the development, implementation and evaluation of eHealth interventions can contribute to a good fit between technology, people and context $[73,74]$.

\subsection{The interdisciplinary nature of eHealth development}

In order to capture the complexity and multi-level nature of eHealth, an interdisciplinary approach towards research and development is required. In such an approach, theories, methods and models from different disciplines are combined and even merged, resulting in new concepts and theories. Paradigms that are relevant for eHealth are, amongst other things, health psychology, implementation science, human-centred design, engineering, and persuasive design [43]. Furthermore, theories from the domain for which the eHealth intervention is developed can be incorporated in the development. For example, in case of forensic mental healthcare, the aforementioned RNR model, GLM, General Theory of Crime [94] or the $1^{3}$ model for intimate partner violence might be used to inspire the goals and content of eHealth interventions [72]. Additionally, this interdisciplinary nature is important when composing the project team that coordinates the development process. Creating a team with members from different disciplines is deemed essential to ensure that all relevant perspectives are actively involved in the development, implementation and evaluation and to prevent tunnel vision [73, 92]. Two different types of people can be involved: professionals with knowledge on eHealth development, such as designers, project managers, researchers and engineers, and people who are an expert on the domain in which the eHealth intervention will be used, such as patients, healthcare professionals or managers [73].

\section{The CeHRes Roadmap}

The CeHRes Roadmap (Figure 1) is grounded in all of the aforementioned principles and is viewed as a useful framework for the holistic development, implementation and evaluation of eHealth $[84,95]$. It can be used to create new eHealth interventions from scratch, but also to re-design, implement or evaluate existing interventions. While the Roadmap consists of five phases, it is not a step-by-step model that prescribes exactly how eHealth should be developed; its goal is to guide interdisciplinary teams in shaping, planning, coordinating and executing develop- 
ment, implementation and evaluation processes in a structured yet flexible way. Consequently, the five phases - contextual inquiry, value specification, design, operationalization and summative evaluation - are intertwined and connected to each other by means of formative evaluation cycles. In that way, the Roadmap answers the call for more flexible and agile intervention development approaches [87, 91]. Below, the five phases of the Roadmap are briefly explained and illustrated. Furthermore, additional approaches and models are discussed when necessary and relevant in order to provide an overview of how to develop, implement and evaluate eHealth in context.

Figure 1. The CeHRes Roadmap [74].

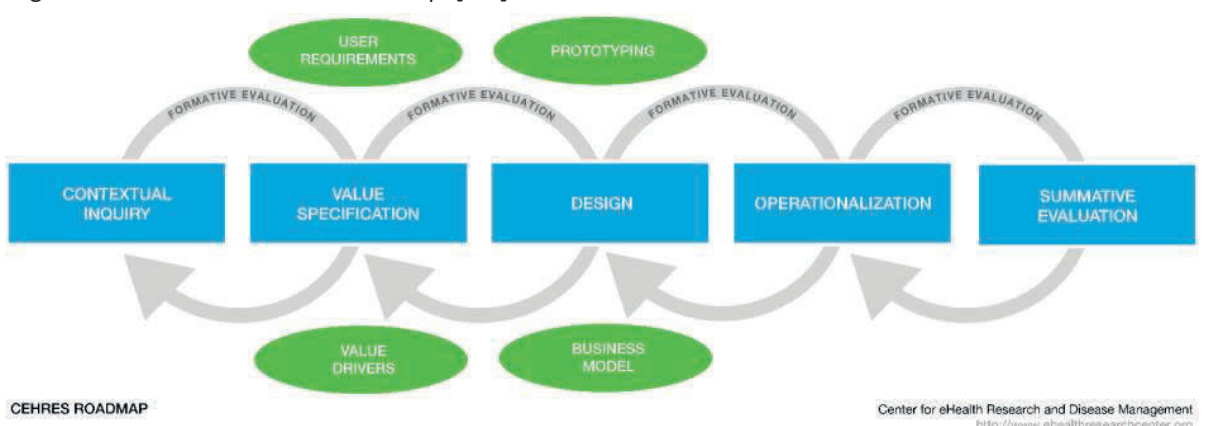

\subsection{Development}

Three phases of the CeHRes Roadmap can be categorized under development, since they all focus the foundation and design of an eHealth intervention. These phases are the contextual inquiry, value specification and design phases, and are briefly described below.

\subsubsection{The contextual inquiry}

Ideally, in any eHealth development project, a contextual inquiry (or needs assessment) has to be carried out to get a good grasp of the context in which a technology will be used. In order for an eHealth intervention to be successful, it has to provide a solution for issues that are considered relevant within a specific setting, it needs to be accepted by stakeholders such as users and managers, and it has to be integrated within the existing environment $[91,93]$. Consequently, the outcomes of the contextual inquiry ensure a focus on the people and their environment and serve as a foundation for the further development process $[80,96]$. In the contextual 
inquiry, multiple methods such as interviews, desk research, questionnaires and literature reviews are combined to answer the following broad questions [97]:

- Who are the relevant stakeholders - people or groups of people who are affected by a potential eHealth intervention?

- What are the tasks, roles and attitudes of the identified stakeholders regarding the to-be-developed eHealth intervention?

- What does the current situation look like and what are weak and strong points where eHealth might be of added value?

\subsubsection{Value specification}

In the value specification, topics that arise from the contextual inquiry are further specified, and ideas on how a technology can address the points of improvements are generated. In this phase, values are formulated to summarize what exactly needs to be improved or supported by means of an eHealth intervention, and to show what its added value should be according to the involved stakeholders [98]. These abstract values serve as input for more specific requirements, which state what exactly is required from the technology with respect to matters like software, hardware, content and design/presentation [98]. Furthermore, in the value specification, the development of a business model can be initiated in order to describe how the involved organizations create, deliver and capture value by means of the eHealth intervention. In all these activities, multiple methods such as focus groups and interviews can be combined. The value specification focuses on the following three main topics:

- Identifying and prioritizing the values of the key-stakeholders.

- Formulating a first version of the requirements for the to-be-developed eHealth intervention, based on the previously determined values.

- Creating an initial version of a business model to describe how the involved organization(s) will conduct their business regarding the eHealth intervention.

\subsubsection{Design}

Based on the outcomes of the contextual inquiry and value specification, a ready-touse technology is created in the design phase. According to principles from humancentred design, a complete, finished eHealth technology should not be designed at once, since this might result in issues that come to light only after its introduction in practice [85]. Instead, multiple low- and high-fidelity paper and digital prototypes 
have to be developed to visualize ideas for the design of a technology. In line with the human-centred design approach, these prototypes are evaluated with stakeholders, for example by means of usability tests or focus groups, to investigate whether they fit the prospective users' skills and needs and identify points of improvements [85]. Besides this, it is important to integrate theory in the prototypes to increase the chance of behaviour change [62]. Amongst other things, elements from the Persuasive System Design (PSD) and behaviour change techniques can be used to support adherence and a change in attitudes and behaviours [64, 65, 68]. To summarize, the following activities are performed in the design phase:

- Developing low- and high-fidelity prototypes of the eHealth intervention.

- Conducting usability tests with end-users, experts on design and content, and other relevant stakeholders.

- Integrating theory such as persuasive elements or behaviour change techniques in the design.

\subsection{Implementation}

While only one phase of the CeHRes Roadmap - operationalization - is specifically focused on implementing an eHealth intervention in practice, implementation is intertwined throughout the entire model. To illustrate: in the value specification phase, developers already gather an overview of matters that will be important for implementation later on, and by creating an intervention that fits the needs of the target group in the design phase, the expectation is that there will be little to no problems with adoption related to usability or content. In the operationalization phase, which is described below, the main focus lies on implementation.

\subsubsection{Operationalization}

The operationalization phase of the CeHRes Roadmap encompasses the planning and actions for introducing, disseminating, adopting and internalizing a technology within a specific context [73]. Besides completing and rolling out the business model, of which the development was already initiated in the value specification, an implementation plan can be created. Ideally, in such a plan, concrete implementation outcomes are formulated [99], for example related to the acceptability, costs, feasibility and sustainability of the eHealth intervention. Based on these outcomes, implementation strategies can be formulated [100]. Examples are training and education, the development new protocols for the use of an intervention, or the creation of communication strategies to increase awareness of the existence of the 
intervention. Consequently, the following activities are relevant in the operationalization phase:

- Finishing the business model (as far as possible) by means of input of stakeholders and implementation theory.

- Making an implementation plan based on implementation frameworks, input from stakeholders and the business model.

- Determining and executing concrete implementation strategies in cooperation with stakeholders.

\subsection{Evaluation}

In the Roadmap, evaluation is an important activity. Its fifth phase focuses on the evaluation of the intervention and its impact and uptake on practice. Furthermore, all phases of the Roadmap are connected by formative evaluation cycles, which focus more on the process. Below, both phases are briefly explained.

\subsubsection{Summative evaluation}

Once a technology has been developed, evaluation studies can show whether it actually reaches its intended added value and whether the predetermined goals are achieved. In evaluation, a holistic approach can be employed, meaning that researchers study the effects of an eHealth intervention on the people and context in order to paint a complete picture of its impact. Consequently, according to this holistic approach, evaluation should go beyond the assessment of clinical, patientrelated outcomes by means of questionnaires. Other, more qualitative variables can also be accounted for to gain insight into whether predetermined values and goals were reached, for example related to treatment motivation, experienced effectiveness or practical advantages. Additionally, attention can be paid to the experiences and opinions of healthcare professionals and other stakeholders, for example regarding saved costs and time, practical benefits and attitudes. The impact of the eHealth intervention on the context can be assessed as well, for example regarding cost-efficiency, an intervention's fit with an organization's mission and vision, and changes in the way care is delivered. Finally, the technology itself can be incorporated in evaluation, for example by assessing in what way it was used and what points of improvement regarding its usability are [73]. All of this leads to the following two main questions that should be answered in this summative evaluation phase:

- What is the impact of an eHealth intervention on the context and its stakeholders, based on the previously determined values? 
- What is the uptake of an eHealth intervention in terms of adoption and use by the predetermined stakeholders and implementation within the intended context?

\subsubsection{Formative evaluation}

In the CeHRes Roadmap, formative evaluation is not a separate phase, but a principle that connects all development, implementation and evaluation activities [73]. Formative evaluation activities provide ongoing information on how to improve the process and the eHealth intervention, and ensure a constant focus on the context and people. Formative evaluation can be applied in two ways: between and within phases. First, formative evaluations can be conducted to check whether the outcomes within a specific phase are in line with the conclusions of a previous phase. To illustrate, values that are formulated should be based on the points of improvement identified in the contextual inquiry. Second, within an activity, formative evaluation can be used to verify whether a specific product or idea fits with the context and people involved. An excellent example of this is usability testing, in which researchers verify whether their ideas on an eHealth intervention are indeed in line with the opinions and characteristics of the prospective users. Consequently, the two main goals of formative evaluation are:

- Checking whether the outcomes of previous phases have been incorporated in the current phase, and if the outcomes of all phases are coherent and related to each other.

- Evaluating ideas and results with stakeholders in order to check whether they are in line with their perspectives and characteristics.

\subsection{Common issues with development, implementation and evaluation}

Frameworks such as the CeHRes Roadmap or the aforementioned ACTS, PBA and intervention mapping offer much-used guidelines to shape the development, implementation and evaluation of eHealth. However, there are some general points of improvements for these activities.

\subsubsection{Development}

While development frameworks provide tools to shape participatory development processes, much remains unknown about which methods to use at which point in the development process, and which methods optimally fit specific target groups and contexts. To illustrate, not much is known about how to optimally involve vulnerable 
patient populations such as forensic psychiatric patients in research [101]. Because a one-size-fits-all approach towards the development of eHealth is not possible, there is a need for more insight into what works for which types of participants and in which context. Furthermore, while the importance of co-creation is widely acknowledged, stakeholders are often still only involved as informants to provide feedback once a problem is already determined or an idea is already developed. In order to shape a bottom-up development process, stakeholders have to be actively involve from the start and can even participate in decision-making. Again, not much is known about how to achieve this active co-creation from the start of a development process. Furthermore, frameworks such as the CeHRes Roadmap provide general directions, but not much is known on how to operationalize these abstract concepts and principles. For example, while the overall goal of values is clear, there is a lack of clear guidelines that can support other researchers in formulating values. The same goes for the integration of theory: how can domain-specific theories be used in the development of a new technology? There appears to be a need for more tools to support researchers in making well-informed decisions on how to operationalize abstract guidelines and to decide which methods to use for specific research questions, contexts and target groups.

\subsubsection{Implementation}

One of the main pitfalls of eHealth implementation is that its importance is often underestimated. Often, the focus lies on creating a new and innovative eHealth intervention, and it is expected that this intervention will automatically be adopted. However, as becomes painfully clear from both research and practice, implementation is extremely complex and very few eHealth technologies are actively used in practice. Additionally, if attention is paid to implementation, only one or two perspectives are included. For example, in many cases, the main implementation strategy is to offer training to healthcare providers. However, since implementation is a process that takes place on multiple levels, only providing skills training doesn't do justice to the complex and multi-level nature of the implementation process. There is a need for more insight into how to take the complexity of the interrelationships between technology, people and the context into account when implementing eHealth.

In order to ensure that all aspects and levels of implementation are accounted for, theories can be used to create an implementation plan [70]. For example, the classic Diffusion of Innovation theory is often used to shape or analyse 
implementation [102]. According to this theory, diffusion is the "process by which an innovation is communicated through certain channels over a period of time among the members of a social system". Factors that can be accounted for and should be influenced to implement innovations are the characteristics of the innovation itself, the communication channels, time and the social system. However, while providing multiple valuable insights, the Diffusion of Innovation theory does not fully account for all different levels of implementation and their interrelationships. Because of this, the Consolidated Framework for Implementation Research (CFIR) has been developed [103]. This comprehensive model is based on an exhaustive review of the literature on multiple existing implementation models. To take the different levels of implementation into account, the CFIR incorporates concepts related to the individuals involved, the intervention, the inner and outer setting, and the implementation process. A second implementation model that focuses specifically on value-based technology in healthcare, is the Nonadoption, Abandonment, Scale-up, Spread and Sustainability (NASSS) framework [104]. This model incorporates elements related to the condition, the technology used, the value proposition, the adopters of the technology, the organization, the wider system and the embedding and adaptation of the technology over time. While there are differences between these implementation models, they all pay attention to the people involved, the characteristics of the intervention, and the context in which a technology is used. However, more knowledge on how to apply these models to eHealth implementation in practice is required in order to be able to further optimize implementation strategies.

\subsubsection{Evaluation}

Despite the broad nature of eHealth evaluation, the predominant evaluation approach is a randomized controlled trial (RCT), an experimental design which mostly focuses on changes in clinical outcomes in patients compared to a control group. However, when looking at the requirements for eHealth evaluation, such an approach has multiple pitfalls $[53,105,106]$. RCTs are most suitable for situations in which it is easy to vary one factor while the rest remains constant, such as in medication research. However, this reasoning becomes problematic when applying it to the evaluation of a multi-component intervention in context. For example, while RCTs can show whether changes in certain predetermined variables occurred, they cannot show in what way and when these changes occurred, amongst other things because eHealth interventions can be used in different ways and during different points in 
time. Therefore, the eHealth intervention remains a black box: it is not clear what happens within the intervention itself and how this contributes to the effectiveness $[106,107]$. Furthermore, behaviour change is a process that occurs over time and might differ between people, which shows the importance of not just assessing changes in outcomes before and after, but also throughout the intervention in order to account for differences between individuals.

It is clear that other types of evaluation methods are required to open the black box of eHealth and gain insight into whether and why an intervention is of added value for a specific target group and context. A possible method to gain more insight into effective elements of an eHealth intervention is a full or fractional factorial design [106]. In this design, different users receive different variations of an intervention, each containing different combinations of components. Through this, researchers can identify the effects of specific features of an intervention by searching for differences in effectiveness between the participants that received different components of an intervention [108]. Another method that can be used to offer insight into how an eHealth technology works is log data analysis. Log data can show how and when the eHealth intervention and its different components were used and by whom [109]. If combined with another design such as an RCT, log data can provide insight into whether the way an intervention is used is related to effectiveness. A method that is suitable for contexts in which there are few eligible participants for research is a single-case experimental design (SCED). SCEDs can be applied to intensively monitor specific outcomes in a limited number of users over a longer period of time [110]. SCEDs allow for high-quality experimental research while overcoming practical limitations, such as difficulties with composing a large, homogenous sample, and also offer more insight in changes in effectiveness over time. Finally, mixed-methods designs in which qualitative and quantitative data are integrated are considered to be very suitable for painting a more complete picture of the impact of an eHealth technology on a specific context [111]. While these types of designs are very fitting for eHealth evaluation, they are not yet widely used; RCTs are still viewed as the golden standard for evaluations of eHealth interventions, despite their limitations $[105,112]$. This shows the need for the application of these new, innovative evaluation methods in order to be able to reflect on them and share lessons learned with other researchers. 


\section{Research questions and thesis outline}

\subsection{Goal of this thesis}

Based on all of the above, there are two main challenges that need to be addressed. First of all, there is an obvious need for more insight into if and how different types of eHealth interventions can be of added value for forensic mental healthcare, and how the current barriers can be overcome. Second, while there are multiple frameworks, models and guidelines for eHealth development, implementation and evaluation, there is much unchartered territory. Amongst other things, there should be more insight into which development and evaluation methods best fit specific types of goals, contexts and target groups. Additionally, it is important to constantly optimize and refine these models and frameworks based on new insights and lessons learned from their use in practice to ensure that they remain up-to-date.

This thesis aims to address all of the above by applying the principles of the CeHRes Roadmap to the development, implementation and evaluation to a specific case: eHealth interventions for treatment of offenders in forensic mental healthcare. Based on the new insights and lessons learned that can be gathered from applying these principles, these principles and the Roadmap itself can be further improved. Consequently, this thesis has two main goals, of which the first one is more applied, and the second one more abstract. The first objective of this thesis is to determine how and why eHealth interventions are of added value for forensic mental healthcare. The second goal is to provide more insight into how eHealth interventions can be optimally developed, implemented and evaluated in complex contexts.

\subsection{Research questions}

In order to reach these goals, several sub-questions will be answered by means of the different chapters in this thesis. Below, these research questions and the accompanying chapters are provided, categorized based on the two objectives of this thesis.

Goal 1: To provide insight into the added value of eHealth for forensic mental healthcare

- What is the current state of affairs of eHealth in treatment of forensic psychiatric patients? (Part 1; chapters 2 \& 3)

- Why and in what way can virtual reality be of added value for treatment in forensic mental healthcare? (Part 2; chapters 4, 5 and 6)

- To what extent can a mobile app increase self-control and reduce reactive aggression? (Part 3; chapter 7) 
Goal 2: To further optimize development, implementation and evaluation of eHealth interventions

- How can novel eHealth interventions be developed in complex settings by means of participatory development? (Chapters 5 \& 6)

- How can the implementation and effectiveness of eHealth interventions be evaluated by means of a holistic approach using multiple methods? (Chapters $3 \& 7$ )

\section{Part 1: The current state of affairs of eHealth in forensic mental healthcare}

In the first part of this thesis, a critical analysis of the current state of affairs regarding eHealth interventions in treatment of forensic psychiatric patients is provided. In Chapter 2, an overview of the scientific literature on eHealth interventions is provided by means of a systematic review. Chapter 3 is focused on the analysis of the implementation of a web-based intervention that has been used for several years in treatment of forensic psychiatric outpatients. In order to do justice to the different levels and complexity of implementation, a mixed-methods approach in which log data analysis, semi-structured interviews and desk research were integrated was applied.

\section{Part 2: The added value of virtual reality}

Because first part of this thesis shows that web-based interventions are often used in practice, but do not seem to optimally fit the characteristics of forensic mental healthcare, the second part is focused on a technology that is expected to be more suitable for this context: virtual reality (VR). In Chapter 4, the potential added value that VR can have for forensic mental healthcare is identified by combining an interview study with an elaborate questionnaire study, which are both inspired by methods from human-centred design. The findings of this chapter serve as the foundation of Chapter 5 , in which it is shown how data from different sources can be combined into values that can be used to guide the development, implementation and evaluation process. In Chapter 6 a description and critical reflection on the participatory development process of an interactive, personalized VR-application are provided, guided by the contextual inquiry, value specification and design phase of the CeHRes Roadmap. By means of the three chapters of this second part, more insight into how VR can be of added value for forensic mental healthcare is generated. Additionally, multiple points of improvements of the development approaches are 
described, and guidelines are provided on how to execute a multi-method, participatory development process in practice.

\section{Part 3: Novel methods to evaluate eHealth}

Chapter 2 of this thesis showed that there are many technologies that can be used to treat forensic psychiatric patients. Consequently, this third part is focused on another type of technology that can be of added value: mobile apps. A self-control training (SCT) app was developed and evaluated with students, as a first step for its further development. In order to do justice to the iterative and holistic nature of eHealth evaluation, two research designs were combined: a pretest-posttest design without control group and a full factorial design. These methods do not only offer insight into the effectiveness of an app and its added value compared to a simple e-mail based SCT, but also show what the most optimal version of the app looks like.

\section{Part 4: Discussion}

In the fourth and final part of this thesis, a reflection on the main findings is provided. On the one hand, considerations and recommendations on how eHealth technologies can be of added value for forensic mental healthcare are described. On the other hand, reflections are provided on the way eHealth interventions can be developed, implemented and evaluated in complex settings by means of suitable and efficient methodologies. Furthermore, several recommendations on how to improve existing eHealth frameworks such as the CeHRes Roadmap are offered. 


\section{References}

1. Bloem O, Nijman H, Bulten B. Psychopathologie onder gedetineerden. Groen, H; Drost, M; Nijman, HLI (ed), Handboek forensische geestelijke gezondheidszorg. 2011:153-62.

2. Mullen PE. Forensic mental health. The British journal of psychiatry. 2000;176(4):307-11.

3. Arboleda-Florez J. Forensic psychiatry: contemporary scope, challenges and controversies. World Psychiatry. 2006;5(2):87.

4. Veiligheid MvJ. Handboek Forensische Zorg. Ministerie van Justitie \& Veiligheid; 2018.

5. Drieschner KHH, J.M. \& Weijters, G.M. . Recidive na forensische zorgtrajecten met uitstroom 2013-2015. Den Haag: Wetenschappelijk Onderzoek- en Documentatiecentrum; 2020.

6. Drieschner $\mathrm{KH}$, Boomsma A. Validation of the treatment motivation scales for forensic outpatient treatment (TMS-F). Assessment. 2008;15(2):242-55.

7. Drieschner KH, Lammers SM, van der Staak CP. Treatment motivation: An attempt for clarification of an ambiguous concept. Clinical Psychology Review. 2004;23(8):1115-37.

8. Tervoort M. Behandelbaarheid. Handboek Forensische Geestelijke Gezondheidszorg Utrecht: De Tijdstroom. 2011:137-52.

9. Deenik J, Tenback DE, Tak EC, Henkemans OAB, Rosenbaum S, Hendriksen IJ, et al. Implementation barriers and facilitators of an integrated multidisciplinary lifestyle enhancing treatment for inpatients with severe mental illness: the MULTI study IV. BMC health services research. 2019;19(1):740.

10. Greenberg E, Dunleavy E, Kutner M. Literacy Behind Bars: Results from the 2003 National Assessment of Adult Literacy Prison Survey. NCES 2007-473. National Center for Education Statistics. 2007.

11. Goethals KR, Vorstenbosch EC, van Marle HJ. Diagnostic comorbidity in psychotic offenders and their criminal history: A review of the literature. 2008.

12. Polaschek DL. An appraisal of the risk-need-responsivity (RNR) model of offender rehabilitation and its application in correctional treatment. Legal and criminological Psychology. 2012;17(1):1-17. 
13. Seppänen A, Törmänen I, Shaw C, Kennedy H. Modern forensic psychiatric hospital design: clinical, legal and structural aspects. International journal of mental health systems. 2018;12(1):58.

14. Goethals K. Forensic Psychiatry and Psychology in Europe: A Cross-Border Study Guide: Springer; 2018.

15. Bonta J, Andrews DA. Risk-need-responsivity model for offender assessment and rehabilitation. Rehabilitation. 2007;6(1):1-22.

16. Ward T, Mann RE, Gannon TA. The good lives model of offender rehabilitation: Clinical implications. Aggression and violent behavior. 2007;12(1):87-107.

17. Capaldi DM, Knoble NB, Shortt JW, Kim HK. A systematic review of risk factors for intimate partner violence. Partner abuse. 2012;3(2):231-80.

18. Ward T, Fortune C-A. The role of dynamic risk factors in the explanation of offending. Aggression and violent behavior. 2016;29:79-88.

19. Douglas KS, Hart SD, Webster CD, Belfrage H, Guy LS, Wilson CM. Historicalclinical-risk management-20, version 3 (HCR-20V3): development and overview. International Journal of forensic mental health. 2014;13(2):93108.

20. Harris AJR, Hanson RK. Clinical, actuarial and dynamic risk assessment of sexual offenders: Why do things keep changing? Journal of Sexual Aggression. 2010;16(3):296-310.

21. Hanson RK, Harris AJ. Where should we intervene? Dynamic predictors of sexual offense recidivism. Criminal Justice and behavior. 2000;27(1):6-35.

22. Hanson RK. Stability and change: Dynamic risk factors for sexual offenders. Sexual offender treatment: Controversial issues. 2006:17-31.

23. Schmucker $M$, Lösel F. Sexual offender treatment for reducing recidivism among convicted sex offenders: a systematic review and meta-analysis. Campbell Systematic Reviews. 2017;13(1):1-75.

24. Papalia N, Spivak B, Daffern M, Ogloff JR. A meta-analytic review of the efficacy of psychological treatments for violent offenders in correctional and forensic mental health settings. Clinical psychology: Science and practice. 2019;26(2):e12282.

25. Lösel F, Schmucker M. The effectiveness of treatment for sexual offenders: A comprehensive meta-analysis. Journal of Experimental Criminology. 2005;1(1):117-46. 
26. Hanson RK, Bourgon G, Helmus L, Hodgson S. A meta-analysis of the effectiveness of treatment for sexual offenders: Risk, need, and responsivity. 2009.

27. Wormith JS, Olver ME. Offender treatment attrition and its relationship with risk, responsivity, and recidivism. Criminal Justice and Behavior. 2002;29(4):447-71.

28. Willis GM, Ward T. The good lives model: Does it work? Preliminary evidence. L Craig, L Dixon, \& TA Gannon (2013), What Works in Offender Rehabilitation: An evidence based approach to assessment and Treatment. 2013:305.

29. Porporino FJ. Bringing sense and sensitivity to corrections: From programmes to 'fix' offenders to services to support desistance. What else works? Creative work with offenders. 2010:61-85.

30. Ward T, Maruna S. Rehabilitation: Routledge; 2007.

31. Ward T, Yates PM, Willis GM. The good lives model and the risk need responsivity model: A critical response to Andrews, Bonta, and Wormith (2011). Criminal Justice and Behavior. 2012;39(1):94-110.

32. Mann RE, Webster SD, Schofield C, Marshall WL. Approach versus avoidance goals in relapse prevention with sexual offenders. Sexual Abuse: A Journal of Research and Treatment. 2004;16(1):65-75.

33. Harkins L, Flak VE, Beech AR, Woodhams J. Evaluation of a community-based sex offender treatment program using a good lives model approach. Sexual Abuse. 2012;24(6):519-43.

34. Andrews DA, Bonta J, Wormith JS. The risk-need-responsivity (RNR) model: Does adding the good lives model contribute to effective crime prevention? Criminal Justice and Behavior. 2011;38(7):735-55.

35. Looman J, Abracen J. The risk need responsivity model of offender rehabilitation: Is there really a need for a paradigm shift? International Journal of Behavioral Consultation and Therapy. 2013;8(3-4):30.

36. Rotter $M$, Carr WA. Reducing criminal recidivism for justice-involved persons with mental illness: risk/needs/responsivity and cognitive-behavioral interventions. Substance Abuse and Mental Health Services Administration, GAINS Center for Behavioral Health and Justice Transformation. 2013.

37. Del Vecchio T, O'Leary KD. Effectiveness of anger treatments for specific anger problems: A meta-analytic review. Clinical psychology review. 2004;24(1):15-34. 
38. Saini M. A meta-analysis of the psychological treatment of anger: Developing guidelines for evidence-based practice. Journal of the American Academy of Psychiatry and the Law Online. 2009;37(4):473-88.

39. Ozkan E, Belhan S, Yaran M, Zarif M. Occupational Therapy in Forensic Settings. Occupational Therapy-Therapeutic and Creative Use of Activity: IntechOpen; 2018.

40. O'Connell M, Farnworth L. Occupational therapy in forensic psychiatry: A review of the literature and a call for a united and international response. British Journal of Occupational Therapy. 2007;70(5):184-91.

41. Kip H, Oberschmidt K, Bierbooms J, Dijkslag D, Kelders S, Roelofsen B. Technologie in de forensische zorg-Crossing borders. Kwaliteit Forensische Zorg. 2019;1.

42. Groen $H$, Drost $M$, Nijman H. Handboek forensische geestelijke gezondheidszzorg. 2011.

43. van Gemert-Pijnen LJ, Kip H, Kelders SM, Sanderman R. Introducing ehealth. eHealth research, theory and development: a multi-disciplinary approach: Routledge; 2018. p. 3-26.

44. Eysenbach G. What is e-health? Journal of medical Internet research. 2001;3(2):e20.

45. Wentzel J, van der Vaart R, Bohlmeijer ET, van Gemert-Pijnen JE. Mixing online and face-to-face therapy: how to benefit from blended care in mental health care. JMIR mental health. 2016;3(1):e9.

46. Kenter RM, van de Ven PM, Cuijpers P, Koole G, Niamat S, Gerrits RS, et al. Costs and effects of Internet cognitive behavioral treatment blended with face-to-face treatment: results from a naturalistic study. Internet Interventions. 2015;2(1):77-83.

47. Fairburn CG, Patel V. The impact of digital technology on psychological treatments and their dissemination. Behaviour research and therapy. 2017;88:19-25.

48. Krausz R, Ramsey D, Wetterlin F, Tabiova K, Thapliyal A. Accessible and CostEffective Mental Health Care Using E-Mental Health (EMH). Advances in Psychiatry: Springer; 2019. p. 129-41.

49. Schueller SM. Mental health and eHealth technology. eHealth research, theory and development: Routledge; 2018. p. 91-110. 
50. Langarizadeh M, Tabatabaei MS, Tavakol K, Naghipour M, Rostami A, Moghbeli F. Telemental health care, an effective alternative to conventional mental care: A systematic review. Acta Informatica Medica. 2017;25(4):240.

51. Andersson G, Cuijpers P, Carlbring P, Riper H, Hedman E. Guided Internetbased vs. face-to-face cognitive behavior therapy for psychiatric and somatic disorders: a systematic review and meta-analysis. World Psychiatry. 2014;13(3):288-95.

52. Cuijpers P, Donker T, van Straten A, Li J, Andersson G. Is guided self-help as effective as face-to-face psychotherapy for depression and anxiety disorders? A systematic review and meta-analysis of comparative outcome studies. Psychological Medicine. 2010;40(12):1943.

53. Mohr DC, Weingardt KR, Reddy M, Schueller SM. Three problems with current digital mental health research... and three things we can do about them. Psychiatric services. 2017;68(5):427-9.

54. Cornet LJM, Mandersloot $\mathrm{M}$, Pool R, De Kogel CH. De'zelfmetende'justitiabele: Een verkennend onderzoek naar technologische zelfmeetmethoden binnen justitiële context. Cahiers 2017. 2017(17).

55. Schoneveld EA, Malmberg M, Lichtwarck-Aschoff A, Verheijen GP, Engels RC, Granic I. A neurofeedback video game (MindLight) to prevent anxiety in children: A randomized controlled trial. Computers in Human Behavior. 2016;63:321-33.

56. Derks YP, Klaassen R, Westerhof GJ, Bohlmeijer ET, Noordzij ML. Development of an Ambulatory Biofeedback App to Enhance Emotional Awareness in Patients with Borderline Personality Disorder: Multicycle Usability Testing Study. JMIR mHealth and uHealth. 2019;7(10):e13479.

57. Hoogsteder L, Horn, J. van, \& Schippers, E. Goede Reactie Is Preventie - GRIP. Theoretische en technische achtergrond. Utrecht: Kwaliteit Forensische Zorg (KFZ); 2018.

58. Turner WA, Casey LM. Outcomes associated with virtual reality in psychological interventions: where are we now? Clinical psychology review. 2014;34(8):634-44.

59. Tuente SK, Bogaerts S, Van Ijzendoorn S, Veling W. Effect of virtual reality aggression prevention training for forensic psychiatric patients (VRAPT): study protocol of a multi-center RCT. BMC psychiatry. 2018;18(1):1-9. 
60. Adery LH, Ichinose M, Torregrossa LJ, Wade J, Nichols H, Bekele E, et al. The acceptability and feasibility of a novel virtual reality based social skills training game for schizophrenia: Preliminary findings. Psychiatry research. 2018;270:496-502.

61. van Loghum BS. Nieuwe separatie-unit moet leiden tot besparing ggz. Zorg en Financiering. 2012;11(10):86-7.

62. Webb T, Joseph J, Yardley L, Michie S. Using the internet to promote health behavior change: a systematic review and meta-analysis of the impact of theoretical basis, use of behavior change techniques, and mode of delivery on efficacy. Journal of medical Internet research. 2010;12(1):e4.

63. Walsh J, Morrissey E. Psychological principles and health behaviour change: Applications to eHealth. eHealth Research, Theory and Development: Routledge; 2018. p. 27-47.

64. Kelders SM, Kok RN, Ossebaard HC, Van Gemert-Pijnen JE. Persuasive system design does matter: a systematic review of adherence to web-based interventions. Journal of medical Internet research. 2012;14(6):e152.

65. Oinas-Kukkonen H, Harjumaa M. Persuasive systems design: Key issues, process model, and system features. Communications of the Association for Information Systems. 2009;24(1):28.

66. Sailer M, Hense J, Mandl J, Klevers M. Psychological perspectives on motivation through gamification. Interaction Design and Architecture Journal. 2014(19):28-37.

67. Ludden GD, van Rompay TJ, Kelders SM, van Gemert-Pijnen JE. How to Increase Reach and Adherence of Web-Based Interventions: A Design Research Viewpoint. J Med Internet Res. 2015;17(7):e172.

68. Michie S, Richardson M, Johnston M, Abraham C, Francis J, Hardeman W, et al. The behavior change technique taxonomy (v1) of 93 hierarchically clustered techniques: building an international consensus for the reporting of behavior change interventions. Annals of behavioral medicine. 2013;46(1):81-95.

69. Bierbooms J, Bouman Y, Dijkslag D, Kimpen R, Muller J, Wieske R. Do's en don'ts van e-health in de forensische ggz. Kwaliteit Forensische Zorg (KFZ). 2015.

70. Pieterse M, Kip H, Cruz-Martinez RR. The complexity of ehealth implementation: a theoretical and practical perspective. eHealth Research, 
Theory and Development: A Multi-Disciplinary Approach: Routledge; 2018. p. 247-70.

71. Slotter EB, Finkel EJ. $\left.\right|^{3}$ theory: Instigating, impelling, and inhibiting factors in aggression. Human aggression and violence: Causes, manifestations, and consequences: American Psychological Association; 2011. p. 35-52.

72. Finkel EJ. The 13 model: Metatheory, theory, and evidence. Advances in experimental social psychology. 49: Elsevier; 2014. p. 1-104.

73. Kip $H$, van Gemert-Pijnen LJ. Holistic development of ehealth technology. eHealth Research, Theory and Development: A Multi-Disciplinary Approach: Routledge; 2018. p. 131-66.

74. van Gemert-Pijnen JE, Nijland N, van Limburg M, Ossebaard HC, Kelders SM, Eysenbach $G$, et al. A holistic framework to improve the uptake and impact of eHealth technologies. Journal of medical Internet research. 2011;13(4):e111.

75. Mohr DC, Lyon AR, Lattie EG, Reddy M, Schueller SM. Accelerating digital mental health research from early design and creation to successful implementation and sustainment. Journal of medical Internet research. 2017;19(5):e153.

76. Bartholomew LK, Parcel GS, Kok G, Gottlieb NH, Schaalma HC, Markham CC, et al. Planning health promotion programs: an intervention mapping approach: Jossey-Bass; 2006.

77. Crutzen R. From eHealth technologies to interventions. Journal of medical Internet research. 2012;14(3):e93.

78. Yardley L, Morrison L, Bradbury K, Muller I. The person-based approach to intervention development: application to digital health-related behavior change interventions. Journal of medical Internet research. 2015;17(1):e30.

79. Michie S, Yardley L, West R, Patrick K, Greaves F. Developing and evaluating digital interventions to promote behavior change in health and health care: recommendations resulting from an international workshop. Journal of medical Internet research. 2017;19(6):e232.

80. Wentzel J, van Velsen L, van Limburg M, de Jong N, Karreman J, Hendrix R. Participatory eHealth development to support nurses in antimicrobial stewardship. BMC medical informatics and decision making. 2014;14(1):45.

81. Beerlage-de Jong N, Wentzel J, Hendrix R, van Gemert-Pijnen L. The value of participatory development to support antimicrobial stewardship with a 
clinical decision support system. American journal of infection control. 2017;45(4):365-71.

82. Bødker K, Kensing F, Simonsen J. Participatory IT design: designing for business and workplace realities: MIT press; 2009.

83. Scaife $M$, Rogers $Y$, Aldrich $F$, Davies $M$, editors. Designing for or designing with? Informant design for interactive learning environments. Proceedings of the ACM SIGCHI Conference on Human factors in computing systems; 1997.

84. Beerlage-de Jong N. eHealth vs. infection: Participatory development of persuasive eHealth to support safe care. 2016.

85. Burns C. Human-centred design. eHealth Research, Theory and Development: Routledge; 2018. p. 207-27.

86. Hekler EB, Klasnja P, Riley WT, Buman MP, Huberty J, Rivera DE, et al. Agile science: creating useful products for behavior change in the real world. Translational behavioral medicine. 2016;6(2):317-28.

87. Patrick K, Hekler EB, Estrin D, Mohr DC, Riper H, Crane D, et al. The Pace of Technologic Change. American Journal of Preventive Medicine. 2016;51(5):816-24.

88. Kelders SM, Howard M. Opportunities of technology to promote health and well-being. eHealth Research, Theory and Development: A Multi-Disciplinary Approach: Routledge; 2018.

89. Dings $\varnothing y r ~ T$, Nerur S, Balijepally V, Moe NB. A decade of agile methodologies: Towards explaining agile software development. The Journal of Systems \& Software. 2012;6(85):1213-21.

90. Nielsen AJ, Mathiassen L. Interpretive Flexibility in Mobile Health: Lessons From a Government-Sponsored Home Care Program. J Med Internet Res. 2013;15(10):e236.

91. Glasgow RE, Phillips SM, Sanchez MA. Implementation science approaches for integrating eHealth research into practice and policy. International Journal of Medical Informatics. 2014;83(7):e1-e11.

92. Feldman SS, Schooley LB, Bhavsar PG. Health Information Exchange Implementation: Lessons Learned and Critical Success Factors From a Case Study. JMIR Med Inform. 2014;2(2):e19.

93. Coiera E. Four rules for the reinvention of health care. BMJ. 2004;328(7449):1197-9. 
94. Gottfredson MR, Hirschi T. A general theory of crime: Stanford University Press; 1990.

95. Wentzel MJ. Keeping an eye on the context: participatory development of eHealth to support clinical practice. 2015.

96. Holtzblatt K, Jones S. Contextual inquiry: A participatory technique for system design. Participatory design: Principles and practices. 1993:177-210.

97. Kip $H$, Beerlage-de Jong N, Wentzel J. The contextual inquiry. eHealth Research, Theory and Development: A Multi-Disciplinary Approach: Routledge; 2018. p. 167-86.

98. Van Velsen L, Wentzel J, Van Gemert-Pijnen JE. Designing eHealth that matters via a multidisciplinary requirements development approach. JMIR research protocols. 2013;2(1):e21.

99. Proctor E, Silmere H, Raghavan R, Hovmand P, Aarons G, Bunger A, et al. Outcomes for implementation research: conceptual distinctions, measurement challenges, and research agenda. Administration and Policy in Mental Health and Mental Health Services Research. 2011;38(2):65-76.

100. Powell BJ, McMillen JC, Proctor EK, Carpenter CR, Griffey RT, Bunger AC, et al. A compilation of strategies for implementing clinical innovations in health and mental health. Medical care research and review. 2012;69(2):123-57.

101. Dugas M, Trottier M-È, Dansokho SC, Vaisson G, Provencher T, Colquhoun H, et al. Involving members of vulnerable populations in the development of patient decision aids: a mixed methods sequential explanatory study. BMC medical informatics and decision making. 2017;17(1):12.

102. Rogers EM. Diffusion of innovations: Simon and Schuster; 2010.

103. Damschroder LJ, Aron DC, Keith RE, Kirsh SR, Alexander JA, Lowery JC. Fostering implementation of health services research findings into practice: a consolidated framework for advancing implementation science. Implementation science. 2009;4(1):1-15.

104. Greenhalgh T, Wherton J, Papoutsi C, Lynch J, Hughes G, Hinder S, et al. Beyond adoption: a new framework for theorizing and evaluating nonadoption, abandonment, and challenges to the scale-up, spread, and sustainability of health and care technologies. Journal of medical Internet research. 2017;19(11):e367.

105. Rauwerdink A, Chavannes NH, Schijven MP. Needed: Evidence Based EHealth! Clinical eHealth. 2019;2:1-2. 
106. Sieverink F, Köhle N, Cheung K, Roefs A, Trompetter H, Keizer J, et al. Evaluating ehealth. eHealth Research, Theory and Development: A MultiDisciplinary Approach: Routledge; 2018.

107. Sieverink F. Opening the Black Box of eHealth. Twente: Universiteit van Twente. 2017.

108. Kelders SM, Bohlmeijer ET, Pots WT, van Gemert-Pijnen JE. Comparing human and automated support for depression: Fractional factorial randomized controlled trial. Behaviour research and therapy. 2015;72:7280.

109. Sieverink F, Kelders S, Akkersdijk S, Poel M, Siemons L, Van Gemert-Pijnen L, editors. Work in progress: A protocol for the collection, analysis, and interpretation of log data from eHealth technology. CEUR Workshop Proceedings; 2016.

110. Dallery J, Cassidy RN, Raiff BR. Single-case experimental designs to evaluate novel technology-based health interventions. Journal of medical Internet research. 2013;15(2):e22.

111. Sieverink F, Kelders S, Braakman-Jansen A, van Gemert-Pijnen J. Evaluating the implementation of a personal health record for chronic primary and secondary care: a mixed methods approach. BMC medical informatics and decision making. 2019;19(1):241.

112. Zanaboni P, Ngangue P, Mbemba GIC, Schopf TR, Bergmo TS, Gagnon M-P. Methods to evaluate the effects of internet-based digital health interventions for citizens: systematic review of reviews. Journal of medical Internet research. 2018;20(6):e10202. 

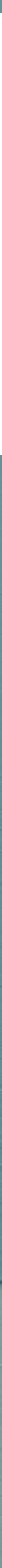


\section{PART 1}

The current state of affairs of eHealth in forensic mental healthcare
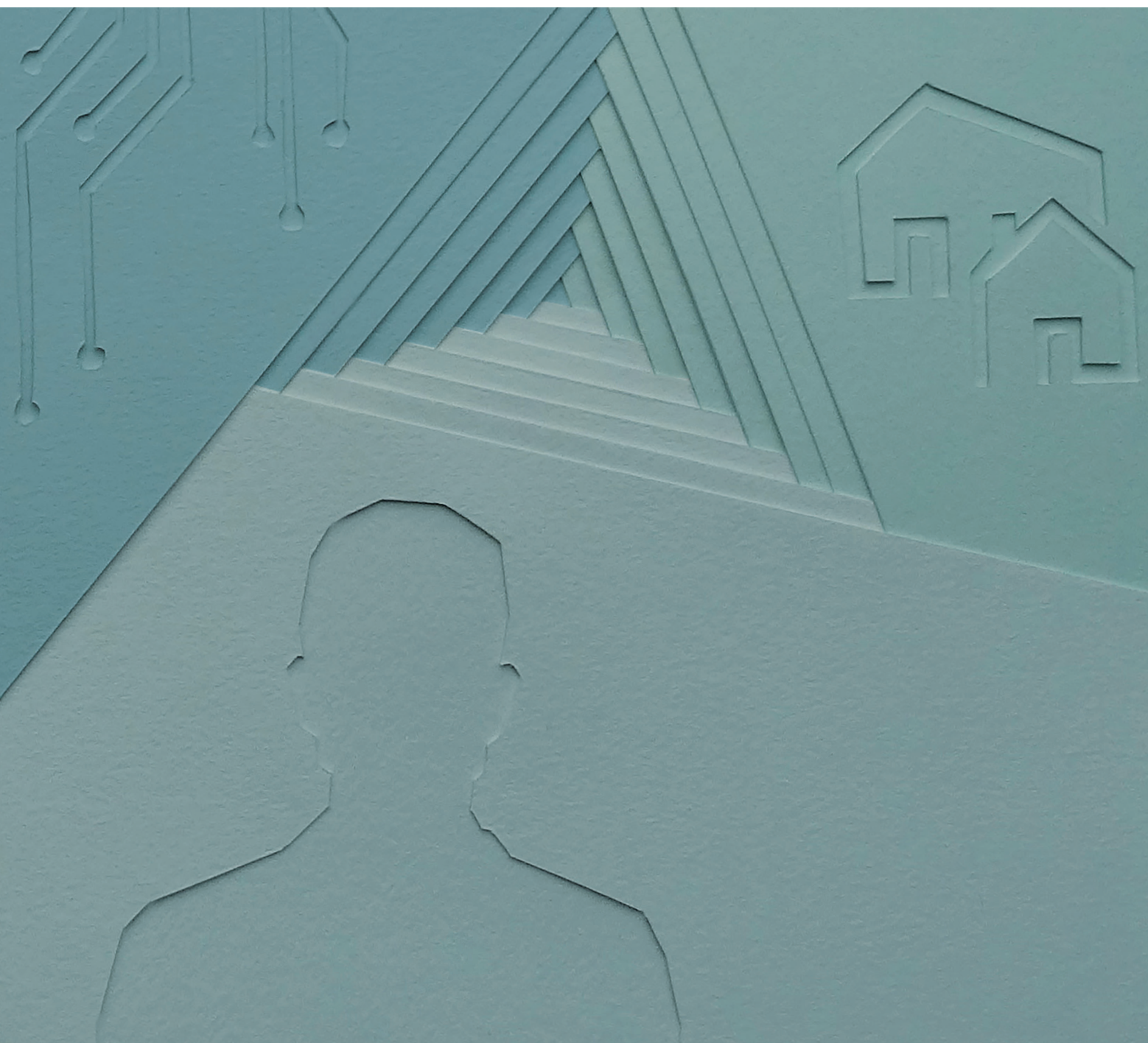



\section{Chapter 2}

eHealth in Treatment of Offenders in Forensic Mental Health: A Review of the Current State

Hanneke Kip, Yvonne H. A. Bouman, Saskia M. Kelders and Lisette J.E.W.C. van Gemert-Pijnen

Frontiers in Psychiatry, 9(42), 2018, https://doi.org/10.3389/fpsyt.2018.00042 


\begin{abstract}
Background: Treatment of offenders in forensic mental health is complex. Often, these in- or outpatients have low treatment motivation, suffer from multiple disorders, and have poor literacy skills. eHealth may be able to improve treatment outcomes because of its potential to increase motivation and engagement, and it can overcome the predominant one-size-fits-all approach by being tailored to individual patients.
\end{abstract}

Objective: To examine its potential, this systematic review studies the way that eHealth has been used and studied in forensic mental health and identifies accompanying advantages and disadvantages for both patients and treatment, including effectiveness.

Methods: A systematic search in Scopus, PsycINFO, and Web of Science was performed up until December 2017. Studies were included if they focused on technological interventions to improve the treatment of forensic psychiatric patients. Results: The search resulted in 50 studies in which eHealth was used for treatment purposes. Multiple types of studies and technologies were identified, such as virtual reality, web-based interventions, and videoconferencing. The results confirmed the benefits of technology, for example, the acquisition of unique information about offenders, effectiveness, and tailoring to specific characteristics, but indicated that these are not fully taken advantage of.

Discussion: To overcome the barriers and obtain the benefits, eHealth has to have a good fit with patients and the forensic psychiatric context. It has to be seamlessly integrated in existing care and should not be added as an isolated element. To bridge the gap between the current situation and eHealth's potential, further research on development, implementation, and evaluation should be conducted. 


\section{Introduction}

Forensic mental health treatment focuses on the intersect between psychiatry and the law by dealing with the relationship between, assessment and treatment of mental illness and criminality of people whose behaviour has led, or could lead, to offending $[1,2]$. Besides treatment of psychiatric disorders, a primary goal is to prevent criminal recidivism via addressing offense-related factors such as antisocial behaviour or coping skills. These factors should be addressed via interventions and therapies based on evidence-based approaches such as cognitive behaviour therapy [3] and the risk-needs-responsivity principles [4]. However, developing and implementing such in-person interventions in this complex field has proven to be challenging. For example, meta analyses on interventions targeting batterers, juvenile offenders, and relapse prevention of offenders found low overall effectiveness on clinical measures [5]. These results indicate that there is room for the improvement in interventions in forensic mental health. A solution might be found in the use of eHealth in treatment. eHealth can be defined as technologies such as web-based interventions, apps, wearables, or virtual reality (VR), to improve and support health, well-being, and quality of care [6]. Many studies acknowledge eHealth's added value for general mental health [e.g. references 7-9] but it is not yet clear what its advantages for forensic mental health treatment could be.

There are multiple complicating factors within forensic mental health that can influence the success of existing in-person interventions. Among other things, the forensic psychiatric population has specific characteristics, such as the low motivation that forensic psychiatric outpatients generally have for their, often mandated, treatment [10]. Studies suggest that mandated treatment outcomes are often worse compared with patients without mandated treatment [11]. Another complicating factor is that a large share of the forensic population displays psychiatric comorbidity $[12,13]$, and that not one, but multiple factors cause delinquent behaviour and should be addressed in treatment [14]. Furthermore, forensic psychiatric patients are often disproportionately poor, unemployed, and have lower literacy rates [15], which might affect their capability of being engaged in and adhering to interventions. Despite the complexity and diversity that the low motivation, low literacy, and comorbidity of forensic psychiatric patients bring to treatment, most interventions have a "one-sizefits-all approach." Many interventions do not take individual differences into account [16] despite the acknowledgment of the importance of tailoring interventions to specific characteristics of individual patients [17-19]. The use of eHealth technology within in-person treatments and interventions, which is referred to as blended care 
[20], could be a way to increase this required fit between interventions and patients. eHealth has several characteristics that could be of added value for forensic mental health.

First of all, the content, way of communicating and design of technology, can be tailored to subgroups or individual users, based on their characteristics, needs, or context [21]. This tailoring or personalization of eHealth interventions creates a better fit between the technology and the individual user and consequently addresses the complexity and diversity of the forensic mental health domain. Tailoring has been proven to enhance user engagement and effectiveness of multiple eHealth interventions [22-25]. The use of tailoring prevents the aforementioned one-size-fits all approach of interventions, which does not seem to suit the complex and broad forensic population [17].

Another way to account for the complexity of the target group is by the use of existing protocols, guidelines, and evidence-based theories in interventions, which is advised for forensic and also general mental health [26, 27]. However, many existing in-person interventions for forensic mental health care are not theory-based, or treatment integrity by therapists is not always satisfactory $[16,28]$. Technology offers the possibility to deliver interventions based on theory and guidelines to patients in a standardized way to increase effectiveness, while still being able to tailor its content to individual patients. Consequently, eHealth can standardize care and interventions by incorporating existing guidelines [29].

eHealth has several characteristics that can increase the motivation of forensic psychiatric patients in managing their own care. If patients are motivated, they are more likely to have higher adherence to an intervention, meaning that they use it in the intended way and obtain positive treatment outcomes compared with disengaged and unmotivated patients [30,31]. Patient engagement can be achieved by using innovative, state-of-the-art technologies that appeal to the patient, like serious gaming, wearable technology, or VR [7, 30, 32]. Many of these new technologies do not primarily rely on conscious cognitive reflection, but mainly create experiences, which suits the lower literacy and education of the average forensic psychiatric patient. The way an intervention is designed can contribute to adherence as well, for example, via the application of principles from persuasive design [33, 34]. Finally, tailoring of a technology can positively impact adherence since it increases the fit with a patient's needs and wishes and can increase the perceived personal relevance of an intervention [34], which has a positive influence on patient motivation. 
Based on research on eHealth in general, many potential benefits of eHealth for forensic mental health can be identified. However, it is not yet clear in how far these advantages are relevant for and actualized in forensic mental health. To determine what the added value of eHealth is, this systematic review aims to provide an overview the current state of affairs of eHealth research in forensic mental health. This is accomplished by studying the types of studies, the studied technologies, and the mentioned advantages and disadvantages. Based on these findings, it can be identified if and how eHealth can have added value for forensic mental health, and domain-specific recommendations can be provided on how it can reach this potential added value. The research questions were generated via the PICOS method. The population was defined as forensic psychiatric patients, and interventions were all types of technologies used in the treatment of forensic psychiatric patients. Because of the explorative nature of this review, we did not address comparators in the research questions. Main outcomes were types of study, types of technology, and advantages and disadvantages. All study designs were included in this explorative review. This leads to the following research questions: (1) What studies are conducted on eHealth technologies used in the treatment of forensic psychiatric patients? (2) Which types of technologies are being researched in the treatment of forensic psychiatric patients? (3) What advantages and disadvantages accompany the different eHealth technologies that are used in the treatment of forensic psychiatric patients?

\section{Methods}

\section{Inclusion and Exclusion Criteria}

Studies that focused on the use of technological interventions to improve the treatment of forensic psychiatric patients were included. The main goal of the technology had to be related to the quality of treatment or the identification of elements essential for treatment, such as criminogenic needs or responsivity. Since the use of technology had to be of added value for the quality of treatment, technologies purely focused on facilitating the diagnostic process, such as computerassisted testing, were excluded. Furthermore, forensic psychiatric patients had to be the main target group and primary user, so technologies aiming to solely support the work process of therapists were excluded. Finally, technologies that were not related to treatment, but merely focused on court-mandated monitoring of the patient's location or assessment for court were excluded. Because of the broad scope and exploratory focus of this study, all study designs were included. 


\section{Literature Search}

Electronic searches of the databases Scopus, PsycINFO, and Web of Science were conducted in December 2017. An information expert specialized in developing and improving search strategies was involved in the construction of the search strategy. The same search strategy was used in each database. Search terms can be found in Section "Full Electronic Search Strategy" in Appendix. They were divided into two categories: one on treatment within forensic mental healthcare and one on technology. Search terms were identified by studying the search terms of relevant literature, and expert consultation with researchers in forensic mental health. Articles published up until December 2017, written in English, Dutch, or German, were included.

After removing duplicates in EndNote, two authors (Saskia Kelders and Hanneke Kip) reviewed the titles. Records were included if titles indicated that the article focused on treatment of forensic psychiatric patients, and if there was a possibility that the study used technology for treatment purposes. Because of the possibility of technology not being mentioned in the title, broad criteria were used to prevent the unjust exclusion of relevant articles. Articles were included if at least one of the authors decided that it was relevant. After screening the titles, obtained abstracts were read by two authors (Yvonne Bouman and Hanneke Kip), using the aforementioned inclusion and exclusion criteria. If technology was not explicitly mentioned in the abstract, did not contribute to treatment, or had a primary user group that did not consist of patients, records were excluded. Records were included if consensus by both authors was reached. Finally, full-text articles were read by one author (Hanneke Kip). Reasons for excluding and doubts about including articles were discussed with other authors (Saskia Kelders and Yvonne Bouman).

\section{Data Extraction}

The data extraction process of this systematic review was mostly based on the guidelines of the Cochrane Handbook for Systematic Reviews of Interventions [35]. However, a quality assessment was not performed because of the heterogeneity of the included study topics and designs: ranging from explorative qualitative studies to RCTs. The data extraction process started with the generation of an elaborate data extraction form, based on the research questions, that was used to standardize the reporting of relevant information from all obtained studies. The data extraction form contained four categories with their own subcategories: type of study, type of technology, and advantages/benefits, disadvantages/barriers. The data extraction 
form was filled in by one author (Hanneke Kip), a second author (Yvonne H. A. Bouman) was consulted in case of any uncertainties. In the first phase of the data extraction process, all relevant information was copied literally into the narrative data extraction forms. After that, the information in the table was summarized or made more concise. To answer the first research question, study designs were categorized inductively. We distinguished between experimental, quasi-experimental, quantitative cross-sectional, qualitative, and literature studies. A brief summary of the study goal as described in the articles was added as well. We also indicated whether the effectiveness of an eHealth intervention was assessed by a study and, if this was the case, whether it was more effective, less effective or ineffective, based on a classification for defining intervention effectiveness of Morrison et al. [36]. According to this classification, interventions can be seen as more effective if they led to improvements on the majority of outcomes, were at least as effective as comparison groups and more effective than no intervention groups. Interventions are classified as less effective if they led to improvements on a minority of outcome measures or were not as effective as comparison groups, but still more effective than waiting list groups. Interventions classified as ineffective did not lead to any improvements. The second research question was answered by coding the studied types of technologies inductively by comparing the nature of the technologies, resulting in six types of technologies. The results table was structured accordingly. For each study, the used technology, its target group, and its goal were described, using the data extraction forms. To answer the third research question, fragments on advantages and disadvantages literally copied from the articles were coded inductively as well. The first author executed the coding process, which included multiple iterations and constant adaptations, until data saturation was reached. During this iterative process, multiple versions of the code schemes were discussed with all authors and adapted accordingly. This resulted in two code schemes with main and subcodes representing different types of main and accompanying specified advantages and disadvantages.

\section{Results}

\section{Search Results}

The search strategy, the number of included articles, and reasons for full-text exclusion are provided in Figure 1. The main reason for excluding full-text articles was that they did not match the inclusion criteria: the goal of technology was not directly related to treatment, e.g., the mere monitoring of patients for security purposes, or the target group did not consist of patients, e.g., therapists. 
Figure 1. Search strategy and results.

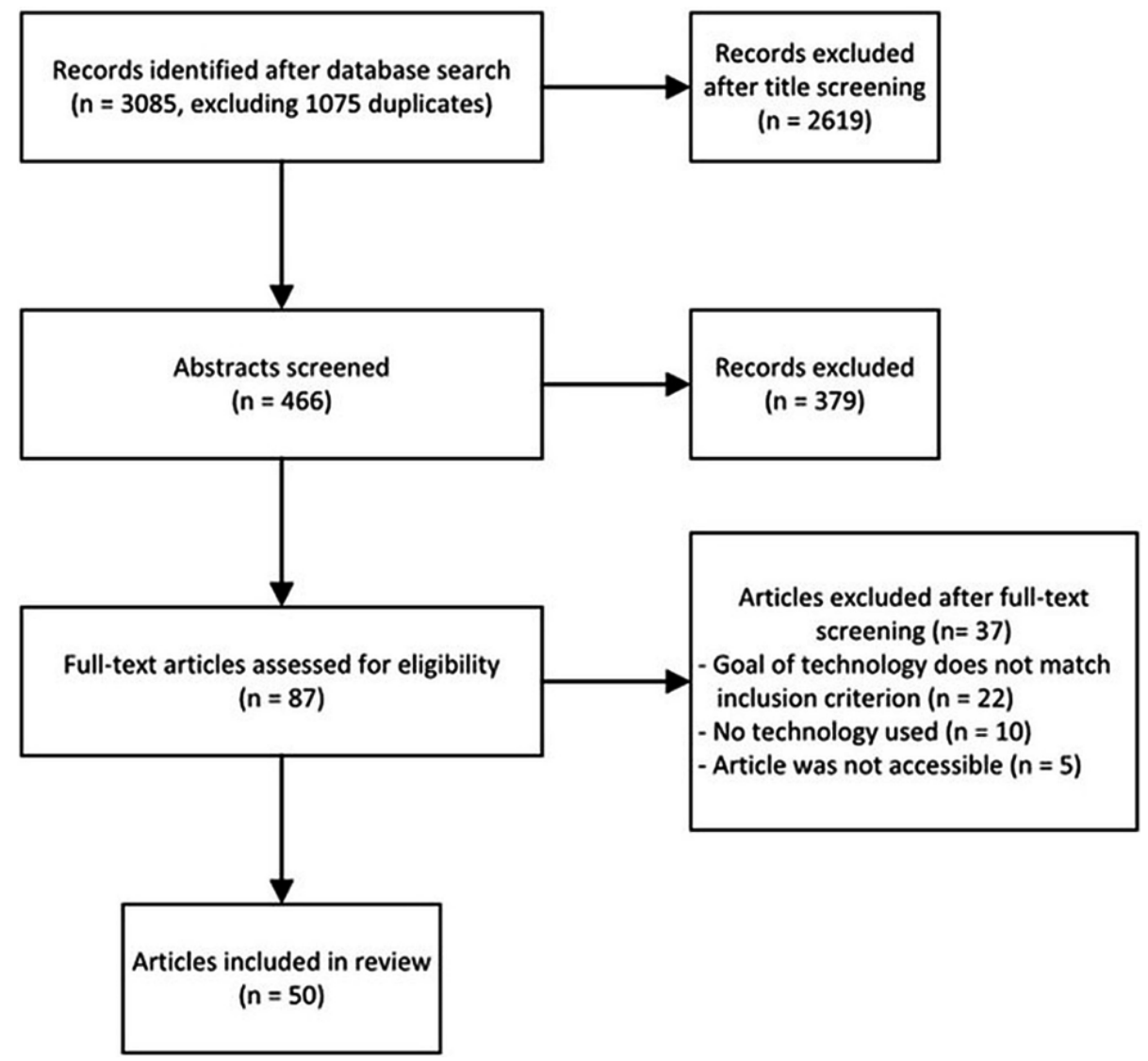

The included 50 studies are provided in Table 1, which is structured based on the research questions. The first column provides the authors and year, the second addresses the first research question by providing the study goal, its design and effectiveness based on the design, the third column describes the technology, and the identified advantages and disadvantages are summarized in the last column. This table serves as the backbone of the result section and can be used to identify references. 


\begin{tabular}{llll}
\hline Auth- & Study & Technology & Advantages and \\
ors, & Study goal, design, & Technology, target group & Disadvantages \\
country & effectiveness & \& goal & \\
\hline
\end{tabular}

\section{Category 1: Interactive, predominantly language-based interventions}

\begin{tabular}{|c|c|c|c|}
\hline $\begin{array}{l}\text { Berman, } \\
\text { Farzanfar } \\
\text { [1]; } \\
\text { Sweden }\end{array}$ & $\begin{array}{l}\text { Goal: Describing of user's flow } \\
\text { through a hearing voices } \\
\text { intervention. } \\
\text { Design: Qualitative study } \\
\text { Effectiveness: Not assessed }\end{array}$ & $\begin{array}{l}\text { Technology: An automated } \\
\text { interactive voice response (IVR) } \\
\text { service of the complex Telephone- } \\
\text { Linked Care (TLC) type which } \\
\text { conducts automated telephone } \\
\text { conversations with patients. } \\
\text { Target group: Forensic psychiatric } \\
\text { outpatients and probationers } \\
\text { convicted of violent crimes. } \\
\text { Goal: Reducing impulsivity by } \\
\text { offering automated psycho- } \\
\text { educational interventions based on } \\
\text { Dialectical Behaviour Therapy, } \\
\text { Cognitive Behaviour Therapy, and } \\
\text { Motivational interviewing. }\end{array}$ & $\begin{array}{l}\text { Advantages: Intervention } \\
\text { accessibility; Simulation of } \\
\text { situations; Potentially } \\
\text { effective } \\
\text { Disadvantages: Difficult to } \\
\text { implement }\end{array}$ \\
\hline $\begin{array}{l}\text { Chaple, } \\
\text { Sacks [2]; } \\
\text { USA }\end{array}$ & $\begin{array}{l}\text { Goal: Evaluating the feasibility } \\
\text { of implementing a } \\
\text { Therapeutic Education System } \\
\text { (TES) in a prison via inmate } \\
\text { participation, satisfaction, and } \\
\text { skills acquisition. } \\
\text { Design: Experimental study } \\
\text { (Stratified Randomized Trial). } \\
\text { Control: treatment-as-usual } \\
\text { Effectiveness: More effective }\end{array}$ & $\begin{array}{l}\text { Technology: Computerized } \\
\text { intervention: Therapeutic Education } \\
\text { System (E-TES) with interactive } \\
\text { multimedia modules } \\
\text { Target group: Prisoners (male and } \\
\text { female) with substance use } \\
\text { disorders } \\
\text { Goal: Learning drug refusal skills, } \\
\text { coping with thoughts about using, } \\
\text { identifying/managing triggers based } \\
\text { on psychosocial treatments. }\end{array}$ & $\begin{array}{l}\text { Advantages: Patient's } \\
\text { opinion; Care in secured } \\
\text { settings; Lowering } \\
\text { threshold; Intervention } \\
\text { accessibility; Tailoring; } \\
\text { Effective; Costs; Easy to } \\
\text { implement; Standardized } \\
\text { delivery } \\
\text { Disadvantages: Patient's } \\
\text { opinion; Therapeutic } \\
\text { relationship; Difficult to } \\
\text { implement }\end{array}$ \\
\hline $\begin{array}{l}\text { Cunningha } \\
\mathrm{m} \text {, Walton } \\
\text { [3]; } \\
\text { Canada }\end{array}$ & $\begin{array}{l}\text { Goal: Comparing computer- } \\
\text { and therapist-delivered } \\
\text { interventions in the } \\
\text { Emergency Department on } \\
\text { feasibility and effectiveness. } \\
\text { Design: Experimental study } \\
\text { (Three-armed randomized } \\
\text { controlled trial). Controls: no } \\
\text { intervention or other } \\
\text { intervention } \\
\text { Effectiveness: More effective }\end{array}$ & $\begin{array}{l}\text { Technology: Interactive multimedia } \\
\text { computer program, viewed on tablet } \\
\text { laptops (SafERteens) } \\
\text { Target group: Adolescents (14-18) } \\
\text { reporting alcohol use and violence in } \\
\text { the past year } \\
\text { Goal: Changing attitudes, self- } \\
\text { efficacy and readiness to change } \\
\text { alcohol use and violence. }\end{array}$ & $\begin{array}{l}\text { Advantages: Patient's } \\
\text { opinion; Fun; Tailoring; } \\
\text { Effective; Costs } \\
\text { Disadvantages: Patient's } \\
\text { opinion }\end{array}$ \\
\hline
\end{tabular}


Cunningha Goal: Evaluating the efficacy

$\mathrm{m}$,

Chermack on peer violence and alcohol

[4];

Canada

$\begin{array}{ll}\text { Elison, } & \text { Goal: Exploring Breaking Free } \\ \text { Weston } & \text { Online's potential to provide } \\ \text { [5]; UK } & \text { support to prisoners' } \\ & \text { substance misuse recovery } \\ & \text { and continuity of care post- } \\ & \text { release. }\end{array}$

Design: Cross-sectional study - quantitative; and qualitative study

Effectiveness: Not assessed

Lee,

Tofighi [6];

Goal: Comparing baseline

USA

$\begin{array}{ll} & \text { Effectiveness: Ineffective } \\ \text { Levesque, } & \text { Goal: The development of a } \\ \text { Johnson } & \text { stage-based computer- } \\ \text { [7]; USA } & \text { tailored intervention and } \\ & \text { assessment of its acceptability } \\ & \text { Design: Qualitative study } \\ & \text { Effectiveness: Not assessed }\end{array}$

Levesque, Goal: Examining whether

Ciavatta Journey to Change could

[8]; USA improve outcomes of domestic violence treatment. Design: Experimental study (RCT). Control: treatment-asusual

Effectiveness: More effective
Technology: Interactive multimedia computer program, viewed on tablet laptops (SafERteens)

Target group: Adolescents (14-18) reporting alcohol use and violence in the past year

Goal: Changing attitudes, selfefficacy and readiness to change alcohol use and violence.

Technology: Computer-assisted therapy (CAT) intervention with several sessions (Breaking Free Online)

Target group: Prisoners with substance misuse difficulties

Goal: Supporting prisoners in strengthening their resilience and build their recovery capital through a range of coping skills, based on Cognitive Behaviour Therapy and Mindfulness.

Technology: Web-based substance use intervention (Therapeutic Education System; TES)

Target group: Forensic outpatients in the first 30 days of their substance abuse treatment program

Goal: Treating addiction via a psychosocial web-based intervention.

Technology: Multimedia computertailored intervention (Rise Above Your Situation)

Target group: Court-mandated juvenile offenders with substance abuse or mental health problems Goal: Addressing responsivity by tailoring assessments and guidance to stage of change based on the Transtheoretical Model of Change. Technology: Multimedia computertailored intervention and print guide (Journey to Change)

Target group: Domestic violence offenders

Goal: Preventing domestic violence perpetration by individualized feedback based on the Transtheoretical Model of Change.

\section{Advantages: Effective} Disadvantages:

Therapeutic relationship; Not effective

\author{
Advantages: Patient's \\ opinion; Lowering \\ threshold; Intervention \\ accessibility; Potentially \\ effective; Time \\ Disadvantages: \\ Technological experience; \\ Misuse of technology; \\ High costs; Difficult to \\ implement

\section{Advantages: Patient's} \\ opinion; Effective \\ Disadvantages: Lack of \\ evidence in general
}

\author{
Advantages: Patient's \\ opinion; Care provider's \\ opinion; Tailoring; \\ Potentially effective; \\ Costs; Time; Sensitive \\ information; Standardized \\ delivery; Behaviour \\ change theory

\section{Advantages: Patient's} \\ opinion; Tailoring; \\ Effective; Costs; Time; \\ Standardized delivery \\ Disadvantages: Not \\ effective
}




$\begin{array}{ll}\begin{array}{ll}\text { Levesque, } \\ \text { Driskell } \\ \text { [9]; USA }\end{array} & \begin{array}{l}\text { Goal: Examining the opinions } \\ \text { of male batterers on an } \\ \text { intervention program. } \\ \text { Design: Cross-sectional study } \\ \text { - quantitative } \\ \text { Effectiveness: Not assessed }\end{array} \\ & \\ & \\ \text { Neville, } & \begin{array}{l}\text { Goal: Exploring the existence } \\ \text { of relevant violence brief }\end{array} \\ \text { [10]; UK } & \begin{array}{l}\text { interventions (VBI). } \\ \text { Design: Literature study } \\ \text { Effectiveness: Not assessed }\end{array}\end{array}$

Spohr, Goal: Assessing preferences

Taxman and evaluating the role of

[11]; USA voluntary electronic reminders in achieving early treatment and probation tasks.

Design: Experimental study (three-armed RCT). Controls: other intervention or treatment-as-usual

Effectiveness: More effective

Tait and Goal: Systematically reviewing

Lenton the evidence for the

[12]; effectiveness of online

Australia interventions in reducing sexual violence or IPV.

Design: Literature study

Effectiveness: Not assessed

Ranney, Goal: Examining the

Goldstick secondary effects of a brief

[13]; USA alcohol-and-violence ED

intervention on depressive symptoms.

Design: Experimental study (three-armed RCT). Controls: other intervention or treatment-as-usual

Effectiveness: More effective

Walters, Goal: Developing a web-based

Ondersma intervention for substance

[14]; USA abusing criminal justice clients.

Design: Qualitative study
Technology: Expert system: computer programs that mimic the reasoning and problem solving of a human expert

Target group: Domestic violence offenders in court-mandated programs

Goal: Activating processes of change in domestic violence offenders based on the Transtheoretical model of Change.

Technology: (1) Computerized brief interventions and (2) a touch-screen computer and a video of Intimate

Partner Violence (IPV)

Target group: Young men undergoing treatment for a violent injury

Goal: Reducing violence.

Technology: Web-based intervention with text or email reminders

(Motivational Assessment Program

to Initiate Treatment MAPIT)

Target group: Drug-involved offenders near the start of probation Goal: Targeting individual substance use and initiating treatment, based on behavioural theories.

Technology: Web-based

technologies

Target group: People who

perpetrate alcohol-related sexual

violence or IPV

Goal: Reducing sexual violence and alcohol use.

Technology: Interactive multimedia computer program, viewed on tablet laptops (SafERteens)

Target group: Adolescents (14-18) reporting alcohol use and violence in the past year

Goal: Changing attitudes, self-

efficacy and readiness to change alcohol use and violence.

Technology: Web-based, automated intervention on a tablet computer (Motivational Assessment Program to Initiate Treatment; MAPIT)
Advantage: Fun; Time Disadvantage: Not effective

\section{Advantages: Effective;} costs

Advantage: Patient's opinion; potentially effective; costs Disadvantage: Patient's opinion

Advantages: Care in secured settings; Lowering threshold Disadvantages: Lack of evidence in general

\section{Advantages: Effective Disadvantages: Not effective}

\section{Advantages: Costs;}

Standardized delivery 
Effectiveness: Not assessed

\begin{tabular}{|c|c|}
\hline $\begin{array}{l}\text { Walton, } \\
\text { Chermack } \\
\text { [15]; USA }\end{array}$ & $\begin{array}{l}\text { Goal: Determining the efficacy } \\
\text { of brief interventions } \\
\text { addressing violence and } \\
\text { alcohol use among } \\
\text { adolescents in an urban ED. } \\
\text { Design: Experimental study } \\
\text { (three-armed RCT). Controls: } \\
\text { other intervention or } \\
\text { treatment-as-usual } \\
\text { Effectiveness: More effective }\end{array}$ \\
\hline $\begin{array}{l}\text { Wannachai } \\
\text { yakul, } \\
\text { Thapinta } \\
\text { [16]; } \\
\text { Thailand }\end{array}$ & $\begin{array}{l}\text { Goal: Investigating the } \\
\text { effectiveness of a } \\
\text { computerized program for } \\
\text { reducing depression among } \\
\text { youths with delinquency } \\
\text { problems. } \\
\text { Design: Experimental study } \\
\text { (RCT). Control: treatment-as- } \\
\text { usual } \\
\text { Effectiveness: More effective }\end{array}$ \\
\hline $\begin{array}{l}\text { Wilson, } \\
\text { Palk, } \\
\text { Sheehan, } \\
\text { Wishart \& } \\
\text { Watson } \\
\text { (2017); } \\
\text { Australia }\end{array}$ & $\begin{array}{l}\text { Goal: Exploring whether an } \\
\text { online intervention is } \\
\text { acceptable, user friendly and } \\
\text { contains useful content. } \\
\text { Design: Qualitative; and cross- } \\
\text { sectional quantitative (pilot } \\
\text { study) } \\
\text { Effectiveness: Not assessed }\end{array}$ \\
\hline
\end{tabular}

Target group: Criminal justice clients with substance abuse problems, near the start of probation Goal: Increasing motivation for substance abuse treatment among clients using illicit substances.

Technology: Tablet laptop computer with an interactive animated program with touch screens and audio via headphones (SafERteens) Target group: Adolescents reporting past-year alcohol use and aggression in the Emergency Department

Goal: Decreasing the occurrence of peer violence following an ED visit.

Technology: Computerized Cognitive Behavioural Therapy

Target group: Youths (14-18 at time of offense) in a juvenile vocational training centre

Goal: Reducing depression among youths in the detention centre who have a different context and have limitations accessing traditional CBT.

Technology: Online web-based intervention, accessible via desktop, mobile phone or tablet.

Target group: First-time convicted drink driving offenders

Goal: Creating awareness in drink driving and associated alcoholrelated behaviour in order to prevent reoffending.

\author{
Advantages: Effective; \\ Standardized delivery \\ Disadvantages: Not \\ effective

\section{Advantages: Fit} \\ technological climate; \\ Effective \\ Disadvantages: Patient's \\ opinion
}

\section{Category 2: Communication technology for synchronous interpersonal interaction}

$\begin{array}{ll}\begin{array}{l}\text { Absalom- } \\ \text { Horby, }\end{array} & \begin{array}{l}\text { Goal: Examining the attitudes } \\ \text { of staff and relatives of } \\ \text { Hare [17]; } \\ \text { UK }\end{array} \\ & \begin{array}{l}\text { forensic patients towards } \\ \text { taking part in an online family } \\ \text { intervention. } \\ \text { Design: } \text { Cross-sectional - } \\ \text { quantitative } \\ \text { Effectiveness: Not assessed }\end{array} \\ & \\ \text { Absalom- } & \begin{array}{l}\text { Goal: Describing the } \\ \text { implementation a web camera }\end{array} \\ & \text { to facilitate a family }\end{array}$

Technology: Video conferencing technology: Web camera facilitation for family intervention (e-FFI)

Target group: Service users of medium secure forensic units with schizophrenia and their family Goal: Delivering psychological interventions through the use of internet technologies such as webcams.

\section{Technology: Video conferencing} technology: Web camera facilitation for family intervention (e-FFI)

\author{
Advantages: Family's \\ opinion; Geographical \\ barriers \\ Disadvantages: Care \\ provider's opinion; \\ family's opinion
}


intervention (e-FF) in the

treatment of schizophrenia.

Design: Cross-sectional quantitative ( $n=1$ study)

Effectiveness: Not assessed

$\begin{array}{ll}\begin{array}{ll}\text { Adjorlolo } \\ \text { and Chan }\end{array} & \begin{array}{l}\text { Goal: Providing issues and } \\ \text { practice considerations that } \\ \text { [19]; China } \\ \text { enhance the results of } \\ \text { forensic assessments with } \\ \text { Video Conferencing. } \\ \text { Design: Literature study } \\ \text { Effectiveness: Not assessed }\end{array} \\ \text { Antonacci, } & \begin{array}{l}\text { Goal: Reviewing empirical } \\ \text { Bloch [20]; }\end{array} \\ \text { USA } & \begin{array}{l}\text { evfence on the use and } \\ \text { forensic psychiatry. }\end{array} \\ & \begin{array}{l}\text { Design: Literature study } \\ \text { Effectiveness: Not assessed }\end{array}\end{array}$

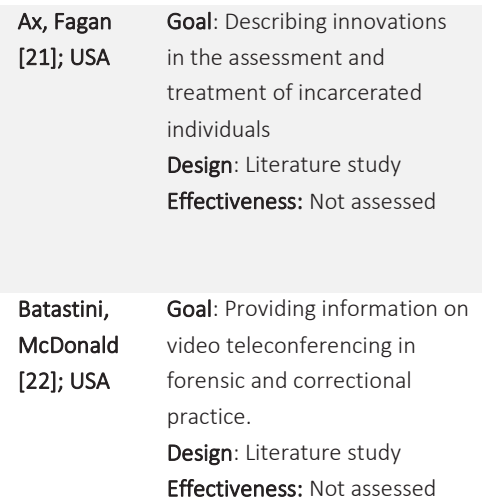

$\begin{array}{ll}\text { Batastini, } & \text { Goal: Summarizing all } \\ \text { King [23]; } & \text { evaluations of } \\ \text { USA } & \text { telepsychological services that } \\ & \text { involve videoconferencing } \\ & \text { equipment in forensic } \\ & \text { psychiatry. }\end{array}$

Target group: Forensic service users on forensic wards with a diagnosis on schizophrenia spectrum and their families

Goal: Treating schizophrenia within a forensic service via family interventions.

\section{Technology: Video conferencing} technology

Target group: Forensic psychiatric patients and psychologists

Goal: Obtaining accurate, reliable and valid assessment results.

Technology: Video conferencing technology

Target group: Forensic psychiatric patients and therapists

Goal: Providing or supporting clinical psychiatric care at a distance.

\section{Technology: Video conferencing} technology

Target group: Correctional mental healthcare; prisoners

Goal: Delivering health care services over a distance between specialty services and nonspecialty correction facilities.

Technology: Video conferencing technology

Target group: Forensic psychiatric patients in criminal justice settings Goal: Several goals: forensic mental health assessment (e.g. competency determinations, sexually violent predator evaluations), juvenile rehabilitation, group treatment for inmates in segregations.

Technology: Video conferencing technology

Target group: Justice-involved substance abusing clients Goal: Connect agencies in need of services to agencies that render such services, therefore reducing relapse

\author{
Advantages: Care in \\ secured settings; Costs \\ Disadvantages: Mental or \\ physical disease; Faulty \\ technology; Slow \\ connection \\ Advantages: Patient's \\ opinion; Care in secured \\ settings; Effectiveness \\ based on reviews

\section{Disadvantages:} \\ Overhearing; lack of \\ evidence in general
}

Advantages: Geographical
barriers; Care in secured
settings
Disadvantages: Lack of
evidence in general; High
costs
Advantages: Patient's
opinion; Geographical
barriers; Care in secured
settings; Lowering
threshold; Fit
technological climate;
Effectiveness based on
reviews; Costs; Time
Disadvantages: Care
provider's opinion;
Overhearing; Therapeutic
relationship; Lack of
evidence in general;
Faulty technology
Advantages: Patient's
opinion; Lowering
threshold; Effectiveness
based on reviews
Disadvantages: Mental or
physical disease;
Technological experience;
Detecting subtle




\begin{tabular}{|c|c|c|c|}
\hline & $\begin{array}{l}\text { Design: Literature study } \\
\text { (systematic review \& meta- } \\
\text { analysis) } \\
\text { Effectiveness: Not assessed }\end{array}$ & $\begin{array}{l}\text { and recidivism among substance } \\
\text { abuse and offender clients. }\end{array}$ & $\begin{array}{l}\text { behaviours; Lack of } \\
\text { evidence in general }\end{array}$ \\
\hline $\begin{array}{l}\text { Brodey, } \\
\text { Claypoole } \\
\text { [24]; USA }\end{array}$ & $\begin{array}{l}\text { Goal: Determining the level of } \\
\text { satisfaction with } \\
\text { telepsychiatry evaluations } \\
\text { Design: Qualitative study } \\
\text { Effectiveness: Not assessed }\end{array}$ & $\begin{array}{l}\text { Technology: Video conferencing } \\
\text { technology } \\
\text { Target group: Forensic psychiatric } \\
\text { patient inmates in a large urban jail } \\
\text { Goal: Using telepsychiatry for } \\
\text { delivering psychiatric services. }\end{array}$ & $\begin{array}{l}\text { Advantages: Patient's } \\
\text { opinion; Geographical } \\
\text { barriers; Potential } \\
\text { effectiveness; Time } \\
\text { Disadvantages: Patient's } \\
\text { opinion }\end{array}$ \\
\hline $\begin{array}{l}\text { Farabee, } \\
\text { Calhoun } \\
\text { [25]; USA }\end{array}$ & $\begin{array}{l}\text { Goal: Comparing the } \\
\text { effectiveness of telepsychiatry } \\
\text { and in-person treatment as } \\
\text { usual among parolees. } \\
\text { Design: Quasi-experimental } \\
\text { study (Randomized field } \\
\text { experiment). Control group: } \\
\text { treatment-as-usual } \\
\text { Effectiveness: More effective }\end{array}$ & $\begin{array}{l}\text { Technology: Video conferencing } \\
\text { technology } \\
\text { Target group: Parolees from } \\
\text { outpatient clinics who received } \\
\text { psychiatric care } \\
\text { Goal: Offering psychiatric treatment } \\
\text { via videoconferencing. }\end{array}$ & $\begin{array}{l}\text { Advantages: Patient's } \\
\text { opinion; Effective } \\
\text { Disadvantages: } \\
\text { Therapeutic relationship; } \\
\text { Faulty technology }\end{array}$ \\
\hline $\begin{array}{l}\text { Khalifa, } \\
\text { Saleem } \\
\text { [26]; UK }\end{array}$ & $\begin{array}{l}\text { Goal: Literature review on } \\
\text { forensic applications of } \\
\text { telepsychiatry. } \\
\text { Design: Literature study } \\
\text { Effectiveness: Not assessed }\end{array}$ & $\begin{array}{l}\text { Technology: Video conferencing } \\
\text { technology } \\
\text { Target group: Forensic psychiatric } \\
\text { patients and their therapists } \\
\text { Goal: Delivering mental health } \\
\text { services from a distance. }\end{array}$ & $\begin{array}{l}\text { Advantages: Patient's } \\
\text { opinion; Care provider's } \\
\text { opinion; Geographical } \\
\text { barriers; Care in secured } \\
\text { settings; Effectiveness } \\
\text { based on reviews; Costs; } \\
\text { Time } \\
\text { Disadvantages: Care } \\
\text { provider's opinion; Data } \\
\text { storage; Overhearing; } \\
\text { Detecting subtle } \\
\text { behaviours; Lack of } \\
\text { evidence in general; High } \\
\text { costs; Difficult to } \\
\text { implement; Faulty } \\
\text { technology }\end{array}$ \\
\hline $\begin{array}{l}\text { Manfredi, } \\
\text { Shupe } \\
\text { [27]; USA }\end{array}$ & $\begin{array}{l}\text { Goal: Determining the } \\
\text { feasibility of telepsychiatric } \\
\text { consultations in an } \\
\text { underserved rural jail. } \\
\text { Design: Qualitative study } \\
\text { Effectiveness: Not assessed }\end{array}$ & $\begin{array}{l}\text { Technology: Video conferencing } \\
\text { technology } \\
\text { Target group: Jail inmates who } \\
\text { requested or were found to be in } \\
\text { need of psychiatric care } \\
\text { Goal: Increasing access to psychiatric } \\
\text { treatment. }\end{array}$ & $\begin{array}{l}\text { Advantages: Patient's } \\
\text { opinion; Care provider's } \\
\text { opinion; Care in secured } \\
\text { settings; Geographical } \\
\text { barriers; Time } \\
\text { Disadvantages: Lack of } \\
\text { evidence in general }\end{array}$ \\
\hline $\begin{array}{l}\text { Miller, } \\
\text { Clark [28]; } \\
\text { USA }\end{array}$ & $\begin{array}{l}\text { Goal: Highlighting the use of } \\
\text { teleconferencing for } \\
\text { improving access to mental } \\
\text { healthcare for forensic } \\
\text { patients. } \\
\text { Design: Literature study } \\
\text { Effectiveness: Not assessed }\end{array}$ & $\begin{array}{l}\text { Technology: Video conferencing } \\
\text { technology } \\
\text { Target group: Forensic clinical } \\
\text { practice patients in a child psychiatry } \\
\text { outpatient clinic } \\
\text { Goal: Improving access to services } \\
\text { like evaluations, assessment, } \\
\text { medication management and } \\
\text { treatment coordination. }\end{array}$ & $\begin{array}{l}\text { Advantages: Patient's } \\
\text { opinion; Care provider's } \\
\text { opinion; Geographical } \\
\text { barriers; Costs } \\
\text { Disadvantages: Data } \\
\text { storage; High costs; } \\
\text { Difficult to implement; No } \\
\text { legislation }\end{array}$ \\
\hline
\end{tabular}




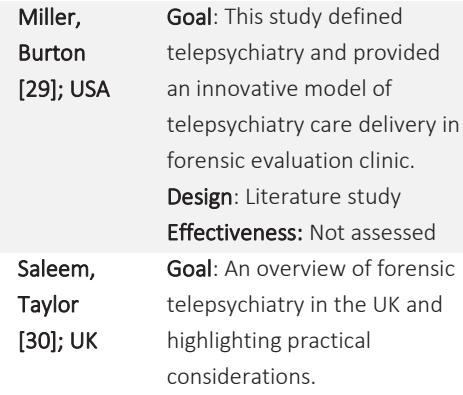

Design: Literature study

Effectiveness: Not assessed

$\begin{array}{ll}\text { Sales, } & \text { Goal: Literature review on } \\ \text { McSweene } & \text { forensic applications of } \\ \text { y, Saleem } & \text { telepsychiatry - update of } \\ \text { \& Khalifa } & \text { Khalifa et al. (2008) } \\ \text { (2017); UK } & \text { Design: Literature study } \\ & \text { Effectiveness: Not assessed }\end{array}$

Sullivan,

Chapman

[31];

Australia

Tucker,

Olfson

[32]; USA

Goal: Assessing inmate preferences for telemedicine psychiatric consultation compared to regular care. Design: Qualitative study Effectiveness: Not assessed
Technology: Video conferencing technology

Target group: Patients of child and adolescent forensic clinics

Goal: Assessing and treating forensic psychiatric patients.

Technology: Videoconferencing

technology

Target group: Community forensic service clients

Goal: Providing mental health services in a medicolegal context: forensic evaluations, clinical consultation and education.

Technology: Video conferencing technology

Target group: Forensic psychiatric patients and their therapists

Goal: Delivering mental health services from a distance.

Technology: Videoconferencing technology

Target group: Forensic psychiatric patients

Goal: Linking remote prisons, courts and psychiatric clinics with distant specialist services, enabling activities including assessment and treatment. Technology: Video conferencing technology

Target group: Inmates who receive psychiatric telemedicine consultations

Goal: Delivering different kinds of mental services via telemedicine.
Advantages: Costs; Time Disadvantages: Care provider's opinion; Data storage; Therapeutic relationship; High costs; Faulty technology; Slow connection; No protocols Advantages: Costs; Time Disadvantages: Care provider's opinion; Therapeutic relationship; Difficult to implement; No legislation

Advantages: Patient's opinion; Geographical barriers; Intervention accessibility; Costs; Time Disadvantages:

Overhearing; Detecting subtle behaviours; Lack of evidence in general; Costs; Implementation; No protocols

Advantages: Patient's opinion; Geographical barriers; Effectiveness based on reviews; Costs; Time

\section{Disadvantages:}

Overhearing; Slow connection; No legislation Advantages: Patient's opinion; Time; Sensitive information

Disadvantages: Patient's opinion

\section{Category 3: Simulations of offense-related realistic situations}

\author{
Arborelius, \\ Goal: Evaluating of a \\ Fors [33]; \\ computer-based system for its \\ Sweden \\ effectiveness in distinguishing \\ between offenders and a \\ comparison group. \\ Design: Cross-sectional study \\ - quantitative \\ Effectiveness: Not assessed
}

Technology: Realistically simulated visual events on a computer

(Reactions on Display)

Target group: Forensic psychiatric patients convicted of violent criminal acts

Goal: Investigating how offenders understand and interpret social

\author{
Advantages: Patient's \\ opinion; Potentially \\ effective
}




\begin{tabular}{|c|c|c|c|}
\hline & & $\begin{array}{l}\text { interactions and react to emotions } \\
\text { and violence, for both assessment } \\
\text { and treatment }\end{array}$ & \\
\hline $\begin{array}{l}\text { Fromberge } \\
\text { r, Jordan } \\
\text { [34]; } \\
\text { Germany }\end{array}$ & $\begin{array}{l}\text { Goal: Showing that Virtual } \\
\text { Reality has an especially high } \\
\text { potential for forensic } \\
\text { psychiatry. } \\
\text { Design: Literature study } \\
\text { Effectiveness: Not assessed }\end{array}$ & $\begin{array}{l}\text { Technology: Virtual Reality } \\
\text { Target group: Forensic psychiatric } \\
\text { patients } \\
\text { Goal: Improving quality of forensic } \\
\text { psychiatric care in general. }\end{array}$ & $\begin{array}{l}\text { Advantages: Care in } \\
\text { secured settings; } \\
\text { Lowering threshold; } \\
\text { Ecological validity } \\
\text { Disadvantages: Misuse of } \\
\text { technology; Lack of } \\
\text { evidence in general }\end{array}$ \\
\hline $\begin{array}{l}\text { Hubal, } \\
\text { Fishbein } \\
\text { [35]; USA }\end{array}$ & $\begin{array}{l}\text { Goal: Using Embodied } \\
\text { Conversational Agents (ECAs) } \\
\text { vignettes for predicting } \\
\text { treatment response and } \\
\text { misconduct. } \\
\text { Design: Quasi-experimental } \\
\text { study (pre-post-test). Control: } \\
\text { no intervention } \\
\text { Effectiveness: Ineffective }\end{array}$ & $\begin{array}{l}\text { Technology: Embodied } \\
\text { Conversational Agents: virtual } \\
\text { characters rendered on a monitor } \\
\text { with whom a user converses } \\
\text { Target group: Prisoners in } \\
\text { correctional institutions } \\
\text { Goal: Measuring social competency } \\
\text { by simulating real interactions with } \\
\text { other people; assessing decision- } \\
\text { making in a social context through } \\
\text { virtual role-playing. }\end{array}$ & $\begin{array}{l}\text { Advantages: Patient's } \\
\text { opinion; Effective; } \\
\text { Ecological validity } \\
\text { Disadvantages: } \\
\text { Technological experience; } \\
\text { Overhearing; Negative } \\
\text { affect; Not effective; } \\
\text { Faulty technology }\end{array}$ \\
\hline $\begin{array}{l}\text { Montgome } \\
\text { ry and } \\
\text { Brooks } \\
\text { [36]; USA }\end{array}$ & $\begin{array}{l}\text { Goal: Reviewing the progress } \\
\text { of incompetent defendants in } \\
\text { a program using a television } \\
\text { crime-drama "Law \& Order. } \\
\text { Design: Quasi-experimental } \\
\text { study (pre- and post-test) } \\
\text { Effectiveness: More effective }\end{array}$ & $\begin{array}{l}\text { Technology: A didactic program, } \\
\text { using a popular crime drama series } \\
\text { (via tv) - Law \& Order } \\
\text { Target group: Defendants } \\
\text { incompetent to stand trial } \\
\text { Goal: Improving the treatment goal } \\
\text { of competency restoration. }\end{array}$ & Advantages: Effective \\
\hline $\begin{array}{l}\text { Sygel, } \\
\text { Kristiansso } \\
\text { n [37]; } \\
\text { Sweden }\end{array}$ & $\begin{array}{l}\text { Goal: Investigating how male } \\
\text { offenders used and reacted to } \\
\text { a new interactive computer } \\
\text { compared to a control group. } \\
\text { Design: Cross-sectional study } \\
\text { - quantitative, and qualitative } \\
\text { study } \\
\text { Effectiveness: Not assessed }\end{array}$ & $\begin{array}{l}\text { Technology: Computer based } \\
\text { simulation: a film of an IPV scenario, } \\
\text { interactive questions (Reactions on } \\
\text { Display/Intimate Partner Violence) } \\
\text { Target group: Male offenders } \\
\text { convicted of IPV towards women } \\
\text { Goal: Facilitating change in the } \\
\text { participant's violent behaviour by } \\
\text { allowing him to reflect upon feelings, } \\
\text { thoughts and actions during a typical } \\
\text { IPV case and practice responses. }\end{array}$ & $\begin{array}{lr}\text { Advantages: } & \text { Patient's } \\
\text { opinion; } & \text { Potentially } \\
\text { effective; } & \text { Sensitive } \\
\text { information } & \\
\begin{array}{l}\text { Disadvantages: } \\
\text { affect }\end{array} & \text { Negative }\end{array}$ \\
\hline $\begin{array}{l}\text { Wijk, } \\
\text { Edelbring } \\
{[38] ;} \\
\text { Sweden }\end{array}$ & $\begin{array}{l}\text { Goal: Developing and pilot } \\
\text { testing a simulation system to } \\
\text { study and support } \\
\text { rehabilitation of mentally } \\
\text { disordered offenders. } \\
\text { Design: Qualitative study } \\
\text { Effectiveness: Not assessed }\end{array}$ & $\begin{array}{l}\text { Technology: Computer-based } \\
\text { simulation system with videos of a } \\
\text { person carrying out everyday } \\
\text { activities and decision points } \\
\text { (Reactions on Display) } \\
\text { Target group: Mentally disordered } \\
\text { ward \& outpatients who conducted } \\
\text { a violent crime, and had a psychotic } \\
\text { illness or autistic traits } \\
\text { Goal: Learning more about patients } \\
\text { and identifying dynamic risk factors, } \\
\text { and improving rehabilitation. }\end{array}$ & $\begin{array}{l}\text { Advantages: Patient's } \\
\text { opinion; Care provider's } \\
\text { opinion; Intervention } \\
\text { accessibility; } \quad \text { Fun; } \\
\text { Ecological validity }\end{array}$ \\
\hline
\end{tabular}




\section{Category 4: Simulations of realistic offense-related stimuli}

$\begin{array}{ll}\text { Benbouric } & \text { Goal: Introducing VR } \\ \text { he, Nolet } & \text { applications in the context of } \\ \text { [39]; } & \text { forensic psychiatry. } \\ \text { Canada } & \text { Design: Literature study } \\ & \text { Effectiveness: Not assessed }\end{array}$

\begin{tabular}{|c|c|}
\hline Dennis, & Goal: Determining the \\
\hline Rouleau & perceived age of virtual \\
\hline [40]; & characters and measuring \\
\hline \multirow[t]{5}{*}{ Canada } & sexual arousal by using \\
\hline & computer-generated images. \\
\hline & Design: Cross-sectional study \\
\hline & - quantitative \\
\hline & Effectiveness: Not assessed \\
\hline \multirow{7}{*}{$\begin{array}{l}\text { Renaud, } \\
\text { Trottier } \\
\text { [41]; } \\
\text { Canada }\end{array}$} & Goal: Comparing a VR \\
\hline & compared to a standard \\
\hline & auditory modality to generate \\
\hline & sexual arousal profiles. \\
\hline & Design: Cross-sectional study \\
\hline & - quantitative \\
\hline & Effectiveness: Not assessed \\
\hline Renaud, & Goal: Validating avatars used \\
\hline Proulx & in the assessment and \\
\hline [42]; & treatment of deviant sexual \\
\hline Canada & preferences. \\
\hline
\end{tabular}

Design: Cross-sectional study - quantitative

Effectiveness: Not assessed
Technology: Virtual Reality of 3D computer generated stimuli of children \& a virtual character expressing pain

Target group: Child sexual abusers and violent offenders

Goal: Measuring deviant sexual interest to predict sexual reoffending and training participants to improve empathic responses. Technology: Large screen with virtual characters and Penile Plethismography (PPG) to measure sexual arousal

Target group: Sex offenders Goal: Reliably differentiating sex offenders by means of partner receptivity.

Technology: Virtual Reality with 3D virtual characters depicted naked, Penile plethysmography (PPG)

Target group: Sex offenders, paedophilia

Goal: Assessing paedophilia and profiles with high ecological validity. Technology: Virtual reality with avatars, eye-tracking devices and penile plethysmography (PPG) Target group: Paraphiliacs with deviant sexual preferences Goal: Assessing and treating deviant sexual preferences in a valid way.
Advantages: Effectiveness based on reviews; Ecological validity; Physiological reactions

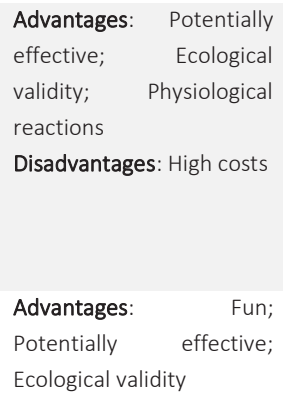

Advantages: Physiological reactions

Disadvantages: Lack of evidence in general

\section{Category 5: Games}

\begin{tabular}{|c|c|c|c|}
\hline $\begin{array}{l}\text { Bacon, } \\
\text { Farnworth } \\
\text { [43]; } \\
\text { Australia }\end{array}$ & $\begin{array}{l}\text { Goal: Describing the use of the } \\
\text { Nintendo Wii Fit in changing } \\
\text { engagement in physical } \\
\text { activity for patients at risk of } \\
\text { obesity. } \\
\text { Design: Cross-sectional study } \\
\text {-quantitative; and qualitative } \\
\text { study(case studies) } \\
\text { Effectiveness: Not assessed }\end{array}$ & $\begin{array}{l}\text { Technology: Wii Fit: competitive Wii } \\
\text { games where bodily movements are } \\
\text { required to play them } \\
\text { Target group: Patients at a secure } \\
\text { forensic mental health hospital with } \\
\text { a BMI between } 25 \text { and } 32 \\
\text { Goal: Use in rehabilitation to assist in } \\
\text { meeting physical activity goals and } \\
\text { increasing wellbeing. }\end{array}$ & $\begin{array}{l}\text { Advantages: Lowering } \\
\text { threshold; Fun; Potentially } \\
\text { effective } \\
\text { Disadvantages: Difficult to } \\
\text { implement }\end{array}$ \\
\hline
\end{tabular}


Goal: Comparing findings from videogame research with those among forensic psychiatry.

Design: Literature study

Effectiveness: Not assessed

\section{Hodge, Goal: Testing the feasibility Davis [45]; and acceptance of a serious UK \\ Reynolds \\ et al. \\ (2017); UK \\ game and describing the development of the prototype game with service users. \\ Design: Qualitative study Effectiveness: Not assessed \\ Goal: A feasibility study to develop and test the acceptability and usability of a serious game developed with and for service users and providers.}

Design: Qualitative study

Effectiveness: Not assessed
Technology: Video games: regular, commercial games

Target group: Forensic clients Goal: Supporting the recovery process and serving as a useful relapse prevention strategy by promoting locus of control.

Technology: Computer-based serious game (StreetWise)

Target group: Secure forensic mental health service users

Goal: Supporting and enhancing the rehabilitation of forensic mental health service users prior to their discharge and return to the community.

Technology: Computer-based serious game (StreetWise)

Target group: Secure forensic mental health service users

Goal: Supporting and enhancing the rehabilitation of forensic mental health service users prior to their discharge and return to the community.
Advantages: Geographical barriers; Care in secured settings; Fit technological climate; Simulation of situations; Fun;

Effectiveness based on reviews

Disadvantages: Negative affect; Lack of evidence in general

Advantages: Patient's opinion; Care provider's opinion; Simulation of situations

Disadvantages: Care provider's opinion;

Technological experience

\section{Advantages: Fit}

technological climate;

Simulation of situations;

Fun; Potential

effectiveness; Ecological

validity; Sensitive

information;

Disadvantages: Patient's opinion; Negative affect; Therapeutic relationship; Misuse of technology; Lack of evidence in general; Difficult to implement

\section{Category 6: Platforms with user-generated and shared content}

\section{Kernsmith \\ and \\ Kernsmith \\ [46]; USA \\ Goal: Exploring processes of change and barriers to \\ rehabilitation in an online self- help group for sex offenders \\ Design: Qualitative study \\ Effectiveness: Not assessed}

Van

Gelder,

Luciano

[47]

Netherlan

ds/USA
Goal: Testing whether a future online self reduces delinquent involvement.

Design: Quasi-experimental study (field experiment). Control group: other intervention.

Effectiveness: More effective
Technology: Website/forum with messages: online self-help group

Target group: Sex offenders

Goal: Facilitating a supportive environment but does not providing therapy, based on a cognitivebehavioural model.

Technology: Social media with daily messages of a future self (Facebook) Target group: Delinquent individuals Goal: Reducing delinquent behaviour/involvement.

\author{
Advantages: Lowering \\ threshold; potentially \\ effective \\ Disadvantages: Misuse of \\ technology
}

\section{Advantages: Fit} technological climate; Effective; Time; Easy to implement 


\section{Study Designs, Research Goals, and Effectiveness}

The included studies were categorized based on their study design (see Table 1). The following categories were identified: experimental studies $(n=9)$, quasi-experimental studies ( $n=4)$, qualitative studies ( $n=12)$, quantitative cross-sectional studies $(n=9)$, and literature studies $(n=16)$. There was much variation in research goals.

All included experimental studies used a randomized controlled trial with either two or three groups. The studies aimed to determine the effectiveness of interventions via measuring treatment outcomes such as depressive complaints, alcohol abuse, and attitudes toward violence. Several studies also paid attention to participation and satisfaction with the intervention. The quasi-experimental studies had differing goals: while some determined effectiveness via outcomes such as delinquent involvement, others were more focused on process-related outcomes such as treatment response and progress. Most of the qualitative studies investigated the perspective of the patient via measuring outcomes such as use of the technology, patient preferences, acceptability, or satisfaction with the intervention. Some studies also described and analysed the development process of eHealth interventions. Studies in the quantitative, cross-sectional category had an especially broad range of research goals. While some determined attitudes and opinions about interventions, others aimed to design and validated realistic stimuli. Further topics that were studied were feasibility, implementation, or potential effectiveness of interventions. Studies focused not only on ready-to-use interventions but also on interventions that were still being developed. The literature studies had in common that they all used scientific literature to provide an overview of the current state of affairs of a specific type of intervention for forensic mental health. However, the included studies ranged from highly structured meta-analyses and systematic reviews to literature reviews and viewpoint papers. Consequently, research goals differed as well: several studies provided a systematic overview of empirical evidence, others provided an overview of existing interventions or technologies, and some focused mainly on the practical applications of technologies in practice.

The effectiveness of an individual intervention was assessed via an experimental or quasi-experimental study by 13 of the 50 studies. Ten of them found that an intervention was as at least as effective as a comparison group and more effective than no intervention groups on most of the outcomes. Three studies found no proof for effectiveness. 


\section{Types of Technology}

To provide an oversight of the studied eHealth interventions, we created a categorization of the technologies described in the included articles, based on the way its content was presented and communicated to the user. This resulted in six types of technology.

\section{Category 1: Interactive, Predominantly Language-Based Interventions}

This type of technology aims to change offense-related cognitions or behaviour, mostly via language-based information, assignments, or exercises ( $n=17$ ). Their content can be delivered via multiple modalities, e.g., written text, videos, or audio, and is often based on theory or existing, evidence-based therapies. The system also reacts on input of the user. Multiple technologies are used in this category, but most included interventions were delivered via a computer or tablet. A broad range of populations was targeted, among others juvenile offenders [27], domestic violence offenders [27, 43], prisoners in general [41], alcohol abusing, violence-involved adolescents [39, 40, 47], and substance abusing prisoners [38]. Several web-based interventions were based on theoretical frameworks such as motivational interviewing, the transtheoretical model, cognitive behavioural therapy or social cognitive theories. These interventions used different ways of delivering content, such as videos, avatars, telephones, tailored written feedback, and emails.

\section{Category 2: Communication Technology for Synchronous Interpersonal Interaction}

This type refers to the use of technology to enable a patient to directly communicate with a care provider, regardless of location $(n=17)$. The patient always interacts with another human being, and not the technology itself. The main goal of these synchronous communication technologies is to provide an alternative for in-person interaction, so multiple modalities such as sound, video, or text are used. All included studies examined video conferencing technology, which is a two-way interactive video and audio communication system. However, despite using the same technology, these studies did differ in the goal and target group: their focus ranged from, for example, video conferencing in forensic mental health in general [54, 57, $63,64,67$ ] to specific target groups, for example, substance abusing patients [58], inmates with psychiatric problems $[56,59,62,68]$, or both schizophrenic patient and family $[52,53]$. 


\section{Category 3: Simulations of Offense-Related Realistic Situations}

This type of technology focuses on the use of simulations in the treatment of forensic psychiatric patients $(n=6)$. In these simulations, visualized scenarios of possible events are presented to patients. The goal of this type of technology is to explore attitudes or behavioural responses to offense-related situations that are viewed as realistic and personally relevant by the user. Some studies used videos with real actors and authentic situations in which the user had to decide on behavioural reactions [69, $73,74]$, while others simulated situations via virtual embodied conversational agents to conduct a dialog with prisoners [71], existing popular crime drama series [72], or VR [70].

\section{Category 4: Simulations of Offense-Related Realistic Stimuli}

This type of technology presented realistic depictions of stimuli related to the offense of forensic psychiatric patients $(n=4)$. The goal of using these stimuli is to elicit behavioural, emotional, cognitive, and/or physiological responses of the patient who are relevant for treatment. These stimuli are not interactive, so they do not respond to the actions of the patient, and are not situations. All included studies primarily focused on sex offenders by presenting computer-animated virtual characters depicting realistic naked human beings of several age categories and genders, via either VR or large screens [75-78].

\section{Category 5: Games}

This type of technology entails both the usage of existing, commercial games for treatment purposes, and serious games developed specifically for the treatment of forensic psychiatric patients $(n=4)$. Game elements are always present: the user has to improve his own achievement, or is competing with other users. Studies examined existing, commercial games to improve the recovery process or meet physical activity goals $[79,80]$, but a serious game specifically developed for rehabilitation purposes was described as well [81].

\section{Category 6: Platforms with User-Generated and Shared Content}

This sixth type refers to technologies in which patients can create and react on content, and add and share existing content $(n=2)$. These platforms can be freely accessible to anyone, e.g., social media, or an approved account can be required, e.g., private forums. The goal of these platforms is for users to share and read material like experiences or opinions to support them in refraining from delinquent behaviour. 
Two studies focused on these kinds of platforms: one was a web-based self-help group for sex offenders [83], the other one made use of social media to reduce delinquent behaviour [84]. 


\section{Advantages}

Types of advantages and disadvantages of eHealth technologies were extracted from the included studies via inductive coding. We identified main codes and accompanying subcodes based on relevant fragments from the article, which are provided in Table 2. The subcodes that were found in each article can be found in Table 1.

Table 2. Main and specified advantages of eHealth and amount of studies they were mentioned by (n).

\begin{tabular}{|c|c|c|}
\hline Main advantage & Specifications & $\mathrm{n}$ \\
\hline \multicolumn{3}{|l|}{ Advantages for individuals } \\
\hline \multirow[t]{3}{*}{ Positive opinion } & Opinion of forensic psychiatric patients & 26 \\
\hline & Opinion of providers of care & 7 \\
\hline & Opinion of family of patient & 2 \\
\hline \multirow{4}{*}{$\begin{array}{l}\text { Increasing patients' access to } \\
\text { care }\end{array}$} & Overcoming geographical barriers & 10 \\
\hline & Receiving care in highly secured settings & 10 \\
\hline & Lower perceived threshold to participate & 8 \\
\hline & Intervention accessible anywhere, anytime & 5 \\
\hline \multirow{4}{*}{$\begin{array}{l}\text { Fit with patient's needs, } \\
\text { preferences and living } \\
\text { environment }\end{array}$} & Fun to use & 7 \\
\hline & Fit with current technological climate & 5 \\
\hline & Simulation of situations perceived as realistic & 4 \\
\hline & Tailored to specific characteristics of patients & 5 \\
\hline \multicolumn{3}{|l|}{$\begin{array}{l}\text { Advantages for forensic mental } \\
\text { healthcare }\end{array}$} \\
\hline \multirow[t]{3}{*}{ Effectiveness } & Potential effectiveness & 13 \\
\hline & Effectiveness based on experimental designs & 13 \\
\hline & Effectiveness based on reviews & 7 \\
\hline \multirow[t]{3}{*}{ Efficiency } & Cost savings & 17 \\
\hline & Time savings & 14 \\
\hline & Easy to implement in practice & 2 \\
\hline \multirow[t]{3}{*}{ Unique information } & Situations with high ecological validity & 7 \\
\hline & Eliciting more sensitive information & 4 \\
\hline & $\begin{array}{l}\text { Measuring physiological or unconscious } \\
\text { reactions }\end{array}$ & 3 \\
\hline \multirow{3}{*}{$\begin{array}{l}\text { Fidelity in delivering } \\
\text { interventions }\end{array}$} & Delivering content and structure in a & 5 \\
\hline & standardized way & \\
\hline & Behaviour change theory & 2 \\
\hline
\end{tabular}


Several types of advantages were relevant for individual people who are in contact with the technology. Multiple articles mentioned the positive opinion about an eHealth intervention of people who were using or in direct contact with it. This opinion could entail positive attitudes, a high satisfaction or high acceptance of an eHealth intervention before, during or after its use. Studies also indicated that technology can increase patients' access to care which makes it easier for them to receive treatment. This can be related to overcoming actual physical barriers to receiving care such as traveling distance, or access to care in highly secured settings. The subjective threshold to following treatment can be influenced by technology as well, for example, via privacy and anonymity, or the possibility of accessing an intervention from home and 24/7. Technology also offers new opportunities to involve loved ones in treatment. Another advantage is that technology can closely fit patients' needs, preferences, and living environment. Patients can find specific technologies fun to use, e.g., serious games or VR, or technology can be developed in such a way that it is automatically tailored to specific characteristics. Also, compared with in-person treatment, technology is better able to create situations that are perceived as realistic and personally meaningful by patients.

Besides individual advantages, studies also described the added value that technology can have for forensic mental health. An important advantage is that eHealth interventions can be as effective as or even more effective than care as usual in reaching their intended goals. Included studies of a more observational nature indicated that the intervention they studied had a lot of potential to be effective, but no definite conclusions could be drawn based on their preliminary qualitative or quantitative results. The included experimental and quasi-experimental studies were able to provide some more insight into effectiveness, and reported mainly positive effects, as can be seen in Table 1. eHealth interventions can also increase the efficiency of forensic mental health care, which refers to practical advantages for forensic settings. Time and costs were claimed to be saved, for example, because eHealth can take away some of the work of therapists, an eHealth intervention can be quicker than in-person care, and many eHealth interventions are easily scalable, so multiple patients are able to follow an intervention at the same time without an increase of labour of care providers or a decrease in safety of patient, provider, or society. However, none of the studies that made statements about reduced costs and time conducted a systematic cost-effectiveness analysis. Studies also stated that eHealth technology can provide unique information that cannot or is difficult to elicit via in-person interventions. Technology was said to create situations with a high 
ecological validity, in which behavioural reactions can be observed and trained as they occur. Furthermore, it can be used to collect non-verbal information about physiological or unconscious reactions via the use of, e.g., biofeedback, eye-tracking, or measuring sexual arousal. A final advantage is related to fidelity: via technology, interventions can be delivered exactly as was intended, without error or unintended deviations from the desired situation. The standard procedures, structure, content, and evidence-based methods of an intervention can be delivered to patients in a standardized way, meaning that every patient gets the same treatment. 


\section{Disadvantages}

Besides advantages, disadvantages were identified as well. They are mentioned and explained in the Table 3 and the accompanying text below.

Table 3. Main and specified disadvantages of eHealth and amount of studies they were mentioned by ( $n)$.

\begin{tabular}{lll}
\hline Main disadvantage & Specification & $\mathrm{n}$ \\
\hline Disadvantages for individuals & Opinion of forensic psychiatric patients & 7 \\
Negative opinion & Opinion of providers of care & 6 \\
& Opinion of family of patient & 1 \\
Not suitable for every patient & Experience with technology & 5 \\
& Mental or physical diseases & 2 \\
Privacy & Patients can be overheard & 6 \\
& Data not stored securely & 3 \\
Decrease or lack in-person contact & Negative influence on therapeutic & 7 \\
& relationship & \\
Adverse negative consequences & Not detecting subtle behaviours or signs & 3 \\
Disadvantages for forensic mental & Patients' misuse of technology & 4 \\
health & Excessive experience of negative affect & 4 \\
Effectiveness & & \\
Inefficiency & & \\
Technological malfunctioning & Not enough evidence in general & 13 \\
Lack of standardization & Single intervention is not effective & 7 \\
& Difficult to implement in practice & 9 \\
\hline & High costs & 7 \\
& Faulty technology & 6 \\
& Slow or lost connection & 3 \\
& No clear protocols, guidelines or standards & 2 \\
& No national legislation & 2 \\
\hline
\end{tabular}

Disadvantages for individual people were identified in the included studies. First of all, negative opinions of people directly involved with an eHealth intervention were reported. Studies found that attitudes about the technology were negative, or that the acceptance of a technology was low. It was also mentioned that not all technologies can be used by every type of patient, for example, if they have hallucinations or are physically incapable of using the system. Patients might also have low eHealth literacy because they lack knowledge and skills to use specific 
technologies, or they might be used to commercial products and are underwhelmed by an eHealth intervention. Another issue for individual patients is related to privacy and the confidentiality of sensitive information. Insecurely stored data can be accessed by unauthorized parties, or, especially in the case of communication technologies, patients might be overheard by staff or other patients. Furthermore, it was proposed that a decrease or lack of in-person contact between patient and therapist when using technology could have a negative impact on the therapeutic relationship, since both parties might perceive a greater emotional distance. Communication via technology can also make it harder or impossible to detect subtle but relevant behaviours or other signs such as fidgeting under the table or smell. eHealth interventions can also give rise to some adverse negative consequences: patients might misuse the technology, for example by using VR stimuli of children to arouse themselves, or technology can arouse excessive, unwanted negative affect in a patient.

eHealth can also have disadvantages for the domain of forensic mental health. The section on advantages already provided insight into the effectiveness of eHealth. However, studies also mentioned the lack of evidence of effectiveness, either for an entire domain, one intervention, or a specific outcome. Reviews often indicated that there is not enough evidence for a type of eHealth technology, for example, teleconferencing or VR. It was said that too little studies were conducted to make statements about their effectiveness. Besides these more general statements, some experimental studies also found that a single eHealth intervention was not effective in general, or on specific outcome measures. eHealth can also be inefficient when its development, implementation, or long-term use have practical negative consequences for an organization. Development, start-up costs, and maintenance of technology were often said to be expensive, and insurance companies did not cover these costs. Also, several studies indicated that implementation in practice is difficult because of multiple reasons, such as unawareness of the existence of eHealth by stakeholders, too much reliance on the time and efforts of staff, or lack of physical space to set up a system. Furthermore, technological malfunctioning can negatively affect the quality of an eHealth intervention: software might contain bugs, equipment can fail, it can be too outdated to use, or the connection might be lost or be too slow. Finally, an observed disadvantage for eHealth is the lack of standardization: clear protocols, guidelines, and national legislation to optimize and standardize the use of eHealth in practice are insufficient or non-existent. 


\section{Combination of Results}

Table 4 combines the results provided in Table 1 to create an overview of the study design, effectiveness, advantages, and disadvantages for each of the six identified types of technology.

Table 4. Study design, effectiveness, advantages, and disadvantages categorized per type of technology.

\begin{tabular}{|c|c|c|c|c|}
\hline & $\begin{array}{l}\text { Study } \\
\text { design }\end{array}$ & Effectiveness & Advantages & Disadvantages \\
\hline $\begin{array}{l}\text { Category 1: } \\
\text { Interactive, } \\
\text { predominantly } \\
\text { language-based } \\
\text { interventions ( } n=17 \text { ) }\end{array}$ & $\begin{array}{l}\text { Experimental: } n \\
=9 \\
\text { Qualitative: } n= \\
4 \\
\text { Quantitative } \\
\text { cross-sectional: } \\
n=2 \\
\text { Literature } \\
\text { study: } n=2\end{array}$ & $\begin{array}{l}\text { More effective: } \mathrm{n} \\
=7 \\
\text { Ineffective: } \mathrm{n}=2 \\
\text { Not assessed: } \mathrm{n} \\
=8\end{array}$ & $\begin{array}{l}\text { Effectiveness: } \mathrm{n}= \\
13 \\
\text { Efficiency: } \mathrm{n}=10 \\
\text { Positive opinion: } \mathrm{n} \\
=8 \\
\text { Fit with patient's } \\
\text { needs, preferences } \\
\text { and environment: } \\
\mathrm{n}=8 \\
\text { Fidelity in } \\
\text { delivering } \\
\text { interventions: } \mathrm{n}= \\
5 \\
\text { Increasing } \\
\text { patient's access to } \\
\text { care: } \mathrm{n}=4 \\
\text { Unique } \\
\text { information: } \mathrm{n}=1\end{array}$ & $\begin{array}{l}\text { Effectiveness: } \mathrm{n}=7 \\
\text { Negative opinion: } \mathrm{n} \\
=4 \\
\text { Inefficiency: } \mathrm{n}=3 \\
\text { Not suitable for } \\
\text { every patient: } \mathrm{n}=2 \\
\text { Decrease or lack of } \\
\text { in-person contact: } \mathrm{n} \\
=2 \\
\text { Adverse negative } \\
\text { consequences: } \mathrm{n}=1\end{array}$ \\
\hline $\begin{array}{l}\text { Category 2: } \\
\text { Communication } \\
\text { technology for } \\
\text { synchronous } \\
\text { interpersonal } \\
\text { interaction } \\
(n=17)\end{array}$ & $\begin{array}{l}\text { Literature } \\
\text { study: } \mathrm{n}=11 \\
\text { Qualitative: } \mathrm{n}= \\
3 \\
\text { Quantitative } \\
\text { cross-sectional: } \\
\mathrm{n}=2 \\
\text { Quasi- } \\
\text { experimental: } \mathrm{n} \\
=1\end{array}$ & $\begin{array}{l}\text { More effective: } \mathrm{n} \\
=1 \\
\text { Not assessed: } \mathrm{n} \\
=16\end{array}$ & $\begin{array}{l}\text { Positive opinion: } \mathrm{n} \\
=13 \\
\text { Increasing } \\
\text { patient's access to } \\
\text { care: } \mathrm{n}=12 \\
\text { Efficiency: } \mathrm{n}=12 \\
\text { Effectiveness: } \mathrm{n}=9 \\
\text { Fit with patient's } \\
\text { needs, preferences } \\
\text { and environment: } \\
\mathrm{n}=1 \\
\text { Unique } \\
\text { information: } \mathrm{n}=1\end{array}$ & $\begin{array}{l}\text { Negative opinion: } \mathrm{n} \\
=7 \\
\text { Privacy: } \mathrm{n}=7 \\
\text { Decrease or lack of } \\
\text { in-person contact: } \mathrm{n} \\
=7 \\
\text { Effectiveness: } \mathrm{n}=7 \\
\text { Technological } \\
\text { malfunctioning: } \mathrm{n}= \\
6 \\
\text { Inefficiency: } \mathrm{n}=6 \\
\text { Lack of } \\
\text { standardization: } \mathrm{n}= \\
5 \\
\text { Not suitable for } \\
\text { every patient: } \mathrm{n}=2\end{array}$ \\
\hline
\end{tabular}




\begin{tabular}{|c|c|c|c|c|}
\hline $\begin{array}{l}\text { Category 3: } \\
\text { Simulations of } \\
\text { offense-related } \\
\text { realistic situations } \\
(n=6)\end{array}$ & $\begin{array}{l}\text { Quasi- } \\
\text { experimental: } n \\
=2 \\
\text { Quantitative } \\
\text { cross-sectional: } \\
n=2 \\
\text { Qualitative: } n= \\
1 \\
\text { Literature } \\
\text { study: } n=1\end{array}$ & $\begin{array}{l}\text { More effective: } \mathrm{n} \\
=1 \\
\text { Ineffective: } \mathrm{n}=1 \\
\text { Not assessed: } \mathrm{n} \\
=4\end{array}$ & $\begin{array}{l}\text { Positive opinion: } \mathrm{n} \\
=4 \\
\text { Effectiveness: } \mathrm{n}=4 \\
\text { Unique } \\
\text { information: } \mathrm{n}=4 \\
\text { Increasing } \\
\text { patient's access to } \\
\text { care: } \mathrm{n}=2 \\
\text { Fit with patient's } \\
\text { needs, preferences } \\
\text { \& environment: } \mathrm{n} \\
=1\end{array}$ & $\begin{array}{l}\text { Adverse negative } \\
\text { consequences: } n=3 \\
\text { Effectiveness: } n=2 \\
\text { Not suitable for } \\
\text { every patient: } n=1 \\
\text { Privacy: } n=1 \\
\text { Technological } \\
\text { malfunctioning: } n= \\
1\end{array}$ \\
\hline $\begin{array}{l}\text { Category } 4 \text { : } \\
\text { Simulations of } \\
\text { offense-related } \\
\text { realistic stimuli }(n=4)\end{array}$ & $\begin{array}{l}\text { Quantitative } \\
\text { cross-sectional: } \\
\mathrm{n}=3 \\
\text { Literature } \\
\text { study: } \mathrm{n}=1\end{array}$ & $\begin{array}{l}\text { Not assessed: } \mathrm{n} \\
=4\end{array}$ & $\begin{array}{l}\text { Unique } \\
\text { information: } \mathrm{n}=4 \\
\text { Effectiveness: } \mathrm{n}=3 \\
\text { Fit with patient's } \\
\text { needs, preferences } \\
\text { and environment: } \\
\mathrm{n}=1\end{array}$ & $\begin{array}{l}\text { Effectiveness: } \mathrm{n}=1 \\
\text { Inefficiency: } \mathrm{n}=1\end{array}$ \\
\hline $\begin{array}{l}\text { Category 5: Games } \\
(n=4)\end{array}$ & $\begin{array}{l}\text { Qualitative: } n= \\
2 \\
\text { Quantitative } \\
\text { cross-sectional: } \\
n=1 \\
\text { Literature } \\
\text { study: } n=1\end{array}$ & $\begin{array}{l}\text { Not assessed: } n \\
=4\end{array}$ & $\begin{array}{l}\text { Fit with patient's } \\
\text { needs, preferences } \\
\text { and environment: } \\
\mathrm{n}=4 \\
\text { Effectiveness: } \mathrm{n}=3 \\
\text { Increasing } \\
\text { patient's access to } \\
\text { care: } \mathrm{n}=2 \\
\text { Positive opinion: } \mathrm{n} \\
=1 \\
\text { Unique } \\
\text { information: } \mathrm{n}=1\end{array}$ & $\begin{array}{l}\text { Negative opinion: } \mathrm{n} \\
=2 \\
\text { Adverse negative } \\
\text { consequences: } \mathrm{n}=2 \\
\text { Effectiveness: } \mathrm{n}=2 \\
\text { Inefficiency: } \mathrm{n}=2 \\
\text { Not suitable for } \\
\text { every patient: } \mathrm{n}=1 \\
\text { Decrease or lack of } \\
\text { in-person contact: } \mathrm{n} \\
=1\end{array}$ \\
\hline $\begin{array}{l}\text { Category 6: Platforms } \\
\text { with user-generated } \\
\text { and shared content ( } \mathrm{n} \\
=2 \text { ) }\end{array}$ & $\begin{array}{l}\text { Quasi- } \\
\text { experimental: } \mathrm{n} \\
=1 \\
\text { Qualitative: } \mathrm{n}= \\
1\end{array}$ & $\begin{array}{l}\text { More effective: } \mathrm{n} \\
=1 \\
\text { Not assessed: } \mathrm{n} \\
=1\end{array}$ & $\begin{array}{l}\text { Effectiveness: } \mathrm{n}=2 \\
\text { Increasing } \\
\text { patient's access to } \\
\text { care: } \mathrm{n}=1 \\
\text { Fit with patient's } \\
\text { needs, preferences } \\
\text { and environment: } \\
\mathrm{n}=1 \\
\text { Efficiency: } \mathrm{n}=1\end{array}$ & $\begin{array}{l}\text { Adverse negative } \\
\text { consequences: } n=1\end{array}$ \\
\hline
\end{tabular}

The table shows that all experimental studies were conducted on interactive, language-based interventions, and most of these studies found that an eHealth intervention is as effective as or even more effective than a control intervention. Effectiveness was found most as both an advantage and disadvantage, and fidelity in delivering content and structure is mentioned only by these studies. The second category on teleconferencing contains almost all literature studies. These reviews mostly include studies on telepsychiatry in general, whereby the authors related their 
findings to forensic psychiatry. Opinions of individuals were found most in this category, as both an advantage and disadvantage. Compared with other categories, a lot of these studies paid attention to the increased access to care for patients. Technologies that simulate situations were studied in various ways. Overall, positive opinions and the unique possibilities of these interactive technologies were identified more often than in most other categories, just as the adverse negative consequences of a technology. No studies on effectiveness were conducted on technologies that simulated realistic stimuli, the fourth category. The possibility of technology to create and acquire unique information was acknowledged by all four included studies. The fifth category, games, also contains no studies on effectiveness. Most advantages and disadvantages were related to the individual patient, with all studies mentioning the advantage of the fit between the patient and the technology. The final category, platforms with user-generated content, comprises only two studies, of which one found evidence for effectiveness.

When looking at all mentioned advantages, effectiveness was stated in studies on all categories, just as the fit of the technology with the patient. However, efficiency was not identified in studies on technologies that simulated situations and stimuli, while the majority of these studies mentioned unique information as an advantage. Overall, less disadvantages then advantages were identified, so most of the disadvantages were stated only once or twice per type of technology. Effectiveness and adverse negative consequences are present in five categories, most other disadvantages are found in less categories. Finally, most of the mentioned disadvantages are complementary to the advantages, for example, both positive and negative opinions were identified in studies on teleconferencing, indicating that this is an important topic for studies on these types of technology.

\section{Discussion}

This systematic review provided an overview of the research on eHealth technologies that are used in the treatment of forensic psychiatric patients. The 50 included studies showed a broad range of eHealth technologies that were studied using different research methods, ranging from RCTs to exploratory qualitative studies. Most studies on effectiveness were conducted on language-based interventions, while most exploratory studies focused on technologies that provided an experience and made less use of language. Despite these differences, many publications mentioned the same type of advantages. The opinions of patients and therapists were positive, access to care was increased, the technology fitted the patient, interventions were - 
or were expected to be - effective and efficient, technology was said to increase fidelity of treatment, and offered new possibilities and information. Disadvantages were that not everyone was enthusiastic about and able to use technology, there were concerns about privacy, in-person contact could decrease, technology could have unintended negative consequences, not every study found strong proof of effectiveness and efficiency, technology could contain errors, and many settings did not have regulations or protocols for eHealth. When comparing the advantages to the disadvantages, it becomes clear that there is a lot of potential and much has been achieved at this point in time, but there are also many opportunities that are not used.

Important advantages of technology were related to technology being able to deal with the complex nature of the forensic psychiatric population. Technology can take the low literacy and education level of forensic psychiatric patients into account [15] by not relying primarily on language and cognitive reflection; it can create real-life, interactive situations in which skills can be trained $[56,70,74,77]$, or information on reactions can be gathered via physiological measures which can be integrated in treatment [27]. However, most of these types of technologies are not thoroughly studied, so more studies on technologies such as VR or wearables that monitor arousal are required to determine whether they actually have added value for forensic psychiatric patients.

When looking at the use of technology in practice, many studies reported positive attitudes of both patients and care providers. A positive attitude increases the motivation to actually use a technology in the intended way [30]. However, none of the studies paid attention to matters related to the use of technology such as engagement and adherence, despite the knowledge that treatment motivation and completion is low in forensic psychiatric patients [10]. Research into the manner in which technology is used by patients and suitable methods to increase their engagement and adherence is required to gain more insight into how and why technology can motivate forensic patients. A way to increase adherence is via persuasive design $[33,34]$, which was recommended by one of the included studies [48]. A specific persuasive element that multiple studies did mention as an advantage is tailoring $[18,27,38,40,58]$. Tailoring has been recommended as a way to overcome the current predominant "one-size-fits-all" approach in forensic mental health by increasing the fit between the technology and the user $[19,51]$. Research has shown that tailoring is of added value for eHealth in general [e.g. 22], but most interventions for forensic mental health did not use this specific possibility. To conclude, more research needs to be conducted on the interrelationships between technology and 
treatment motivation, and ways to increase engagement and adherence such as tailoring need to be identified.

Most included experimental and quasi-experimental studies found promising results for web-based interventions. In the majority of the included studies, web-based interventions were as effective as and, in some cases, more effective than in-person interventions. However, many technologies were not studied as extensively as this category, so to create a thorough evidence base for all categories, more evaluation studies are recommended $[58,60,76]$. A more specific recommendation provided by several studies was to determine what types of interventions work best for which type of patients, and which mechanisms of change contribute to these differences between individuals [47, 48, 59, 76, 83]. Insight in these mechanisms enables better tailoring of interventions to specific groups of patients. These kinds of recommendations are in line with recent visions on eHealth evaluations in general $[85,86]$, which stress the importance of determining what works best for whom to gain more insight into the working mechanisms.

A final advantage that was mentioned by several included studies is the possibility to incorporate existing guidelines and treatment approaches in eHealth interventions. Blended care, a format in which the use of eHealth is combined and integrated with in-person care, is an especially promising possibility [20]. However, only one included study recommended that it should be examined how to best implement computer-delivered interventions in real world settings [48]. Most studies did not pay attention to the implementation and integration of eHealth in existing care pathways. For eHealth to be as effective and efficient as possible, it needs to fit the context in which it is used seamlessly: technology should not be used as a separate, standalone tool, but has to be embedded within the current situation [87], among other things via integration in evidence-based treatment approaches such as cognitive behaviour therapy and the risk-need-responsivity model. Especially studies on telepsychiatry stressed the need for protocols, standards, and guidelines to achieve this.

Based on the results of this review, it becomes clear that an issue important for eHealth in general also applies to forensic mental health: despite promising studies that show potential, there still is a large gap between potential and current practice, and most interventions fail to have actual clinical benefit in real world settings [86]. To bridge this gap and achieve eHealth's potential, it is essential to create a good fit between the technology, the people involved, and the existing context with its treatment approaches or interventions. 
A way to increase the fit between technology, people, and their context is by conducting a good development process $[88,89]$. Not many of the included studies discussed the development of their interventions. The ones who did discuss it pointed out the importance of iterative development with continuous evaluation cycles [37, $53,59]$ and the incorporation of opinions, preferences, and characteristics of people $[37,54,57,71,81,82]$. This is in line with recent insights into eHealth development, which state that a good development process requires iterative, evidence-based strategies that acknowledge the complex interrelations between people, technology, and the health-care context $[85,86]$. These strategies should be derived from multiple disciplines, such as persuasive design, human-centred design, participatory development, business modelling, engineering, and psychology [87]. Interventions should not be developed in an expert-driven, non-iterative way (86), but this seemed to be the case for most of the included interventions. Also, due to a virtual absence of insight into the development process, little knowledge on the most optimal way to develop eHealth that fits with forensic mental health practice is present. Consequently, more studies on eHealth in forensic mental health should apply, describe, and critically evaluate development methods.

Implementation was another essential activity to which not much studies paid attention, despite the fact that research and practice have shown that it is a very important yet difficult endeavour [90]. Some studies made recommendations for the implementation: they mentioned the necessity of accounting for resistance by patients and therapists, creating an infrastructure for dissemination, and financing $[27,42,48,53,55]$. The importance of these kinds of activities has indeed been acknowledged by other studies and can be accounted for via using approaches such as business modelling [91] and participatory development [92].

\section{Strengths and Limitations}

The main strength of this study is that it used a systematic approach based on the Cochrane guidelines to provide a broad and extensive overview of the current state of research on eHealth interventions in forensic mental health. Despite the thorough execution of this review, it has several limitations. First of all, time between the development and evaluation of a technology and the publication of a study might take up to a couple of years [85], which causes that the most recent interventions and studies that are being conducted at the moment could not be accounted for in this review. Furthermore, because the goal of this systematic review was to provide an overview of the current state of affairs of research, all available studies were included, 
regardless of their quality and type of results. Consequently, not all results of included studies might be valid or reliable and thus it cannot be guaranteed that all advantages and disadvantages mentioned by these studies are factual and objective. Some advantages and disadvantages mentioned in the articles were based on qualitative results or non-systematic observations combined with reasoning based on existing literature. Again, more research is required to determine whether they can be objectively observed in forensic mental health care. We recommend that a systematic review specifically focused on effectiveness is executed in the near future, when more experimental studies on this increasingly studied topic have been published.

\section{Conclusion}

Based on the results of this review, we conclude that eHealth has many actual and potential advantages for forensic mental health. Some especially promising advantages are tailoring, effectiveness-which was mostly examined in web-based interventions-and, specifically relevant for non-language-based technologies, the acquisition of unique information via the use of technology. However, most interventions did not yet fully benefit from the possibilities of the different types of available technologies. To take eHealth in forensic mental health to the next level, it is important to ensure that the use of technology has actual added value for the patient and treatment. eHealth technology needs to be integrated in in-person treatment instead of using it as a separate addition to care, and it needs to closely fit the needs and preferences of both patients and therapists. Consequently, to achieve the benefits and overcome the barriers, eHealth should be developed in such a way that there is a good fit between technology, people, and the context.

\section{Author Contributions}

HK, YB, and SK designed the study and wrote the protocol. HK conducted literature searches. HK and SK screened the titles, while HK and YV screened the abstracts and analysed the data. HK wrote the first draft of the manuscript and YB, SK, and LG-P contributed to and have approved the final manuscript.

\section{Conflict of Interest Statement}

All authors declare that they have no conflicts of interest. The reviewer ND and handling editor declared their shared affiliation. 


\section{Funding}

Funding for this study was provided by Stichting Vrienden van Oldenkotte. They had no role in the study design, collection, analysis or interpretation of the data, writing the manuscript, or the decision to submit the paper for publication. 


\section{References}

1. Arboleda-Flórez J. Forensic psychiatry: contemporary scope, challenges and controversies. World Psychiatry (2006) 5(2):87-91.

2. Mullen PE. Forensic mental health. Br J Psychiatry (2000) 176:307-11. doi:10.1192/bjp.176.4.307

3. Landenberger NA, Lipsey MW. The positive effects of cognitive-behavioral programs for offenders: a meta-analysis of factors associated with effective treatment.J Exp Criminol (2005) 1(4):451-76. doi:10.1007/s11292-0053541-7

4. Andrews DA, Bonta J. Rehabilitating criminal justice policy and practice. Psychol Public Policy Law (2010) 16(1):39. doi:10.1037/a0018362

5. Babcock JC, Green CE, Robie C. Does batterers' treatment work? A metaanalytic review of domestic violence treatment. Clin Psychol Rev (2004) 23(8):1023-53. doi:10.1016/j.cpr.2002.07.001

6. van Gemert-Pijnen JEWC, Kip H, Kelders SM, Sanderman R, Kelders SM, Kip H. (2020).. Introducing eHealth. In: van Gemert-Pijnen JEWC, editor. eHealth Research, Theory and Development: A Multi-Disciplinary Approach. Abingdon, UK: Routledge.

7. Aardoom JJ, Dingemans AE, Van Furth EF. E-health interventions for eating disorders: emerging findings, issues, and opportunities. Curr Psychiatry $\operatorname{Rep~(2016)~18(4):1-8.~doi:10.1007/s11920-016-0673-6~}$

8. Huguet A, Rao S, McGrath PJ, Wozney L, Wheaton M, Conrod J, et al. A systematic review of cognitive behavioral therapy and behavioral activation apps for depression. PLoS One (2016) 11(5):e0154248. doi:10.1371/journal.pone.0154248

9. Morland LA, Greene CJ, Rosen CS, Kuhn E, Hoffman J, Sloan DM. Telehealth and eHealth interventions for posttraumatic stress disorder. Curr Opin Psychol (2016) 14:102-8. doi:10.1016/j.copsyc.2016.12.003

10. Drieschner $\mathrm{KH}$, Boomsma A. The treatment motivation scales for forensic outpatient treatment (TMS-F) construction and psychometric evaluation. Assessment (2008) 15(2):224-41. doi:10.1177/1073191107311650

11. Perron BE, Bright $\mathrm{CL}$. The influence of legal coercion on dropout from substance abuse treatment: results from a national survey. Drug Alcohol Depend (2008) 92(1-3):123-31. doi:10.1016/j.drugalcdep.2007.07.011 
12. Bloem O, Bulten B, Nijman H. Psychopathologie onder gedetineerden. In: Groen NH editors. Handboek Forensische Geestelijke Gezondheidszorg. Utrecht: De Tijdstroom (2011). p. 153-62.

13. Goethals KR, Vorstenbosch ECW, van Marle HJC. Diagnostic comorbidity in psychotic offenders and their criminal history: a review of the literature. Int J Forensic Ment Health (2008) 7(2):147-56. doi:10.1080/14999013.2008.9914411

14. Tervoort MGA. Behandelbaarheid. In: Groen H, Drost M, Nijman HLI, editors. Handboek Forensische Geestelijke Gezondheidszorg. Utrecht: De Tijdstroom (2011). p. 137-52.

15. Greenberg E, Dunleavy E, Kutner M. Literacy Behind Bars: Results from the 2003 National Assessment of Adult Literacy Prison Survey. NCES 2007-473. Washington, DC: National Center for Education Statistics (2007).

16. Whitaker DJ, Morrison S, Lindquist C, Hawkins SR, O'Neil JA, Nesius AM, et al. A critical review of interventions for the primary prevention of perpetration of partner violence. Aggress Violent Behav(2006) 11(2):151-66. doi:10.1016/j.avb.2005.07.007

17. Birgden A. Therapeutic jurisprudence and responsivity: finding the will and the way in offender rehabilitation. Psychol Crime Law (2004) 10(3):283-95. doi:10.1080/10683160410001662771

18. Levesque DA, Johnson JL, Welch CA, Prochaska JM, Fernandez AC. Computertailored intervention for juvenile offenders. J Soc Work Pract Addict (2012) 12(4):391-411. doi:10.1080/1533256X.2012.728107

19. Polaschek DLL. Many sizes fit all: a preliminary framework for conceptualizing the development and provision of cognitive-behavioral rehabilitation programs for offenders. Aggress Violent Behav(2011) 16(1):20-35. doi:10.1016/j.avb.2010.10.002

20. Wentzel J, van der Vaart R, Bohlmeijer ET, van Gemert-Pijnen JEWC. Mixing online and face-to-face therapy: how to benefit from blended care in mental health care. JMIR Ment Health (2016) 3(1):e9. doi:10.2196/mental.4534

21. Oinas-Kukkonen $H$, Harjumaa $M$. Persuasive systems design: key issues, process model, and system features. Commun Assoc Info Syst (2009) 24(1):28.

22. Alley S, Jennings C, Plotnikoff RC, Vandelanotte C. Web-based video-coaching to assist an automated computer-tailored physical activity intervention for 
inactive adults: a randomized controlled trial. J Med Internet Res (2016) 18(8):e223. doi:10.2196/jmir.5664

23. Broekhuizen K, van Poppel MN, Koppes LL, Kindt I, Brug J, van Mechelen W. Can multiple lifestyle behaviours be improved in people with familial hypercholesterolemia? Results of a parallel randomised controlled trial. PLOS One (2012) 7(12):e50032. doi:10.1371/journal.pone.0050032

24. Brouwer W, Kroeze W, Crutzen R, de Nooijer J, de Vries NK, Brug J, et al. Which intervention characteristics are related to more exposure to Internetdelivered healthy lifestyle promotion interventions? A systematic review. J Med Internet Res (2011) 13(1):e2. doi:10.2196/jmir.1639

25. Lustria MLA, Cortese J, Noar SM, Glueckauf RL. Computer-tailored health interventions delivered over the web: review and analysis of key components. Patient Educ Couns (2009) 74(2):156-73. doi:10.1016/j.pec.2008.08.023

26. Schleg S, Bürger C, Schmidt L, Herbst N, Voderholzer U. The potential of technology-based psychological interventions for anorexia and bulimia nervosa: a systematic review and recommendations for future research. J Med Internet Res (2015) 17(3):e85. doi:10.2196/jmir.3554

27. Levesque DA, Ciavatta MM, Castle PH, Prochaska JM, Prochaska JO. Evaluation of a stage-based, computer-tailored adjunct to usual care for domestic violence offenders. Psychol Violence(2012) 2(4):368-84. doi:10.1037/a0027501

28. Hoogsteder LM, van Horn JE, Stams GJJ, Wissink IB, Hendriks J. The relationship between the level of program integrity and pre-and post-test changes of responsive-aggression regulation therapy (Re-ART) outpatient: a pilot study. Int J Offender Ther Comp Criminol(2016) 60(4):435-55. doi:10.1177/0306624X14554828

29. Black AD, Car J, Pagliari C, Anandan C, Cresswell K, Bokun T, et al. The impact of eHealth on the quality and safety of health care: a systematic overview. PLOS Med (2011) 8(1):e1000387. doi:10.1371/journal.pmed.1000387

30. Barello S, Triberti S, Graffigna G, Libreri C, Serino S, Hibbard J, et al. eHealth for patient engagement: a systematic review. Front Psychol (2015) 6:2013. doi:10.3389/fpsyg.2015.02013

31. Bornkessel A, Furberg R, Lefebvre RC. Social media: opportunities for quality improvement and lessons for providers - a networked model for patient- 
centered care through digital engagement. Curr Cardiol Rep (2014) 16(7):19. doi:10.1007/s11886-014-0504-5

32. Crutzen R, Ruiter RA, de Vries NK. Can interest and enjoyment help to increase use of Internet-delivered interventions? Psychol Health (2014) 29(11):1227-44. doi:10.1080/08870446.2014.921300

33. Kelders SM, Kok RN, Ossebaard HC, Van Gemert-Pijnen JE. Persuasive system design does matter: a systematic review of adherence to web-based interventions. J Med Internet Res (2012) 14(6):e152. doi:10.2196/jmir.2104

34. Short CE, Rebar AL, Plotnikoff RC, Vandelanotte C. Designing engaging online behaviour change interventions: a proposed model of user engagement. Eur Health Psychol (2015) 17(1):32-8.

35. Higgins JP, Green S, editors. Cochrane Handbook for Systematic Reviews of Interventions. (Vol. 4). Hoboken, NJ: John Wiley \& Sons (2011).

36. Morrison LG, Yardley L, Powell J, Michie S. What design features are used in effective e-health interventions? A review using techniques from critical interpretive synthesis. Telemed E Health (2012) 18(2):137-44. doi:10.1089/tmj.2011.0062

37. Berman AH, Farzanfar R, Kristiansson M, Carlbring P, Friedman RH. Design and development of a telephone-linked care (TLC) system to reduce impulsivity among violent forensic outpatients and probationers. J Med Syst (2012) 36(3):1031-42. doi:10.1007/s10916-010-9565-1

38. Chaple M, Sacks S, McKendrick K, Marsch LA, Belenko S, Leukefeld C, et al. Feasibility of a computerized intervention for offenders with substance use disorders: a research note. J Exp Criminol(2014) 10(1):105-27. doi:10.1007/s11292-013-9187-y

39. Cunningham RM, Walton MA, Goldstein A, Chermack ST, Shope JT, Bingham $\mathrm{CR}$, et al. Three-month follow-up of brief computerized and therapist interventions for alcohol and violence among teens. Acad Emerg Med (2009) 16(11):1193-207. doi:10.1111/j.1553-2712.2009.00513.x

40. Cunningham RM, Chermack ST, Zimmerman MA, Shope JT, Bingham CR, Blow FC, et al. Brief motivational interviewing intervention for peer violence and alcohol use in teens: one-year follow-up. Pediatrics (2012) 129(6):108390. doi:10.1542/peds.2011-3419

41. Elison S, Weston S, Davies G, Dugdale S, Ward J. Findings from mixedmethods feasibility and effectiveness evaluations of the "breaking free online" treatment and recovery programme for substance misuse in 
prisons. Drugs Educ Prev Policy (2016) 23(2):176-85. doi:10.3109/09687637.2015.1090397

42. Lee JD, Tofighi B, McDonald R, Campbell A, Hu MC, Nunes E. Acceptability and effectiveness of a web-based psychosocial intervention among criminal justice involved adults. Health Justice (2017) 5(1):3. doi:10.1186/s40352017-0048-z

43. Levesque DA, Driskell MM, Prochaska JM, Prochaska JO. Acceptability of a stage-matched expert system intervention for domestic violence offenders. Violence Vict(2008) 23(4):434-45. doi:10.1891/08866708.23.4.432

44. Neville FG, Goodall CA, Williams DJ, Donnelly PD. Violence brief interventions: a rapid review. Aggress Violent Behav (2014) 19(6):692-8. doi:10.1016/j.avb.2014.09.015

45. Spohr SA, Taxman FS, Walters ST. The relationship between electronic goal reminders and subsequent drug use and treatment initiation in a criminal justice setting. Addict Behav (2015) 51:51-6. doi:10.1016/j.addbeh.2015.07.005

46. Tait RJ, Lenton S. Online alcohol interventions, sexual violence and intimate partner violence: a systematic review. Internet Interv (2015) 2(2):152-60. doi:10.1016/j.invent.2015.03.001

47. Ranney ML, Goldstick J, Eisman A, Carter PM, Walton M, Cunningham RM. Effects of a brief ED-based alcohol and violence intervention on depressive symptoms. Gen Hosp Psychiatry (2017) 46:44-8. doi:10.1016/j.genhosppsych.2017.01.008

48. Walters ST, Ondersma SJ, Ingersoll KS, Rodriguez M, Lerch J, Rossheim ME, et al. MAPIT: development of a web-based intervention targeting substance abuse treatment in the criminal justice system. J Subst Abuse Treat (2014) 46(1):60-5. doi:10.1016/jjsat2013.07.003

49. Walton MA, Chermack ST, Shope JT, Bingham CR, Zimmerman MA, Blow FC, et al. Effects of a brief intervention for reducing violence and alcohol misuse among adolescents: a randomized controlled trial. JAMA (2010) 304(5):52735. doi:10.1001/jama.2010.1066

50. Wannachaiyakul S, Thapinta D, Sethabouppha H, Thungjaroenkul $P$, Likhitsathian S. Randomized controlled trial of computerized cognitive behavioral therapy program for adolescent offenders with depression. Pac Rim Int J Nurs Res (2017) 21(1):32-43. 
51. Wilson HJ, Palk G, Sheehan MC, Wishart D, Watson B. Steering clear of driving after drinking: a tailored e-health intervention for reducing repeat offending and modifying alcohol use in a high-risk cohort. Int J Behav Med (2017) 24(5):694-702. doi:10.1007/s12529-017-9664-1

52. Absalom-Horby V, Hare DJ, Gooding P, Tarrier N. Attitudes of relatives and staff towards family intervention in forensic services using Q methodology. J Psychiatr Ment Health Nurs (2012) 19(2):162-73. doi:10.1111/j.13652850.2011.01770.x

53. Absalom-Hornby V, Gooding $P$, Tarrier N. Family intervention using a web camera (e-FFI) within forensic services: a case study and feasibility study. $\mathrm{Br}$ J Forensic Pract (2012) 14(1):60-71. doi:10.1108/14636641211204478

54. Adjorlolo S, Chan HC. Forensic assessment via videoconferencing: issues and practice considerations. J Forensic Psychol Pract(2015) 15(3):185-204. doi:10.1080/15228932.2015.1015363

55. Antonacci DJ, Bloch RM, Saeed SA, Yildirim Y, Talley J. Empirical evidence on the use and effectiveness of telepsychiatry via videoconferencing: implications for forensic and correctional psychiatry. Behav Sci Law (2008) 26(3):253-69. doi:10.1002/bsl.812

56. Ax RK, Fagan TJ, Magaletta PR, Morgan RD, Nussbaum D, White TW. Innovations in correctional assessment and treatment. Crim Justice Behav (2007) 34(7):893-905. doi:10.1177/0093854807301555

57. Batastini AB, McDonald BR, Morgan RD. Videotele conferencing in forensic and correctional practice. In: Myers K, Turvey CL, Myers K, Turvey CL, editors. Telemental Health: Clinical, Technical, and Administrative Foundations for Evidence-Based Practice. Amsterdam, Netherlands: Elsevier (2013). p. 251-71.

58. Batastini AB, King CM, Morgan RD, McDaniel B. Telepsychological services with criminal justice and substance abuse clients: a systematic review and meta-analysis. Psycho/ Serv (2016) 13(1):20-30. doi:10.1037/ser0000042

59. Brodey BB, Claypoole KH, Motto J, Arias RG, Goss R. Satisfaction of forensic psychiatric patients with remote telepsychiatric evaluation. Psychiatr $\operatorname{Serv}$ (2000) 51(10):1305-7. doi:10.1176/appi.ps.51.10.1305

60. Farabee D, Calhoun S, Veliz R. An experimental comparison of telepsychiatry and conventional psychiatry for parolees. Psychiatr Serv (2016) 67(5):562-5. doi:10.1176/appi.ps.201500025 
61. Khalifa N, Saleem Y, Stankard P. The use of telepsychiatry within forensic practice: a literature review on the use of videolink. J Forens Psychiatry Psychol (2008) 19(1):2-13. doi:10.1080/14789940701560794

62. Manfredi L, Shupe J, Batki SL. Rural jail telepsychiatry: a pilot feasibility study. Telemed J E Health (2005) 11(5):574-7. doi:10.1089/tmj.2005.11.574

63. Miller TW, Clark J, Veltkamp LJ, Burton DC, Swope M. Teleconferencing model for forensic consultation, court testimony, and continuing education. Behav Sci Law (2008) 26(3):301-13. doi:10.1002/bsl.809

64. Miller TW, Burton DC, Hill K, Luftman G, Veltkemp LJ, Swope M. Telepsychiatry: critical dimensions for forensic services. J Am Acad Psychiatry Law (2005) 33(4):539-46.

65. Saleem Y, Taylor MH, Khalifa N. Forensic telepsychiatry in the United Kingdom. Behav Sci Law (2008) 26(3):333-44. doi:10.1002/bsl.810

66. Sales CP, McSweeney L, Saleem Y, Khalifa N. The use of telepsychiatry within forensic practice: a literature review on the use of videolink-a ten-year follow-up.J Forensic Psychiatr Psychol (2017) 28:1-16. doi:10.1080/14789949.2017.1396487

67. Sullivan DH, Chapman M, Mullen PE. Videoconferencing and forensic mental health in Australia. Behav Sci Law (2008) 26(3):323-31. doi:10.1002/bsl.815

68. Tucker W, Olfson M, Simring S, Goodman W, Bienenfeld S. A pilot survey of inmate preferences for on-site, visiting consultant, and telemedicine psychiatric services. CNS Spectr(2006) 11(10):783-7. doi:10.1017/S1092852900014905

69. Arborelius L, Fors U, Svensson AK, Sygel K, Kristiansson M. A new interactive computer simulation system for violence risk assessment of mentally disordered violent offenders. Crim Behav Ment Health (2013) 23(1):30-40. doi:10.1002/cbm.1849

70. Fromberger P, Jordan K, Müller JL. Anwendung virtueller Realitäten in der forensischen Psychiatrie. Ein neues Paradigma? = Use of virtual reality in forensic psychiatry. A new paradigm? Nervenarzt (2014) 85(3):298-303. doi:10.1007/s00115-013-3904-7

71. Hubal RC, Fishbein DH, Sheppard MS, Paschall MJ, Eldreth DL, Hyde CT. How do varied populations interact with embodied conversational agents? Findings from inner-city adolescents and prisoners. Comput Hum Behav (2008) 24(3):1104-38. doi:10.1016/j.chb.2007.03.010 
72. Montgomery J, Brooks MH. Use of a television crime-drama series to promote legal understanding in mentally ill, incompetent defendants: a pilot study. J Forensic Sci (2005) 50(2):465-9. doi:10.1520/JFS2004050

73. Sygel K, Kristiansson M, Furberg R, Fors U. Reactions on display/intimate partner violence (ROD/IPV) - a study of a new interactive computer simulation program for the treatment of men convicted of intimate partner violence. Int J Forensic Ment Health(2014) 13(4):369-80. doi:10.1080/14999013.2014.951104

74. Wijk L, Edelbring S, Svensson AK, Karlgren K, Kristiansson M, Fors U. A pilot for a computer-based simulation system for risk estimation and treatment of mentally disordered offenders. Inform Health Soc Care (2009) 34(2):106-15. doi:10.1080/17538150903014395

75. Benbouriche M, Nolet K, Trottier D, Renaud P. Virtual reality applications in forensic psychiatry. Paper Presented at the Proceedings of the 2014 Virtual Reality International Conference. Laval, France (2014).

76. Dennis E, Rouleau JL, Renaud P, Nolet K, Saumur C. A pilot development of virtual stimuli depicting affective dispositions for penile plethysmography assessment of sex offenders. Can J Hum Sex(2014) 23(3):200-8. doi:10.3138/cjhs.2529

77. Renaud P, Trottier D, Rouleau JL, Goyette M, Saumur C, Boukhalfi T, et al. Using immersive virtual reality and anatomically correct computergenerated characters in the forensic assessment of deviant sexual preferences. Virtual Real(2014) 18(1):37-47. doi:10.1007/s10055-0130235-8

78. Renaud P, Proulx J, Rouleau J, Bouchard S, Madrigrano G, Bradford J, et al. The recording of observational behaviors in virtual immersion: a new clinical tool to address the problem of sexual preferences with paraphiliacs. Annu Rev Cyberther Telemed (2005) 3:85-92.

79. Bacon N, Farnworth L, Boyd R. The use of the WII fit in forensic mental health: exercise for people at risk of obesity. Br J Occup Ther (2012) 75(2):61-8. doi:10.4276/030802212X13286281650992

80. Gooch $\mathrm{P}$, Living R. The therapeutic use of videogames within secure forensic settings: a review of the literature and application to practice. $\mathrm{Br} J$ Occup Ther (2004) 67(8):332-40. doi:10.1177/030802260406700802 
81. Hodge P, Davis J, Maiden N, Mann B, Nidsjo A, Simpson A, et al. StreetWise: a valid ecology for a serious game in a secure forensic mental health setting. Paper Presented at the Procedia Computer Science (2015) 63:252-9.

82. Reynolds LM, Davies JP, Mann B, Tulloch S, Nidsjo A, Hodge P, et al. StreetWise: developing a serious game to support forensic mental health service users' preparation for discharge: a feasibility study. J Psychiatr Ment Health Nurs (2017) 24(4):185-93. doi:10.1111/jpm.12340

83. Kernsmith PD, Kernsmith RM. A safe place for predators: online treatment of recovering sex offenders.J Technol Hum Serv(2008) 26(2-4):223-38. doi:10.1080/15228830802096598

84. Van Gelder JL, Luciano EC, Weulen Kranenbarg M, Hershfield HE. Friends with my future self: longitudinal vividness intervention reduces delinquency. Criminology (2015) 53(2):158-79. doi:10.1111/17459125.12064

85. Hekler EB, Klasnja P, Riley WT, Buman MP, Huberty J, Rivera DE, et al. Agile science: creating useful products for behavior change in the real world. Transl Behav Med(2016) 6(2):317-28. doi:10.1007/s13142-0160395-7

86. Patrick K, Hekler EB, Estrin D, Mohr DC, Riper H, Crane D, et al. The pace of technologic change: implications for digital health behavior intervention research. Am J Prev Med (2016) 51(5):816-24. doi:10.1016/j.amepre.2016.05.001

87. van Gemert-Pijnen J, Peters O, Ossebaard HC. Improving eHealth. Den Haag, Netherlands: Eleven International Publishing (2013).

88. Kushniruk AW, Bates DW, Bainbridge M, Househ MS, Borycki EM. National efforts to improve health information system safety in Canada, the United States of America and England. Int J Med Inform (2013) 82(5):e149-60. doi:10.1016/j.ijmedinf.2012.12.006

89. van Gemert-Pijnen JE, Nijland N, van Limburg M, Ossebaard HC, Kelders SM, Eysenbach $G$, et al. A holistic framework to improve the uptake and impact of eHealth technologies.J Med Internet Res(2011) 13(4):e111. doi:10.2196/jmir.1672

90. WHO Regional Office for Europe. From Innovation to Implementation. eHealth in the WHO European Region. Copenhagen: Publications WHO Regional Office for Europe (2016). 
91. van Limburg M, Wentzel J, Sanderman R, van Gemert-Pijnen L. Business modeling to implement an eHealth portal for infection control: a reflection on co-creation with stakeholders. JMIR Res Protoc(2015) 4(3):e104. doi:10.2196/resprot.4519

92. Beerlage-de Jong N, Wentzel J, Hendrix R, van Gemert-Pijnen L. The value of participatory development to support antimicrobial stewardship with a clinical decision support system. Am J Infect Control (2017) 45(4):365-71. doi:10.1016/j.ajic.2016.12.001 


\section{Appendix}

\section{A. Full Electronic Search Strategy}

Search string \#1 on treatments in forensic mental health settings

forensic

violen*

crim*

delinquen*

offend*

maximum secur*

$\mathrm{W} / 3$

treatment*

psychiatr*

patient*

setting*

assessment*

diagno*

rehabilitation

parole

probation

therap*

coach*

intervention*

Search string \#2 on technology

E-Health

eHealth

M-Health

mHealth

technolog*

device*

platform*

videoc*

tele*

mobile

*phone

SMS;

web* 
"virtual Reality"

virtual

"augmented reality"

wearable*

smart*watch*

game*

online

computer 



\section{Chapter 3}

Integrating People, Context, and Technology in the Implementation of a Web-Based Intervention in Forensic Mental Health Care: Mixed-Methods Study

Hanneke Kip, Floor Sieverink, Lisette J.E.W.C. van Gemert-Pijnen, Yvonne H.A. Bouman \& Saskia M. Kelders 


\begin{abstract}
Background: While eMental health interventions can have many potential benefits for mental health care, implementation outcomes are often disappointing. In order to improve these outcomes, there is a need for a better understanding of complex, dynamic interactions between a broad range of implementation-related factors. These interactions and processes should be studied holistically, paying attention to factors related to context, technology, and people.
\end{abstract}

Objective: The main objective of this mixed-method study was to holistically evaluate the implementation strategies and outcomes of an eMental health intervention in an organization for forensic mental health care.

Methods: First, desk research was performed on 18 documents on the implementation process. Second, the intervention's use by 721 patients and 172 therapists was analysed via log data. Third, semi-structured interviews were conducted with all 18 therapists of one outpatient clinic to identify broad factors that influence implementation outcomes. The interviews were analysed via a combination of deductive analysis using the Nonadoption, Abandonment, Scale-up, Spread, and Sustainability (NASSS) framework and inductive, open coding.

Results: The timeline generated via desk research showed that implementation strategies focused on technical skills training of therapists. Log data analyses demonstrated that 1019 modules were started, and 18.65\% (721/3865) of patients of the forensic hospital started at least one module. Of these patients, $18.0 \%$ (130/721) completed at least one module. Of the therapists using the module, $54.1 \%$ (93/172 sent at least one feedback message to a patient. The median number of feedback messages sent per therapist was 1 , with a minimum of 0 and a maximum of 460. Interviews showed that therapists did not always introduce the intervention to patients and using the intervention was not part of their daily routine. Also, therapists indicated patients often did not have the required conscientiousness and literacy levels. Furthermore, they had mixed opinions about the design of the intervention. Important organization-related factors were the need for more support and better integration in organizational structures. Finally, therapists stated that despite its current low use, the intervention had the potential to improve the quality of treatment.

Conclusions: Synthesis of different types of data showed that implementation outcomes were mostly disappointing. Implementation strategies focused on technical training of therapists, while little attention was paid to changes in the organization, design of the technology, and patient awareness. A more holistic approach toward 
implementation strategies - with more attention to the organization, patients, technology, and training therapists - might have resulted in better implementation outcomes. Overall, adaptivity appears to be an important concept in eHealth implementation: a technology should be easily adaptable to an individual patient, therapists should be trained to deal flexibly with an eMental health intervention in their treatment, and organizations should adapt their implementation strategies and structures to embed a new eHealth intervention. 


\section{Introduction}

Mental health issues cause an increasing number of personal, social, and financial burdens and form a growing challenge for health care systems [1, 2,3]. Technology can be used to address this challenge by supporting treatment of mental health problems in an efficient manner $[3,4]$, while maintaining comparable clinical outcomes as standard in-person treatment [5-7]. The application of technology in mental health care is often referred to as eMental health: the use of technology for treating or preventing mental health disorders [8]. Multiple types of technology can be used. Multimodal web-based interventions based on cognitive behavioural therapies have been studied most often; other examples are mobile apps or virtual reality [8-11]. eMental health technologies can be used as a stand-alone tool, used individually by a person, but often they are integrated within in-person treatment, delivered by one or more therapists. The combination of offline, in-person treatment and online technologies in mental health care is referred to as blended care [12]. Blended care can offer various advantages. Among other things, it has the potential to increase patient engagement and sense of ownership for their treatment, reduce barriers toward receiving mental health care, offer treatment in a more standardized, evidence-based manner, and save time and decrease costs; it can also be personalized to optimally fit patients $[4,8,13-15]$. However, while eMental health has a broad range of potential benefits, most are not observed in practice $[8,16]$.

An important reason for this gap between the potential and the current situation can be found in issues related to implementation. Implementation of eHealth (electronic health) refers to the strategies that are undertaken to realize the adoption, dissemination, and integration of eHealth innovation into care $[17,18]$. Examples of such implementation strategies are training and education of stakeholders, changing an organization's infrastructure, using evaluative strategies, or supporting clinicians in using the intervention [19]. Ideally, these implementation strategies have a positive impact on implementation outcomes, defined in Table 1 $[20,21]$. However, studies show a broad range of issues with implementation outcomes for eMental health interventions, including acceptance by therapists and patients [22], therapists' lack of knowledge on how to optimally combine eMental health and in-person treatment [14], a suboptimal fit with existing technologies such as electronic patient records, and practical barriers such as continuous maintenance of the technology or good internet access [16]. Consequently, to further actualize the benefits that eMental health can offer, implementation strategies should be improved. In order to identify relevant points of improvement, a recent review of 
eHealth implementation recommended that there is a need for more studies that critically analyse implementation strategies and outcomes of eMental health technologies in practice [23].

Several studies have focused on this issue and identified barriers and facilitators for the use of eMental health in practice [14,24-26]. However, as a recent review pointed out, most of the studies that analyse implementation of eMental health focus on one level (e.g., factors related to patients) [16]. In order to get a good grasp of implementation of eMental health, attention needs to be paid to other levels as well (e.g., organizational [16] or policy levels [13]). These recommendations on eMental health are in line with more general implementation models and literature: implementation should be seen as a multilevel and complex process [27] that requires a holistic approach $[28,29]$. Implementation models like the consolidated framework for implementation research (CFIR) [30] and the nonadoption, abandonment, scaleup, spread, and sustainability (NASSS) framework [31] account for the dynamic interaction between different factors and emphasize the interrelationship between characteristics and perspectives of users, organizations, and the intervention itself. Consequently, analysing and integrating characteristics and perspectives of users; the context in which the eHealth intervention will be used; and the content, design, and use of the technology itself is expected to result in a complete, realistic picture of the implementation process and outcomes [20,28-32]. 
Table 1. Implementation outcomes and their definitions, adapted from Proctor et al [21].

\begin{tabular}{|c|c|}
\hline $\begin{array}{l}\text { Implementation } \\
\text { outcome }\end{array}$ & Definition \\
\hline Acceptability & $\begin{array}{l}\text { The intervention is agreeable, palatable, or satisfactory among } \\
\text { implementation stakeholders. }\end{array}$ \\
\hline Adoption & $\begin{array}{l}\text { The intention, initial decision, or action to try or employ an } \\
\text { intervention by a care provider or organization. }\end{array}$ \\
\hline Appropriateness & $\begin{array}{l}\text { The perceived fit, relevance, or compatibility of the intervention for } \\
\text { a given practice setting, provider, or consumer; and/or perceived fit } \\
\text { of the innovation to address a particular issue or problem. }\end{array}$ \\
\hline Cost & $\begin{array}{l}\text { The cost impact of an implementation effort, dependent on the } \\
\text { costs for the intervention, the implementation strategy used, and } \\
\text { the location of service delivery. }\end{array}$ \\
\hline Feasibility & $\begin{array}{l}\text { The extent to which a new intervention can be successfully used or } \\
\text { carried out within a given setting. }\end{array}$ \\
\hline Fidelity & $\begin{array}{l}\text { The degree to which an intervention was implemented as it was } \\
\text { prescribed in the original protocol or as it was intended by the } \\
\text { program developers. }\end{array}$ \\
\hline Penetration & $\begin{array}{l}\text { The integration of an intervention within a service setting and its } \\
\text { subsystems. }\end{array}$ \\
\hline Sustainability & $\begin{array}{l}\text { The extent to which a newly implemented intervention is } \\
\text { maintained or institutionalized within a service setting's ongoing, } \\
\text { stable operations }\end{array}$ \\
\hline
\end{tabular}

In order to apply such a holistic approach to eHealth implementation, a combination of different types of data that provide insight into the different aspects of eHealth implementation is necessary. Collecting multiple types of data does justice to the dynamic, complex interaction between factors that influence implementation, as opposed to analysing these factors separately [33]. Also, from a holistic point of view, implementation should be studied from multiple angles and perspectives to gain indepth insight into the technology, context, and people involved $[18,28]$. To illustrate: if only quantitative data from questionnaires are used to analyse implementation, an in-depth understanding of the reasons for the use of eMental health might be lacking [24]. However, when only using qualitative methods like interviews, information might not be as reliable or objective as is necessary for a thorough analysis of implementation [34]. Consequently, a mixed-methods approach where different types of quantitative and qualitative data are triangulated does justice to the complex 
integration of factors related to people, technology, and context. This is required for wielding a holistic approach toward the evaluation of eHealth implementation [3538].

This study applied a mixed-methods approach to the holistic evaluation of the implementation process and outcomes of a blended eMental health intervention introduced in routine care by an organization for forensic mental health care. This setting provides an interesting context to study implementation in practice. First, the evaluation of implementation processes of eMental health technologies that have been implemented in routine care by an organization is expected to result in more ecologically valid results, as opposed to technologies that are being used because of research-initiated studies $[20,35]$. Second, our study focused on the implementation of an online eMental health platform with multiple modules that has been used for over 4 years in an organization that offers forensic mental health care to both in- and outpatients, which is expected to provide novel insights into long-term implementation processes in practice. Third, forensic mental health care is a branch of mental health care that focuses on treatment of a broad range of in- and outpatients who have committed or were on the verge of committing an aggressive or sexual offense, partly caused by one or more psychiatric disorders [39]. Because of the complex nature of this type of mental health care, and because not much is known about implementation in this type of setting [40], forensic mental health care offers an interesting setting to study implementation strategies and outcomes. Consequently, the goal of our study was to apply a mixed-methods approach to the holistic evaluation of the implementation strategies and outcomes of an eMental health intervention in an organization that offers forensic mental health care. The main research questions are as follows:

- Which implementation strategies were employed by the organization?

- What are the implementation outcomes in terms of adoption, fidelity, and penetration of the eMental health intervention?

- How do therapists perceive and explain implementation strategies and outcomes in terms of factors related to context, technology, and people? 


\section{Methods}

\section{Design}

This mixed-methods study has evaluated the long-term use of a web-based application from multiple perspectives. A convergent parallel mixed-methods design was used [41] in which qualitative and quantitative data were collected in parallel, analysed separately, and then merged. First, qualitative desk research was used to describe implementation strategies of the organization. Second, quantitative log data were used to analyse the objective use of an eMental health intervention by therapists and patients to gain insight into implementation outcomes. Third, interviews with therapists were conducted to gain more insight into implementation strategies and outcomes and analyse how they perceive and explain these strategies and outcomes. The purpose of this design is complementary [42]: the qualitative results are used to explain, illustrate, and provide more depth to the results from the quantitative log data, and the quantitative log data are used to enhance and illustrate the qualitative results in order to improve the interpretation of these findings and substantiate conclusions [43]. In order to answer the research questions, results were synthesized in the discussion by means of the aforementioned implementation strategies and outcomes. In Figure 1, an overview of this mixed-method study is provided.

Figure 1. Overview of methods used in this study with types of outcomes seen in each method.

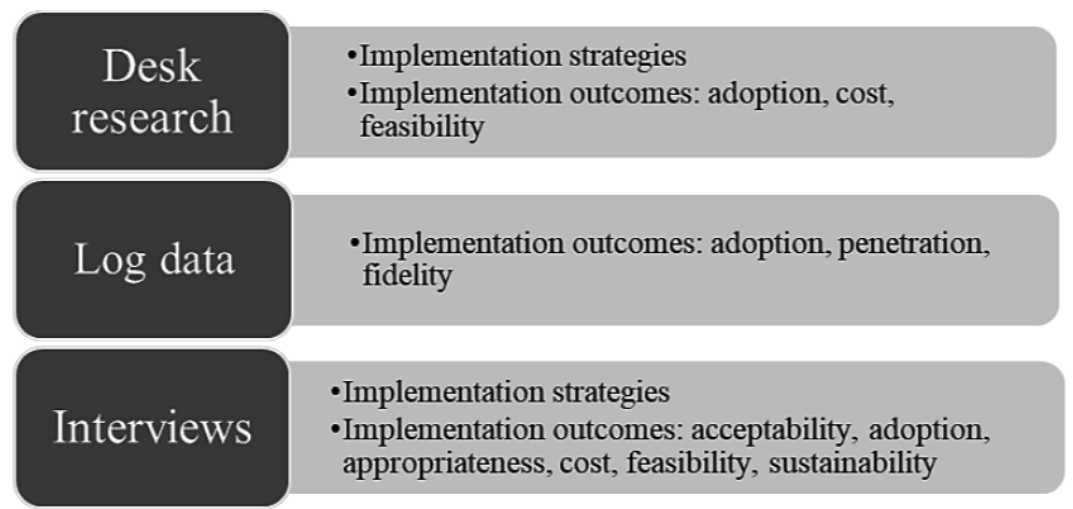




\section{Setting}

\section{Organization}

This study focused on the implementation strategies and outcomes of implementation of an eMental health intervention within one forensic mental health care organization. This organization started a pilot with the intervention in 2012 and gradually implemented the intervention in the entire organization around the beginning of 2014. The Dutch organization in which this study took place offers forensic mental health care to both in- and outpatients. From January 1, 2014, until May 30, 2019, 3865 in- and outpatients were treated at one of the locations of the forensic hospital. The hospital has two main outpatient clinics, where approximately $85 \%$ of patients are treated, and three main inpatient clinics, where the remaining $15 \%$ are treated. A total of 252 therapists worked at the hospital between 2014 and 2019.

Electronic patient records show that from January 1, 2014, until May 30, 2019, 2076 patients were treated in the outpatient clinic where the interview study took place, which is $54 \%$ of the total patient population of the forensic hospital. According to electronic patient records, $23.27 \%$ (483/2076) of the patients had a level of education of primary school or none at all, 22.74\% (472/2076) attended secondary school, mostly vocational, $16.33 \%$ (339/2076) completed vocational secondary education, 3.32\% (69/2076) completed higher secondary education at (applied) universities, and for 34.49\% (716/2076), no information was available. Comorbidity was high in this patient population, and there was a broad range of diagnoses for psychiatric disorders (e.g., personality, attention deficit, sexual, anxiety, depression, schizophrenia, and substance use disorders).

\section{Online Intervention}

The eMental health intervention that is the topic of this study is a website containing a collection of different types of modules. The intervention is suitable for all types of mental health care, not just forensic mental health care. The intervention was designed by a commercial company, and organizations that want to use it must pay for a subscription. In total, 234 modules were available in May 2019. These modules cover a broad range of topics including attention deficit hyperactivity disorder (ADHD), autism, social skills, mindfulness, personality disorders, trauma, addiction, and relaxation. The intervention also contains 6 modules specifically developed for forensic mental health care. These modules focus on creating offense chains and prevention plans, patient recovery, positive self-image, and leading a meaningful life. 
However, since forensic patients suffer from a broad range of psychiatric disorders and psychosocial problems, other, non-forensic modules are often suitable as well. Therapists must choose which module they find most fitting for their patient; they are able to assign any of the 234 modules. If a therapist does not assign a module, a patient is not able to use the intervention.

Each module consists of multiple sessions provided in a fixed order and accessed via a browser. These sessions consist of a combination of elements (e.g., written information about the topic, a story from a peer (in video or text), written assignments derived from cognitive behavioural therapy, and videos to provide additional information about the topic of the session). The underlying assumption is that a patient must complete all sessions in order to be adherent to a module. In our study, the intervention is used as part of blended care, which means that the patient is asked to complete assignments in each session on which the therapist provides written feedback. The patient can only continue with the module once the therapist has provided feedback on a session.

\section{Desk Research}

In order to identify the implementation strategies employed by the organization, desk research was conducted. In total, 18 documents describing the pilot project and implementation of the eMental health intervention were obtained from a policy advisor of the forensic organization who has been involved in the implementation of the intervention from the start. Examples of included documents are reports on the planning, progress, and outcomes of the pilot; communication with management; and brief research reports. In order to summarize the implementation process, a timeline with a chronological description of decisions, products, and events was distilled.

\section{Log Data Analysis}

Log data from the entire organization from December 2013 until May 2019 were collected and analysed. These data were analysed to gain insight into the following implementation outcomes: adoption by therapists and patients, fidelity, and penetration of the eMental health intervention in the organization. Log data refers to anonymous records containing information of every action performed by every user [36]. To be able to analyse the log data, several files with anonymized log data were retrieved from the platform. First, multiple files with information on modules assigned to patients and sessions completed were downloaded. The raw data were combined and organized into an overview of modules and accompanying lessons by means of a 
macro in Excel (Microsoft Inc). Second, a file with the monthly number of feedback messages sent by individual therapists was retrieved. All log data were stored and processed anonymously and in line with privacy regulations relevant at that point in time. Ethical approval (No. 18408) was obtained from the ethics committee of the Faculty of Behavioural, Management, and Social Sciences from the University of Twente.

\section{Interview Study}

\section{Participants}

In order to gain a deeper insight into how therapists perceive and explain implementation strategies and outcomes, interviews were conducted with therapists working at one outpatient clinic of the forensic hospital. In this clinic, therapists were expected to use the eMental health intervention. Therapists were interviewed because of their key role in implementation: if they did not introduce the intervention to the patients, patients could not participate. The attitudes and actions of health care professionals appear to have an essential role in eHealth implementation [44]. At the time of the interviews, 20 therapists were working at the outpatient clinic. All therapists were invited to participate by the manager of the outpatient clinic, but two of them were excluded because they did not receive training and had no experience with the eMental health intervention.

\section{Materials and Procedure}

The main goal of the interview study was to identify factors which, according to therapists, are related to the use and non-use of the eMental health intervention. These factors provide insight into implementation strategies and outcomes. In order to achieve this, semi-structured interviews with the 18 therapists were conducted in April and May 2018 by two researchers (KR \& NtC) at the outpatient clinic. The interviews were audio-recorded and took between 21 and 61 minutes, with an average of 41 (SD 10) minutes. Ethical approval (No. 18239) for the interview study was given by the ethics committee of the Faculty of Behavioural, Management, and Social Sciences of the University of Twente.

The interview started with a brief explanation of the goal and content of the study. After that, informed consent was signed. The interview scheme consisted of 6 main categories with accompanying open questions. First, sociodemographic questions were asked. Second, experiences with the introduction of the eMental health intervention were discussed. Third, the participant was asked to describe in 
what way, how often, and with which patients he or she used the eMental health intervention. Reasons for nonadherence were also discussed. The fourth part contained questions on the potential and experienced added value of the eMental health intervention for the therapist, patient, and organization. Fifth, participant was asked to describe what the ideal situation with regard to the use of the eMental health intervention would look like. In the sixth part, barriers for using the intervention were discussed. These questions were divided into 5 topics, loosely based on 5 relevant domains of the NASSS framework [31]: barriers related to patients, therapists, and the forensic health care organization; the wider context; and characteristics of the eMental health intervention. The NASSS framework was used because its holistic nature, in which attention is paid to different types of factors and their interrelationships, fits the research goal of this study. The interview's final question focused on what should be done to overcome these barriers and optimize benefits.

\section{Analysis}

The interviews were transcribed verbatim. In order to answer the research questions, deductive, top-down coding via the NASSS framework was combined with an inductive, bottom-up analysis of all fragments belonging to a domain of the NASSS framework. First, all relevant fragments were analysed deductively by categorizing them into 1 of the 7 domains of the NASSS framework. This deductive analysis ensured a clear main structure of the results in line with the holistic focus of the research goals. The NASSS framework was used to structure the analysis because of its focus on technology in health care and holistic approach [31]. After deductive analysis using domains of the NASSS framework, fragments within each domain were analysed inductively to look for more specific factors important for the use of the technology according to the interviewed therapists. A coding scheme was iteratively created based on all fragments of the first 5 interviews by one researcher (HK) via the method of constant comparison [45]. Using this coding scheme, the 165 fragments of these first 5 interviews were independently analysed by a second researcher (FS) to determine interrater reliability of the coding scheme. The joint probability of agreement was 89\%. After deliberation of the fragments that were assessed differently by the researchers, agreement was reached on all fragments, and several definitions of the code scheme were fine-tuned. No further adaptations to the underlying structure of the code scheme were required. Because of the high interrater reliability, one researcher (HK) coded the remaining 572 fragments and 
discussed them with the other researcher (FS) in case of doubt. Again, definitions of codes were adapted throughout the process.

\section{Synthesis}

In this mixed-methods study, results were synthesized via the implementation strategies and outcomes. Figure 1 shows which method was used to provide information for which implementation outcome. To synthesize the results, implementation strategies were summarized using all three methods. Also, the most important findings per implementation outcome were described and supported by outcomes of desk research, log data analyses, and codes that arose from the inductive analysis of the interviews.

\section{Results}

\section{Desk Research}

In order to describe the implementation strategies, desk research was conducted with documents generated by the organization. Before the online intervention was disseminated throughout the organization, a pilot was conducted in which the intervention was used on a small scale. This pilot was coordinated by a project team consisting of therapists and policy advisors, and its timeline is visualized in Figure 2. The goal of the pilot was to improve the content and usability of the intervention and develop a good strategy regarding communication about the eMental health intervention to the organization. The pilot started with an exploratory phase, after which 90 employees were trained and instructed to use the intervention for several months. Desk research did not show how many therapists and patients participated in the pilot. The experiences of the pilot were used to create a strategy and recommendation for implementation of the intervention in the organization. Example of recommendations that arose from the pilot were to provide all employees with the training that participants of the pilot received and write guidelines on how to embed the intervention's modules in existing care programs. 
Figure 2. Timeline of the pilot phase of the online intervention.

\section{Timeline of the pilot for the online intervention}

March 2012 - October 2013

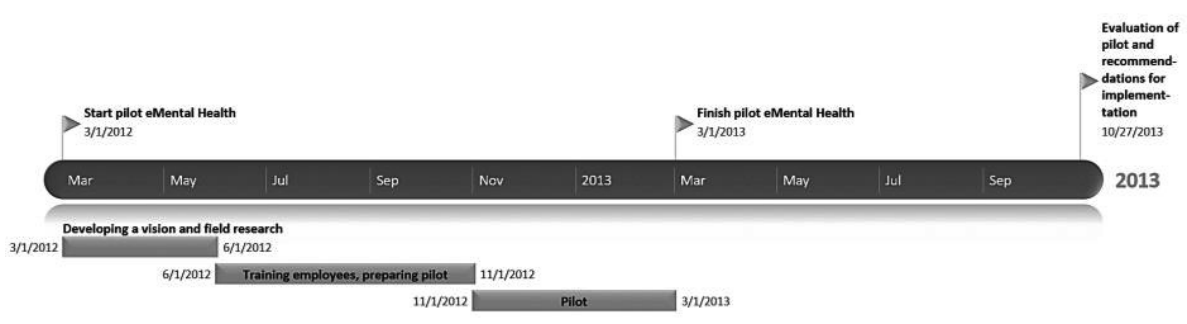

After the pilot, the online intervention was introduced to all therapists of the organization. An overview of the timeline, until July 2018 when the interview study of this paper was finalized, is provided in Figure 3. The main goal of the implementation was to fully integrate the eMental Health intervention in all primary and supportive processes. Consequently, all therapists received training and were expected to use the intervention. However, because use in practice was not as high as expected, an evaluation was conducted in 2016 that resulted in several recommendations, including that management should improve communication about targets of the eMental health intervention to therapists, a clear overview of useful modules should be created, some skilled therapists should be appointed as champions who can support colleagues in using the intervention, and therapists should motivate patients more by, for example, calling them if they did not use the intervention. When the recommendations did not lead to any major improvements, a new project team to installed to improve implementation in 2017; that team initiated this study. 
Figure 3. Timeline of implementation strategies for the online intervention.

\section{Timeline of the implementation of the online intervention \\ October 2013 - July 2018}

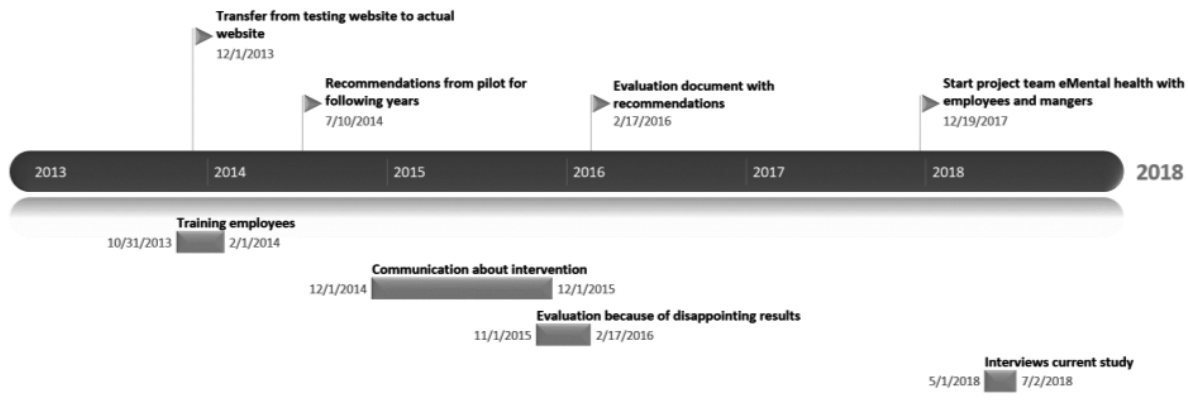

\section{Log data analysis}

Patients

In order to gain insight into implementation outcomes, log data that provide insight into patient use of the intervention were analysed. From December 2013 until May 2019,721 unique patients were assigned to at least one module of the eMental health intervention by their therapist. In total, 1019 modules were assigned to these 721 patients. Most patients (514/721, 71.3\%) were assigned 1 module, 16.8\% (121/721) were assigned 2 modules, 6.4\% (46/721) were assigned 3 modules, and 2.5\% (18/721) worked on 4 modules. The remaining 2.8\% (20/721) worked on 5 to 10 modules. Finally, there were 2 patients who worked on many different modules: one patient worked on 23 modules and another patient on 28. Of the patients, 18.0\% (130/721) fully completed at least 1 module, 50.6\% (365/721) completed 1 or more lessons but did not complete at least 1 module, and 30.0\% (216/721) patients did not complete any lessons at all.

In total, 98 different modules were assigned to patients. The median number of patients assigned to an individual module was 4 . The offense script and prevention plan module was assigned to the most patients (104/721), and 18 modules were assigned to only 1 patient. Table 2 provides an overview of all modules that were assigned to at least 10 patients, including an overview of how many patients completed all lessons of the module, completed 1 or more lessons, or did not complete any lessons. When looking at all modules and patients, 180 of the 1019 modules (17.66\%) were completed, meaning that all lessons were finished. For 448 of the 1019 modules (43.96\%) at least 1 lesson was finished, but not the entire module. On average, when a module was started but not completed, $43.17 \%$ 
(2155/4992) of the modules' lessons were completed. When looking at the longer modules containing 10 to 26 lessons, 44.43\% (1994/4488) of the lessons were completed. Of the shorter modules with 9 or fewer lessons, $40.28 \%$ (203/504) of the lessons were completed. Finally, in 412 of the 1019 modules (40.43\%), no lesson was finished. 
Table 2. Overview of the total and relative number of patients that completed, didn't complete, or partially completed modules that were assigned to at least 10 patients.

\begin{tabular}{|c|c|c|c|c|c|c|c|c|}
\hline \multirow[t]{2}{*}{ Topic of module } & \multirow[t]{2}{*}{$\begin{array}{l}\# \\
\text { les- } \\
\text { sons }\end{array}$} & \multirow[t]{2}{*}{$\mathrm{N}$} & \multicolumn{2}{|c|}{$\begin{array}{l}\text { Module } \\
\text { comple- } \\
\text { ted }\end{array}$} & \multicolumn{2}{|c|}{$\begin{array}{l}\text { Module } \\
\text { not } \\
\text { comple- } \\
\text { ted; } \geq 1 \\
\text { lesson } \\
\text { finished }\end{array}$} & \multicolumn{2}{|c|}{$\begin{array}{l}\text { Module } \\
\text { not } \\
\text { comple- } \\
\text { ted; no } \\
\text { lessons } \\
\text { finished }\end{array}$} \\
\hline & & & $\mathrm{n}$ & $\%$ & $\mathrm{n}$ & $\%$ & $\mathrm{n}$ & $\%$ \\
\hline Offense script and prevention plan & 25 & 104 & 14 & $13 \%$ & 71 & $68 \%$ & 19 & $18 \%$ \\
\hline Aggression & 14 & 94 & 7 & $7 \%$ & 48 & $51 \%$ & 39 & $41 \%$ \\
\hline Autism psycho-education & 10 & 76 & 12 & $16 \%$ & 36 & $47 \%$ & 28 & $37 \%$ \\
\hline Substance abuse problems & 15 & 63 & 5 & $8 \%$ & 37 & $59 \%$ & 21 & $33 \%$ \\
\hline Mindfulness & 9 & 59 & 6 & $10 \%$ & 32 & $54 \%$ & 21 & $36 \%$ \\
\hline $\begin{array}{l}\text { Offense script and prevention plan } \\
\text { (short version) }\end{array}$ & 17 & 55 & 12 & $22 \%$ & 34 & $62 \%$ & 9 & $16 \%$ \\
\hline Expert of yourself & 10 & 53 & 11 & $21 \%$ & 26 & $48 \%$ & 16 & $30 \%$ \\
\hline $\begin{array}{l}\text { ADHD (adults): Understand your } \\
\text { ADHD }\end{array}$ & 3 & 40 & 11 & $28 \%$ & 9 & $23 \%$ & 20 & $50 \%$ \\
\hline Thought scheme & 2 & 29 & 9 & $31 \%$ & 10 & $34 \%$ & 10 & $34 \%$ \\
\hline Skills for mild intellectual disorders & 9 & 22 & 3 & $14 \%$ & 11 & $50 \%$ & 8 & $36 \%$ \\
\hline Loved ones of patients & 9 & 20 & 3 & $15 \%$ & 11 & $55 \%$ & 6 & $30 \%$ \\
\hline Forensic: Positive self-image & 4 & 18 & 9 & $50 \%$ & 3 & $17 \%$ & 6 & $33 \%$ \\
\hline Social skills & 1 & 17 & 5 & $29 \%$ & 5 & $29 \%$ & 7 & $41 \%$ \\
\hline Social skills: Saying 'no' & 2 & 15 & 6 & $40 \%$ & 5 & $33 \%$ & 4 & $27 \%$ \\
\hline Information on psychotic disorders & 9 & 14 & 5 & $36 \%$ & 7 & $50 \%$ & 2 & $14 \%$ \\
\hline $\begin{array}{l}\text { Psycho-education for personality } \\
\text { disorders }\end{array}$ & 4 & 14 & 3 & $21 \%$ & 2 & $14 \%$ & 9 & $64 \%$ \\
\hline Generalized anxiety & 9 & 12 & 2 & $17 \%$ & 7 & $58 \%$ & 3 & $25 \%$ \\
\hline $\begin{array}{l}\text { ADHD (adults): I want to think before I } \\
\text { act }\end{array}$ & 9 & 11 & 6 & $55 \%$ & 0 & $0 \%$ & 5 & $45 \%$ \\
\hline $\begin{array}{l}\text { ADHD (adults): I want to clear my mind } \\
\text { more }\end{array}$ & 1 & 10 & 2 & $20 \%$ & 0 & $0 \%$ & 8 & $80 \%$ \\
\hline Aggression in your relationship & 14 & 10 & 0 & $0 \%$ & 7 & $70 \%$ & 3 & $30 \%$ \\
\hline
\end{tabular}




\section{Therapists}

Therapists' use of the intervention was analysed as well to gain insight into implementation outcomes. A main task of the therapist in using the eMental health intervention was to give feedback on patient assignments. A patient could only continue with the next lesson once the therapist provided feedback, and all lessons required feedback. In total, 172 therapists had accounts, which means they could use the intervention and provide feedback. The median number of feedback messages sent per therapist was 1 , with a minimum of 0 and maximum of 460 . Of the $54.1 \%$ (93/172) of therapists who gave feedback from January 2014 to May 2019, 25.0\% (43/172) gave feedback 1 to 5 times, 25.0\% (43/172) gave feedback 6 to 19 times, 25.0\% (43/172) gave feedback 20 to 50 times, and 25.0\% (43/172) gave feedback 51 to 460 times. Table 3 shows how many therapists sent how many feedback messages, showing one major outlier who gave feedback 460 times. The therapist who gave the second highest amount of feedback sent 251 messages.

Table 3. Number of feedback messages sent by therapists.

\begin{tabular}{ll}
\hline Messages sent & Number of therapists \\
\hline $0-35$ & 144 \\
$35-70$ & 12 \\
$70-105$ & 7 \\
$105-140$ & 2 \\
$140-175$ & 0 \\
$175-210$ & 4 \\
$210-245$ & 1 \\
$245-280$ & 1 \\
$280-315$ & 0 \\
$315-350$ & 0 \\
$350-385$ & 0 \\
$385-420$ & 0 \\
$420-455$ & 0 \\
$455-490$ & 1 \\
\hline
\end{tabular}


Finally, Figure 4 shows the total number of feedback messages that were sent over time, from the introduction of the eMental health intervention until May 2019. The figure shows an increase in sent feedback messages with a peak in 2016, after which the number of messages decreased and seemed to stabilize at approximately 60 messages per month.

Figure 4. Number of feedback messages sent by therapists over time.

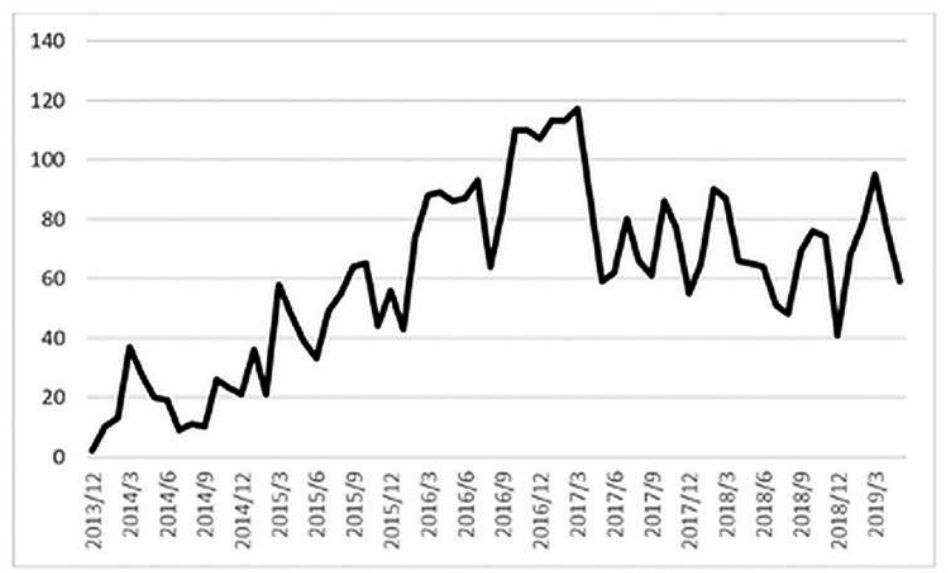

\section{Interviews}

\section{Participants}

In order to gain insight into factors related to implementation outcomes, 18 therapists from one outpatient clinic were interviewed. The therapists had different occupations: 8 psychologists, 6 social workers, 2 system therapists, 1 trauma therapist, and 1 forensic nurse were interviewed. Participants had an average age of 42.5 (SD 10.46) years with a range of 28 to 60 years, and 10 were female. At the time of interviewing, they had been working in forensic care for an average 13.18 (SD 8.68) years with a range from 8 months to 29 years. 
First Impressions, Introduction, and Subjective Use of the Intervention

When asked about their first impression of the eMental health intervention and its introduction by the organization, most therapists were positive, as can be seen in Table 4.

Table 4. Therapist responses to survey questions.

\begin{tabular}{llllll}
\hline Survey question & $\begin{array}{l}\text { Very } \\
\text { bad }\end{array}$ & Bad & Neutral & $\begin{array}{l}\text { Good } \\
\text { Fery } \\
\text { good }\end{array}$ \\
\hline $\begin{array}{l}\text { First impression of the } \\
\text { intervention }\end{array}$ & 0 & 0 & 6 & 11 & 1 \\
\begin{tabular}{l} 
Introduction by the organization \\
\hline
\end{tabular} & 0 & 1 & 5 & 10 & 2 \\
\hline
\end{tabular}

When asked about use of the intervention, 4 therapists indicated that they received training but never used the intervention with a patient. The other 14 therapists had used the intervention with on average 8 patients, with a minimum of 2 and a maximum of 15. Therapists used the intervention in different ways in their in-person sessions with patients. Some discussed the assignments completed by patients very irregularly or never, whereas others discussed them structurally in each session. All therapists saw the intervention as an addition to treatment and used it in a blended manner, where in-person contact was seen as more important. Almost all therapists indicated that most patients did not finish modules and it was hard to keep them motivated.

\section{Coding Schemes}

\section{Overview of Codes}

The NASSS framework was used to structure the interview scheme and guide the coding process. Consequently, the main codes that were identified in the interviews are mostly aligned with the domains of the NASSS framework, as can be seen in Table 5. However, since a combination of deductive and inductive coding was used, there are several differences between the codes and domains of the NASSS framework. First of all, the adopter domain was split into a therapist and patient code. Integrating all these subcodes into one main adopter code would not have done justice to the differences between these types of factors. Furthermore, the embedding and adaptation over time domain of the NASSS model was not identified in interviews because therapists had difficulties providing a long-term vision on the technology and organization. 
Table 5. Main codes, their definitions, number of interviews quote was mentioned (Nint), and number of times code was mentioned (Ntot).

\begin{tabular}{|c|c|c|c|}
\hline Main code & Definition & Nint & Ntot \\
\hline $\begin{array}{l}\text { Adopters - } \\
\text { therapists }\end{array}$ & $\begin{array}{l}\text { Characteristics, cognitions or behaviours of } \\
\text { therapists that influence the use of technology } \\
\text { in treatment. }\end{array}$ & 18 & 203 \\
\hline $\begin{array}{l}\text { Adopters - } \\
\text { patients }\end{array}$ & $\begin{array}{l}\text { Characteristics, cognitions or behaviours of } \\
\text { patients that, according to therapists, } \\
\text { influence the use of technology in treatment. }\end{array}$ & 18 & 194 \\
\hline Value proposition & $\begin{array}{l}\text { The (desired) added value that a technology } \\
\text { has or should have for treatment, according to } \\
\text { the therapists. }\end{array}$ & 18 & 121 \\
\hline Technology & $\begin{array}{l}\text { The influence of the technology's features on } \\
\text { the usage by therapists and patients. }\end{array}$ & 18 & 104 \\
\hline Organization & $\begin{array}{l}\text { The characteristics, culture and activities of } \\
\text { the organization that influence the use of } \\
\text { technology by therapists. }\end{array}$ & 18 & 94 \\
\hline Wider system & $\begin{array}{l}\text { The influence of activities by the broader } \\
\text { context on the use of technology by } \\
\text { organizations and therapists. }\end{array}$ & 11 & 7 \\
\hline Condition & $\begin{array}{l}\text { The extent to which the nature of the } \\
\text { patient's condition (or disorder) influences the } \\
\text { use of the technology according to therapists. }\end{array}$ & 3 & 4 \\
\hline
\end{tabular}

\section{Adopters - Therapists}

This main code was mentioned most often and refers to characteristics, cognitions, or behaviours of therapists that influence the use of eHealth in treatment. This code was found in all interviews, and 203 fragments belonging to this main code were identified. The subcodes are reported, defined, and illustrated with one or two quotes in Table 6. As can be seen in the table, therapists discussed a broad range of factors related to themselves that could influence the intervention's use. The most mentioned code referred to them not putting in enough time or effort to start or keep using the intervention. This could result in a lack of knowledge and skills to optimally use the intervention. The perceived lack of time was partly attributed to high workload but also to lack of enthusiasm to use the intervention. Among other things, not all participants were keen to work with technology in general. Several therapists 
believed that the intervention did not have enough benefits for their patients, and some felt that the technology was not easy to embed within standard treatment. Related to this, many therapists indicated that using the intervention was not in their system: while they often were willing to try it, most of the time they simply forgot about it because it was not part of their treatment routine. Consequently, many therapists did not introduce the intervention to their patients or did not motivate them enough to keep using it. Because the intervention was often not on the top of their minds, therapists indicated that they hardly discussed it with their colleagues. Finally, according to several participants, an important reason for successful use was having experienced benefits of the intervention for the patient: if the intervention fits an individual patient's skills and problems, chances on successful use were said to be higher.

Table 6. Subcodes of the main code "adopters-therapists," their definitions, illustrative quote, number of interviews the quote was mentioned (Nint), and number of times code was mentioned (Ntot).

\begin{tabular}{|c|c|c|c|c|}
\hline Sub code & Definition & Illustrative quote & Nint & Ntot \\
\hline $\begin{array}{l}\text { Investing } \\
\text { effort and } \\
\text { time }\end{array}$ & $\begin{array}{l}\text { The effort and } \\
\text { time the } \\
\text { therapist is able } \\
\text { and/or willing to } \\
\text { invest in getting } \\
\text { acquainted with } \\
\text { and structurally } \\
\text { using the } \\
\text { technology. }\end{array}$ & $\begin{array}{l}\text { "You have to know what happens in } \\
\text { the module, what it contains. And then } \\
\text { you have to check which assignments } \\
\text { have been completed, and then give } \\
\text { feedback on it. That costs extra time. } \\
\text { Perhaps that's why people are } \\
\text { hesitant." (pp. 13) } \\
\text { "It can't be like you saying: 'hey, just fill } \\
\text { it in, but l'll never look at it again'. You } \\
\text { have to make time to thoroughly look } \\
\text { into it and to familiarize yourself with } \\
\text { it." (pp. 4) }\end{array}$ & 18 & 48 \\
\hline $\begin{array}{l}\text { Supporting } \\
\text { patients }\end{array}$ & $\begin{array}{l}\text { The extent to } \\
\text { which a therapist } \\
\text { actively } \\
\text { introduces the } \\
\text { technology to } \\
\text { patients and/or } \\
\text { tries to motivate } \\
\text { and support } \\
\text { patients to keep } \\
\text { using it. }\end{array}$ & $\begin{array}{l}\text { "Sometimes I know in advance: 'this } \\
\text { one will not use it', and maybe that's a } \\
\text { self-fulfilling prophecy, that might be. } \\
\text { But still, I'm not really inclined to start } \\
\text { then." (pp. 7) } \\
\text { "Because I've tried a lot of times to } \\
\text { start with a certain module with } \\
\text { patients who are not passionate about } \\
\text { it. [...] But I notice it with myself: } \\
\text { because the passion is there I can often }\end{array}$ & 17 & 37 \\
\hline
\end{tabular}


make it work. So that's very

necessary." (pp. 12)

$\begin{array}{ll}\begin{array}{l}\text { Integration } \\ \text { of }\end{array} & \text { The extent to } \\ \text { technology } & \text { which the } \\ \text { in routines } & \text { technology in } \\ & \text { integrated in the } \\ & \text { routine and/or } \\ & \text { whether he/she } \\ & \text { automatically } \\ & \text { thinks of using } \\ & \text { the technology. }\end{array}$

"Yeah, I don't know what's the reason, $16 \quad 36$

I cannot really explain it, but despite

that I like the modules, it's not on the

top of my mind. So there is something

that's stopping me from diving into my

computer to find out which module fits

with a patient. And I don't really know

why it doesn't come up." (pp. 15)

"Well, I agreed with a patient that they

would hand it in next week Tuesday.

Well ok, but then I didn't receive it and

I forgot about it myself. The patient

stopped doing it and well, it kind of

disappears into the background. I now

resolved it by planning appointments in

my calendar, so that l'll be reminded to

send reminders to patients." (pp. 6)

Knowledge The therapist's "I also find it difficult to figure out

and skills level of

which module fits which patient. [...]

knowledge about And I think that in my case, l'd just

the technology

have to know which modules exist. And

and skills to

then I can just say 'this fits you nicely,

appropriately use

I'd like to recommend this, see if it's

it in treatment.

possible' and then get to work." (pp. 7)

Attitude

The therapist's

"I think it depends on in which

opinion on and

generation you've grown up, I think

technology feelings towards

younger colleagues have more feeling

using technology

with it. [...] and that asks for a

in treatment.

considerable adjustment,

transformation, also for a number of

older colleagues." (pp. 1)

"And working with people, I still like

doing that. Except for all that technical

fuss, computers mean nothing to me,

and also smartphones... I don't have

any feeling with that and experience it

as a burden." (pp. 2) 


\begin{tabular}{|c|c|c|c|c|}
\hline $\begin{array}{l}\text { Discussing } \\
\text { technology } \\
\text { with } \\
\text { colleagues }\end{array}$ & $\begin{array}{l}\text { Technology as a } \\
\text { topic of } \\
\text { conversation } \\
\text { among therapists } \\
\text { inside and } \\
\text { outside of official } \\
\text { meetings. }\end{array}$ & $\begin{array}{l}\text { "Then I'll say in our team: 'I'm hearing } \\
\text { this and this and this', and sometimes } \\
\text { someone in the team says: 'hey, } \\
\text { eMental Health is something'. I think } \\
\text { that if people in our team say 'maybe } \\
\text { eMental health is an option' more } \\
\text { often... And if that rhythm isn't there, } \\
\text { that's the reason why there is very little } \\
\text { eMental health. Or at least within our } \\
\text { team." (pp. 12) }\end{array}$ & 10 & 21 \\
\hline $\begin{array}{l}\text { Experienced } \\
\text { benefits }\end{array}$ & $\begin{array}{l}\text { The extent to } \\
\text { which a therapist } \\
\text { perceives that } \\
\text { the technology } \\
\text { has positive } \\
\text { effects on the } \\
\text { patient's } \\
\text { treatment } \\
\text { outcomes. }\end{array}$ & $\begin{array}{l}\text { "So then we try to shape the treatment } \\
\text { in another way, instead of continuing } \\
\text { with something [the module] of which } \\
\text { you have the idea that it doesn't have } \\
\text { that much effect." (pp. 3) }\end{array}$ & 2 & 4 \\
\hline
\end{tabular}

\section{Adopters - Patients}

The main code "adopters-patients" was mentioned by all 18 therapists and refers to characteristics, cognitions, or behaviours of patients that influence the use of eHealth in their treatment. In total, 8 subcodes, presented in Table 7, and 194 fragments related to this main code were found. Therapists discussed multiple types of patientrelated factors that, according to them, could influence the use of the intervention. It was frequently mentioned that many forensic psychiatric patients are often not motivated to start or keep working on the intervention. Therapists indicated that this was in line with low motivation for their treatment in general, which is partly due to the often obligatory nature of these patients' treatment. Furthermore, therapists stated that a large share of the patient population has cognitive impairments due to psychiatric disorders - such as problems with focusing-or received very little education (e.g., having finished only primary school). According to the therapists, this can cause problems with patients understanding the mostly text-based intervention, completing written assignments, being able to individually reflect on their behaviour, and having the required technological skills to be able to practically use the intervention. Furthermore, patients have to work in the intervention individually in their own time, which some therapists compared with homework. Therapists stated 
that many patients have difficulty with this: a large share of the patient population was not seen as conscientious enough to independently work on the intervention. For example, patients often do not stick to agreements about when assignments were to be completed. Furthermore, therapists indicated that forensic psychiatric patients often have multiple psychiatric disorders and problems within their social environment, which might negatively influence their use of the intervention. When severe psychosocial issues occur, patients might be too preoccupied with these issues to use the intervention. Furthermore, not all patients have access to a computer or laptop, or they do not have a quiet place where they can comfortably work on the intervention.

Table 7. Subcodes of the main code "adopters-patients," their definitions, illustrative quote, number of interviews quote was mentioned (Nint), and number of times code was mentioned (Ntot).

\begin{tabular}{|c|c|c|c|c|}
\hline Sub code & Definition & Illustrative quote & Nint & Ntot \\
\hline Motivation & $\begin{array}{l}\text { The extent to which a } \\
\text { patient is motivated, } \\
\text { enthusiastic or open } \\
\text { towards working with } \\
\text { the technology in his } \\
\text { or her treatment. }\end{array}$ & $\begin{array}{l}\text { "I kind of think that, I think I've } \\
\text { mentioned before that if that } \\
\text { motivation is present, if they } \\
\text { have the feeling that eMental } \\
\text { Health fits their problems. And } \\
\text { that has to be the case. They } \\
\text { don't have to think: 'well, what } \\
\text { about the problems I have...'. } \\
\text { They do have to see the } \\
\text { connection to be motivated." } \\
\text { (pp. 4) } \\
\text { "Because very demotivated } \\
\text { patients who don't want to be } \\
\text { here anyhow... See, it's easier to } \\
\text { not work on eMental Health at } \\
\text { home, then not attending a } \\
\text { face-to-face appointment. } \\
\text { They'd earlier drop the eMental } \\
\text { health then not coming here." } \\
\text { (pp. 9) }\end{array}$ & 14 & 40 \\
\hline $\begin{array}{l}\text { Conscien- } \\
\text { tiousness }\end{array}$ & $\begin{array}{l}\text { The extent to which a } \\
\text { patient is diligent in } \\
\text { working on the } \\
\text { technology and fulfils }\end{array}$ & $\begin{array}{l}\text { "Reading comprehension, } \\
\text { making assignments, those } \\
\text { kinds of things. If you're not } \\
\text { used to doing homework, if }\end{array}$ & 14 & 27 \\
\hline
\end{tabular}


commitments

regarding the use of the technology outside of treatment.

\section{Literacy and educational level}

Experienced
benefits

The patient's ability to
write, read and
understand treatment-
related information in
the technology.

The extent to which a patient experiences a positive influence on his or her treatment because of the use of the technology. you've never done homework in your live-emental Health is actually homework. So that's a skill in itself. They have to be able to do it." (pp. 9)

"Next, we open the module and then it seems to go well for about 1 or 2 sessions. But then there's always an 'appointment forgotten' or 'not finished' or those kind of things. After three months someone has stopped filling in the assignments, and only completed two sessions." (pp. 11)

\section{"But I noticed that it wasn't} really working. We've done it a couple of times, but there were a lot of difficult words. And if I explain the words, he'll forget what it means after that." (pp. 4)

"And whether the module fits $14 \quad 22$ the treatment and problems of the patient. [...] If you for example have a module on autism, and someone recognizes himself in that, in a module on psycho-education for example. Then it can actually be useful in their daily lives." (pp. 6)

"And also what I said earlier, that a module fits the needs of a patient. So if you use a sleeping module on someone with sleeping problems, chances are higher that he will continue with it." (pp. 16) 


\begin{tabular}{|c|c|c|c|c|}
\hline & $\begin{array}{l}\text { The level stability of a } \\
\text { patient's personal life } \\
\text { and/or mental state } \\
\text { that is required to use } \\
\text { a technology. }\end{array}$ & $\begin{array}{l}\text { "I don't really think about it with } \\
\text { people who are in a crisis } \\
\text { situation. Because in my } \\
\text { experience, they really don't } \\
\text { have the need to discuss [the } \\
\text { intervention]. You have to be in } \\
\text { clearer waters, before they at } \\
\text { least... Yes, that's my } \\
\text { experience, before you can } \\
\text { make a connection with } \\
\text { someone who's overwhelmed } \\
\text { by stress. If you for example } \\
\text { have trouble about your social } \\
\text { security benefit, or trouble with } \\
\text { the neighbors, or trouble with } \\
\text { your spouse, then it doesn't } \\
\text { really work for those people } \\
\text { anymore." (pp. 10) } \\
\text { "Patients who are very prone to } \\
\text { psychiatric crisis [...] or have so } \\
\text { many psychosocial problems, } \\
\text { well, then it won't work. Then } \\
\text { you're only trying to stabilize } \\
\text { them and you cannot use } \\
\text { eMental health." (pp. 9) }\end{array}$ & 13 & 28 \\
\hline $\begin{array}{l}\text { Technological } \\
\text { skills }\end{array}$ & $\begin{array}{l}\text { The level of practical } \\
\text { skills that are required } \\
\text { for successfully using } \\
\text { information and } \\
\text { communication } \\
\text { technologies such as } \\
\text { computers or } \\
\text { smartphones. }\end{array}$ & $\begin{array}{l}\text { "And I also notice that with } \\
\text { eMental Health, the problem is } \\
\text { that If a patient doesn't know } \\
\text { anything about the computer, } \\
\text { who isn't focused on that, you } \\
\text { won't be able to make it work. } \\
\text { You can jump high or low, but } \\
\text { you won't get it done." (pp. 12) }\end{array}$ & 12 & 17 \\
\hline $\begin{array}{l}\text { Availability of } \\
\text { technological } \\
\text { resources }\end{array}$ & $\begin{array}{l}\text { The patient's access to } \\
\text { necessary } \\
\text { preconditions to use } \\
\text { the intervention: a } \\
\text { technological device, } \\
\text { an appropriate } \\
\text { working area and a }\end{array}$ & $\begin{array}{l}\text { "I think that in their own } \\
\text { environment, where they like } \\
\text { doing it. They have to be able to } \\
\text { do it privately, not that there's } \\
\text { someone around the entire } \\
\text { time. So privacy is important for } \\
\text { them, I think. We can't facilitate }\end{array}$ & 11 & 18 \\
\hline
\end{tabular}




\begin{tabular}{|c|c|c|c|c|}
\hline & $\begin{array}{l}\text { good internet } \\
\text { connection. }\end{array}$ & $\begin{array}{l}\text { that; they have to arrange that } \\
\text { themselves. Or we'd have to } \\
\text { offer them a place to work here, } \\
\text { so they can sit behind a } \\
\text { computer here." (pp. 7) } \\
\text { "But I have had several people } \\
\text { who were pretty positive about } \\
\text { it, but who didn't have a } \\
\text { computer, or their computer } \\
\text { broke." (pp .8) }\end{array}$ & & \\
\hline $\begin{array}{l}\text { Reflective } \\
\text { skills }\end{array}$ & $\begin{array}{l}\text { The patient's ability to } \\
\text { independently write } \\
\text { about and reflect on } \\
\text { emotions, cognitions } \\
\text { and behaviours in the } \\
\text { technology. }\end{array}$ & $\begin{array}{l}\text { "I'm dealing with a lot of } \\
\text { patients that find it really } \\
\text { difficult to put their emotions } \\
\text { and feelings on paper. They } \\
\text { don't talk about those things } \\
\text { regularly, like conflicts with their } \\
\text { wife. Those people just didn't } \\
\text { learn that. And yeah, if that's } \\
\text { already difficult in a } \\
\text { conversation to tell what you } \\
\text { feel, what you want or what you } \\
\text { want differently, it's even more } \\
\text { difficult to type it if you're } \\
\text { alone, sitting behind a } \\
\text { computer. That's on another } \\
\text { level." (pp. 10) } \\
\text { Because the simplest question- } \\
\text { he understands them, but he } \\
\text { said to me: 'I simply cannot put } \\
\text { it into words'. And if you have to } \\
\text { do such assignments, and } \\
\text { answer things... The fact that he } \\
\text { hardly gives an answer, that } \\
\text { partly has to do with him not } \\
\text { being able to visualize and } \\
\text { verbalize." (pp. 1) }\end{array}$ & 11 & \\
\hline
\end{tabular}




\section{Value Proposition}

The main code "value proposition" refers to the added value that a technology has or should have for treatment, according to the therapists. It was mentioned by all 18 therapists, 5 subcodes were identified, and 121 fragments were found in all interviews. As can be seen in the previous tables, not all therapists were positive about the intervention and did not use it often, but they were able to identify a broad range of potential and actual advantages of the eMental health intervention. These focused, among other things, on the content of the treatment: the intervention was said to have the potential to improve the quality of treatment by, for example, providing more structure to the treatment. Also, because therapists often also read the text of the intervention, several participants indicated that using the intervention might further improve or deepen existing knowledge about disorders. The intervention can also support patients in gaining new knowledge and skills (e.g. new insights about a psychiatric disorder or an improvement of reflective or coping skills). Furthermore, several therapists explained that because patients must work on the intervention individually, their feeling of responsibility for their own treatment might increase, and they might ascribe positive changes more to themselves instead of their therapists. Moreover, several practical advantages were mentioned, among which saving time of therapists and patients because of less traveling time and replacing part of in-person treatment with the intervention, an increase of patients' access to care because they can individually work on their treatment at their own pace, and providing a new way of delivering treatment to patients. The subcodes are presented in Table 8. 
Table 8. Subcodes of the main code "value proposition," their definitions, illustrative quote, number of interviews quote was mentioned (Nint), and number of times code was mentioned (Ntot).

\begin{tabular}{|c|c|c|c|c|}
\hline Sub code & Definition & Illustrative quote & Nint & Ntot \\
\hline $\begin{array}{l}\text { Improving } \\
\text { treatment }\end{array}$ & $\begin{array}{l}\text { The } \\
\text { possibility of } \\
\text { technology } \\
\text { to improve } \\
\text { the quality of } \\
\text { and further } \\
\text { structure } \\
\text { face-to-face } \\
\text { treatment. }\end{array}$ & $\begin{array}{l}\text { "It does help you to focus the } \\
\text { treatment on what someone needs. } \\
\text { And it helps to not get bogged down in } \\
\text { other, less relevant matters that } \\
\text { people bring up, where it actually } \\
\text { shouldn't be about. Someone has a } \\
\text { treatment goal and the program fits } \\
\text { that goal and that is what you will be } \\
\text { doing. So it really helps to frame your } \\
\text { therapy." (pp. 11) } \\
\text { "Often, there are also things in there } \\
\text { that I don't have on the top of my } \\
\text { mind. And sometimes it's pretty nice to } \\
\text { work via a protocol, that you } \\
\text { encounter things of which you think: } \\
\text { 'hey, I didn't think about that at all!'” } \\
\text { (pp. 2) }\end{array}$ & 14 & 39 \\
\hline $\begin{array}{l}\text { Practical } \\
\text { benefits }\end{array}$ & $\begin{array}{l}\text { Benefits for } \\
\text { patients, } \\
\text { therapists } \\
\text { and the } \\
\text { organization } \\
\text { related to } \\
\text { practical } \\
\text { matters such } \\
\text { as time and } \\
\text { money. }\end{array}$ & $\begin{array}{l}\text { "Well, I think it's very nice that you can } \\
\text { put patients to work at a time which } \\
\text { suits you, and that they can work } \\
\text { whenever it suits them. So planning } \\
\text { appointments is less of a hassle. And } \\
\text { it's just like communication via } \\
\text { WhatsApp or e-mail: you all do it in } \\
\text { your own time, so in that sense it's } \\
\text { easier insertable in everyone's } \\
\text { schedule." (pp. 16) } \\
\text { "Well, the patient can work on it at } \\
\text { home. He'd have to come here less } \\
\text { often, face-to-face. So you'd have to } \\
\text { plan an appointment less often, which } \\
\text { can enable you to see more other } \\
\text { patients." (pp. 5) }\end{array}$ & 14 & 26 \\
\hline $\begin{array}{l}\text { Increase of } \\
\text { knowledge and } \\
\text { skills }\end{array}$ & $\begin{array}{l}\text { The } \\
\text { possibility for } \\
\text { the patient }\end{array}$ & $\begin{array}{l}\text { "An advantage for a patient with } \\
\text { whom I have done the aggression } \\
\text { module is that he did really gain more }\end{array}$ & 13 & 22 \\
\hline
\end{tabular}




\begin{tabular}{|c|c|c|c|c|}
\hline & $\begin{array}{l}\text { or therapist } \\
\text { to acquire } \\
\text { new insights } \\
\text { and skills } \\
\text { into the } \\
\text { patient or } \\
\text { the disorder. }\end{array}$ & $\begin{array}{l}\text { self-insight and came a little closer to } \\
\text { himself. With the other patients I didn't } \\
\text { really have a hallelujah-experience, but } \\
\text { with him it seemed like the penny has } \\
\text { dropped." (pp. 15) } \\
\text { "What I like about that is that you also } \\
\text { go through the content yourself. [...] } \\
\text { And I really like that of the modules, } \\
\text { that you learn things from it yourself, } \\
\text { and him as well." (pp. 12) }\end{array}$ & & \\
\hline $\begin{array}{l}\text { Increase of } \\
\text { patients' } \\
\text { independence }\end{array}$ & $\begin{array}{l}\text { Enabling the } \\
\text { patients to } \\
\text { work more } \\
\text { independentl } \\
\text { y on and feel } \\
\text { more } \\
\text { ownership } \\
\text { for their } \\
\text { treatment. }\end{array}$ & $\begin{array}{l}\text { "Well, the fact that someone does it } \\
\text { himself with the module, that they are } \\
\text { prouder at themselves because they've } \\
\text { achieved something. That it wasn't the } \\
\text { therapist who helped you, but that } \\
\text { you've done it yourself." (pp. 16) } \\
\text { "If they're in my room, I often have a } \\
\text { fairly high pace, I am pulling and } \\
\text { pushing them. But with the } \\
\text { intervention, they're in a calm } \\
\text { environment and can think calmly." } \\
\text { (pp 2) }\end{array}$ & 13 & 19 \\
\hline $\begin{array}{l}\text { More options } \\
\text { for treatment }\end{array}$ & $\begin{array}{l}\text { The } \\
\text { possibility of } \\
\text { technology } \\
\text { to offer a } \\
\text { broader } \\
\text { range and } \\
\text { different } \\
\text { types of } \\
\text { treatment to } \\
\text { patients. }\end{array}$ & $\begin{array}{l}\text { "Well, for example if a patient is } \\
\text { working on the offense chain, you } \\
\text { might notice that he has the need to } \\
\text { practice more skills. Or wants to read a } \\
\text { bit more about certain relaxation } \\
\text { exercises. And if we're not there yet in } \\
\text { the module, I move these topics } \\
\text { forward, so that we can work on those } \\
\text { at that point in time. Or I check in } \\
\text { another module if there's something } \\
\text { there, that they can work on a topic in } \\
\text { between. [...] Then I think: 'this fits well } \\
\text { at this point in time', and then we can } \\
\text { continue with the treatment." (pp. 9) }\end{array}$ & 11 & 17 \\
\hline
\end{tabular}




\section{Technology}

This main code was mentioned in all 18 interviews and focuses on the influences of the technology's features on use by therapists and patients. In total, 3 subcodes and 104 fragments were identified, as can be seen in Table 9. Usability of the technology was often mentioned by therapists. While a few were fairly positive, most found the technology not easy to use for themselves or for patients: it did not fit their preferences and way of working. Furthermore, while most therapists were relatively positive about the intervention's look and feel, it was mentioned that the way the content was presented was not very suitable for many patients, for example, due to a lot of text or too many sessions within modules.

Table 9. Subcodes of the main code "technology," their definitions, illustrative quote, number of interviews quote was mentioned (Nint), and number of times code was mentioned (Ntot).

\begin{tabular}{|c|c|c|c|c|}
\hline Sub code & Definition & Illustrative quotes & Nint & Ntot \\
\hline Ease of use & $\begin{array}{l}\text { The extent to } \\
\text { which therapists } \\
\text { find the use of } \\
\text { the technology } \\
\text { intuitive, clear } \\
\text { and structured. }\end{array}$ & $\begin{array}{l}\text { "I feel that the eMental health } \\
\text { intervention is too big, or too fuzzy. As I } \\
\text { just mentioned, all these modules, I } \\
\text { know a few, but I think that there are a } \\
\text { lot, also specified on other diagnoses. } \\
\text { But I find it tricky to find these things. } \\
\text { So I don't think it's very well-arranged." } \\
\text { (pp. 9) } \\
\text { "I'd see that as tiles in [the electronic } \\
\text { patient record] which we are using } \\
\text { currently. In User you have multiple tiles } \\
\text { and the patient record, and it should } \\
\text { also have a tile of [the intervention], on } \\
\text { which you click and then you can start. } \\
\text { [...] If there would be a block of [the } \\
\text { intervention], it would be really easy to } \\
\text { go to it. I think that would be more user } \\
\text { friendly than when you have to go to } \\
\text { the website yourself to log in, because } \\
\text { then you have taken multiple additional } \\
\text { steps." (pp. 7) }\end{array}$ & 16 & 68 \\
\hline $\begin{array}{l}\text { Presentation } \\
\text { of content }\end{array}$ & $\begin{array}{l}\text { The therapist's } \\
\text { opinion on the } \\
\text { ways in which }\end{array}$ & $\begin{array}{l}\text { "The modules itself should be shorter. } \\
\text { Both the individual sessions and the } \\
\text { number of sessions in a specific module }\end{array}$ & 8 & 21 \\
\hline
\end{tabular}


the treatment-

related content

of the

technology is

presented to

the patients.
I'd make shorter. I feel that certain

explanations are too difficult for some

patients. So I think there is not enough

supply for people with a low

intelligence, and a large number of our

people has a lower than average

intelligence." (pp. 18)

\begin{tabular}{|c|c|c|c|}
\hline Appearance & $\begin{array}{l}\text { The therapist's } \\
\text { opinion on the } \\
\text { overall look and } \\
\text { feel of the } \\
\text { design of the } \\
\text { technology. }\end{array}$ & $\begin{array}{l}\text { "Because I think those modules are } \\
\text { really cool. I'm thinking 'wow, the } \\
\text { person that came up with this has it } \\
\text { right!' But it's just fresh, I'd almost say } \\
\text { happy, but also friendly, and user- } \\
\text { friendly. And if you can have these } \\
\text { things together in a module text, with } \\
\text { some videos and some other things and } \\
\text { some explanation, that's just amazing!" } \\
\text { (pp. 12) } \\
\text { "With regard to the design, with videos } \\
\text { and images, it's stimulating and } \\
\text { appealing. It's not a boring booklet that } \\
\text { you hand out." (pp. 4) }\end{array}$ & 10 \\
\hline
\end{tabular}

\section{Organization}

This main code refers to the characteristics, culture, and activities of the organization that influence the use of technology by therapists, and was mentioned in all 18 interviews. In total, 94 fragments for 4 subcodes were identified, which are explained in Table 10. Almost all interviewed therapists explained that the intervention was introduced to them by means of a course in which they gained practical skills to use it. According to therapists, the organization did not pay a lot of attention to the intervention after this course. Multiple therapists indicated that the intervention was often not discussed in official meetings. This was viewed as a partial explanation for therapists not remembering to use the intervention on a regular basis. Also, several therapists indicated that they did not experience enough support for questions about the content of the intervention or the way they could embed it in treatment. To illustrate, some therapists required more support when working with unmotivated patients or had questions about how to integrate assignments of the intervention in their in-person treatment sessions. Besides content-related support, therapists also 
mentioned several practical barriers that the organization should address, such as a slow internet connection.

Table 10. Subcodes of the main code "organization," their definitions, illustrative quote, number of interviews quote was mentioned (Nint), and number of times code was mentioned (Ntot).

\begin{tabular}{|c|c|c|c|c|}
\hline Sub code & Definition & Illustrative quote & Nint & Ntot \\
\hline $\begin{array}{l}\text { Introduction } \\
\text { of technology } \\
\text { to therapists }\end{array}$ & $\begin{array}{l}\text { The activities that } \\
\text { the organization } \\
\text { undertook to } \\
\text { introduce the } \\
\text { technology and } \\
\text { train therapists' } \\
\text { necessary skills } \\
\text { and knowledge, } \\
\text { according to } \\
\text { therapists. }\end{array}$ & $\begin{array}{l}\text { "Hmm, much less, because, I think I } \\
\text { had a course once, just in the } \\
\text { beginning, and there's not really a } \\
\text { follow-up." (pp. 10) } \\
\text { "We've received a very clear } \\
\text { explanation, I believe an entire day } \\
\text { and you just started practicing. And } \\
\text { I liked that. But now I'm thinking, if } \\
\text { I'd have to use it with a patient, I'd } \\
\text { really have to ask with the people } \\
\text { who gave the course. He'd have to } \\
\text { quickly explain to me how it works. } \\
\text { That knowledge has faded." (pp. 1) }\end{array}$ & 17 & 27 \\
\hline $\begin{array}{l}\text { Providing } \\
\text { support for } \\
\text { therapists }\end{array}$ & $\begin{array}{l}\text { The ways in which } \\
\text { the organization } \\
\text { offers content- } \\
\text { related support to } \\
\text { the therapists for } \\
\text { using the } \\
\text { technology in } \\
\text { treatment. }\end{array}$ & $\begin{array}{l}\text { "I just think that, well, for the long } \\
\text { term the organization has to pay } \\
\text { more attention to it, for the team. } \\
\text { And I also think that you have to } \\
\text { implement the trainer-trainer idea. } \\
\text { That you pick a couple of people } \\
\text { who work well with it or are a bit } \\
\text { better in it, that they are appointed } \\
\text { as a source of information, and } \\
\text { that other people know about } \\
\text { that." (pp. 9) } \\
\text { Currently I'm trying to figure it out } \\
\text { myself, but how do you really shape } \\
\text { a blended treatment? If there } \\
\text { would be education about that! } \\
\text { Also about the more challenging } \\
\text { cases, if there is very little } \\
\text { motivation." (pp. 4) }\end{array}$ & 14 & 34 \\
\hline
\end{tabular}




\begin{tabular}{|c|c|c|c|c|}
\hline $\begin{array}{l}\text { Integration in } \\
\text { organizational } \\
\text { structures }\end{array}$ & $\begin{array}{l}\text { The extent to } \\
\text { which a } \\
\text { technology is } \\
\text { structurally } \\
\text { featured in } \\
\text { activities or } \\
\text { products for which } \\
\text { the organization is } \\
\text { responsible, such } \\
\text { as meetings, } \\
\text { treatment } \\
\text { protocols, targets, } \\
\text { or performance } \\
\text { reviews. }\end{array}$ & $\begin{array}{l}\text { "But it doesn't get indicated a lot in } \\
\text { the intake or in meetings. Often the } \\
\text { one who's done the intake has to } \\
\text { bring it up themselves, but it's not } \\
\text { something that other people in the } \\
\text { meeting bring up or come up with, } \\
\text { that that's also an option. My } \\
\text { personal experience. If I bring it up, } \\
\text { they say 'oh yeah it's a good idea', } \\
\text { but if I say nothing, they hardly ever } \\
\text { come up with it." (pp. 18) } \\
\text { "So that management says: } \\
\text { 'eMental health guys, don't forget } \\
\text { about that!'" (pp. 6) }\end{array}$ & 11 & 21 \\
\hline $\begin{array}{l}\text { Providing } \\
\text { necessary } \\
\text { conditions for } \\
\text { use }\end{array}$ & $\begin{array}{l}\text { The extent to } \\
\text { which the } \\
\text { organization } \\
\text { ensures boundary } \\
\text { conditions such as } \\
\text { the availability of } \\
\text { sufficient } \\
\text { technological } \\
\text { resources and } \\
\text { time for } \\
\text { therapists. }\end{array}$ & $\begin{array}{l}\text { "Internet is often slow. Then you've } \\
\text { planned half an hour, and you } \\
\text { think, I'm going to do it. Well, it } \\
\text { doesn't work. It's also a technical } \\
\text { issue. From the division around it, } \\
\text { the internet, that's so slow. And if } \\
\text { you have to start a program such } \\
\text { as [the intervention], well, you can } \\
\text { do something else in that time... } \\
\text { Then you constantly have to wait, } \\
\text { well, then I drop out." (pp. 2) } \\
\text { "And that time is actually } \\
\text { scheduled for people. You have to } \\
\text { really work on it, so it cannot } \\
\text { disappear in the other activities, } \\
\text { because you will forget it. If you } \\
\text { really have an hour to only work on } \\
\text { eMental health, it will remove some } \\
\text { barriers and other arguments." (pp. } \\
\text { 18) }\end{array}$ & 7 & 10 \\
\hline
\end{tabular}




\section{Wider System}

This main code refers to the influence of activities by the broader context on use of technology by organizations and therapists and consists of 2 subcodes, which can be found in Table 11. This code was identified 17 times in 11 interviews. Therapists discussed the wider system less often than previous codes. Several participants briefly mentioned health insurance companies and government but did not elaborate on the role of the wider system.

Table 11. Subcodes of the main code "wider system," their definitions, illustrative quote, number of interviews quote was mentioned (Nint), and number of times code was mentioned (Ntot).

\begin{tabular}{|c|c|c|c|c|}
\hline Sub code & Definition & Illustrative quote & Nint & Ntot \\
\hline $\begin{array}{l}\text { Demands of } \\
\text { health } \\
\text { insurance } \\
\text { companies }\end{array}$ & $\begin{array}{l}\text { The therapist's } \\
\text { perception } \\
\text { about the } \\
\text { financial } \\
\text { incentives for } \\
\text { using the } \\
\text { technology } \\
\text { offered by health } \\
\text { insurance } \\
\text { companies. }\end{array}$ & $\begin{array}{l}\text { "I don't know, that's something } \\
\text { from the health insurer, that they } \\
\text { say that we have to do something } \\
\text { with [the intervention]. That's a bit } \\
\text { how it feels. That we received that } \\
\text { assignment because we have to } \\
\text { meet the numbers." (pp. 7) }\end{array}$ & 9 & 12 \\
\hline $\begin{array}{l}\text { Encouragement } \\
\text { of government }\end{array}$ & $\begin{array}{l}\text { The extent to } \\
\text { which the use of } \\
\text { a technology is } \\
\text { encouraged by } \\
\text { the government. }\end{array}$ & $\begin{array}{l}\text { "First, they should make a } \\
\text { statement as organization, } \\
\text { together with other organizations, } \\
\text { to say: 'yeah it's all good and you } \\
\text { can want it in this way but we're } \\
\text { going higher to the government } \\
\text { and say to the government: this is } \\
\text { not ok.' There are so many } \\
\text { administrative tasks that don't... If } \\
\text { you do something and you have to } \\
\text { account for this it's fine, but it can } \\
\text { be a lot easier." (pp 12) }\end{array}$ & 4 & 4 \\
\hline
\end{tabular}




\section{Condition}

This code refers to the extent to which the nature of the patient's condition (or psychiatric disorder) influences use of the technology according to therapists. The subcode was mentioned 4 times in 3 interviews, as can be seen in Table 12. Therapists often did not discuss their patients' diagnoses as a separate factor that directly influences the intervention's use.

Table 12. Subcodes of the main code "condition," their definitions, illustrative quote, number of interviews quote was mentioned (Nint), and number of times code was mentioned (Ntot).

\begin{tabular}{lllll}
\hline Sub code & Definition & Illustrative quote & Nint & Ntot \\
\hline ADHD & The impact of & "So I cannot really... I do know that those & 3 & 4 \\
& (symptoms & ADHD patients, that it takes too long for & & \\
& of) ADHD on & them. They're too easily distracted, or find a & & \\
& the patient's & question too difficult. It's not that everyone & & \\
& use of the & has that." (pp 2) & & \\
& technology. & & \\
\end{tabular}

\section{Synthesis}

When looking at the implementation strategies described by Waltz et al [19], desk research and interviews showed that in this study, most attention was paid to training of therapists, as mostly becomes clear in the subcode introduction of the technology to therapists of the main code "organization." However, little to no strategies related to changes in the organizations' infrastructure, engagement of patients, and adaptation of technology to the context were conducted. This is further illustrated by all subcodes of the main code "organization," but also by the therapist- and patientrelated subcodes integration of technology in routines, knowledge and skills, discussing technology with colleagues, and motivation. Furthermore, desk research showed that support and assistance for therapists was available, but most interviewed therapists did not experience this as such, which becomes most clear in the "organization"-related subcode providing support for therapists. Desk research showed that besides training, several relatively minor evaluation strategies were conducted by the organization itself, during and shortly after the pilot. However, the outcomes of these evaluations did not lead to major changes to the implementation strategies, so no lasting improvements in the use of the intervention were observed in the log data. This is visualized in Figure 4; a short peak in sent messages can be observed during the time of the evaluation, but this increase in sent messages only 
lasted several months. To conclude, implementation strategies were mostly focused on training of therapists, but little attention was paid to adaptiveness of the technology, changes in the organization, and patient awareness.

The results of the desk research, log data analysis, and interviews were used to assess the implementation outcomes described by Proctor et al [21] from a holistic perspective, structured via the NASSS framework [31]. First, the interviews showed that acceptability of the intervention was relatively high, with therapists being positive about the intervention and able to identify its added value. This fairly high acceptability is illustrated in Table 4, which shows overall good first impressions of the intervention, and is further supported by the main code "values," which points out that therapists are able to mention a broad range of potential and actual advantages. However, despite the fairly positive acceptability, log data analyses and interviews clearly showed that adoption was low; a large share of therapists and patients did not use the intervention at all. Furthermore, the intervention's penetration in the organization was low; log data showed that only a small fraction of therapists and patients used the intervention. Only $54 \%$ of the eligible therapists actually used the intervention, and Figure 4 shows that the largest share those who did use it, did not use it a lot. When the intervention was used, fidelity was often low, as can be seen in Table 2. Only $18 \%$ of the modules were fully completed, and of the remaining $82 \%$, modules were either not started or not fully completed, implying that they were not used as intended. An explanation for this can be found in the appropriateness of the intervention. Log data showed that several modules were completed, and several therapists indicated that they were able to successfully use the module with some patients. However, therapists indicated that the intervention did not optimally fit most patients' skills and preferences. This is illustrated by the patient-related subcodes conscientiousness, literacy and education level, technological skills, and reflective skills. The mismatch between patient characteristics and the intervention also becomes clear in the main code "technology," which shows that usability, design, and content are not optimally tailored to the forensic psychiatric patient population. Furthermore, the intervention also seems not to be appropriate for many therapists, who indicated that they prefer in-person contact and often felt not fully equipped to integrate the intervention in their treatment. This means that currently, the intervention's costs in terms of finances and time investment seem to be higher than the benefits. Also, sustainability was low: therapists stated that the intervention was often not discussed in meetings and was not integrated in electronic patient records they used. While this theme appears in multiple codes, it becomes especially clear in 
the organizational subcode integration in organizational structures. Consequently, therapists often did not even think of the possibility to use the intervention in treatment, which is represented by the therapist-related subcode integration of technology in routines. Currently, the feasibility of the intervention is low because of a suboptimal fit between the features of the technology; needs, wishes, and skills of therapists and patients; and characteristics and activities of the organization. It appears that since the implementation strategies were not conducted from a holistic perspective but mainly focused on training the therapists, the implementation outcomes are disappointing.

\section{Discussion}

\section{Principal Findings}

This mixed-method study evaluated the implementation strategies and outcomes of an eMental health intervention in forensic mental health care from a holistic perspective, where attention is paid to factors related to people, organizational context, and technology. Triangulation of the outcomes of desk research, log data analyses, and interviews with therapists showed that the technology did not optimally fit the therapists, patients, and organization. Furthermore, the implementation process was mostly focused on skill training of therapists and not executed from a holistic perspective; not enough attention was paid to changes in the organization, patients, and other required changes in therapists. The results of this mixed-methods study will be discussed in more detail structured by the main elements of the holistic approach that was applied: the people using the eMental health intervention, the organization in which it was used, and the technology.

\section{Therapists}

The interviews and log data showed that although several therapists were active users of the intervention, most of them only tried it once or twice, and a relatively large share of the therapists did not even use the intervention at all. Nevertheless, almost all interviewed therapists were fairly positive about the intervention and able to identify its added value. This shows that cognitions, intentions, and feelings of users are not fully predictive of successful use. Nevertheless, models that focus on individual factors predicting technology acceptance, such as the technology acceptance model (TAM) [46] or the unified theory of acceptance and use of technology [47], are still used regularly to analyse or plan implementation. While these types of models are useful to create an overview of individual beliefs and 
attitudes that influence a person's intention to use a technology [48], they pay little to no attention to influences of the context, characteristics of the technology, and interrelationships between them $[48,49]$. Consequently, implementation models or frameworks that apply such a holistic approach like CFIR [30] or the NASSS framework [31] seem to be more useful in this context because of their focus on a broad range of contextual and (inter)personal factors and not merely individual factors of end users.

Despite the fact that all therapists in the organization had received training, only a relatively small proportion actively used the intervention. This implies that skills training only did not suffice for successful implementation: more than just a how-to instruction seems to be necessary to fully equip therapists to embed the intervention in their treatment sessions. Among other things, therapists also need to know how to persuade patients to start with the intervention, they need to be able to keep motivating patients to complete exercises, and they must embed the content of the intervention and the patient's answers in treatment $[14,50,51]$. This implicates that the use of eMental health might also change the role of the (forensic) mental health professional [51]. In this new way of working, patients might be more in the lead and supported by professionals, and the structure and content of treatment may not be determined only by the professional but also by the intervention. Such a technologyinduced role change in domains where communication previously only took place between persons requires changes on a multitude of levels, like management, education, or government [52], and not merely a skills training of therapists. More research on the nature of this role change and implications for implementation strategies is required.

When looking at implementation strategies, it might also be useful to conduct more research on the need to better tailor these strategies to different types of therapists. In this study, there appeared to be a lot of differences in therapists regarding their subjective attitudes and objective use of the intervention. This is in line with a recent study that showed that therapists differ in the types of drivers and barriers they perceive with regard to the use of eMental health [24]. This might imply that different types of therapists benefit from different types of implementation strategies. For example, therapists with a low level of enthusiasm and skills might need to receive a different type of training than enthusiastic and tech-savvy therapists. In line with this, multiple researchers stated that one-size-fits-all interventions are not very suitable for forensic mental health care and that tailoring is advised [40,53-57]. This argument can be extended to professionals: adaptive 
implementation strategies that fit different types or subgroups of therapists' needs, skills, and attitudes might be beneficial for implementation outcomes. Subsequent research might focus on the identification of different subgroups of therapists, for example, in terms of attitude or eHealth literacy and tailoring implementation strategies to these characteristics. Also, researchers should assess whether tailoring implementation strategies to different types of professionals actually results in better implementation outcomes.

\section{Patients}

Therapists indicated that the eMental health intervention requires a relatively high level of reading and writing skills, cognitive reflection, and conscientiousness. However, according to desk research and other literature, forensic psychiatric patients often have low education levels $[58,59]$, which might explain the low number of patients that completed modules. This shows that there seems to be a poor fit between most users' skills and the content of the eHealth technology, which might be a major cause for non-use or nonadherence $[60,61]$. Several solutions might address this issue: therapists can support patients more in working on difficult elements of the intervention, or texts and assignments can be shortened and made easier. However, it might also be possible that the studied eMental health intervention is not very suitable for this context and another type of technology would be a better fit for most patients. For example, multiple recent studies point out the potential of interactive virtual reality interventions for forensic mental health care [62-66], among other things because they allows patients to actually practice with behaviour instead of talking or writing about it. Another possibility is wearables, which can be used to collect physiological data associated with aggressive outbursts or as electronic momentary assessment devices to gather information about a patient's emotional state $[67,68]$. This study underlines the importance of adaptability of eMental health to optimally fit the needs and characteristics of individual patients.

\section{Organization}

As was mentioned before, the organization focused implementation strategies mostly on skills training of therapists but did not pay much attention to the implementation of the intervention on other levels. The disappointing implementation outcomes show the importance of the use of multiple types of implementation strategies to ensure that an eMental Health intervention is thoroughly embedded in a forensic organization's infrastructure $[40,50]$. This is in line with literature on eHealth 
implementation in general, which emphasizes the importance of integrating technologies in existing organizational structures or even changing the way care is delivered or organized $[28,29,32,33,69]$. One way to achieve this in the studied organization is by ensuring that therapists structurally discuss the possibility of using an eMental health intervention at predetermined moments in treatment (e.g. during a patient's intake). This can be done by means of the existing "fit for blended care" instrument [12], which aims to support therapists in shaping their blended treatment in cooperation with the patient. This instrument can be adapted to fit the specific forensic mental health organization by means of the patient-related factors identified in this study. Furthermore, the eMental health intervention might need to become a permanent item on the agenda of team meetings to ensure that it is discussed regularly [50]. Moreover, therapists indicated that they hardly discussed the intervention with colleagues, as opposed to other parts of their treatment, so peercoaching sessions to discuss the use of the intervention might be organized [50]. It is important that research is conducted to determine whether these types of strategies actually boost implementation outcomes [23]. Generating more knowledge on suitable and successful implementation strategies will support other organizations in planning implementation and prevent them from reinventing the wheel, which will eventually save time and money.

\section{Technology}

One reason for the low use of the intervention was that not all therapists were positive about the user-friendliness of the intervention's design: among other things, they indicated that the website did not give them a clear overview of suitable modules for specific patients. Log data indeed showed that only a fraction of modules were used frequently. Adding more persuasive elements to the intervention might support therapists in using the intervention. An example is tunnelling: the system can guide the therapist through the process of selecting suitable modules for a patient [70]. Additional research can be conducted to evaluate and improve the persuasiveness of the intervention (e.g., by means of the Perceived Persuasiveness Questionnaire [71]), which might increase its use [72].

A characteristic of the intervention that might have hindered use is the lack of possibilities for personalization. As was mentioned before, the technology does not seem to fit most patients according to therapists: there were too many sessions within a module, there was too much text, and the subject matter was too complex for most patients. Therapists expressed the need for multiple versions of the modules in order 
to personalize the intervention. Examples are the possibility to choose between videos or text or the option to select texts with different levels of difficulty. Studies on eHealth in general have stated that personalization can increase adherence [7375], so a more personalized version of the intervention might result in better implementation outcomes. However, more research is necessary on what elements should be personalized, how this should be done, and if this actually positively impacts use and adherence. Ideally, this redesign of the technology should be done in close cooperation with end users to ensure that it better fits their needs $[29,64]$, since cocreation can also have a positive influence on implementation outcomes $[28,76]$.

\section{Strengths and Limitations}

This study took place at one forensic psychiatric hospital in the Netherlands, which might raise questions about the generalizability of the results. However, other studies on eHealth in forensic care have identified similar types of implementation issues $[50,53,56,63,77]$. On top of that, many of the identified issues have been reported for eHealth in general (e.g. lack of enthusiasm in therapists, low adherence by patients, or lack of integration of a technology in an organization's structure $[32,33,69]$. This implies that, on an abstract level, our findings are relevant for other types of (mental) health care as well. A related strength of this study is that all therapists working at the outpatient clinic could be interviewed, which prevented a self-selection bias from occurring.

Furthermore, while use of the NASSS framework to structure the qualitative analysis was a strength of this study, several issues arose during the coding process. A chief example of this is the domain "condition." As opposed to a patient population that suffers from one disorder (e.g. depression or diabetes), the forensic psychiatric population is not characterized by one condition: comorbidity is very common among forensic patients, and patients have committed a broad range of offenses [78-80]. This raises the question on how to characterize certain behaviours or cognitions: as part of a patient's personality or as a symptom of a disorder. To illustrate: if a patient has trouble focusing, which hinders the use of an eHealth intervention, should this be viewed as a consequence of the patient's ADHD or as a part of their personality? We therefore recommend that more studies apply the NASSS framework to evaluation of implementation and report on its applicability and suitability, which might lead to possible revisions or fine-tuning of the framework. 
Finally, a strength of this study was the combination of different types of data to evaluate the implementation process. By using a mixed-methods approach, objective and more subjective data were combined, which proved to be valuable for gaining insight into a multilevel and elaborate implementation process. It was decided to not interview patients and management, since therapists were asked about the patient perspective and desk research provided insight into the strategies of management. Including these perspectives in interviews would probably not have produced much new information, but it is possible that factors were overlooked. Further research could focus on analysing the patient perspective in implementation and investigate whether there are any discrepancies between therapist perspectives on patients and the patients' own perceptions. Finally, desk research was combined with interviews to provide a full picture of the implementation strategies, but not all information could be retrieved from the desk research (e.g. number of participating therapists in the pilot). This shows the importance of carefully and fully documenting relevant information about implementation strategies from the start.

\section{Conclusion}

This study showed that the fit between the characteristics and needs of the therapists and patients, the organization, and the technology was suboptimal, which has led to suboptimal implementation outcomes. An explanation for this could be the lack of a holistic approach in implementation: the implementation strategies mainly focused on training therapists' technical skills, while more attention should have been paid to necessary changes in the organization, an attitude change in therapists, and design of the technology. Here, adaptivity appears to be an important concept: a technology should be easily adaptable to an individual patient, therapists should be trained to be able to deal with an eMental health intervention in their treatment in a flexible way, and organizations must adapt their implementation strategies and structures to embed a new eHealth intervention. Consequently, in implementation, the holistic nature of eHealth and ensuring adaptivity on multiple levels appear to be pivotal.

\section{Acknowledgments}

Funding for this study was provided by Stichting Vrienden van Oldenkotte. We would like to thank Karen Rienks and Nathalie ten Cate, who conducted and transcribed the interviews, and Dirk Dijkslag for his help with the desk research and log data retrieval. 


\section{References}

1. Murray CJL, Vos T, Lozano R, Naghavi M, Flaxman AD, Michaud C, et al. Disability-adjusted life years (DALYs) for 291 diseases and injuries in 21 regions, 1990-2010: a systematic analysis for the Global Burden of Disease Study 2010. Lancet 2012 Dec 15;380(9859):2197-2223.

2. Whiteford HA, Degenhardt L, Rehm J, Baxter AJ, Ferrari AJ, Erskine HE, et al. Global burden of disease attributable to mental and substance use disorders: findings from the Global Burden of Disease Study 2010. Lancet 2013 Nov 9;382(9904):1575-1586.

3. Patel V, Chisholm D, Parikh R, Charlson FJ, Degenhardt L, Dua T, DCP MNS Author Group. Addressing the burden of mental, neurological, and substance use disorders: key messages from Disease Control Priorities, 3rd edition. Lancet 2016 Apr 16;387(10028):1672-1685.

4. Christensen $\mathrm{H}$, Hickie IB. E-mental health: a new era in delivery of mental health services. Med J Aust 2010 Jun 07;192(11 Suppl):S2-S3.

5. Lindefors N, Andersson G. Guided Internet-Based Treatments in Psychiatry. Berlin: Springer; 2016.

6. Andersson G, Cuijpers P. Internet-based and other computerized psychological treatments for adult depression: a meta-analysis. Cogn Behav Ther 2009;38(4):196-205.

7. Cuijpers P, Donker T, van Straten A, Li J, Andersson G. Is guided self-help as effective as face-to-face psychotherapy for depression and anxiety disorders? A systematic review and meta-analysis of comparative outcome studies. Psychol Med 2010 Dec;40(12):1943-1957.

8. Schueller S. Mental health and eHealth technology. In: eHealth Research, Theory and Development. London: Routledge; 2018:111-130.

9. Linardon J, Cuijpers P, Carlbring P, Messer M, Fuller-Tyszkiewicz M. The efficacy of app-supported smartphone interventions for mental health problems: a meta-analysis of randomized controlled trials. World Psychiatry 2019 Oct;18(3):325-336

10. Valmaggia LR, Latif L, Kempton MJ, Rus-Calafell M. Virtual reality in the psychological treatment for mental health problems: an systematic review of recent evidence. Psychiatry Res 2016 Feb 28;236:189-195.

11. Carlbring P, Andersson G, Cuijpers P, Riper H, Hedman-Lagerlöf E. Internetbased vs. face-to-face cognitive behavior therapy for psychiatric and somatic 
disorders: an updated systematic review and meta-analysis. Cogn Behav Ther 2018 Jan;47(1):1-18.

12. Wentzel J, van der Vaart R, Bohlmeijer ET, van Gemert-Pijnen JEWC. Mixing online and face-to-face therapy: how to benefit from blended care in mental health care. JMIR Ment Health 2016;3(1):e9

13. Lal S, Adair CE. E-mental health: a rapid review of the literature. Psychiatr Serv 2014 Jan 1;65(1):24-32.

14. van der Vaart $R$, Witting $M$, Riper $H$, Kooistra L, Bohlmeijer ET. Blending online therapy into regular face-to-face therapy for depression: content, ratio and preconditions according to patients and therapists using a Delphi study. BMC Psychiatry 2014;14(1):355

15. Gaggioli A. The bright future of technology in mental health. Cyberpsychol Behav Soc Networking 2018 Jun;21(6):399-400.

16. Vis C, Mol M, Kleiboer A, Bührmann L, Finch T, Smit J, et al. Improving implementation of emental health for mood disorders in routine practice: systematic review of barriers and facilitating factors. JMIR Ment Health 2018 Mar 16;5(1):e20

17. Powell BJ, McMillen JC, Proctor EK, Carpenter CR, Griffey RT, Bunger AC, et al. A compilation of strategies for implementing clinical innovations in health and mental health. Med Care Res Rev 2012 Apr;69(2):123-157

18. van Gemert-Pijnen L, Kelders M, Kip H, Sanderman R. eHealth Research, Theory and Development: A Multi-Disciplinary Approach. London: Routledge; 2018.

19. Waltz TJ, Powell BJ, Matthieu MM, Damschroder LJ, Chinman MJ, Smith JL, et al. Use of concept mapping to characterize relationships among implementation strategies and assess their feasibility and importance: results from the Expert Recommendations for Implementing Change (ERIC) study. Implement Sci 2015 Aug 07;10:109

20. Proctor EK, Landsverk J, Aarons G, Chambers D, Glisson C, Mittman B. Implementation research in mental health services: an emerging science with conceptual, methodological, and training challenges. Adm Policy Ment Health 2009 Jan;36(1):24-34

21. Proctor E, Silmere H, Raghavan R, Hovmand P, Aarons G, Bunger A, et al. Outcomes for implementation research: conceptual distinctions, measurement challenges, and research agenda. Adm Policy Ment Health 2011 Mar;38(2):65-76 
22. Emmelkamp PMG. Technological innovations in clinical assessment and psychotherapy. Psychother Psychosom 2005;74(6):336-343.

23. Varsi C, Solberg Nes L, Kristjansdottir OB, Kelders SM, Stenberg U, Zangi HA, et al. Implementation strategies to enhance the implementation of ehealth programs for patients with chronic illnesses: realist systematic review. J Med Internet Res 2019 Sep 27;21(9):e14255

24. Feijt MA, de Kort YA, Bongers IM, IJsselsteijn WA. Perceived drivers and barriers to the adoption of emental health by psychologists: the construction of the levels of adoption of emental health model. J Med Internet Res 2018 Dec 24;20(4):e153

25. Aref-Adib G, McCloud T, Ross J, O'Hanlon P, Appleton V, Rowe S, et al. Factors affecting implementation of digital health interventions for people with psychosis or bipolar disorder, and their family and friends: a systematic review. Lancet Psychiatry 2019 Mar;6(3):257-266.

26. Kivi $M$, Eriksson MC, Hange D, Petersson E, Björkelund C, Johansson B. Experiences and attitudes of primary care therapists in the implementation and use of internet-based treatment in Swedish primary care settings. Internet Interventions 2015 Sep;2(3):248-256.

27. Ross J, Stevenson F, Lau R, Murray E. Factors that influence the implementation of e-health: a systematic review of systematic reviews (an update). Implement Sci 2016 Oct 26;11(1):146

28. van Gemert-Pijnen JEWC, Nijland N, Ossebaard HC, Kelders SM, Eysenbach $G$, Seydel ER. A holistic framework to improve the uptake and impact of eHealth technologies. J Med Internet Res 2011;13(4):e111

29. van Gemert-Pijnen JEWC, Kip H, Kelders S, Sanderman R. Introducing eHealth. In: eHealth Research, Theory and Development. London: Routledge; 2018:23-46.

30. Damschroder LJ, Aron DC, Keith RE, Kirsh SR, Alexander JA, Lowery JC. Fostering implementation of health services research findings into practice: a consolidated framework for advancing implementation science. Implement Sci 2009;4:50

31. Greenhalgh T, Wherton J, Papoutsi C, Lynch J, Hughes G, A'Court C, et al. Beyond adoption: a new framework for theorizing and evaluating nonadoption, abandonment, and challenges to the scale-up, spread, and sustainability of health and care technologies. J Med Internet Res 2017 Nov 01;19(11):e367 
32. Pieterse M, Kip H, Martinez R. The complexity of eHealth implementation: a theoretical and practical perspective. In: eHealth Research, Theory and Development: A Multi-Disciplinary Approach. London: Routledge; 2018:247270.

33. Greenhalgh T, Robert G, Macfarlane F, Bate P, Kyriakidou O. Diffusion of innovations in service organizations: systematic review and recommendations. Milbank Q 2004;82(4):581-629.

34. Johnson RB, Onwuegbuzie AJ. Mixed methods research: a research paradigm whose time has come. Educ Res 2016 Jul;33(7):14-26.

35. Vis C, Kleiboer A, Prior R, Bønes E, Cavallo M, Clark SA, et al. Implementing and up-scaling evidence-based eMental health in Europe: the study protocol for the MasterMind project. Internet Interventions 2015 Nov;2(4):399-409.

36. Sieverink F, Kelders S, Poel M, van Gemert-Pijnen L. Opening the black box of electronic health: collecting, analyzing, and interpreting log data. JMIR Res Protoc 2017 Aug 07;6(8):e156.

37. Venkatesh V, Brown S, Sullivan Y. Guidelines for conducting mixed-methods research: an extension and illustration. J Assoc Inf Syst 2016 Aug;17(7):435494.

38. Sieverink F, Kelders S, Braakman-Jansen A, van Gemert-Pijnen J. Evaluating the implementation of a personal health record for chronic primary and secondary care: a mixed methods approach. BMC Med Inform Decis Mak 2019 Nov 27;19(1):1.

39. Mullen PE. Forensic mental health. Br J Psychiatry 2000 Apr;176:307-311.

40. Kip H, Bouman YHA, Kelders SM, van Gemert-Pijnen JEWC. eHealth in treatment of offenders in forensic mental health: a review of the current state. Front Psychiatry 2018;9:42.

41. Creswell J, Clark V. Designing and Conducting Mixed Methods Research. Thousand Oaks: Sage Publications; 2017.

42. Greene J. Mixed Methods in Social Inquiry, Vol. 9. Hoboken: John Wiley \& Sons; 2007.

43. Leech N, Onwuegbuzie A. Guidelines for conducting and reporting mixed research in the field of counseling and beyond. J Couns Devel 2010;88(1):6169.

44. Nazi KM. The personal health record paradox: health care professionals' perspectives and the information ecology of personal health record systems in organizational and clinical settings. J Med Internet Res 2013;15(4):e70 
45. Boeije H. A purposeful approach to the constant comparative method in the analysis of qualitative interviews. Qual Quant 2002;36(4):391-409.

46. Venkatesh V, Davis FD. A theoretical extension of the technology acceptance model: four longitudinal field studies. Manag Sci 2000 Feb;46(2):186-204.

47. Venkatesh V, Morris M, Davis G, Davis F. User acceptance of information technology: toward a unified view. MIS Quarterly 2003;27(3):425.

48. van Velsen L, Evers M, Bara C, Op den Akker H, Boerema S, Hermens H. Understanding the acceptance of an eHealth technology in the early stages of development: an end-user walkthrough approach and two case studies. JMIR Form Res 2018 Jun 15;2(1):e10474

49. Legris $\mathrm{P}$, Ingham J, Collerette P. Why do people use information technology? A critical review of the technology acceptance model. Inf Manag 2003 Jan;40(3):191-204.

50. Kip H. Technologie in de forensische zorg-Crossing borders. Kwaliteit Forensische Zorg 2019.

51. Barakat A, Woolrych RD, Sixsmith A, Kearns WD, Kort HSM. eHealth technology competencies for health professionals working in home care to support older adults to age in place: outcomes of a two-day collaborative workshop. Med 20 2013;2(2):e10

52. Bowen DE. The changing role of employees in service theory and practice: an interdisciplinary view. Hum Resource Manag Rev 2016 Mar;26(1):4-13.

53. Bierbooms J. Kwaliteit Forensische Zorg (KFZ). 2015. Do's en don'ts van ehealth in de forensische ggz. URL: https://tinyurl.com/y98w9xlh [accessed 2020-04-14]

54. Birgden A. Therapeutic jurisprudence and responsivity: finding the will and the way in offender rehabilitation. Psychol Crime Law 2004 Sep;10(3):283295.

55. Levesque DA, Johnson JL, Welch CA, Prochaska JM, Fernandez AC. Computertailored intervention for juvenile offenders. J Soc Work Pract Addict 2012 Jan 1;12(4):391-411.

56. Wild TSN, Fromberger P, Jordan K, Müller I, Müller JL. Web-based health services in forensic psychiatry: a review of the use of the internet in the treatment of child sexual abusers and child sexual exploitation material offenders. Front Psychiatry 2018;9:763. 
57. Polaschek DL. Many sizes fit all: a preliminary framework for conceptualizing the development and provision of cognitive-behavioral rehabilitation programs for offenders. Aggr Violent Behav 2011 Jan;16(1):20-35.

58. Howner K, Andiné $P$, Bertilsson G, Hultcrantz M, Lindström E, Mowafi F, et al. Mapping systematic reviews on forensic psychiatric care: a systematic review identifying knowledge gaps. Front Psychiatry 2018;9:452.

59. Greenberg E, Dunleavy E, Kutner M. Literacy behind bars: results from the 2003 National Assessment of Adult Literacy Prison Survey. URL: https://nces.ed.gov/pubs2007/2007473.pdf [accessed 2020-04-14]

60. Dansky KH, Thompson D, Sanner T. A framework for evaluating eHealth research. Eval Program Plann 2006 Nov;29(4):397-404.

61. Abd-Alrazaq A, Bewick BM, Farragher T, Gardner P. Factors affecting patients' use of electronic personal health records in England: cross-sectional study. J Med Internet Res 2019 Jul 31;21(7):e12373.

62. Smeijers D, Koole SL. Testing the effects of a virtual reality game for aggressive impulse management (VR-GAIME): study protocol. Front Psychiatry 2019;10:83.

63. Cornet L, Den Besten A, van Gelder J. Virtual reality en augmented reality in justitiële context. 2019. URL: https://ris.utwente.nl/ws/portalfiles/portal/107053177/Rapport_VRA R_in_justitie_context.pdf [accessed 2020-04-14].

64. Kip H, Kelders SM, Weerink K, Kuiper A, Brüninghoff I, Bouman YHA, et al. Identifying the added value of virtual reality for treatment in forensic mental health: a scenario-based, qualitative approach. Front Psychol 2019;10:406.

65. Klein Tuente S, Bogaerts S, van IJzendoorn S, Veling W. Effect of virtual reality aggression prevention training for forensic psychiatric patients (VRAPT): study protocol of a multi-center RCT. BMC Psychiatry 2018 Aug 06;18(1):251.

66. Fromberger $\mathrm{P}$, Jordan K, Müller JL. [Use of virtual reality in forensic psychiatry. A new paradigm?]. Nervenarzt 2014 Mar;85(3):298-303.

67. de Looff P, Noordzij ML, Moerbeek M, Nijman H, Didden R, Embregts P. Changes in heart rate and skin conductance in the 30 min preceding aggressive behavior. Psychophysiology 2019 Oct;56(10):e13420.

68. Cornet L, Mandersloot M, Pool R, de Kogel C. De 'zelfmetende'justitiabele. $2017 . \quad$ URL: https://www.wodc.nl/binaries/Cahier\%20201717_2716a_Volledige\%20tekst_v1_tcm28-299893.pdf [accessed 2020-0414]. 
69. Glasgow RE, Phillips SM, Sanchez MA. Implementation science approaches for integrating eHealth research into practice and policy. Int J Med Inform 2014 Jul;83(7):e1-e11.

70. Oinas-Kukkonen $H$, Harjumaa M. Persuasive systems design: key issues, process model, and system features. Comm Assoc Inf Syst 2009;24(1):28.

71. Lehto $T$, Oinas-Kukkonen H, Drozd F. Factors affecting perceived persuasiveness of a behavior change support system. 2012 Presented at: Thirty-Third International Conference on Information Systems; 2012; Orlando.

72. Kelders SM, Kok RN, Ossebaard HC, van Gemert-Pijnen JEWC. Persuasive system design does matter: a systematic review of adherence to web-based interventions. J Med Internet Res 2012;14(6):e152

73. Ludden GD, van Rompay TJ, Kelders SM, van Gemert-Pijnen JE. How to increase reach and adherence of web-based interventions: a design research viewpoint. J Med Internet Res 2015;17(7):e172

74. Asbjørnsen R, Smedsrød M, Solberg L, Wentzel J, Varsi C, Hjelmesæth J, et al. Persuasive system design principles and behavior change techniques to stimulate motivation and adherence in electronic health interventions to support weight loss maintenance: scoping review. J Med Internet Res 2019;21(6):e14265.

75. Beatty L, Binnion C. A systematic review of predictors of, and reasons for, adherence to online psychological interventions. Int J Behav Med 2016 Dec;23(6):776-794.

76. van Limburg M, Wentzel J, Sanderman R, van Gemert-Pijnen L. Business modeling to implement an eHealth portal for infection control: a reflection on co-creation with stakeholders. JMIR Res Protoc 2015 Aug 13;4(3):e104.

77. Potter J, Poulton R. Towards an evidence-informed plan of action for mental health and addiction in New Zealand. 2018. URL: https://tinyurl.com/y7mg7nj2 [accessed 2020-04-14].

78. Degl' Innocenti A, Hassing LB, Lindqvist A, Andersson H, Eriksson L, Hanson $\mathrm{FH}$, et al. First report from the Swedish National Forensic Psychiatric Register (SNFPR). Int J Law Psychiatry 2014;37(3):231-237.

79. Goethals KR, Vorstenbosch EC, van Marle HJ. Diagnostic comorbidity in psychotic offenders and their criminal history: a review of the literature. Int J Forensic Mental Health 2008 Jan;7(2):147-156. 
80. Bloem O, Nijman H, Bulten B, Groen H, Drost M. Psychopathologie onder gedetineerden. In: Groen $H$, Drost $M$, Nijman $H$, editors. Handboek Forensische Geestelijke Gezondheidszorg. Utrecht: Uitgeverij De Tijdstroom; 2011:153-162. 
3 

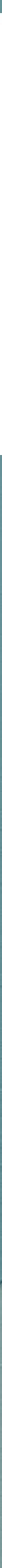


\section{PART 2}

The added value of virtual reality

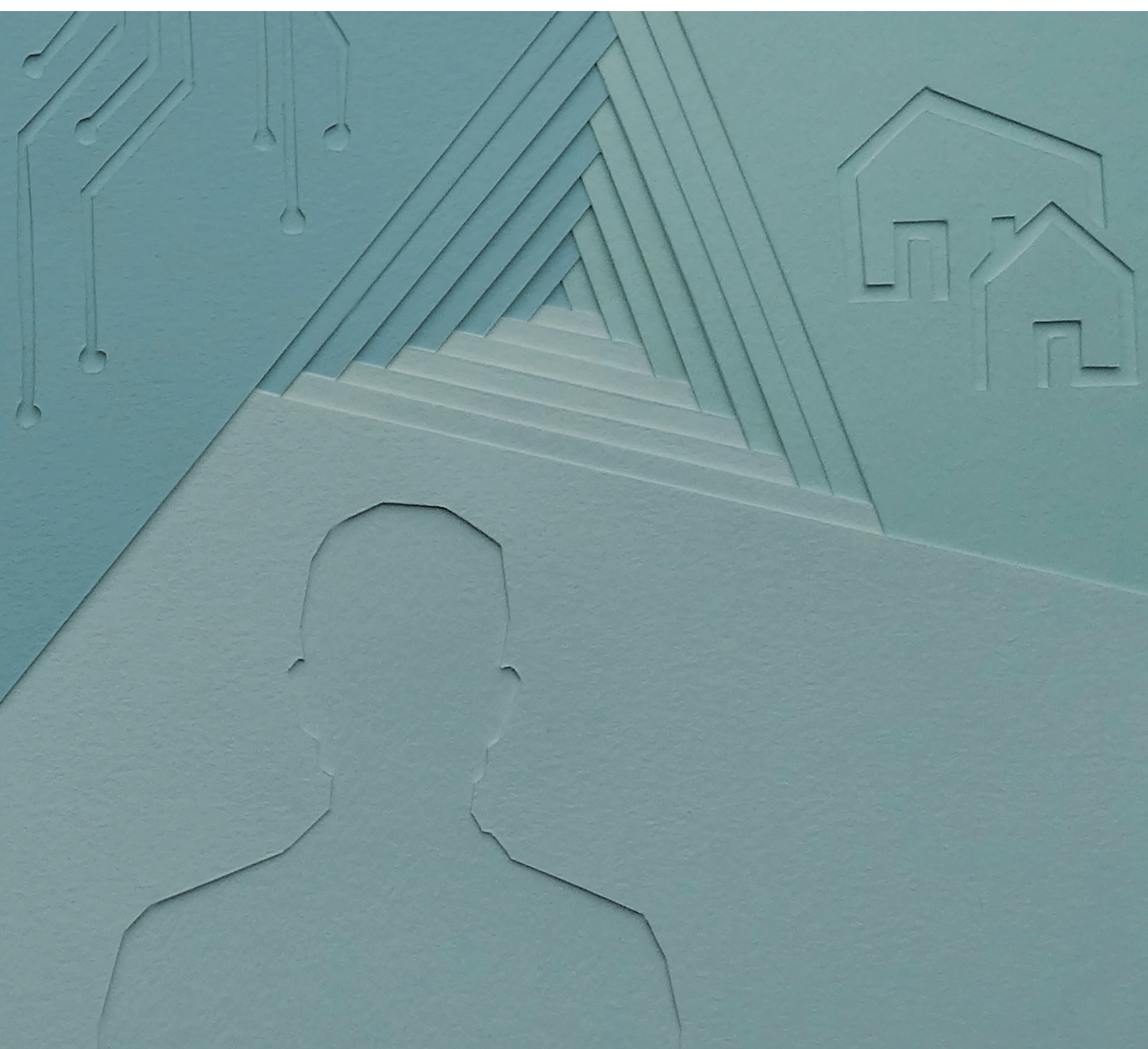





\section{Chapter 4}

Identifying the Added Value of Virtual Reality for Treatment in Forensic Mental Health: A Scenario-Based, Qualitative Approach

Hanneke Kip, Saskia M. Kelders, Kirby Weerink, Ankie Kuiper, Ines Brüninghoff, Yvonne H. A. Bouman, Dirk Dijkslag and Lisette J.E.W.C. van Gemert-Pijnen 


\section{Abstract}

Background: Although literature and practice underline the potential of virtual reality (VR) for forensic mental healthcare, studies that explore why and in what way VR can be of added value for treatment of forensic psychiatric patients is lacking.

Goals: This study aimed to identify (1) points of improvements in existing forensic mental health treatment of in- and outpatients, (2) possible ways of using VR that can improve current treatment, and (3) positive and negative aspects of the use of VR for the current treatment according to patients and therapists.

Methods: Two scenario-based methods were used. First, semi-structured interviews were conducted with eight therapists and three patients to elicit scenarios from them. Based on these results, six scenarios about possibilities for using VR in treatment were created and presented to 89 therapists and 19 patients in an online questionnaire. The qualitative data from both methods were coded independently by two researchers, using the method of constant comparison.

Results: In the interviews, six main codes with accompanying sub codes emerged. Ideas for improvement of treatment were grouped around the unique characteristics of the forensic setting, characteristics of the complex patient population, and characteristics of the type of treatment. For possibilities of VR, main codes were skills training with interaction, observation of situations or stimuli without interaction, and creating insight for others into the patient. The questionnaire resulted in a broad range of insights into potential positive and negative aspects of VR related to the current treatment, the patient, the content of a VR application, and practical matters.

Conclusion: VR offers a broad range of possibilities for forensic mental health. Examples are offering training of behavioural and cognitive skills in a realistic context to bridge the gap between a therapy room and the real world, increasing treatment motivation, being able to adapt a VR application to individual patients, and providing therapists with new insights into a patient. These findings can be used to ground the development of new VR applications. Nevertheless, we should remain critical of when in the treatment process and for whom VR could be of added value. 


\section{Introduction}

Virtual reality (VR) has been rapidly gaining ground in mental health research and practice, and evidence so far has warmed many researchers and clinicians up to VR's potential in improving treatment. In VR, patients can enter computer-generated environments, which substitute real-world sensory visual and auditory perceptions w ith virtual ones [1]. Ideally, this will elicit a sense of presence, which is the illusion of actually being in a place, while one is physically situated in another [2-4]. VR has several advantages for mental healthcare. Among other things, it can increase treatment motivation of patients because they enjoy using the technology; ensure that the content and form of interventions are tailored to the needs of individual patients; decrease treatment costs because of higher efficiency; and facilitate therapy within a specific environment that cannot be accessed from a therapist's office [5-7]. These qualities make VR an especially appealing technology for psychological treatment, since mental health problems such as phobias, alcoholism or even extreme paranoia are closely intertwined with the perceived environment $[1,8]$. Reviews have indeed shown positive effects of VR interventions for mental disorders such as specific phobias [7], PTSS [9], psychoses [10], and eating disorders [11]. According to several reviews, few studies focused on the use of VR with very complex and multifaceted disorders, patients and types of treatment [1,5]. Examples are patients suffering from multiple disorders, mental retardation, chronic psychiatric problems, and (closed) mental health settings such as hospital wards or forensic units [1]. Nevertheless, our recent review pointed out that forensic psychiatric patients often residing in secured settings and suffering from complex disorders - might especially benefit from the immersive qualities of VR [12]. More research into the ways VR can be used for these intricate mental disorders, mental health settings and types of patients is required.

Forensic mental health is a subdomain of psychiatry which deals with the assessment and treatment of in- and outpatients whose behaviour has led, or could lead, to offending [13]. Forensic mental health has several specific characteristics. It's main difference with regular mental healthcare is that preventing delinquent behaviour is an important treatment goal, so treatment takes place at the intersection between law and psychiatry [14]. Furthermore, forensic patients often have little treatment motivation, low literacy levels, and are heterogeneous in type of offense, psychopathology and risk factors, so different patients have different treatment goals $[15,16]$. Also, there are differences in security level: forensic outpatients live at home and receive treatment at an outpatient clinic, whereas inpatients reside in forensic 
hospitals while preparing for their return to society. All of this points out that forensic mental health is a setting with multiple unique characteristics. VR has been suggested by multiple authors as a potentially effective intervention strategy for forensic in- and outpatients [12, 17-20]. VR can elicit emotional responses similar to those in real-life situations that are inaccessible for in- and outpatients because of security levels or ethical concerns, for example in the case of sexual offenders $[19,20]$. Furthermore, specific behavioural skills and coping strategies can be trained in controlled environments that are tailored to the individual patient's dynamic risk factors, without endangering others [20]. Unfortunately, there is little empirical proof to support these claims: to our knowledge, no experimental studies on the use of VR in forensic mental health have been published yet. Most published studies on VR in forensic mental health focus on the assessment of sexual offenders (e.g. [19]), and even less is known about possibilities for other types of forensic patients. These gaps in knowledge cannot be filled by generalizing findings from studies on VR in other mental healthcare domains to forensic mental health because of its aforementioned unique characteristics. Especially when not much is known yet, VR applications for specific domains should be thoughtfully developed [6] to ensure that they fit the context, patients and therapists that will use it.

While a new wave of VR intervention development is approaching - or perhaps has already arrived [5] -, very little attention has been paid to how these interventions should actually be developed and which development methods are suitable for complex domains and disorders [1, 21]. The importance of a good development process to guarantee a fit between technology, people and the context has been acknowledged by multiple studies [22-26]. A sound development process should start with a thorough contextual inquiry in which stakeholders such as patients and therapists are actively involved [26]. During a contextual inquiry, multiple methods are used to get a good grasp of areas of improvements of a specific context, to investigate how technology can contribute to resolving these issues, and to determine who might benefit from the technology in what way [27]. Especially when there is little knowledge on the use of a technology in a specific domain, it is important to thoroughly analyse when and how a technology can be of added value. A way to do this is via participatory development, which promotes a structural cooperation with end-users and other important stakeholders via the use of multiple methods, mainly to ensure that the perspectives of these stakeholders are accounted for [26, 28]. Scenario-based design is a method that fits well with participatory development. On the one hand it can be used to elicit concrete narratives from stakeholders about 
situations that illustrate which aspects of a current situation can be improved $[29,30]$. On the other hand, scenarios can be created by researchers to explicitly describe the hypothetical use of a to-be-developed product. These concrete scenarios can be used to support stakeholders in making their needs and preferences explicit [26]. Because methods from scenario-based design can be used to identify points of improvement and preferences regarding a technology according to stakeholders, this approach is a good first step in determining in which ways VR can be used to be of added value for forensic mental health.

In order to create a broad, multifaceted picture of the potential of VR for forensic mental health, the current study combined two scenario-based methods with stakeholders. In interviews, therapists and patients have been asked to provide scenarios themselves to gain insight into the current treatment situation and broad possibilities for VR. Based on these scenarios, concrete examples of the application of VR in forensic mental health have been be created. Scenarios that illustrate the use of these examples in treatment have been be presented to patients and therapists in an online questionnaire, in order to gain a more detailed view of their opinions, preferences and ideas for the use of VR in treatment. Via the combination of these two scenario-based methods, a broad, multifaceted picture of the possibilities that VR offers treatment in forensic mental health can be painted. This information can serve as a foundation for the development of VR applications in forensic mental health, and possibly also settings that bear similarities to forensic mental health, such as closed psychiatric hospital wards. The main goal of this paper is to identify what the added value of VR for treatment in forensic mental health can be. The three accompanying research goals are to identify (1) points of improvements in existing forensic mental health treatment of a forensic hospital with in- and outpatients, (2) possible ways of using VR that can improve current treatment, and (3) positive and negative aspects of the use of VR for the current treatment according to patients and therapists.

\section{Materials and Methods}

In the current study, multiple methods have been used to answer the research questions. The results from two focus groups with patients and therapists were used to structure the interview scheme that was used to interview other patients and therapists. The results of these interviews served as the foundation for six scenarios on possible VR applications that were used in an online questionnaire. In this paper, 
the focus lies on the interview and questionnaire, of which the methods are described below.

\section{Study 1 - Interviews}

\section{Participants}

Both therapist and patients were included in this study since they are important stakeholders and (potential) end-users of a future VR intervention. Therapists and patients were recruited at a forensic hospital with in- and outpatients in the east of the Netherlands. All therapists directly involved in any type of treatment were eligible to participate in this study. Convenience sampling via team leaders was used to include therapists. Eight different locations that were representative of the forensic hospital were selected, and one therapist was recruited from each location. Patients were recruited via two therapists who were part of a project team for the development of a VR application. Patients could not participate if they were diagnosed with a current psychosis or mental retardation, or if a therapist indicated that dangerous situation during the interview might arise. Participation was only allowed when a therapist indicated that the interview would not be uncomfortable or damaging for the patient. Initially, the goal was to involve eight patients, but inclusion was found to be difficult due to unwillingness to participate, so three patients were interviewed.

\section{Study Procedure and Interview Scheme}

The eleven interviews were conducted in May and June 2017 by one researcher (KW) and had taken place at the location of the forensic hospital that was most convenient for the participant. The interviews took between 25 and $50 \mathrm{~min}$, with an average of 32 min, excluding the introduction and signing of the informed consent. All interviews were audio-recorded and transcribed verbatim.

A semi-structured interview scheme was used to elicit scenarios of treatment situations that could be improved via VR, according to therapists and patients. Throughout the interview, probing questions were asked to gain more information about classic scenario elements such as actors, their goals, the setting, activities and possible events [31]. The interview started with a brief introduction. The introduction began with demographic questions and an explanation of the nature of the interview, which focused on eliciting concrete examples of situations that could be improved with VR. During this introduction, it was explicitly pointed out that the goal of the interview was not to come up with concrete ideas for the content of a VR intervention. 
In the first part of the interview, the participant was asked to come up with areas of improvements in current treatment, without any input or structuring from the researcher. During the second part of the interview, three categories of possible applications of VR were presented and participants were asked to describe situations in treatment where these might be beneficial. The three categories of types of VR were based on the outcomes of two previously held focus groups with, respectively, 14 patients and 23 therapists from the same forensic hospital. During these focus groups, participants were asked to come up with ideas for VR-applications for forensic mental healthcare individually and in small groups. The generated ideas were coded and categorized by one researcher (HK). The coding process of the focus group data resulted in the three main categories below, which were briefly explained in the second part of the interview to provide the participants with inspiration for their answers.

- Skills. The use of VR to develop or practice behavioural or cognitive skills that are useful in generic, daily-life situations (e.g., social skills or skills for daily living such as grocery shopping), or directly related to the offense (e.g., aggression regulation or saying no to drugs).

- Treatment of mental disorder. The use of VR to treat, prevent or support patients in dealing with mental disorders such as anxiety disorder (e.g., PTSD or phobia), psychosis (e.g., facilitate early recognition), depression (e.g., using relaxing environments), and autism (e.g., training emotion recognition).

- Insight. The use of VR to create insight into criminal behaviour by looking at behaviour from another perspective. This can be by achieved observing one's own behaviour from the perspective of another (e.g., seeing a fight between parents from the child's perspective); providing others with the patient's perspective (e.g., showing a significant other what a psychosis looks like); or observing how a patient reacts to a realistic situation with triggers (e.g., patient's response to an environment with alcohol).

Two researchers, a therapist and a patient all provided feedback on the content and structure interview scheme. A pilot test was conducted with a psychologist and former patient, and minor adjustments were made accordingly. Ethical approval was given by the Ethics Committee of the University of Twente (Behavioural, Management and Social Sciences). 


\section{Data Analysis}

Two coders independently coded all transcripts (HK and SK), using the method of constant comparison [32]. First, the coders read the transcripts to familiarize themselves with the content. Then, all fragments that were related to either one of the research questions were selected. We distinguished between fragments that focused on points of improvement in the current situation (research question 1) and possible application of VR that could be of added value (research question 2). Based on these fragments, two preliminary coding schemes were created inductively: codes were based on the content of the fragments and not established beforehand. We identified several main codes with accompanying sub codes and used the sub codes to code the fragments. The coders used this first version coding scheme to code the first two interviews separately. The disagreement between the two coders was discussed, and adaptations were made to the coding scheme accordingly. Both coders coded all interviews using this adapted coding scheme. After that, the outcomes of both coders were again compared. 178 Fragments were coded, and researchers agreed on 131 of these fragments and disagreed on 47. In case of disagreement, discussion took place until consensus was reached. Minor adaptations were made to the coding scheme throughout the process to ensure that the codes and their definitions optimally fit the data.

\section{Study 2 - Online Questionnaire}

\section{Participants}

The target group of the online questionnaire consisted of (former) patients and therapists in forensic mental health in the Netherlands. We made use of convenience sampling and recruited participants in several ways. On a national level, the link to the questionnaire was posted on national websites, in newsletters and via a national conference on forensic mental health. Additional sampling activities were conducted in the forensic hospital in the east of the Netherlands where the interviews took place. Flyers were distributed amongst employees and the in- and outpatients, the link was posted on the website of the forensic hospital and e-mails were send to the staff.

\section{Study Procedure and Questionnaire}

In the scenario-based questionnaire, six examples of the use of VR in forensic mental health were presented to the participants via six videos of on average $1.5 \mathrm{~min}$. These scenarios were generated by a multidisciplinary project group consisting of researchers, patients and therapists, and were based on the outcomes of the 
interviews. A brief explanation of the content of the six ideas is presented in Attachment 1 , and the videos can be watched here: https://bit.ly/2sYkbTM. The questionnaire started with a brief introduction, an informed consent and questions on demographics and other relevant background information. After that, the videos were presented to the participants in randomized order in order to ensure that all videos would receive a comparable number of responses. After watching each video, participants were asked to grade the idea and filled in the Personal Involvement Inventory [33]. Since the goals of the current study are of qualitative nature these quantitative results are beyond the scope of this paper and will be discussed elsewhere (Kip et al., unpublished). After the grade and the PII, three open-ended questions were presented: one question on what participants found positive, interesting or exciting about the idea, one question on what they found negative, less appealing or unfavourable, and one on suggestions to improve the idea. In total, 108 participants, of which 19 (18\%) were patients and 89 (82\%) therapists, participated in the questionnaire. On average, participants spend 21 min on the questionnaire, and $49 \%$ of all participants fully completed the questionnaire. Ethical approval for this study was given by the Ethics Committee of the University of Twente (Behavioural, Management and Social Sciences).

\section{Data Analysis}

For the analysis, the answers to the three open-ended questions of all six scenarios were analysed together because we were interested in positive and negative aspects of VR in general, and not specific for each idea. Two coders independently coded all answers (AK and IB), applying an inductive, iterative approach based on the method of constant comparison. Consequently, the data of the questionnaire was analysed in the same way as the interview data. Two coding schemes were created: one on potential positive, and one on potential negative aspects of VR. Most answers to the question on suggestions could be categorized under either positive or negative aspects. The remaining suggestions were either too specific or focused on details of the ideas, so they could not be used to answer this study's research question. Consequently, we did not provide a separate table with suggestions. The initial two coding schemes were developed by the two researchers based on the answers that were given for two ideas. After elaborate discussions with another researcher (HK), the coding schemes were adapted and used to code all data. Throughout this process, constant adaptations were made to make sure the codes fit the data as closely as 
possible. The same main codes were identified for the positive and negative aspects, but both coding schemes contain different sub codes.

\section{Results}

\section{Study 1 - Interviews}

\section{Demographics}

A total of 11 participants were included in this study, of which eight therapists and three patients. Three therapists were male and five were female, their average age was 46.88 (SD = 14.11), and their experience in forensic mental health ranged from 1 to 30 years, with an average of 14 years. Two therapists were psychologists, five were forensic nurses/socio-therapists, and one was an art therapist. Half of them worked in inpatient care, three in outpatient care, and one therapists worked in Forensic Flexible Assertive Community Treatment (ForFACT). All three included patients were male and were on average 48.67 years old $(S D=2.89)$. They had received an average of 2.83 years of forensic treatment, with a range of $1-4$ years. One patient received inpatient care, the other two were outpatients.

\section{Points of Improvement in Treatment}

Therapists and patients provided scenarios of situations in current treatment that could be improved, without coming up with concrete solutions. The identified main and sub codes and their accompanying definitions are provided in Table 1.

Table 1. Points of improvements of the current treatment according to therapists and patients $(n=11)$.

\begin{tabular}{|c|c|c|c|c|}
\hline Main and sub codes & Definition of code & Codes $^{a}$ & Ther. $^{b}$ & Pat. $^{c}$ \\
\hline \multicolumn{5}{|c|}{ Characteristics of the forensic setting } \\
\hline $\begin{array}{l}\text { Return to society - } \\
\text { emotions and } \\
\text { cognitions }\end{array}$ & $\begin{array}{l}\text { Patients can lack knowledge or are } \\
\text { anxious to return to society }\end{array}$ & 7 & $3(7)$ & \\
\hline $\begin{array}{l}\text { Return to society - } \\
\text { skills }\end{array}$ & $\begin{array}{l}\text { Patients can lack practical skills } \\
\text { which are required for functioning } \\
\text { in society }\end{array}$ & 10 & $4(10)$ & \\
\hline $\begin{array}{l}\text { Return to society - } \\
\text { recidivism }\end{array}$ & $\begin{array}{l}\text { Patients might have a high chance } \\
\text { on reoffending after or during } \\
\text { treatment }\end{array}$ & 9 & $5(8)$ & $1(1)$ \\
\hline
\end{tabular}




\begin{tabular}{|c|c|c|c|c|}
\hline \multicolumn{5}{|l|}{ Patient characteristics } \\
\hline $\begin{array}{l}\text { Treatment } \\
\text { motivation }\end{array}$ & $\begin{array}{l}\text { Patients can have little motivation } \\
\text { for their treatment }\end{array}$ & 7 & $4(7)$ & \\
\hline $\begin{array}{l}\text { Patients' low } \\
\text { educational level }\end{array}$ & $\begin{array}{l}\text { Patients might not have the } \\
\text { cognitive skills to understand } \\
\text { (parts of) their treatment }\end{array}$ & 6 & $4(6)$ & \\
\hline Emotion regulation & $\begin{array}{l}\text { Patients can have difficulties in } \\
\text { controlling their emotions during } \\
\text { treatment or daily life }\end{array}$ & 7 & $5(7)$ & \\
\hline \multicolumn{5}{|l|}{$\begin{array}{l}\text { Treatment } \\
\text { characteristics }\end{array}$} \\
\hline $\begin{array}{l}\text { Skills training in } \\
\text { context }\end{array}$ & $\begin{array}{l}\text { Patients cannot practice skills in a } \\
\text { real-life context }\end{array}$ & 14 & $6(13)$ & $1(1)$ \\
\hline $\begin{array}{l}\text { Therapist's insight in } \\
\text { patient }\end{array}$ & $\begin{array}{l}\text { Therapists do not always have } \\
\text { enough insight into the cognitions } \\
\text { or behaviour of a patient }\end{array}$ & 9 & $4(8)$ & $1(1)$ \\
\hline \multirow[t]{2}{*}{ Exposure therapy } & $\begin{array}{l}\text { Therapy in which the patient is } \\
\text { exposed to fear-eliciting stimuli } \\
\text { has practical difficulties }\end{array}$ & 3 & $3(3)$ & \\
\hline & $\begin{array}{l}\text { Little attention is paid to physical } \\
\text { activity of patients }\end{array}$ & 2 & $2(2)$ & \\
\hline \multicolumn{5}{|l|}{ Physical activity } \\
\hline $\begin{array}{l}\text { Involvement of } \\
\text { significant others }\end{array}$ & $\begin{array}{l}\text { Significant others often do not } \\
\text { participate in treatment }\end{array}$ & 3 & $2(2)$ & $1(1)$ \\
\hline
\end{tabular}

${ }^{a}$ The total number of times a code was mentioned in all interviews

${ }^{b}$ The number of different therapists that mentioned a code, and (\#) the total number of times the code was found in all interviews with therapists

cThe number of patient that mentioned a code, and (\#) the total number of times the code was found in all interviews with patients

\section{Characteristics of the Forensic Setting}

This main code is related to the unique characteristics of the forensic setting that distinguish it from most types of regular mental healthcare and can be accompanied by fairly unique issues. Preventing delinquent behaviour and successfully reintegrating in society are important treatment goals, especially for patients that are excluded from society for a longer period of time. According to the participants, the transfer from a closed setting to living independently again is often a big transition, and it can be hard to fully prepare patients for this in a therapy room. First of all, inpatients might not be emotionally or cognitively prepared for their return to society. 
Especially after several years of residing in a closed setting, changes will have occurred within society or in the patient himself. Consequently, some patients have a lack of knowledge or insight into activities that are required to function well in society, e.g., using the public transport or the internet. Also, some inpatients feel anxious about their return.

Second, inpatients can lack practical skills that are required for successful societal participation. Daily living skills can be underdeveloped because patients didn't learn or practice these activities during their stay in a closed setting, as was explained by Participant 2:

"Someone who has been locked up for 10 years doesn't know 'outside' anymore, so also doesn't know the entire digital world. He'll still go to the bank and wants to fill in paper forms while that doesn't even exist anymore." Third, multiple participants indicated that another important skill is dealing with a new status as an offender: patients can find it hard to explain their delinquent background in situations that are important for functioning well in society, such as job interviews or meeting new people. Finally, multiple participants indicated that an important issue related to forensic mental health specifically is that the chances for recidivism are high after return to society. Besides re-offending, patients can show other undesirable behaviour such as drug abuse. Participant 7 explained some of these problems:

"We do make early recognition plans: how do you recognize signals in yourself, and what can someone else do in that, and what can you do yourself? But it remains a piece of paper, it remains: I should do this, or should do that. But we all know that we are driving through a red traffic light every once in a while, and that we actually shouldn't do that. Sometimes people do things they actually shouldn't have done."

\section{Patient Characteristics}

This main code refers to difficulties in treatment that arise because of specific characteristics of the forensic psychiatric patient population, which was seen as complex by multiple therapists.

Participants mentioned that an important element of this complexity is a low motivation for treatment and an accompanying resistance to actively participate in all parts of their therapy. Also, according to therapists, a large share of the patients lack the cognitive skills to grasp all elements of their treatment. This might be because treatment activities or assignments require a certain level of abstract reasoning and 
reflecting that is too difficult, or the reasoning of a therapist is hard to understand, which is illustrated by a quote of Participant 4:

"They often don't understand things and become angry and nervous because of that. If you explain things, it should be very brief, otherwise they don't get it. There is much to gain there."

Finally, therapists indicated that many forensic psychiatric patients have difficulties in regulating their emotions. On the one hand, patients might be too anxious or stressed before or during treatment, while on the other hand, it might be difficult to provoke specific emotions that are required for specific types of treatment, as is explained in the quote below of Participant 1 on EMDR:

"Well, with EMDR you are working with eliciting that trauma, you want the anxiety to be as high as possible, and only then you start decentration. And with some people that doesn't always work, it is advised against for people who don't feel emotions, for example."

\section{Treatment Characteristics}

This main code refers to issues that arise because of the nature of the therapy, which often takes place one-on-one, and in a closed setting or therapy room that does not resemble the real world. An often-mentioned sub code was skills training in context. Participants mentioned that patients have to develop, practice and improve behavioural or cognitive skills that are required for their functioning in society during therapy sessions, such as social, emotion regulation, or relaxation skills. However, these types of skills can often only be practiced in a therapy setting - which requires a lot of imagination - and not in a realistic context with realistic stimuli and environments. Therapists are often restricted to discussing situations instead of actually practicing them, as was illustrated by Participant 2:

"People who keep finding it difficult, who have been incarcerated for a long time or don't have good social skills anyway. Then you'll say: hey, practice! Some things are already being done with eMental Health, but I think that you cannot learn social skills from a screen: you have to experience and do."

Another issue related to the limitations of treatment is that therapists do not always have as much insight into a patient's mental disorder, problematic behaviour or triggers of delinquent behaviour as they might require for optimal treatment. This can be caused by difficulties with self-reporting instruments, the inability to observe specific, offense-related behaviour in context, or social desirability during conversations with a therapist, which was explained by Participant 2: 
"I do have a patient, and I'm thinking: what is this, then? There's always especially with sexual offenders - social desirability. And in social desirability, me and other colleagues as well are wondering: is this the patient? Or is this the patient in the social desirability that has been admitted to the clinic, and that knows: 'I have to do this to progress in my treatment'? So in how far is someone calculating, and is someone controlling certain things?"

Furthermore, multiple therapists indicated that there are forensic psychiatric patients with anxiety disorders that require exposure therapy, but this can be difficult to arrange, either because of legal restrictions which prescribe that a patient is to remain in a closed setting, or because of practical constraints which make it difficult to present the fear-eliciting stimuli or situations to a patient, e.g., in case of a fear of flying. Also, several participants mentioned that currently, little attention is paid to the physical activity of patients, either during their day-to-day life in a closed setting, or during therapy sessions. Finally, another point of improvement was that significant others of patients could be more involved in their treatment, partly because of their (often) important role in the prevention of re-offending.

\section{Possibilities of VR to Improve Treatment}

Besides points of improvement, therapists and patients also provided multiple scenarios of possible ways of using VR to improve the current treatment situation. The identified main and sub codes that arose from the inductive analysis of the interview and their accompanying definitions are provided in Table 2.

Table 2. Possibilities of VR to improve current treatment according to therapists and patients $(n=11)$.

\begin{tabular}{|c|c|c|c|c|}
\hline Main and sub codes & Definition of code & Codes & Ther. & Pat. \\
\hline \multicolumn{5}{|l|}{ Skills training with } \\
\hline \multicolumn{5}{|l|}{ interaction } \\
\hline $\begin{array}{l}\text { Training daily living } \\
\text { skills }\end{array}$ & $\begin{array}{l}\text { Development and improvement of } \\
\text { general practical skills required for daily } \\
\text { living }\end{array}$ & 8 & $5(8)$ & \\
\hline Training social skills & $\begin{array}{l}\text { Development and improvement of skills } \\
\text { that are required for proper social } \\
\text { interactions }\end{array}$ & 14 & $\begin{array}{l}5 \\
(13)\end{array}$ & $\begin{array}{l}1 \\
(1)\end{array}$ \\
\hline $\begin{array}{l}\text { Training emotion } \\
\text { regulation skills }\end{array}$ & $\begin{array}{l}\text { The development and improvement of } \\
\text { skills to not give in to impulses }\end{array}$ & 16 & $\begin{array}{l}8 \\
(15)\end{array}$ & $\begin{array}{l}1 \\
(1)\end{array}$ \\
\hline
\end{tabular}




\section{Observing without interaction}

Exposure to emotion-eliciting Experiencing stimuli that elicit negative 21 63 stimuli Observing daily life emotions and cognitions

Observing regular, realistic daily life 3 1 (1) 1 situations or environments

Observing Observing desirable or undesirable 16 behaviour from the perspective of an behaviour outsider

6

\section{Creating insight for \\ others}

\begin{tabular}{|c|c|c|c|}
\hline $\begin{array}{l}\text { Insight into } \\
\text { reactions to } \\
\text { triggers }\end{array}$ & $\begin{array}{l}\text { Observing the reaction of a patient in an } \\
\text { ecologically valid way }\end{array}$ & 10 & $\begin{array}{l}5 \\
(10)\end{array}$ \\
\hline $\begin{array}{l}\text { Insight into the } \\
\text { patient's situation }\end{array}$ & $\begin{array}{l}\text { Therapist and significant others can } \\
\text { observe the point of view of the patient }\end{array}$ & 10 & $5(7)$ \\
\hline
\end{tabular}

a The total number of times a code was mentioned in all interviews

${ }^{b}$ The number of different therapists that mentioned a code, and (\#) the total number of times the code was found in all interviews with therapists

c The number of patient that mentioned a code, and (\#) the total number of times the code was found in all interviews with patients

\section{Skills Training with Interaction}

This main code refers to the possibility of VR to develop, practice and improve specific skills in a realistic context, in which interaction with virtual avatars is possible. This type of interaction can be seen as a more realistic form of roleplaying during treatment because an ecologically valid context can be added to the interaction between therapist and patient. VR can be used for different types of skills. Participants pointed out that VR provides many opportunities for patients to develop and improve basic, practical skills that are required for daily living and functioning well in modernday society. Participant 3 provided some examples of these types of skills:

"I would really like it if the people here can bear some more responsibilities and will also take those. That we can also offer them these responsibilities. And that ranges from daily living activities, to working, to going to the city, to 
getting up on your feet again, to searching a girlfriend again: the entire range."

Second, participants suggested that social skills can be practiced in virtual environments. This refers to skills that are required for good and healthy social interactions that will not lead to any undesirable behaviour. Third, emotion regulation skills can be trained in VR: coping skills that support the patient in not giving in to impulses when confronted with difficult, emotion-eliciting situations or stimuli. The following quote of Participant 7 explains this in the case of aggression:

"Yeah, and then for aggression, because I was talking about it a while ago with a patient who said: 'if someone's looking at me and that person doesn't look away, it doesn't even have to be an acquaintance...'. That patient really feels like: I am the boss and if the other one doesn't look away... Then you get macho behaviour and it goes wrong. I would like to be able to practice that. So regulating emotions, regulating aggression, eliciting aggression. That really adds something."

\section{Observing Without Interaction}

This main code refers of using VR to facilitate the patient in the mere observation of virtual situations or environments, in which communication with another person does not play a role. An option that was mentioned, was the use of VR to expose forensic psychiatric patients to stimuli or situations that elicit negative emotions and cognitions. These stimuli or situations can be associated with phobias or anxieties, but might also be related to the offense, for example children in case of a paedophile. An example on exposure to drugs was provided by Participant 9, a patient:

"How do you respond to being exposed to drugs? Yes, a coffee shop in VR, or, let's keep it simple, just a dealer on the street. And how does someone respond to it?"

Also, multiple participants suggested that forensic psychiatric inpatients can observe regular, realistic daily life situations or environments to get re-acquainted with society. Furthermore, VR might be used to observe desirable or undesirable behaviour, in order to increase the patient's insight. Participants mentioned that patients can watch themselves from the perspective of an outsider but can also watch similar behaviour displayed by another person. Patients can observe mental disorders such as schizophrenia, but also offense-related behaviour, which was illustrated by Participant 1: 
"There was domestic violence and he was then, he moved to another place. And then he heard the upstairs neighbour who was being, well, beat up by her partner. And then he said: 'only then I realized what that looks like from the outside, through a window, so to speak'. So it worked really well there, so I believe that it will definitely have added value."

\section{Creating Insight for Others}

This main code refers to the possibility of VR to give the patient's therapists and significant others new insights into problematic behaviour and/or mental disorders of a patient, in order to increase their understanding and to better support the patient. According to participants, VR can be used to provide the therapist with an increased insight into the patient's reactions to realistic triggers when he or she is confronted with a stimulus or situation in an ecologically valid way. This can increase a therapists' knowledge of a patient, which was illustrated by Participant 7:

"The one person doesn't look away, the other one doesn't look away, and then things start stirring up inside. Now you can talk about it, but if it actually happens you are not there. And in VR you are actually there, and you can see how someone responds and what it does to someone physically."

Furthermore, therapists and significant others can actually see the point of view of a patient. VR can be used to provide a realistic experience of how it is to suffer from a mental disorder, for example a psychosis. Another way to gain insight into the point of view of a patient is to view how the patient experienced a situation in which an offense took place, as was explained by a patient, Participant 10:

"Yes I think especially loved ones, for me that's the case. [...] And she doesn't see why I have become this way, so to say."

\section{Study 2-Online Questionnaire Demographics}

In total, 19 forensic psychiatric patients ( 2 female; mean age 41.53; SD = 7.37) and 89 therapists (62 female; mean age 38.79; SD = 12.51) working in forensic mental health participated in the questionnaire. In total, six inpatients participated, the remainder were outpatients. On average, they were treated in forensic mental healthcare for on average 7.44 years $(S D=7.89)$. Four patients were treated for aggressive delinquent behaviour, six for sexual delinquent behaviour, and nine patients did not indicate the main focus of their treatment. 89 therapists of 22 different Dutch forensic mental institutions participated. On average, they had 9.45 years of experience in forensic 
mental health $(S D=8.84)$. Several therapists worked in multiple settings: 49 participants worked with inpatients in closed settings, 61 delivered outpatient care.

\section{Potential Positive Aspects of VR}

Patients and therapists evaluated the scenarios provided in the questionnaire and wrote down aspects they found positive, interesting or exciting about the examples. The codes that resulted from these answers are provided in Table 3.

Table 3. Potential positive aspects of the use of VR in treatment according to therapists ( $n=89)$ and patients ( $n=19)$.

\begin{tabular}{|c|c|c|c|c|}
\hline $\begin{array}{l}\text { Main and sub } \\
\text { codes }\end{array}$ & Definition of code & Total $^{a}$ & Ther. $^{b}$ & Pat. ${ }^{c}$ \\
\hline \multicolumn{5}{|l|}{$\begin{array}{l}\text { Treatment } \\
\text { characteristics }\end{array}$} \\
\hline $\begin{array}{l}\text { Good way to } \\
\text { practice }\end{array}$ & $\begin{array}{l}\text { VR is a good way to train } \\
\text { behaviour in a realistic way }\end{array}$ & $\begin{array}{l}48 \\
(10 \%)\end{array}$ & $\begin{array}{l}44 \\
(92 \%)\end{array}$ & $\begin{array}{l}4 \\
(8 \%)\end{array}$ \\
\hline $\begin{array}{l}\text { Addition to } \\
\text { treatment }\end{array}$ & $\begin{array}{l}\text { VR offers new possibilities for } \\
\text { and/or works better than current } \\
\text { treatment }\end{array}$ & $\begin{array}{l}36 \\
(8 \%)\end{array}$ & $\begin{array}{l}33 \\
(92 \%)\end{array}$ & $\begin{array}{l}3 \\
(8 \%)\end{array}$ \\
\hline $\begin{array}{l}\text { Fit current } \\
\text { treatment }\end{array}$ & $\begin{array}{l}\text { VR can be used well within the } \\
\text { current way of treating patients }\end{array}$ & $\begin{array}{l}31 \\
(7 \%)\end{array}$ & $\begin{array}{l}28 \\
(90 \%)\end{array}$ & $\begin{array}{l}3 \\
(10 \%)\end{array}$ \\
\hline $\begin{array}{l}\text { Input for } \\
\text { conversation }\end{array}$ & $\begin{array}{l}\text { The use of VR can lead to } \\
\text { relevant topics for treatment }\end{array}$ & $\begin{array}{l}21 \\
(5 \%)\end{array}$ & $\begin{array}{l}21 \\
(100 \%)\end{array}$ & $\begin{array}{l}0 \\
(0 \%)\end{array}$ \\
\hline $\begin{array}{l}\text { Insight into } \\
\text { patient's } \\
\text { behaviour }\end{array}$ & $\begin{array}{l}\text { The therapist gains new insights } \\
\text { into the patient by observing his } \\
\text { behaviour in VR }\end{array}$ & $\begin{array}{l}20 \\
(4 \%)\end{array}$ & $\begin{array}{l}19 \\
(95 \%)\end{array}$ & $\begin{array}{l}1 \\
(5 \%)\end{array}$ \\
\hline $\begin{array}{l}\text { Practicing in a safe } \\
\text { way }\end{array}$ & $\begin{array}{l}\text { Patients can practice in VR } \\
\text { without harming themselves or } \\
\text { their environment }\end{array}$ & $\begin{array}{l}13 \\
(3 \%)\end{array}$ & $\begin{array}{l}13 \\
(100 \%)\end{array}$ & $\begin{array}{l}0 \\
(0 \%)\end{array}$ \\
\hline \multicolumn{5}{|l|}{$\begin{array}{l}\text { Patient } \\
\text { characteristics }\end{array}$} \\
\hline $\begin{array}{l}\text { Insight into own } \\
\text { behaviour }\end{array}$ & $\begin{array}{l}\text { The patient becomes more } \\
\text { aware of his own behaviour and } \\
\text { its consequences }\end{array}$ & $\begin{array}{l}61 \\
(13 \%)\end{array}$ & $\begin{array}{l}50 \\
(82 \%)\end{array}$ & $\begin{array}{l}11 \\
(18 \%)\end{array}$ \\
\hline $\begin{array}{l}\text { Improvement } \\
\text { future behaviour }\end{array}$ & $\begin{array}{l}\text { The use of VR leads to a positive } \\
\text { change in the future behaviour of } \\
\text { the patient }\end{array}$ & $\begin{array}{l}23 \\
(5 \%)\end{array}$ & $\begin{array}{l}17 \\
(74 \%)\end{array}$ & $\begin{array}{l}6 \\
(26 \%)\end{array}$ \\
\hline
\end{tabular}




\begin{tabular}{|c|c|c|c|c|}
\hline $\begin{array}{l}\text { Suitable for } \\
\text { specific target } \\
\text { groups }\end{array}$ & $\begin{array}{l}\text { VR can be used well for specific } \\
\text { types of patients }\end{array}$ & $\begin{array}{l}21 \\
(5 \%)\end{array}$ & $\begin{array}{l}19 \\
\text { (90\%) }\end{array}$ & $\begin{array}{l}2 \\
(10 \%)\end{array}$ \\
\hline $\begin{array}{l}\text { Insight into } \\
\text { other's behaviour }\end{array}$ & $\begin{array}{l}\text { The patient learns to better } \\
\text { understand and interpret the } \\
\text { behaviour of others }\end{array}$ & $\begin{array}{l}13 \\
(3 \%)\end{array}$ & $\begin{array}{l}8 \\
(62 \%)\end{array}$ & $\begin{array}{l}5 \\
(38 \%)\end{array}$ \\
\hline $\begin{array}{l}\text { Support in reliving } \\
\text { situations }\end{array}$ & $\begin{array}{l}\text { VR can be used to help a patient } \\
\text { re-experience a specific offense- } \\
\text { related scenario }\end{array}$ & $\begin{array}{l}13 \\
(3 \%)\end{array}$ & $\begin{array}{l}11 \\
(85 \%)\end{array}$ & $\begin{array}{l}2 \\
(15 \%)\end{array}$ \\
\hline $\begin{array}{l}\text { Treatment } \\
\text { motivation }\end{array}$ & $\begin{array}{l}\text { An increase in motivation to } \\
\text { actively participate in treatment } \\
\text { because of the use of VR }\end{array}$ & $\begin{array}{l}9 \\
(2 \%)\end{array}$ & $\begin{array}{l}6 \\
(67 \%)\end{array}$ & $\begin{array}{l}3 \\
(33 \%)\end{array}$ \\
\hline \multicolumn{5}{|l|}{ Content } \\
\hline $\begin{array}{l}\text { Adaptation of } \\
\text { scenarios }\end{array}$ & $\begin{array}{l}\text { The content of virtual scenarios } \\
\text { can be adapted to the needs of } \\
\text { an individual patient }\end{array}$ & $\begin{array}{l}36 \\
(8 \%)\end{array}$ & $\begin{array}{l}31 \\
(86 \%)\end{array}$ & $\begin{array}{l}5 \\
(14 \%)\end{array}$ \\
\hline $\begin{array}{l}\text { Adaptation of } \\
\text { environments }\end{array}$ & $\begin{array}{l}\text { The appearance of virtual } \\
\text { environments can be adapted to } \\
\text { the needs of an individual patient }\end{array}$ & $\begin{array}{l}31 \\
(7 \%)\end{array}$ & $\begin{array}{l}27 \\
(87 \%)\end{array}$ & $\begin{array}{l}4 \\
(13 \%)\end{array}$ \\
\hline $\begin{array}{l}\text { Realism of } \\
\text { behaviour }\end{array}$ & $\begin{array}{l}\text { Behaviour of and interaction } \\
\text { between virtual people seem } \\
\text { realistic to the user }\end{array}$ & $\begin{array}{l}23 \\
(5 \%)\end{array}$ & $\begin{array}{l}22 \\
(96 \%)\end{array}$ & $\begin{array}{l}1 \\
(4 \%)\end{array}$ \\
\hline $\begin{array}{l}\text { Adaptation of } \\
\text { persons }\end{array}$ & $\begin{array}{l}\text { The appearance of virtual people } \\
\text { can be adapted to the needs of } \\
\text { an individual patient }\end{array}$ & $\begin{array}{l}21 \\
(5 \%)\end{array}$ & $\begin{array}{l}17 \\
(81 \%)\end{array}$ & $\begin{array}{l}4 \\
(19 \%)\end{array}$ \\
\hline \multicolumn{5}{|l|}{ Practical } \\
\hline Visual realism & $\begin{array}{l}\text { Environments and people in VR } \\
\text { look similar to environments and } \\
\text { people in real life }\end{array}$ & $\begin{array}{l}29 \\
(6 \%)\end{array}$ & $\begin{array}{l}28 \\
(97 \%)\end{array}$ & $\begin{array}{l}1 \\
(3 \%)\end{array}$ \\
\hline New technology & $\begin{array}{l}\text { VR offers a possibility to use new, } \\
\text { innovative technology within } \\
\text { treatment }\end{array}$ & $\begin{array}{l}17 \\
(4 \%)\end{array}$ & $\begin{array}{l}9 \\
\text { (53\%) }\end{array}$ & $\begin{array}{l}8 \\
(47 \%)\end{array}$ \\
\hline Total & & $\begin{array}{l}466 \\
(100 \%)\end{array}$ & $\begin{array}{l}403 \\
(86 \%)\end{array}$ & $\begin{array}{l}63 \\
(14 \%)\end{array}$ \\
\hline
\end{tabular}

As is shown in the table, therapists accounted for $86 \%$ of the codes and patients for $14 \%$. This ratio is comparable to the division between participants: $82 \%$ were therapists and $18 \%$ patients. The main code Treatment characteristics focuses on advantages of VR that were seen as potentially beneficial for the current treatment. The use of VR to learn new or improve specific types of offense-related behaviour in 
a realistic way during treatment was mentioned most by the participants. Furthermore, only therapists and no patients mentioned the possibility of VR to practice behaviour in a safe way, and the generation of new topics that can be discussed in treatment. Compared to the code Treatment characteristics, relatively more patients mentioned codes within the Patient characteristics category, which focuses on advantages of VR for patients. The most-mentioned advantage by all participants combined was the possibility to offer the patient new insights into his or her behaviour. Also, many patients mentioned the use of VR to gain more understanding in the behaviour of others, and the use of VR to increase their motivation for treatment. In the Content code, the focus lies on the composition of possible VR applications, for example the visual design and storylines. Three of the four codes addressed the possibility to adapt certain aspects of a VR application to an individual patient. It was also pointed out that realistic behaviour of virtual avatars is important and beneficial. The last main code, Practical, addresses advantages that are not related to content of VR or treatment, but about the characteristics of the technology and practical criteria for its use. A relatively high number of patients found the use of a new, innovative technology positive, while most therapists addressed the importance of a VR application that looks and feels realistic to the user.

\section{Potential Negative Aspects of VR}

Patients and therapists also wrote down points that they found negative, less appealing or unfavourable about the examples. The codes that resulted from these answers are provided in Table 4.

Table 4. Potential negative aspects of the use of $V R$ in treatment according to therapists $(n=89)$ and patients $(n=19)$.

\begin{tabular}{|c|c|c|c|c|}
\hline Main and sub codes & Definition of code & Total & Ther. & Pat. \\
\hline \multicolumn{5}{|c|}{ Treatment characteristics } \\
\hline $\begin{array}{l}\text { No fit with current } \\
\text { treatment }\end{array}$ & $\begin{array}{l}\text { A VR application cannot be used } \\
\text { within the current way of } \\
\text { treating patients }\end{array}$ & $\begin{array}{l}14 \\
(8 \%)\end{array}$ & $\begin{array}{l}14 \\
(100 \%)\end{array}$ & $\begin{array}{l}0 \\
(0 \%)\end{array}$ \\
\hline $\begin{array}{l}\text { No new addition to } \\
\text { current treatment }\end{array}$ & $\begin{array}{l}\text { A VR application does not have } \\
\text { any added value for the current } \\
\text { treatment }\end{array}$ & $\begin{array}{l}12 \\
(7 \%)\end{array}$ & $\begin{array}{l}10 \\
(83 \%)\end{array}$ & $\begin{array}{l}2 \\
(17 \%)\end{array}$ \\
\hline
\end{tabular}




\begin{tabular}{|c|c|c|c|c|}
\hline VR not necessary & $\begin{array}{l}\text { Instead of using VR, regular, } \\
\text { other activities can better be } \\
\text { used to reach a goal }\end{array}$ & $\begin{array}{l}6 \\
(4 \%)\end{array}$ & $\begin{array}{l}5 \\
(83 \%)\end{array}$ & $\begin{array}{l}1 \\
(17 \%)\end{array}$ \\
\hline \multicolumn{5}{|l|}{ Patient characteristics } \\
\hline $\begin{array}{l}\text { Unsuitable for specific } \\
\text { target groups }\end{array}$ & $\begin{array}{l}\text { VR might not be suitable for } \\
\text { treatment of some types of } \\
\text { patients }\end{array}$ & $\begin{array}{l}22 \\
(13 \%)\end{array}$ & $\begin{array}{l}17 \\
(77 \%)\end{array}$ & $\begin{array}{l}5 \\
(23 \%)\end{array}$ \\
\hline $\begin{array}{l}\text { Elicitation negative } \\
\text { feelings }\end{array}$ & $\begin{array}{l}\text { The use of VR causes } \\
\text { unnecessary, non-functional } \\
\text { negative emotions in a patient }\end{array}$ & $\begin{array}{l}15 \\
(9 \%)\end{array}$ & $\begin{array}{l}9 \\
(60 \%)\end{array}$ & $\begin{array}{l}6 \\
(40 \%)\end{array}$ \\
\hline No effect & $\begin{array}{l}\text { A VR scenario does not elicit or } \\
\text { improve emotions, cognitions or } \\
\text { behaviour of a patient }\end{array}$ & $\begin{array}{l}10 \\
(6 \%)\end{array}$ & $\begin{array}{l}8 \\
(80 \%)\end{array}$ & $\begin{array}{l}2 \\
(20 \%)\end{array}$ \\
\hline $\begin{array}{l}\text { Dishonesty about own } \\
\text { history }\end{array}$ & $\begin{array}{l}\text { Patients do not give honest } \\
\text { information that is necessary for } \\
\text { using a VR application }\end{array}$ & $\begin{array}{l}6 \\
(4 \%)\end{array}$ & $\begin{array}{l}6 \\
(100 \%)\end{array}$ & $\begin{array}{l}0 \\
(0 \%)\end{array}$ \\
\hline $\begin{array}{l}\text { Dishonesty about } \\
\text { effect }\end{array}$ & $\begin{array}{l}\text { Patients are not honest about } \\
\text { the feelings and thoughts that } \\
\text { are elicited by a VR application }\end{array}$ & $\begin{array}{l}2 \\
(1 \%)\end{array}$ & $\begin{array}{l}1 \\
\text { (50\%) }\end{array}$ & $\begin{array}{l}1 \\
(50 \%)\end{array}$ \\
\hline \multicolumn{5}{|l|}{ Content } \\
\hline $\begin{array}{l}\text { Not generalizable to } \\
\text { real life }\end{array}$ & $\begin{array}{l}\text { The behavioural or cognitive } \\
\text { skills learned in VR cannot be } \\
\text { transferred to daily life }\end{array}$ & $\begin{array}{l}15 \\
(9 \%)\end{array}$ & $\begin{array}{l}12 \\
(80 \%)\end{array}$ & $\begin{array}{l}3 \\
(20 \%)\end{array}$ \\
\hline $\begin{array}{l}\text { No realism of } \\
\text { behaviour }\end{array}$ & $\begin{array}{l}\text { The behaviour of and interaction } \\
\text { between virtual persons is not } \\
\text { perceived as realistic }\end{array}$ & $\begin{array}{l}11 \\
(7 \%)\end{array}$ & $\begin{array}{l}8 \\
(73 \%)\end{array}$ & $\begin{array}{l}3 \\
(27 \%)\end{array}$ \\
\hline \multicolumn{5}{|l|}{ Practical } \\
\hline No visual realism & $\begin{array}{l}\text { The visuals of a VR application } \\
\text { do not resemble the real world } \\
\text { enough }\end{array}$ & $\begin{array}{l}18 \\
(11 \%)\end{array}$ & $\begin{array}{l}18 \\
(100 \%)\end{array}$ & $\begin{array}{l}0 \\
(0 \%)\end{array}$ \\
\hline Difficult to use & $\begin{array}{l}\text { The use of VR in treatment is } \\
\text { difficult for the therapist and } \\
\text { patient }\end{array}$ & $\begin{array}{l}12 \\
(7 \%)\end{array}$ & $\begin{array}{l}6 \\
(50 \%)\end{array}$ & $\begin{array}{l}6 \\
(50 \%)\end{array}$ \\
\hline $\begin{array}{l}\text { Time to use in } \\
\text { treatment }\end{array}$ & $\begin{array}{l}\text { The use of VR within treatment } \\
\text { takes too much time }\end{array}$ & $\begin{array}{l}6 \\
(4 \%)\end{array}$ & $\begin{array}{l}5 \\
(83 \%)\end{array}$ & $\begin{array}{l}1 \\
(17 \%)\end{array}$ \\
\hline Costs & $\begin{array}{l}\text { The development or purchase of } \\
\text { VR technology are too expensive }\end{array}$ & $\begin{array}{l}6 \\
(4 \%)\end{array}$ & $\begin{array}{l}6 \\
(100 \%)\end{array}$ & $\begin{array}{l}0 \\
(0 \%)\end{array}$ \\
\hline $\begin{array}{l}\text { Too little options for } \\
\text { adaptation of scenario }\end{array}$ & $\begin{array}{l}\text { VR does not offer enough ways } \\
\text { of adapting scenarios to fit an } \\
\text { individual patient }\end{array}$ & $\begin{array}{l}4 \\
(2 \%)\end{array}$ & $\begin{array}{l}3 \\
(75 \%)\end{array}$ & $\begin{array}{l}1 \\
(25 \%)\end{array}$ \\
\hline
\end{tabular}




\begin{tabular}{|c|c|c|c|c|}
\hline $\begin{array}{l}\text { Too little options for } \\
\text { adaptation of persons }\end{array}$ & $\begin{array}{l}\text { VR does not offer enough ways } \\
\text { of adapting virtual persons to fit } \\
\text { an individual patient }\end{array}$ & $\begin{array}{l}3 \\
(2 \%)\end{array}$ & $\begin{array}{l}2 \\
(67 \%)\end{array}$ & $\begin{array}{l}1 \\
(33 \%)\end{array}$ \\
\hline $\begin{array}{l}\text { Too little options for } \\
\text { adaptation of } \\
\text { environments }\end{array}$ & $\begin{array}{l}\text { VR does not offer enough ways } \\
\text { of adapting environments to fit } \\
\text { an individual patient }\end{array}$ & $\begin{array}{l}3 \\
(2 \%)\end{array}$ & $\begin{array}{l}2 \\
(67 \%)\end{array}$ & $\begin{array}{l}1 \\
(33 \%)\end{array}$ \\
\hline Learning to use VR & $\begin{array}{l}\text { Acquiring the skills to use VR will } \\
\text { take too much time and effort } \\
\text { from therapists }\end{array}$ & $\begin{array}{l}3 \\
(2 \%)\end{array}$ & $\begin{array}{l}2 \\
(67 \%)\end{array}$ & $\begin{array}{l}1 \\
(33 \%)\end{array}$ \\
\hline Total & & $\begin{array}{l}168 \\
(100 \%)\end{array}$ & $\begin{array}{l}134 \\
(80 \%)\end{array}$ & $\begin{array}{l}34 \\
\text { (20\%) }\end{array}$ \\
\hline
\end{tabular}

For the disadvantages, the percentage of codes mentioned by therapists and patients is again comparable to the ratio of patients and therapists as participants. For the main code Treatment characteristics, potential disadvantages or barriers for using VR in treatment were discussed. Most of these codes were mentioned by therapists. The issue that was mentioned most often, was that a VR application might not fit or complement their current way of working. Again, relatively more patients mentioned codes belonging to the Patient characteristics. The code that was identified most often was that VR might not be suitable for specific types of patients, for example patients with a current psychosis. Relatively many patients pointed out that the use of VR could cause unintended, unnecessary negative feelings, for example an abundance of anxiety because of a specific stimulus. Relatively few codes were identified for the main code Content, in which possible disadvantages or pitfalls of the content of a VR application were discussed. Participants worried that skills learned via the VR application would not be relevant for real life and indicated that behaviours and conversations with virtual avatars should resemble the real world as closely as possible. A broad range of codes was identified for the last main code, Practical. The most mentioned disadvantage was that the visual design of a virtual environment would not look realistic enough. This disadvantage was only mentioned by therapists, not by patients. Relatively many patients mentioned that VR might be difficult to use and that learning to use VR might take a lot of time and effort.

When looking at the tables, it becomes apparent that more positive (466) than negative (168) codes have been identified. While both tables provide a broad range of codes that differ from each other, some positive and negative codes seem to contradict each other. For example, visual realism is mentioned as an advantage, but also as a potentially negative aspect. Also, the fit with the current treatment was 
seen as a positive, but the lack of a good fit with the current way of working was mentioned as a disadvantage as well. Finally, a potentially positive aspect of VR was its suitability for specific groups of patients, but it's non-suitability for specific types of patients was also seen as a barrier.

\section{Discussion}

This study aimed to identify points of improvement of current forensic mental health treatment, to find possible ways of using VR to improve the current situation and to identify potential positive and negative aspects of VR according to therapists and patients. Several points of improvement arose from the interviews. First, being isolated from society might cause difficulties for inpatients when preparing for or actually returning to society. Second, the complex and diverse nature of the often low educated patient population was described as difficult. Third, treatment often doesn't take place in the setting where problematic behaviour is displayed, and thus a realistic context for skills training or the observation of behaviour by a therapist is lacking. During the interviews, multiple ways in which VR can address these points of improvements have been identified. While the results of the questionnaire pointed out some new possibilities, most of the findings from the interviews were underlined and specified by these results. First, VR can overcome issues related to the - often closed - forensic setting by offering skills-training in and observations of realistic scenarios, which can be used to overcome practical, legal and safety barriers. Via VR, new behaviour can be learned or improved. Second, VR can fit the forensic psychiatric patient population via emphasis on doing instead of abstract talking. Also, virtual persons and scenarios can be adapted to the needs of individual patients, resulting in a personalized intervention, which might also improve treatment motivation. Third, VR addresses characteristics of treatment by providing the therapists with new ways of gaining insight into a patient's behaviour and cognitions, and by letting significant others experience the point of view of a patient. With regard to potential negative aspects, therapists and patients feared that a VR application cannot be sufficiently adapted to an individual, might not be realistic enough, or that it does not have any added value for existing treatment. The answers of both methods show several contradicting codes, which partly points out the differences between the opinions and preferences of the different participants. Based on these results, it becomes apparent that there are numerous ways in which VR can be of added value for treatment in forensic mental health, as long as the opportunities technology offers are adapted to the characteristics of the patients, therapists and forensic context. 
An important finding that arose from both the interviews and questionnaire, was that VR should serve as a bridge between a closed setting or therapy room, and real-life situations. The broad range of possibilities of VR to practice behaviour in a realistic context and to equip offenders with cognitive and behavioural skills to prevent recidivism, without endangering others, has been pointed out by multiple authors $[19,20,35]$. Many therapists indicated in the interviews that a large share of the forensic psychiatric patient population has difficulties with abstract reasoning and lacks a certain amount of imagination required for roleplaying. According to participants of the interviews and questionnaires, performing behaviour in a realistic virtual scenario instead of discussing it can be of much added value for these patients. This possibility is underlined by a recent review, in which the authors stated that people can react and behave in a genuine, realistic way in VR environments [39]. Experiencing emotions and behaving in VR as one would do in circumstances in reality is a behavioural correlate of a sense of 'presence' $[37,38]$. This sense of presence can improve skill acquisition and knowledge transfer, partly because of a situated performance in VR [39]. However, several participants of the questionnaire indicated that skills learned in VR might not be transferable to real life. More research is required on transfer of skills and the added value of VR compared to in-person roleplaying. Nevertheless, the findings of our studies, combined with existing literature on presence in VR, endorse the potential of VR in overcoming current problems with practicing and observing behaviour in context.

Another theme that often recurred in the interviews and questionnaires is related to the potential of VR to acquire new insights into patients. Current risk assessment instruments provide evidence-based ways of gaining a thorough understanding of a patient's static and dynamic risk factors, but the accuracy of such risk assessment tools is imperfect, for example with regard to predictive validity - the extent to which the scores on these tools can predict recidivism [40]. Interviewed therapists indeed indicated that there still remains a lot that is unknown about a patient, for example about behaviour outside of the therapy setting or reactions to realistic triggers such as drugs or aggressive others. Because of VR's aforementioned qualities, participants suggested that therapists can study patient's responses to a VRscenario in an ecologically valid way. Via this information, therapists can gain more insight into risk factors and make their treatment even more responsive to the individual patient. Several researchers have used VR in a comparable way: they studied the use of VR to assess reactions to virtual children in paedophilic men and combined this with Penile Plethysmography (PPG) to also assess physiological arousal 
$[19,35,41]$. Eye tracking was also suggested as a means of improving assessment of sexual offenders in VR [42]. Based on the ideas of the interviewed participants, it seems that this way of using VR can be applied to other types of patients and offenses in an ethical sound, ecologically valid and safe way as well, e.g., to identify triggers for reactive aggression. However, there is much research that needs to be done to answer questions about reliability and validity of such approaches. Furthermore, it is important to ensure that these types of VR applications fit existing assessment and treatment approaches, such as the Risk-Needs-Responsivity model [43].

A third important finding is related to the importance of personalization of VR. Both the conducted interviews and literature show the broad nature of the forensic psychiatric patient population [16]. Therefore, participants also provided a broad range of areas of applications of VR, e.g., for aggression, autism, mental retardation, sexual offenders, psychosis, etcetera. This implies that a one-size-fits-all intervention is not suitable for forensic psychiatric patients [12]. Indeed, an important theme that came forward in the answers to the questionnaire was the importance of adapting virtual persons, environments and scenarios to the needs of individual patients. Consequently, it should be possible to personalize a VR-intervention to the characteristics of individual patients, mainly to ensure that a technology is personally relevant. Participants of the questionnaire indicated that the virtual environment, persons, and the scenarios should be personalized. This might be especially important for patients that have difficulties with abstract reasoning and imagination. Studies on personalization of eHealth in general showed that adapting an intervention to a specific individual can lead to more effectiveness [44,45]. Furthermore, personalization might also lead to more treatment motivation, which was an important topic in both interviews and questionnaires, especially for patients. Based on the results of the current study, we expect that personalization of VR interventions would be beneficial for treatment, but since not much is known about the working mechanisms and benefits of personalization in VR yet, more research on this topic is required. Merely stating that personalization is important will not suffice on the long-term: once a personalized VR intervention is developed, evaluation studies should pay attention to questions about the added value of personalization, which way of using VR works best for which type of patient, and if VR can and should be used for all types of patients. Finally, it is important to note that the results of this study do not serve as ready-to-use ideas for interventions: the identified avenues should be further developed in a systematic way, for example via the multidisciplinary CeHRes Roadmap [26]. 


\section{Strengths and Limitations}

The main strength of this study is the combination of two scenario-based methods. The results of the interviews provided much insight into the current situation and could be used to create valid, realistic scenarios for the questionnaire. The findings of both methods complemented each other: the results of the questionnaires were used to further specify the results of the interviews and validate the most important conclusions. This combination of methods resulted in conclusions and recommendations with a solid foundation.

In the interviews, patients and therapists were asked about scenarios on their own experiences and ideas in an open, explorative manner. Often, stakeholders are involved as mere informants who are asked to react to ideas of researchers or designers [46], but by applying this bottom-up approach, we gained many valuable insights into the current situation and promising directions. When used with therapists, this method resulted in a broad range of points of improvements and possibilities. No new codes were identified in the last interviews. Nevertheless, this way of interviewing appeared to be difficult because it requires a specific way of asking probing questions to elicit complete scenarios. Because several scenarios were not as elaborate as they should have been, there was some disagreement between researchers during the coding process, but after discussion, consensus was reached on all codes. While this way of interviewing seemed to be suitable for therapists, it proved to be more difficult for patients. They especially struggled with the first, broad part of the interview in which no input was provided by the researcher. We found slightly more points of improvements in the second part, in which the categories from the focus groups were used. This is in line with another study on participatory eHealth development, which stated that merely asking about needs and wishes requires a too great amount of imagination, so concrete examples should be used to prompt reactions and ideas (Beerlage-de Jong et al., 2017). Since the interviews with patients did not provide us with enough results and including patients proved to be very difficult, we decided not to continue with the interviews and initiated a complementary method: a questionnaire that made use of concrete scenarios.

While including patients in the questionnaire proved to be more difficult than therapists, the quality of the patients' responses proved to be much higher than in the interviews. This is underlined by the fact that the percentage of codes found in the answers of patients were in line with the ratio of patients that participated. Consequently, time-consuming methods that require a certain level of abstract thinking, such as the hour-long interviews, might not be suitable for most forensic 
psychiatric patients, while methods that are experienced as enjoyable, such as an online questionnaire with videos, can promote more involvement in vulnerable populations [21]. Still, including patients in the questionnaire proved to be more difficult than including therapists. There might be several reasons for this. Dugas et al. [21] state that participating in research should be rewarding for vulnerable patients. It might be that forensic patients did not perceive any direct rewards or positive consequences in participating in the interviews and questionnaire. Also, forensic patient populations are known for their low treatment motivation [15], which might explain the low motivation to participate in research. Unfortunately, too little research on methods that are suitable for these types of populations is available. To support researchers in choosing methods that fit vulnerable target groups with specific characteristics, for example low educational level or severe psychiatric disorders, studies should pay attention to the development process of their eHealth intervention, publish about these processes in a replicable and transparent way, and critically reflect on the used methods.

An important limitation of both studies regards the representativeness of the population. The interviews were conducted in one forensic hospital in the Netherlands, which might raise questions about the generalizability of results to other forensic hospitals. However, half of the therapists that participated in the questionnaire worked in other forensic settings in the Netherlands, which enhances the generalizability of the results. Most patients that filled in the questionnaire received treatment from the same hospital in which the interviews were held, but on average they received 7,5 years in forensic care, which makes it very plausible that a large share of these patients has experience with different types of treatment with differing levels of security, which increases the generalizability of their opinions. Finally, while the Dutch forensic mental healthcare system differs from that of other countries, most findings of the current study seem to be consistent with recommendations of studies from other countries (e.g. [20,35]), so we believe that the identified possibilities of VR are valuable for different countries as well.

\section{Conclusion}

The results of both qualitative, scenario-based studies provide insights into the added value of VR in treatment of complex populations such as forensic in- and outpatients, and can also serve as input for new, meaningful VR-interventions that have the potential to improve quality of care, if developed and implemented thoroughly. There is not one optimal way of using VR, but a broad range of possibilities that can improve 
treatment in forensic mental health, e.g., developing new skills in context, exposing patients to the outside world, or providing therapists with more insight into a patient. This study pointed out that personalization is essential to make the most out of all these possibilities: VR scenarios should fit the individual needs, characteristics and treatment goals of a patient. While there is much potential, we should remain critical of when VR has added value and for whom. A thorough and continuous development and evaluation approach, in which methods that are suitable for this complex setting are used, is key for sustainable use of VR in forensic mental health.

\section{Author Contributions}

$H K, K W, D D$, and $Y B$ contributed to the design and planning of the study. $H K, D D$, and YB collected the focus group data. KW collected the interview data. HK and DD collected the questionnaire data. HK and SK analysed the interview data, AK, IB, and $H K$ analysed the questionnaire data. All authors contributed to the reporting and interpretation of the results and approved the manuscript.

\section{Funding}

This study was part of a larger project on virtual reality, VooRuit met VR, funded by Stichting Vrienden van Oldenkotte. 


\section{References}

1. Freeman, D., et al., Virtual reality in the assessment, understanding, and treatment of mental health disorders. Psychological Medicine, 2017: p. 1-8.

2. Diemer, J., et al., The impact of perception and presence on emotional reactions: a review of research in virtual reality. Frontiers in Psychology, 2015. 6: p. 26.

3. Witmer, B.G. and M.J. Singer, Measuring presence in virtual environments: A presence questionnaire. Presence, 1998. 7(3): p. 225-240.

4. Riva, G., F. Davide, and W. IJsselsteijn, Being there: The experience of presence in mediated environments. Being there: Concepts, effects and measurement of user presence in synthetic environments, 2003. 5.

5. Turner, W.A. and L.M. Casey, Outcomes associated with virtual reality in psychological interventions: where are we now? Clinical Psychology Review, 2014. 34(6): p. 634-644.

6. Kim, B., et al. Virtual Reality Behavioral Therapy. in Proceedings of the Human Factors and Ergonomics Society Annual Meeting. 2016. SAGE Publications Sage CA: Los Angeles, CA.

7. Botella, C., et al., Recent progress in virtual reality exposure therapy for phobias: a systematic review. Current psychiatry reports, 2017. 19(7): p. 42.

8. Organization, W.H., Promoting mental health: Concepts, emerging evidence, practice: Summary report. 2004.

9. Botella, C., et al., Virtual reality exposure-based therapy for the treatment of post-traumatic stress disorder: a review of its efficacy, the adequacy of the treatment protocol, and its acceptability. Neuropsychiatric disease and treatment, 2015. 11: p. 2533.

10. Veling, W., S. Moritz, and M. Van Der Gaag, Brave new worlds-review and update on virtual reality assessment and treatment in psychosis. Schizophrenia bulletin, 2014. 40(6): p. 1194-1197.

11. Ferrer-García, M. and J. Gutiérrez-Maldonado, The use of virtual reality in the study, assessment, and treatment of body image in eating disorders and nonclinical samples: A review of the literature. Body Image, 2012. 9(1): p. 111.

12. Kip, $\mathrm{H}_{\text {., }}$ et al., eHealth in Treatment of Offenders in Forensic Mental Health: A Review of the Current State. Frontiers in Psychiatry, 2018. 9(42).

13. Mullen, P.E., Forensic mental health. 2000, RCP. 
14. Arboleda-Florez, J., Forensic psychiatry: contemporary scope, challenges and controversies. World Psychiatry, 2006. 5(2): p. 87.

15. Drieschner, K.H. and A. Boomsma, The Treatment Motivation Scales for Forensic Outpatient Treatment (TMS-F) Construction and Psychometric Evaluation. Assessment, 2008. 15(2): p. 224-241.

16. van der Veeken, F.C., J. Lucieer, and S. Bogaerts, Forensic psychiatric treatment evaluation: The clinical evaluation of treatment progress with repeated forensic routine outcome monitoring measures. International Journal of Law and Psychiatry, 2018. 57: p. 9-16.

17. Benbouriche, M., et al., Self-regulation and virtual reality in forensic psychiatry: An emphasis on theoretical underpinnings. Encephale, 2016. 42(6): p. 540-546.

18. Renaud, P., et al., Virtual characters designed for forensic assessment and rehabilitation of sex offenders: standardized and made-to-measure. Journal of Virtual Reality and Broadcasting, 2010. 7(5): p. 1860-2037.

19. Renaud, P., et al., Using immersive virtual reality and anatomically correct computer-generated characters in the forensic assessment of deviant sexual preferences. Virtual Reality, 2014. 18(1): p. 37-47.

20. Fromberger, P., K. Jordan, and J.L. Müller, Anwendung virtueller Realitäten in der forensischen Psychiatrie. Der Nervenarzt, 2014. 85(3): p. 298-303.

21. Dugas, M., et al., Involving members of vulnerable populations in the development of patient decision aids: a mixed methods sequential explanatory study. BMC Medical Informatics and Decision Making, 2017. 17: p. 12.

22. Nielsen, A.J. and L. Mathiassen, Interpretive Flexibility in Mobile Health: Lessons From a Government-Sponsored Home Care Program. J Med Internet Res, 2013. 15(10): p. e236.

23. Glasgow, R.E., S.M. Phillips, and M.A. Sanchez, Implementation science approaches for integrating eHealth research into practice and policy. International Journal of Medical Informatics, 2014. 83(7): p. e1-e11.

24. Feldman, S.S., L.B. Schooley, and P.G. Bhavsar, Health Information Exchange Implementation: Lessons Learned and Critical Success Factors From a Case Study. JMIR Med Inform, 2014. 2(2): p. e19.

25. Coiera, E., Four rules for the reinvention of health care. BMJ (Clinical research ed.), 2004. 328(7449): p. 1197-1199. 
26. van Gemert-Pijnen, J.E., et al., A holistic framework to improve the uptake and impact of eHealth technologies. Journal of medical Internet research, 2011. 13(4).

27. Holtzblatt, K. and S. Jones, Contextual inquiry: A participatory technique for system design. Participatory design: Principles and practices, 1993: p. 177210.

28. Beerlage-de Jong, N., eHealth vs. Infection: participatory development of persuasive eHealth to support safe care. 2016: Universiteit Twente.

29. Anggreeni, I. and M. Voort, Classifying Scenarios in a Product Design Process: a study towards semi-automated scenario generation. 2008.

30. Lim, Y.K. and K. Sato, Describing multiple aspects of use situation: applications of Design Information Framework (DIF) to scenario development. Design Studies, 2006. 27(1): p. 57-76.

31. Rosson, M.B. and J.M. Carroll, Usability engineering: scenario-based development of human-computer interaction. 2002: Morgan Kaufmann.

32. Boeije, H., A Purposeful Approach to the Constant Comparative Method in the Analysis of Qualitative Interviews. Quality and Quantity, 2002. 36(4) : p. 391-409.

33. Zaichkowsky, J.L., The personal involvement inventory: Reduction, revision, and application to advertising. Journal of advertising, 1994. 23(4): p. 59-70.

34. Kip, H., Kip, H., Kelders, S. M., Bouman, Y. H., \& van Gemert-Pijnen, L. J. (2019). The importance of systematically reporting and reflecting on eHealth development: Participatory development process of a virtual reality application for forensic mental health care. Journal of medical internet research, 21(8), e12972.

35. Benbouriche, M., et al. Virtual reality applications in forensic psychiatry. in Proceedings of the 2014 Virtual Reality International Conference. 2014. ACM.

36. Gonzalez-Franco, M. and J. Lanier, Model of Illusions and Virtual Reality. Frontiers in Psychology, 2017. 8(1125).

37. Slater, M. and M.V. Sanchez-Vives, Enhancing Our Lives with Immersive Virtual Reality. Frontiers in Robotics and Al, 2016. 3(74).

38. Riva, G., Presence, actions and emotions: A theoretical framework. Journal of CyberTherapy and Rehabilitation, 2011. 4(2): p. 204-206.

39. Martirosov, S. and P. Kopecek, Virtual reality and its influence on training and education-literature review. Annals of DAAAM \& Proceedings, 2017. 28. 
40. Douglas, T., et al., Risk assessment tools in criminal justice and forensic psychiatry: The need for better data. European Psychiatry, 2017. 42: p. 134137.

41. Renaud, P., et al., The recording of observational behaviors in virtual immersion: A new clinical tool to address the problem of sexual preferences with paraphiliacs. Annual review of Cybertherapy and Telemedecine, 2005. 3: p. 85-92.

42. Fromberger, P., et al., Virtual viewing time: the relationship between presence and sexual interest in androphilic and gynephilic Men. PloS one, 2015. 10(5): p. e0127156.

43. Bonta, J. and D.A. Andrews, Risk-need-responsivity model for offender assessment and rehabilitation. Rehabilitation, 2007. 6(1): p. 1-22.

44. Kaptein, M., et al., Personalizing persuasive technologies: Explicit and implicit personalization using persuasion profiles. International Journal of HumanComputer Studies, 2015. 77: p. 38-51.

45. Lentferink, A.J., et al., Key Components in eHealth Interventions Combining Self-Tracking and Persuasive eCoaching to Promote a Healthier Lifestyle: A Scoping Review. Journal of Medical Internet Research, 2017. 19(8): p. e277.

46. Scaife, M., et al. Designing for or designing with? Informant design for interactive learning environments. in Proceedings of the ACM SIGCHI Conference on Human factors in computing systems. 1997.

47. Beerlage-de Jong, N., et al., The value of participatory development to support antimicrobial stewardship with a clinical decision support system. American journal of infection control, 2017. 45(4): p. 365-371.

48. Ministerie van Justitie \& Veiligheid, Handboek forensische zorg. 2018. 


\section{Attachment 1 - Description of the Scenarios Used in the Questionnaire}

All videos were between 1 and 2 min and all contained a brief explanation of the goal of the VR application, the embedment in the existing therapy, and an example to illustrate the idea, and an explanation of the desired outcomes. Voice-overs were added to clarify the video and provide further explanation where necessary. The ideas used in the videos are described below. All videos (audio in Dutch, but with English subtitles) can be watched via the links after the descriptions of the video.

\section{Triggers and Helpers}

This type of VR application focuses on dealing with specific triggers, which can elicit undesirable feelings, thoughts and behaviours in patients. Examples are alcohol, fans of another football club, drug dealers or, as shown in the video, women. In this type of VR application patient and therapist can look for helpers that support the patient in dealing with triggers (https://youtu.be/cKg6M1yoSa8).

\section{Observing and Interpreting Body Language}

This VR application focuses on the reaction of patients to the body language of another person in daily life. The patient observes situations in which the non-verbal behaviour of another is central. Think of a person that walks too close by, a cashier that seems to ignore you, or someone on a terrace who stares at you. The patient discusses the thoughts and feelings that arise in these situations with the therapist, and together they look for more appropriate reactions

(https://youtu.be/iBOizRzOxG8).

\section{Body Language and the Effect on Others}

This application focuses on insight of a patient into the influence of his or her body language on another person. The influence of the environment, e.g., a quiet or crowed room, is also accounted for in this. The patient gains more insight into the effect of one's own body language, such as an intimidating posture or restless, agitated movements (https://youtu.be/7sIKte7Dmo0). 


\section{Roleplaying in Context}

This idea for a VR application focuses on practicing social skills via a roleplay in a virtual environment. The therapist can play the other person via a voice-distorting microphone. The physical appearance and environment can be adapted to optimally fit the patient. An example is a roleplay in a train compartment, a crowded bar or a football stadium. Via this application, the patient can develop and improve social skills in a realistic context (https://youtu.be/T5njasY9YBg).

\section{Moments of Choice}

This VR application focuses on gaining insight into the consequences of one's own behaviour. The patient can be placed in different types of virtual scenarios. During a scenario, multiple moments of choice are presented and the patient has to indicate what he or she would do and why. Based on the decision, the consequences are displayed in the virtual scenario, and this is discussed with the therapist (https://youtu.be/1wGGynUqTCM).

\section{Offense Script}

In this VR application, patient and therapist are working with a virtual construction box to create virtual environments. They can create an individualized crime scenario that the patient can enter via VR goggles. In this environment he can analyse behaviour and antecedents of behaviour with the therapist, and together they can look for alternative, better behaviour (https://voutu.be/ZJCJMQEnfc4). 
4 



\section{Chapter 5}

Putting the in Value VR. How to systematically and iteratively develop a value-based VR application with a complex target group

Hanneke Kip, Saskia M. Kelders and Lisette van Gemert-Pijnen

Proceedings of the $2019 \mathrm{CHI}$ Conference on Human Factors in Computing Systems

(pp. 1-12), 2019 


\begin{abstract}
In development, implementation and evaluation of eHealth it is essential to account for stakeholders' perspectives, opinions and values, which are statements that specify what stakeholders want to achieve or improve via a technology. The use of values enables developers to systematically include stakeholders' perspectives and the context of use in an eHealth development process. However, there are relatively few papers that explain how to use values in technology development. Consequently, in this paper we show how we formulated values during the multi-method, interdisciplinary and iterative development process of a VR application for a complex setting: forensic mental healthcare. We report the main foundations for these values: the outcomes of an online questionnaire with patients, therapists and other stakeholders $(n=146)$ and interviews with patients and therapists $(n=18)$. We show how a multidisciplinary project team used these qualitative results to formulate and adapt values and create lo-fi prototypes of a VR application. We discuss the importance of a systematic development process with multiple formative evaluations for eHealth and reflect on the role of values within this.
\end{abstract}




\section{Introduction}

For an eHealth technology to be successful in practice, a good fit with the end-users and their context is key [1-3] This is not something that can be achieved from behind a desk: in line with approaches such as user-centred design, researchers and developers should apply a thorough development process that pays close attention to the needs and wishes of stakeholders such as patients and therapists [3-5]. However, potential end-users such as healthcare professionals and patients often lack time and motivation to participate, so a well-planned and structured approach is important because it is impossible to apply endless iterations [6]. In order to achieve this and overcome the aforementioned major challenges, studies that show how this can be done in different contexts are essential. In order to prevent that the incorporation of stakeholder's needs and wishes is non-systematic and nonreplicable, more studies that apply a theory-based development process and show which steps can be undertaken to involve end-users are required. One way to account for the perspectives of stakeholders and their context is by eliciting values: an ideal or interest a stakeholder aspires to or has $[3,6]$. Values specify what stakeholders want to achieve or improve via a technology. This study aims to show one approach towards eliciting these values from intended end-users and other stakeholders such as healthcare managers and technology developers. The approach is applied to the development process of a VR application for forensic mental healthcare. In this approach, methods and principles from user-centred design are applied by constantly evaluating with potential end-users and creating and evaluating prototypes and scenarios [4].

Especially in settings with end-users that are hard to reach, motivate and keep involved it is important to conduct a good development process that emphasizes the needs and wishes of these people. It appears to be especially challenging to design for vulnerable populations that may be disadvantaged because of for example mental illness, low literacy, little education, low income or drug dependencies $[7,8]$. Especially with vulnerable people that might have difficulties in formulating their opinions, it is important to determine what their values are. Yet, there seem to be very few studies that show how to do this by means of putting their values central. Consequently, this study will focus on a part of the development process of an eHealth technology for such a vulnerable population: forensic psychiatric in- and outpatients. Treatment of forensic patients takes place at the intersect between law and mental health. One of its main goals is to prevent recidivism of aggressive or sexual offending [9]. Studies show that many forensic patients are unmotivated for their often 
mandated treatment [10]. Also, forensic patients often suffer from multiple psychiatric disorders [11], are disproportionately poor, unemployed and lower educated [12]. Partly because of the complex and unique nature of this population, existing eHealth technologies cannot be copy-pasted into this domain and are often not as successful as expected [13]. Consequently, more attention should be paid to the development of useful technologies for this target group and accompanying development methods that suit its unique characteristics [14].

A technology that seems to fit the forensic psychiatric patient population is virtual reality (VR). Multiple studies indeed point out the added value of VR for forensic patients [14-16]. A recent qualitative study we conducted showed a broad range of potential advantages of VR for forensic mental healthcare [17]. Important advantages are the emphasis on practicing skills instead of abstract talking, the use of VR as a bridge between a closed therapy room and the outside world and the possibility of exposing patients to offense-related situations to create new insights for therapists and patients themselves. However, these results are broad, abstract directions and are not yet suitable for creating a VR application. The current study builds upon the results of this qualitative study by showing how concrete values for a VR application for Dutch forensic mental healthcare have been elicited by using multiple methods, derived from user-centred design principles. We will show how to formulate values in a systematic yet iterative way for a complex end-user group and context.

\section{Background and related work}

\section{Technology and forensic mental health}

A recent systematic review pointed out that technology can be of added value for patients, therapists and the quality of care in forensic mental health in multiple ways [14]. This review included 50 studies that focused on a broad range of technologies, for example web-based interventions, serious games, videoconferencing, social platforms and virtual reality. Based on the advantages that were mentioned in these articles, it was concluded that an important way in which technology can add value to treatment is its ability to allow users to interact with realistic situations taking place in the outside world, as opposed to regular treatment in a therapy room. Furthermore, multiple studies found that therapists and even patients often have a positive attitude towards working with technologies such as VR in treatment, which might increase the usually low treatment motivation of patients [10]. Also, an important benefit of technology is that it can be tailored to individual patient 
characteristics to overcome a one-size-fits-all approach that does not fit the diverse forensic patient population [14]. A technology which has characteristics that are aligned with these benefits is virtual reality.

\section{Virtual reality}

An important characteristic of VR is that patients can enter computer-generated worlds in which real-world sensory visual and auditory perceptions are replaced with virtual ones [18]. This can create a sense of presence, which is the feeling of actually being in a virtual place while being somewhere else [19]. This sense of presence allows for a broad range of possibilities of VR for treatment of psychiatric disorders. Indeed, VR interventions prove to be efficacious and promising forms of psychological treatment in general [20]. While very little is known about VR in forensic mental health, there are many possible advantages [14-17]. For example, inpatients often reside in secured settings for longer periods of time, which makes it difficult for them to practice skills in a realistic way [17]. VR can serve as a bridge between a closed setting and the outside world. Furthermore, VR can be used to validly assess offenders' behavioural and physiological responses to stimuli, for example by showing virtual young children to paedophiles [21]. Furthermore, VR can be used to overcome practical issues with exposure therapy. To illustrate, inpatients are often not allowed to go outside, which results in difficulties with exposure therapy for fear of heights. Also, it might be helpful to expose addicted patients to drugs, but showing real narcotics for this provides ethical and practical issues [17]. Most of these advantages are potential, since not much research on the use of VR in forensic mental health has been published [14].

Especially when not much is known about a technology within a specific context, a good development process is important to ensure that a VR application is of added value for this context and that it fits the needs and characteristics of the users [3, 22]. However, there is still relatively little knowledge on how to develop VR interventions for healthcare [18], especially in complex settings with vulnerable patients. With regard to technology development in the forensic setting, the earlier mentioned systematic review showed that only a few of the included studies discussed technology development in forensic mental health. The ones who did pointed out the importance of incorporating the opinions, preferences and characteristics of users and recommended iterative development with multiple evaluation cycles [14]. However, the suggestions on development were mostly in 
general terms and abstract: no examples or specific recommendations on how to do this were provided.

\section{eHealth development}

When looking at literature on eHealth development in general, the importance of incorporating stakeholder perspectives and continuous formative evaluations is indeed deemed essential [3, 23-26]. However, most papers recommend this in general terms and do not provide concrete examples on how to operationalize these principles. A study that aims to overcome this gap in knowledge by showing part of a participatory, iterative development process in practice is that of Van Velsen et al. [6]. In this paper, the authors formulate values, attributes and accompanying requirements by means of user expressions. The use of requirements is deemed essential for good eHealth development, mostly to ensure that a to-be-developed technology fits the needs, characteristics and goals of its users and their context [3, $4,27]$. Besides requirements, values that state what stakeholders' ideals and interests are should also be formulated [6]. This should be done to prevent a mismatch between the goal of a technology and problems or needs of stakeholders and their context. Values can serve as a bridge between the stakeholder perspective and the technology. Concrete requirements should be matched with abstract values to ensure that they are aligned with the more abstract goals, problems and interests of stakeholders. However, there is a gap between abstract values and very specific requirements. Consequently, to further specify these conceptual values, more concrete attributes are necessary, which are summaries of the needs or wishes that are spoken out by stakeholders [6]. Van Velsen and colleagues aim to show how to formulate values, attributes and requirements via an approach based on the multidisciplinary CeHRes Roadmap for eHealth development. This Roadmap is grounded by, among other things, principles from user-centred design, requirements engineering and value proposition design [1,3]. The current study is embedded in the CeHRes Roadmap as well. It is mainly based on its second phase, the value specification. Here, results from the previous contextual inquiry phase and newly collected data are used to formulate values, attributes and requirements to establish what a technology should do and look like in order to be of as much added value for stakeholders as possible [3].

While our approach has similarities with that of Van Velsen et al. [6], we operationalized the principles of the CeHRes Roadmap in different ways. Among other things, we use abstract codes from multiple methods instead of user expressions to 
base values on. Also, the roles of formative evaluations and involvement of users such as patients and therapists are emphasized more, for example by means of an interdisciplinary project team [3,28]. Finally, the current study focuses on abstract values instead of concrete requirements to point out the importance of first determining the goals and ideals of stakeholders before starting with design. Only after the abstract values have been mapped, researchers should start to formulate specific requirements. Consequently, this paper aims to show the systematic, iterative and multi-method process that was used to formulate values for a VR application for treatment in forensic mental healthcare.

\section{Methods}

\section{Study design and ethics}

This paper is based on a larger project, called VooRuit met VR, that took place in a forensic hospital in the east of the Netherlands. The main goal of this project was to develop a VR intervention for forensic mental health, using the CeHRes Roadmap [1, 3]. This project was coordinated by a multidisciplinary project team consisting of patients, therapists and researchers. Multiple research methods in which stakeholders were constantly involved were used, and an iterative process with formative evaluation cycles was applied. In the current paper, an online questionnaire, the value formulation and interviews are presented, see Figure 1 for an overview of the order and interrelationship of these methods. The content of the questionnaire is based on the outcomes of previous research activities of the larger project: focus groups with patients and therapists on possibilities of VR, interviews with patients and therapists on points of improvements in the current situation; and a systematic literature review on VR in treatment of forensic patients. 
Figure 1. A visualization of the methods of this study and their interrelationships.

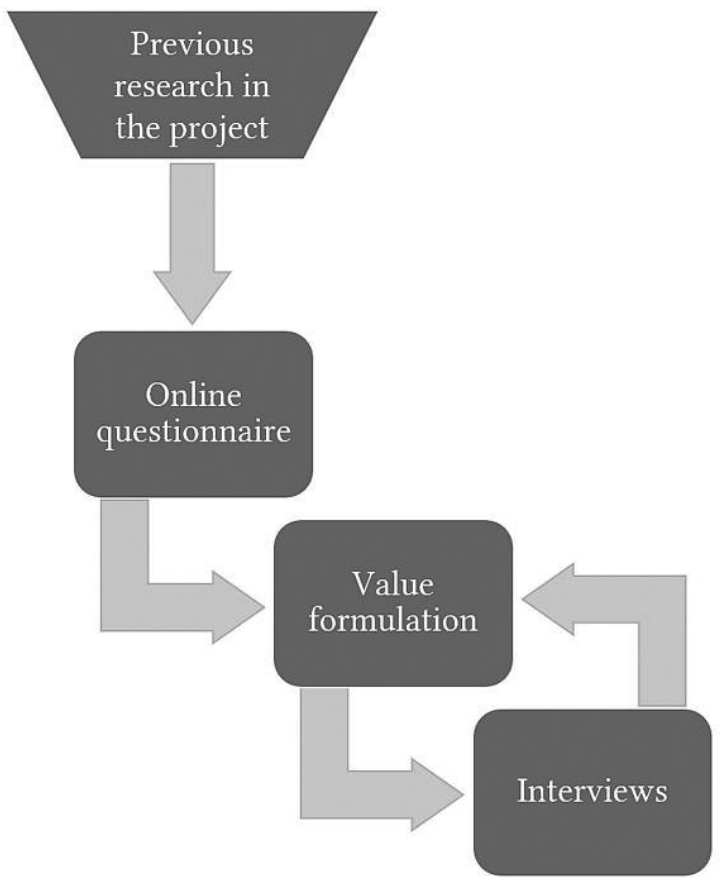

Since the project took place in practice and involved vulnerable patients, special attention was paid to ethics. Especially the patients and therapists that were part of the multidisciplinary project team played an important role in this. They were actively involved in setting up the studies and paid attention to whether the form and content of the used methods was appropriate for patients and therapists. Among other things, they ensured that the language was understandable and that no sensitive questions were asked. Furthermore, all used materials were elaborately pilot tested with therapists and patients before the actual data collection took place. We also used informed consent forms in all research activities and made sure to inform participants clearly and elaborately on the nature and goal of each study in a way that fits with the patient's abilities. Finally, when including patients in research, we always first contacted involved therapists who knew these patients to ensure that participation would not result in dangerous or uncomfortable situations for patient or researcher. 


\section{Online questionnaire}

\section{Participants}

An online questionnaire was created to gain insight into the preferences and opinions of stakeholders regarding VR in forensic mental health. We aimed to included current and former psychiatric patients, therapists working in forensic mental healthcare and other stakeholders who have a relationship with forensic mental healthcare, such as managers, government employees and technology developers that have experience with designing for forensic mental health. Multiple sampling methods were used to form a convenience sample of these three types of participants.

First, we conducted several activities to include participants from the entire country. The link to the questionnaire was posted on several national websites, newsletters and message boards visited by people working in forensic mental health. Also, we distributed flyers and presented the questionnaire on a national conference on forensic mental health, and made use of the national professional networks of members of the project team. Second, additional sampling activities were undertaken in the forensic hospital where the project group resided. Flyers were distributed in all departments of the hospital and were targeted at employees and in- and outpatients. The link to the questionnaire was posted on the website of the forensic hospitals and was sent to all staff members via e-mail. These activities resulted in a convenience sample of 146 people started the questionnaire, of which 19 were patients ( 2 female; mean age 41.53; SD = 7.37), 89 therapists working in forensic mental health (62 female; mean age 38.79; SD = 12.51) and the remaining 38 participants were other stakeholders (25 female; mean age 43.95; SD = 14.01).

\section{Materials and procedure}

The online questionnaire started with a brief explanation and questions on demographics and background information. Since providing concrete examples has proven to be more suitable for eliciting participants' opinion, as opposed to merely asking them for it [5], six short videos on possible applications of VR in forensic mental health were created by a multidisciplinary project group, consisting of two patients, three therapists, two researchers and a manager. The ideas were based on earlier research that took place in the larger project: the team based the ideas on the outcomes of a previously conducted interview study on the possibilities of VR [17], focus groups and literature research on existing VR applications. All videos took between one and two minutes and contained a brief explanation of the goal of the VR application, the embedment in the existing treatment, an example to illustrate the 
idea, and an explanation of the desired outcomes. The names of the videos were as followed: (1) Triggers and helpers; (2) Observing and interpreting body language; (3) Body language and the effect on others; (4) Roleplaying in context; (5) Moments of choice; and (6) Crime script. Screenshots of these videos are provided in Figure 2. After watching each video, participants were asked to write down the positive and negative elements of the idea. They were also asked to provide suggestions for improvement. Two quantitative measures were included.

First, we used the Personal Involvement Inventory (PII), a 10-item validated questionnaire that measures a person's perceived personal relevance of an idea or product [29]. Since not much is known yet about the PII's suitability for this type of developmental eHealth research [30], participants were also asked to grade the ideas on a scale of 1 to 10 . Filling in the questionnaire took most participants between 30 and 40 minutes.

Figure 2. Screenshots of the six videos shown in the online questionnaire: (1) Triggers and helpers; (2) Observing and interpreting body language; (3) Body language and the effect on others; (4) Roleplaying in context; (5) Moments of choice; and (6) Crime script.
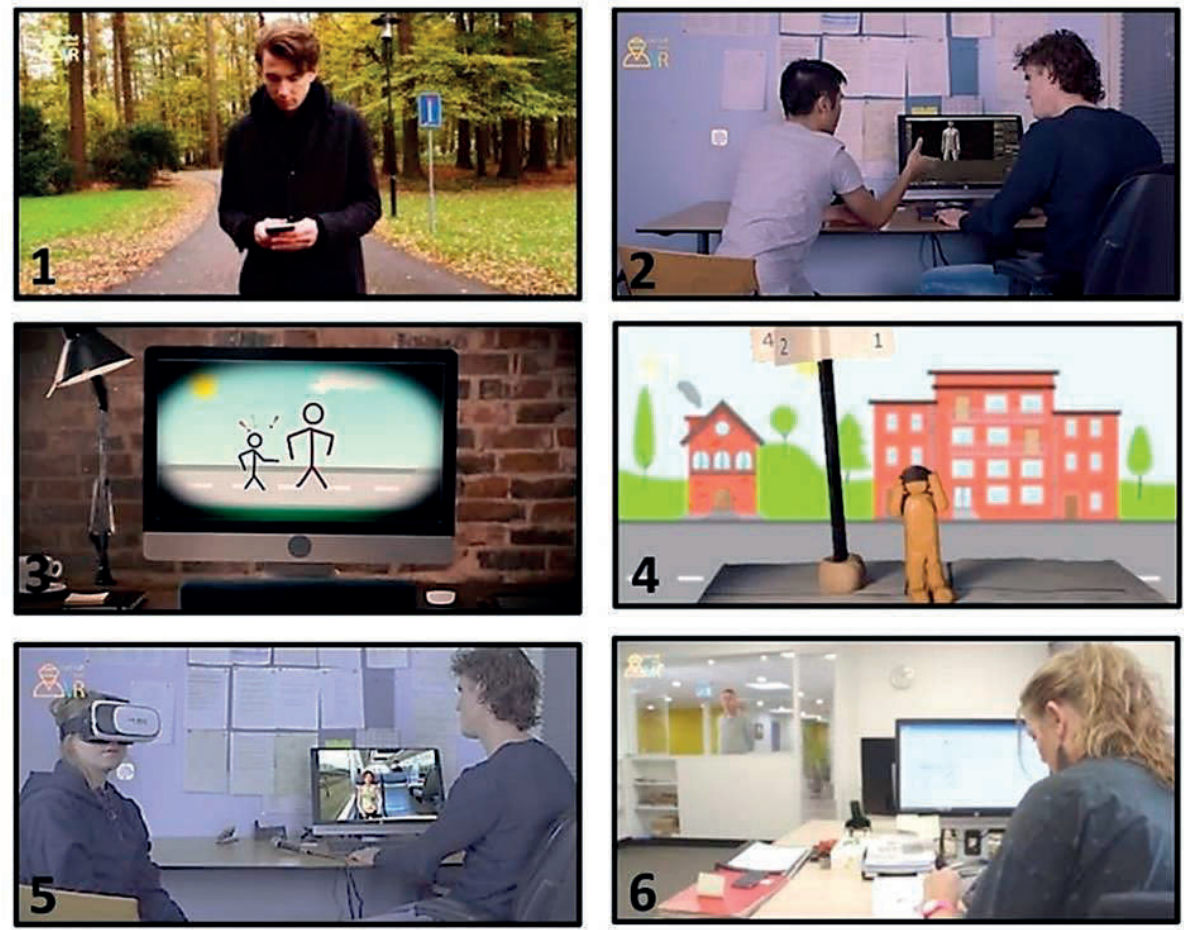


\section{Analysis}

Because the data were not normally distributed, nonparametric tests were conducted to detect differences between ideas and the three target groups on the scores PII and grades on a significance level of $\alpha<.05$. The qualitative data was coded inductively by three researchers, using the constant comparative method [31].

\section{Value formulation}

Values and accompanying attributes were formulated to map what the added value of the technology should be for patients, healthcare professionals and the forensic treatment, according to stakeholders [3, 6, 32]. First, two researchers independently formulated attributes using the codes of the questionnaires, supplemented with minutes of the project team meetings and literature and code schemes from previous research activities. An attribute is 'a summary of the need or wish that is spoken out by stakeholders' [6]. The lists with attributes from both researchers were compared and combined, resulting in one list with attributes that summarized the preferences of the stakeholders. Next, the two researchers composed groups consisting of attributes that addressed the same type of topic. Based on these groups of attributes, accompanying values were phrased. Values are 'an ideal or interest a stakeholder aspires to or has'. In other words: what do stakeholders want to achieve or improve via the technology? Using the attributes, definitions for the values were written to describe as clearly as possible what the value entailed. The list with values and their definitions was shown to other researchers and the project group in order to receive feedback. Based on their suggestions, the initial table with values, their definitions and accompanying attributes was fine-tuned.

\section{Interviews}

During two two-hour project group meetings, the multidisciplinary project team developed a broad idea for a VR application. First, the values, attributes and the positively evaluated elements of the six ideas that were presented in the online questionnaire were discussed, since they served as the foundation for the idea. Next, an initial, broad idea for a VR application was developed means of brainstorming. This process was structured by means of questions such as 'What should the main goal of the idea be?' and 'What elements should it contain?'. Throughout the development process of this idea, the project team continuously checked whether the idea was still consistent with the values. The eventual idea was an elaborated version of one of the six ideas that was presented in the questionnaire: Triggers and Helpers. Positively 
evaluated elements from the other five ideas were added to the initial Triggers and Helpers idea, resulting in a more elaborate idea, which was also called 'Triggers and Helpers'.

\section{Participants}

The idea for the VR application, Triggers and Helpers, was presented to patients and therapists in an interview. The goals were (1) to check in how far the participants' opinions of the idea match the previously formulated values and (2) to determine if any changes to the values and the idea are required to optimally fit the stakeholders' preferences. Via purposive sampling, eight therapists and ten patients of eight different locations of one Dutch forensic hospital were included. The researchers contacted each location of the hospital and aimed to recruit at least one therapist and one patient per location to ensure that perspectives from all types of care were included. This resulted in a sample of eight therapists, of which five were male, four worked in an inpatient clinic, and four worked mainly with outpatients. Ten male patients were interviewed, of which five were outpatients and five were inpatients.

\section{Materials and procedure}

Semi-structured interviews of approximately 20 minutes were conducted with the 18 participants. To ensure that the idea and its application in treatment were as clear as possible to the participants, it was presented via a lo-fi prototype and a scenario [4]. In the scenario, the researcher provided an example of how the VR application could be used in treatment of an imaginary patient to identify triggers and train helpers. Here, triggers refer to stimuli that elicit undesired behaviour in patients, while helpers are activities that can support patients in successfully dealing with these triggers. The scenario revolved around a fictional forensic psychiatric inpatient with an alcohol addiction, a bipolar disorder and aggression regulation problems. After four years in forensic care, the patient still had no insight in what triggers his aggressive outbursts. The VR application can be used to look for triggers and effective helpers in a personalized way. Via a dashboard with multiple options, the patient and therapist can choose a personally meaningful environment, for example a bar, living room or street. After that, personalized virtual avatars and their emotions can be chosen, such as an angry, broadly built male or an attractive female. Also, visual and auditive stimuli such as alcohol, barking dogs or loud background noises can be picked from a predetermined list. Once the virtual environment is created, the therapist can play the virtual person via a voice morphing microphone to interact with the patient in a 
virtual role-play. During this role-play the patient and therapist can look for triggers that elicit undesired responses in the patient. In the virtual environment, the patient is able to practice skills to deal with triggers, for example counting to ten or looking for distraction on his or her phone. The environment and stimuli can constantly be adapted to better fit the needs of the patient.

To investigate whether this idea matches the stakeholders' needs and wishes, a semi-structured interview with open-ended questions was conducted with the 18 participants. The interview consisted of two parts. First, to check whether the participants would want to use the VR application, open-ended questions based on an adapted version of the Technology Acceptance Model (TAM [33]) were asked. The TAM was used because of its usefulness in creating a general overview of the cognitions that influence an individual's intention to use a technology [34], in this case the idea for the VR application. Questions were asked to get insight into the participant's attitude towards the idea, the potential perceived usefulness, the potential perceived ease of use in treatment, and the intention to use the to-bedeveloped VR application. However, studies show that the TAM lacks a focus on characteristics of the person and the context and thus does not provide enough information for a development team in formulating a broad set of values that also address the people and context $[34,35]$. In order to obtain this information, the second part of the interview addressed the participant's ideas on the added value of the VR application for the forensic context, patients and therapists. Also, suggestions on the idea itself and its future use in practice were discussed.

\section{Analysis}

The interviews were transcribed verbatim and deductively coded by two researchers. First, the elements of the adapted version of the TAM were used as codes to gain insight into intentions and attitudes towards the technology. Second, the interviews were coded with the values that were formulated in a previous phase to check if the participants' opinions and thoughts on the technology were consistent with these values. If necessary, adaptations to the values and the idea for the VR application were made based on the interviews. 


\section{Results}

\section{Online questionnaire}

Wilcoxon signed-rank tests showed no significant differences between the PII scores and grades for the different ideas. The qualitative answers to the three open questions provided more insight into the stakeholder perspective. Table 1 shows the outcomes of the inductive qualitative analysis. Based on the questions, three main categories were created: positive remarks, negative remarks and suggestions on VR in forensic mental health. Each category contained the same main codes, but the sub codes differed. These codes were created to serve as the foundation for the values.

Table 1. The codes of the answers to the three open questions, structured by the five main codes that were identified in all three questions.

\begin{tabular}{|c|c|c|c|c|}
\hline Judgement & $\begin{array}{l}\text { Therapist/ } \\
\text { treatment }\end{array}$ & Patient & Content & Practical \\
\hline \multicolumn{5}{|c|}{ Positive remarks } \\
\hline $\begin{array}{l}\text { Positive } \\
\text { judgement } \\
\text { without } \\
\text { explanation }\end{array}$ & $\begin{array}{l}\text { Good addition to } \\
\text { therapy; } \\
\text { practicing safely; } \\
\text { good exercise; } \\
\text { insight into } \\
\text { behaviour } \\
\text { patient; cause for } \\
\text { conversation; } \\
\text { good addition to } \\
\text { current } \\
\text { treatment }\end{array}$ & $\begin{array}{l}\text { Improvement } \\
\text { (future) } \\
\text { behaviour; insight } \\
\text { own behaviour; } \\
\text { insight behaviour } \\
\text { others; treatment } \\
\text { motivation; } \\
\text { suitable for } \\
\text { specific target } \\
\text { group; supporting } \\
\text { in reliving }\end{array}$ & $\begin{array}{l}\text { Realism of } \\
\text { behaviour; } \\
\text { personalization of } \\
\text { persons; } \\
\text { personalization of } \\
\text { scenario; } \\
\text { personalization of } \\
\text { environment }\end{array}$ & $\begin{array}{l}\text { Visual } \\
\text { realism; } \\
\text { new, } \\
\text { different } \\
\text { technology }\end{array}$ \\
\hline
\end{tabular}




\begin{tabular}{|c|c|c|c|c|}
\hline \multicolumn{5}{|l|}{ Negative remarks } \\
\hline $\begin{array}{l}\text { Negative } \\
\text { judgement } \\
\text { without } \\
\text { substantiation }\end{array}$ & $\begin{array}{l}\text { Not or } \\
\text { difficult to } \\
\text { use in } \\
\text { treatment; } \\
\text { not of } \\
\text { added value } \\
\text { to current } \\
\text { treatment }\end{array}$ & $\begin{array}{l}\text { Dishonesty } \\
\text { about effect; } \\
\text { dishonesty } \\
\text { about input } \\
\text { scenario; not } \\
\text { suitable for } \\
\text { specific } \\
\text { group; no } \\
\text { effect; } \\
\text { elicitation } \\
\text { negative } \\
\text { feelings }\end{array}$ & $\begin{array}{l}\text { Not enough } \\
\text { options for } \\
\text { adaptation of } \\
\text { persons, } \\
\text { scenarios and } \\
\text { environment; } \\
\text { not } \\
\text { generalizable to } \\
\text { real life; } \\
\text { important } \\
\text { element is } \\
\text { lacking; no } \\
\text { realistic } \\
\text { behaviour; use } \\
\text { of VR is not } \\
\text { necessary to } \\
\text { reach same goal }\end{array}$ & $\begin{array}{l}\text { No visual } \\
\text { realism; hard to } \\
\text { use; high costs; } \\
\text { takes time during } \\
\text { treatment; takes } \\
\text { time to learn to } \\
\text { use }\end{array}$ \\
\hline \multicolumn{5}{|l|}{ Suggestions } \\
\hline $\begin{array}{l}\text { Negative or } \\
\text { positive } \\
\text { recommendation } \\
\text { about } \\
\text { introduction in } \\
\text { practice }\end{array}$ & $\begin{array}{l}\text { Apply for } \\
\text { specific type } \\
\text { of } \\
\text { treatment; } \\
\text { good } \\
\text { training of } \\
\text { therapist; } \\
\text { input for VR } \\
\text { scenario } \\
\text { should be } \\
\text { well- } \\
\text { prepared }\end{array}$ & $\begin{array}{l}\text { Check } \\
\text { whether VR } \\
\text { is suitable } \\
\text { for patient; } \\
\text { co-creation } \\
\text { of scenario } \\
\text { with patient; } \\
\text { apply to } \\
\text { specific } \\
\text { target group }\end{array}$ & $\begin{array}{l}\text { Combine ideas; } \\
\text { use realistic } \\
\text { situations; } \\
\text { change an } \\
\text { aspect of the } \\
\text { application }\end{array}$ & $\begin{array}{l}\text { Combine with } \\
\text { other } \\
\text { technologies; } \\
\text { improve visual } \\
\text { realism; offer } \\
\text { many choices in } \\
\text { persons, } \\
\text { scenarios \& } \\
\text { environments; } \\
\text { context use VR; } \\
\text { posture use VR; } \\
\text { constant } \\
\text { development }\end{array}$ \\
\hline
\end{tabular}




\section{Value formulation}

In total, 43 attributes were identified, each based on the analyses of at least one executed research activity within the larger project, for example interviews conducted in an earlier phase of this project, a literature review on VR in treatment of forensic patients, previously held focus groups or the questionnaire. The attributes stated what stakeholders found important and relevant in the to-be-developed VR application with regard to a broad range of topics, for example content, usability and use in practice. Several examples of attributes are provided in Table 2. By clustering these relatively concrete attributes by topic, 13 abstract values were created. These values provide insight into what the technology needs to achieve or improve in treatment, in the forensic hospital, and in individual patients and therapists. An example of the relationship between values, attributes and their foundations can be found in Table 2.

Table 2. Two examples of a value, accompanying attributes, and their foundations.

\begin{tabular}{|c|c|}
\hline Foundation & Attributes \\
\hline Value: Skills training/practice & $\begin{array}{l}\text { Stakeholders think it is important } \\
\text { that... }\end{array}$ \\
\hline Codes questionnaire & - the patient can acquire or \\
\hline Good exercise; Safe practicing; & improve daily living skills \\
\hline Improvement (future) behaviour & - the patient can acquire or \\
\hline Literature & improve social skills \\
\hline Fromberger, Jordan \& Muller (2014); & - the patient can acquire or \\
\hline Renaud et al. (2014) & improve emotion regulation skills \\
\hline Project team & - interaction with a virtual other, \\
\hline Minutes meeting 8 \& 10 & played by the therapist, is \\
\hline Codes interviews previous phase [1] & possible \\
\hline $\begin{array}{l}\text { Training daily living skills; Training social } \\
\text { skills; Training emotion regulation skills; } \\
\text { Skills training in context }\end{array}$ & $\begin{array}{l}\text { - behaviour of virtual others is } \\
\text { realistic }\end{array}$ \\
\hline
\end{tabular}




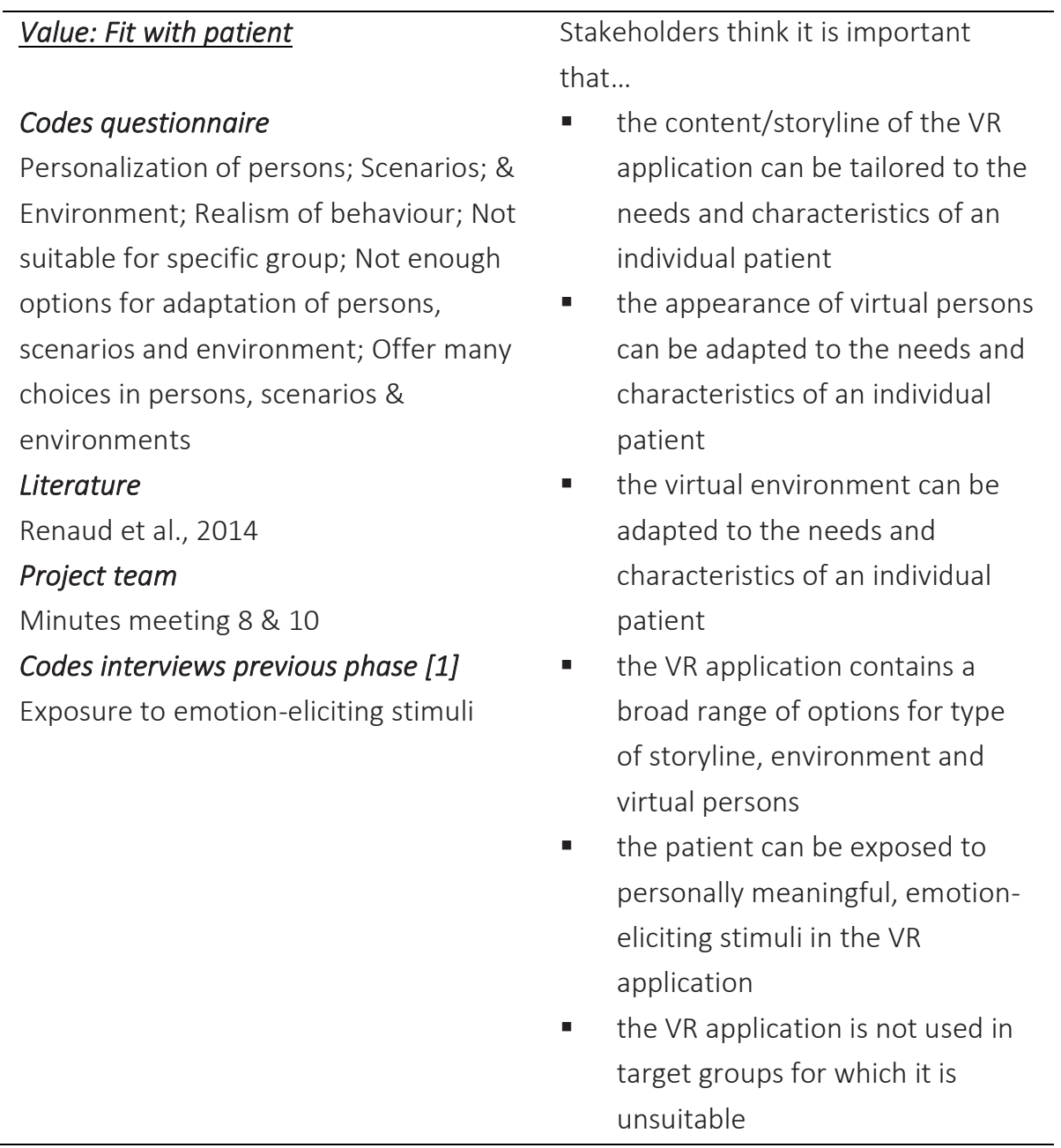

\section{Interviews}

Overall, 17 out of 18 participants had a positive attitude towards the idea. In Table 3, the number of interviews in which a specific value was mentioned is provided. Based on the interviews, it was decided to split the initial value 'easy to use within treatment' into a content and practice-related value. All other values could be retrieved in the evaluations of the participants and no new values were identified, so overall, the values appeared to be a good reflection of the opinion of the users. By using the values to code the data, several important points of attention arose. First of all, practical issues such as ease of use, suitability for specific patients and affordability were seen as potential problems by participants. Implementation appeared to be 
important. Second, several values were mentioned by almost all participants: personalization, realistic skills training, gaining insight and new possibilities. This might imply that these values are especially important for the participants and thus might have to receive additional attention throughout the development, implementation and evaluation process.

Table 3. The number of interviews with therapists $(n=8)$ and patients $(n=10)$ that contained both positive remarks and points of attention or negative remarks related to a specific value.

\begin{tabular}{|c|c|c|c|c|c|c|}
\hline \multirow[t]{3}{*}{ Values } & \multirow{2}{*}{\multicolumn{3}{|c|}{ Potential value }} & \multirow{2}{*}{\multicolumn{3}{|c|}{$\begin{array}{l}\text { Points of } \\
\text { (negative) }\end{array}$}} \\
\hline & & & & & & \\
\hline & $\begin{array}{l}\text { Total } \\
(n=18)\end{array}$ & $\begin{array}{l}\text { Ther. } \\
(n=8)\end{array}$ & $\begin{array}{l}\text { Pat. } \\
(n=10)\end{array}$ & $\begin{array}{l}\text { Total } \\
(n=18)\end{array}$ & $\begin{array}{l}\text { Ther. } \\
(n=8)\end{array}$ & $\begin{array}{l}\text { Pat. } \\
(n=10)\end{array}$ \\
\hline \multicolumn{7}{|l|}{ Aim application } \\
\hline Fit with patient & 16 & 8 & 8 & 4 & 3 & 1 \\
\hline $\begin{array}{l}\text { Bridge between therapy room and } \\
\text { outside world }\end{array}$ & 14 & 7 & 7 & 4 & 2 & 2 \\
\hline $\begin{array}{l}\text { Insight into behaviour, thoughts and } \\
\text { feelings }\end{array}$ & 14 & 8 & 6 & 2 & 1 & 1 \\
\hline Improvement of skills & 7 & 5 & 2 & 0 & 0 & 0 \\
\hline Generalization of skills to daily life & 5 & 4 & 1 & 2 & 1 & 1 \\
\hline Safety & 1 & 1 & 0 & 5 & 2 & 3 \\
\hline Treatment motivation & 1 & 0 & 1 & 6 & 2 & 4 \\
\hline \multicolumn{7}{|l|}{ Embedment in treatment } \\
\hline $\begin{array}{l}\text { Unique addition to current } \\
\text { treatment }\end{array}$ & 13 & 6 & 7 & 1 & 0 & 1 \\
\hline $\begin{array}{l}\text { Cooperation between patient and } \\
\text { therapist }\end{array}$ & 11 & 6 & 5 & 2 & 1 & 1 \\
\hline $\begin{array}{l}\text { Content fits well with current } \\
\text { treatment }\end{array}$ & 6 & 5 & 1 & 2 & 2 & 0 \\
\hline $\begin{array}{l}\text { Practically easy to use in current } \\
\text { treatment }\end{array}$ & 5 & 2 & 3 & 8 & 7 & 1 \\
\hline \multicolumn{7}{|l|}{ Use application in practice } \\
\hline Constant adaptation of application & 5 & 3 & 2 & 0 & 0 & 0 \\
\hline Widely applicable & 1 & 1 & 0 & 9 & 4 & 5 \\
\hline Affordability & 0 & 0 & 0 & 2 & 1 & 1 \\
\hline
\end{tabular}




\section{Discussion}

\section{Applying a systematic approach}

This study showed how we formulated values for a VR application for a complex setting: forensic mental healthcare. Multiple methods based on principles of usercentred design were used: we created lo-fi prototypes and scenarios and asked stakeholders to evaluate them [4]. A pitfall of such a development approach is that it might become 'messy' because many different types of data are collected and results can be conflicting. In order to structure the development and decision-making process, a multidisciplinary project team coordinated the project, which is in line with recommendations on eHealth development $[3,28,36,37]$. Also, to deal with the large amounts of data, this project's approach consisted of systematic and structured research activities. Yet, the approach was also iterative with continuous formative evaluation cycles that allowed for continuous adaptation of ideas and products, which is essential for good eHealth development $[3,23,26]$. In each step, we used a similar cycle to operationalize this structured yet iterative approach, which is visualized in Figure 3. First, we created or updated an idea and made it tangible via methods such as prototyping or scenarios, e.g. the six videos and the scenario of the idea that was used in the interviews. Second, the idea was presented to participants using a method that suits their characteristics. We used a questionnaire with brief videos since we expected that participants would prefer to watch videos instead of reading about ideas, and used relatively short interviews. Third, we thoroughly and systemically analysed the data by first using an inductive approach to stay close to the data and then a deductive approach to study in how far the values matched the stakeholders' opinions. Fourth, the outcomes of the analyses were used to improve or update the idea for the VR application, the values or other development products such as requirements. In this study, we used the outcomes of the questionnaire to create first versions of attributes and values and combined the six ideas into one. The results of the interviews were used to update the values and their definitions and to make minor improvements to the idea. Because of our positive experiences with this systematic approach, we recommend that in following steps and similar research, this research cycle is used to ensure a structured approach. 
Figure 3. A visualized overview of the systematic and iterative development process of this study.

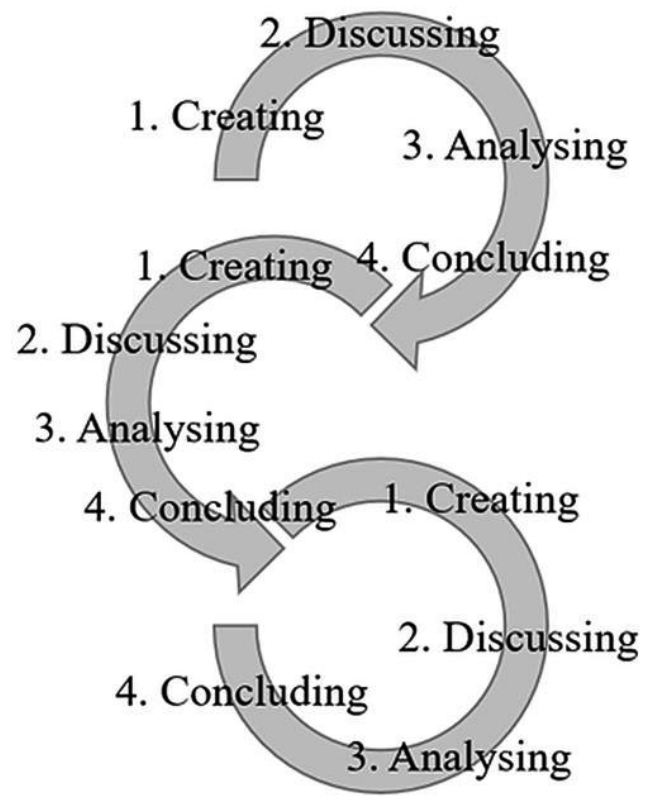

\section{Values and formative evaluation}

Values state what a technology should achieve according to a stakeholder and can serve as the foundation for a technology throughout the development process $[3,6]$. In this study we showed how we formulated values using abstract codes of data from questionnaires and interviews that were conducted in a previous phase of the project [17]. In comparable studies, user expressions from interviews were directly used to ground values and requirements $[6,32,38]$. However, we recommend to also base values and requirements on analysed results - such as codes - to prevent that researchers get lost in the data. This is especially relevant when much data from different sources is collected, which was the case in the questionnaire, and when using multiple methods. The use of multiple methods was important to create and adapt values and ideas that fit the target group, context and previous results as closely as possible. Central in our process was formative evaluation, which refers to continuous evaluation activities to ensure that there is a fit between the development activities and the stakeholder perspective [3]. Multiple papers on eHealth development acknowledge the importance of such an approach with multiple feedback and evaluation loops $[23,25,26]$. Formative evaluation is an important 
principle that underlies the four-step cycle that we used multiple times. Ideas that are created should first of all be based on previous results and checked with stakeholders by means of suitable research methods. Second, researchers should make sure that the idea still matches the previously created values. Finally, the results of evaluations of ideas with stakeholders should be used to improve or adapt the idea and, if necessary, the values. A systematic approach with multiple methods supports developers in conducting good formative evaluation activities.

\section{Using values for evaluation}

Values can serve as foundations for the design of a technology, but they can also play an important role in implementation and evaluation of eHealth. eHealth implementation is not a separate activity, but is relevant from the beginning of the development process $[1,3,39]$. Consequently, researchers should pay attention to potential implementation issues from the start in order to account for them as soon as possible. One way to do this is by using values. For example, in the interviews, participants made critical remarks or had questions on the value 'practically easy to use'. This implies that the development team should pay close attention to the usability of the VR application before and during implementation since apparently, this value was not apparent enough for stakeholders, which might hinder implementation. Values can also structure evaluation. Since values state what a technology has to achieve, improve or add, it makes sense to base concrete evaluation goals on values [3]. To illustrate: the value 'treatment motivation' states that the VR application should be appealing for patients and increase their motivation to participate in treatment. This suggests that treatment motivation has to be accounted for in the evaluation of the VR application. Another example is the value 'widely applicable': researchers should evaluate whether the VR application is being used in a wide range of patients instead of only a specific group. To our knowledge, there is no research which translates values into evaluation goals and accompanying methods for summative evaluation, so future studies should pay attention to the role of values in evaluation. In order to ensure that development, implementation and evaluation are coherent and intertwined, we recommend that suitable development models are used, for example the CeHRes Roadmap, which is partly based on value proposition design and user-centred design [1, 3]. 


\section{Dealing with conflicting values}

Good eHealth technology closely fits the stakeholder perspective, but this does not mean that all of their needs and CHI 2019 Paper CHI 2019, May 4-9, 2019, Glasgow, Scotland, UK Paper 135 Page 9 wishes have to be incorporated without question: conflicting values or inconsistencies with existing knowledge might occur [3]. This became apparent in the questionnaire, which showed that while some participants had a very favourable opinion towards one of the six ideas, other participants evaluated the same idea more negatively. Also, the interviews showed that some stakeholders believed that the VR application should be applicable to a broad range of patients, but a majority of the participants questioned if this was possible. There also were conflicts between the stakeholder perspective and scientific knowledge. The results of the questionnaire showed that according to multiple stakeholders, the VR application should look as realistic as possible, comparable to movies. However, animated VR applications are very capable of inducing a sense of presence, which is the feeling of actually being somewhere [40]. On top of that, studies hypothesize that if an animated environment looks too realistic, inconsistencies that disturb believability might arise [41], so an extremely high level of visual realism does not necessarily cause a higher sense of presence. The current study dealt with these types of conflicting values via the multidisciplinary project team that was responsible for decision-making. The team critically discussed conflicting values during meetings and decided how to deal with this. Based on this, we can conclude that developers always have to keep a critical eye on the stakeholders' suggestions to check if they are consistent with scientific knowledge and whether there are any conflicting values. Inconsistencies should be discussed by a multidisciplinary team with a broad range of expertise, ideally also including a member with technical knowledge.

\section{Strengths and limitations}

An important strength of this study was the thorough analysis of the qualitative data [31]. However, these data might have been influenced by a selection bias during convenience sampling. Since only participants with an interest in VR might have participated, the perspective of stakeholders with no interest or a negative attitudes towards VR might be underrepresented. Also, most questionnaire participants and all interview participants were aligned with one forensic hospital in the Netherlands. These two matters might have influenced the generalizability of the results. However, the main goal of both methods was not to paint a generalizable picture, but to provide input for the development of VR. Also, the results were constantly checked by the 
project team as critically as possible, so we expect that this will not influence the quality of the design. Another issue related to sampling is focused on involving patients. Especially in the questionnaire study, it became clear that including patients was challenging, despite our efforts to tailor the content and sampling materials to their characteristics. One explanation is that the questionnaire was too long: watching the videos and answering the open and closed questions often took participating patients over 40 minutes. Especially when working with vulnerable forensic populations who are not always intrinsically motivated to participate, might have difficulties with reading, or have short attention spans [10-12], it seems to be important to keep the data collection as brief as possible [8]. It was indeed easier to recruit patients to participate for the interviews, which only took about 15 to 20 minutes. Furthermore, while we allotted five VR glasses under the participants to reward participating, it might be that this type of rewarding was not tangible enough for the patients. Dugas et al. [8] indeed suggest that participating should have a direct, personally relevant reward for patients. A final limitation is that, while other stakeholders such as developers and healthcare managers participated in the questionnaire, they did not provide their opinions on the idea in the interviews. The values of these types of stakeholders might have differed from those of patients and therapists, so important information could have been missed. However, in following steps, the perspective of other stakeholders will again be incorporated.

\section{Conclusion}

Based on this study, we can conclude that values cannot be drawn up from scratch: they have to be based on the results of multiple methods and should be specified via attributes and, later, requirements. This requires a systematic approach to prevent researchers from getting lost in the process and data. First, creating or improving an idea; second, evaluating the idea with stakeholders; third, thoroughly analysing the data and fourth, making adaptations or improvements to the idea, values or other products. An iterative approach during which values can be constantly fine-tuned is pivotal, mainly to ensure that the values are a good reflection of the stakeholders' opinion. Value elicitation is not a separate step: values should be intertwined throughout and form the foundations of the development, implementation and evaluation of eHealth technology. 


\section{Acknowledgements}

Funding for this study was provided by Stichting Vrienden van Oldenkotte. We would like to thank the members of the 'VooRuit met VR' project: Dirk Dijkslag, Yvonne Bouman, Kirby Weerink, Ron Voorhuis, Jakob Visser, Kevin Krimmel and Anne Marike Halma. We thank Ines Brüninghoff and Ankie Kuiper, who helped with the analyses of the questionnaire and interview data. 


\section{References}

1. Julia EWC van Gemert-Pijnen, Nicol Nijland, Maarten van Limburg, Hans C Ossebaard, Saskia M Kelders, Gunther Eysenbach, and Erwin R Seydel. A holistic framework to improve the uptake and impact of ehealth technologies. Journal of medical Internet research, 13(4), 2011.

2. Russell E Glasgow, Siobhan M Phillips, and Michael A Sanchez. Implementation science approaches for integrating ehealth research into practice and policy. International journal of medical informatics, 83(7):e1e11, 2014.

3. Hanneke Kip and Lisette JEWC van Gemert-Pijnen. Holistic development of eHealth technology, pages 151-186. Routledge, 2018.

4. Catherine Burns. Human-centred design, Chapter 10. Routledge, Abingdon, 2018.

5. Nienke Beerlage-de Jong, Jobke Wentzel, Ron Hendrix, and Lisette van Gemert-Pijnen. The value of participatory development to support antimicrobial stewardship with a clinical decision support system. American journal of infection control, 45(4):365-371, 2017.

6. Lex Van Velsen, Jobke Wentzel, and Julia E. W. C. Van Gemert-Pijnen. Designing ehealth that matters via a multidisciplinary requirements development approach. JMIR Research Protocols, 2(1):e21, 2013.

7. Jacquelyn $\mathrm{H}$ Flaskerud and Betty J Winslow. Conceptualizing vulnerable populations health-related research. Nursing research, 47(2):69-78, 1998.

8. Michèlle Dugas, Marie-Ève Trottier, Selma Chipenda Dansokho, Gratianne Vaisson, Thierry Provencher, Heather Colquhoun, Maman Joyce Dogba, Sophie Dupéré, Angela Fagerlin, and Anik MC Giguere. Involving members of vulnerable populations in the development of patient decision aids: a mixed methods sequential explanatory study. BMC medical informatics and decision making, 17(1):12, 2017.

9. Paul E Mullen. Forensic mental health. The British journal of psychiatry, 176(4):307-311, 2000.

10. Klaus H Drieschner and Anne Boomsma. The treatment motivation scales for forensic outpatient treatment (tms-f) construction and psychometric evaluation. Assessment, 15(2):224-241, 2008.

11. Kris R Goethals, Ellen CW Vorstenbosch, and Hjalmar JC van Marle. Diagnostic comorbidity in psychotic offenders and their criminal history: A 
review of the literature. International Journal of Forensic Mental Health, 7(2), 2008.

12. Elizabeth Greenberg, Eric Dunleavy, and Mark Kutner. Literacy behind bars: Results from the 2003 national assessment of adult literacy prison survey. nces 2007-473. National Center for Education Statistics, 2007.

13. Joyce Bierbooms, Yvonne Bouman, Dirk Dijkslag, Rob Kimpen, José Muller, and Rosemarie Wieske. Do's en don'ts van e-health in de forensische ggz. Kwaliteit Forensische Zorg (KFZ), 2015.

14. Hanneke Kip, Yvonne HA Bouman, Saskia M Kelders, and Lisette JEWC van Gemert-Pijnen. eHealth in treatment of offenders in forensic mental health: a review of the current state. Frontiers in psychiatry, 9(42), 2018.

15. P Fromberger, K Jordan, and JL Müller. Anwendung virtueller realitäten in der forensischen psychiatrie. Der Nervenarzt, 85(3):298-303, 2014.

16. [16] Massil Benbouriche, Kevin Nolet, Dominique Trottier, and Patrice Renaud. Virtual reality applications in forensic psychiatry. In Proceedings of the 2014 Virtual Reality International Conference, page 7. ACM, 2014.

17. Hanneke Kip, Saskia M Kelders, Kirby Weerink, Ankie Kuiper, Ines Brüninghoff, Yvonne H A Bouman, Dirk Dijkslag, and Lisette JEWC van Gemert-Pijnen. Identifying the added value of virtual reality for treatment in forensic mental health: a scenario-based, qualitative approach. Frontiers in Pyschology, 10(406), 2019.

18. Daniel Freeman, Sarah Reeve, A Robinson, Anke Ehlers, David Clark, Bernhard Spanlang, and Mel Slater. Virtual reality in the assessment, understanding, and treatment of mental health disorders. Psychological medicine, 47(14):2393-2400, 2017.

19. Julia Diemer, Georg W Alpers, Henrik M Peperkorn, Youssef Shiban, and Andreas Mühlberger. The impact of perception and presence on emotional reactions: a review of research in virtual reality. Frontiers in psychology, 6:26, 2015.

20. Wesley A Turner and Leanne M Casey. Outcomes associated with virtual reality in psychological interventions: where are we now? Clinical psychology review, 34(8):634-644, 2014.

21. Patrice Renaud, Dominique Trottier, Joanne-Lucine Rouleau, Mathieu Goyette, Chantal Saumur, Tarik Boukhalfi, and Stephane Bouchard. Using immersive virtual reality and anatomically correct computergenerated 
characters in the forensic assessment of deviant sexual preferences. Virtual Reality, 18(1):37-47, 2014.

22. Byeol Kim, Warren Schwartz, Danny Catacora, and Monifa Vaughn Cooke. Virtual reality behavioral therapy. Proceedings of the Human Factors and Ergonomics Society Annual Meeting, 60(1):356-360, 2016.

23. Susan Michie, Lucy Yardley, Robert West, Kevin Patrick, and Felix Greaves. Developing and evaluating digital interventions to promote behavior change in health and health care: recommendations resulting from an international workshop. Journal of medical Internet research, 19(6), 2017.

24. Lucy Yardley, Leanne Morrison, Katherine Bradbury, and Ingrid Muller. The person-based approach to intervention development: application to digital health-related behavior change interventions. Journal of medical Internet research, 17(1), 2015.

25. Eric B Hekler, Predrag Klasnja, William T Riley, Matthew P Buman, Jennifer Huberty, Daniel E Rivera, and Cesar A Martin. Agile science: creating useful products for behavior change in the real world. Translational behavioral medicine, 6(2):317-328, 2016.

26. Kevin Patrick, Eric B Hekler, Deborah Estrin, David C Mohr, Heleen Riper, David Crane, Job Godino, and William T Riley. The pace of technologic change: implications for digital health behavior intervention research, American Journal of Preventive Medicine, 51(5), 2016.

27. Hossein Saiedian and Robert Dale. Requirements engineering: making the connection between the software developer and customer. Information and Software Technology, 42(6):419-428, 2000.

28. Sue S Feldman, Benjamin L Schooley, and Grishma P Bhavsar. Health information exchange implementation: lessons learned and critical success factors from a case study. JMIR medical informatics, 2(2), 2014.

29. Judith Lynne Zaichkowsky. The personal involvement inventory: Reduction, revision, and application to advertising. Journal of advertising, 23(4):59-70, 1994.

30. Saskia M Kelders. Involvement as a working mechanism for persuasive technology. In International Conference on Persuasive Technology, pages 314. Springer, 2015.

31. Hennie Boeije. A purposeful approach to the constant comparative method in the analysis of qualitative interviews. Quality and quantity, 36(4):391-409, 2002. 
32. Jobke Wentzel, Lex van Velsen, Maarten van Limburg, Nienke de Jong, Joyce Karreman, Ron Hendrix, et al. Participatory eHealth development to support nurses in antimicrobial stewardship. BMC medical informatics and decision making, 14(1):45, 2014.

33. Viswanath Venkatesh and Fred D Davis. A theoretical extension of the technology acceptance model: Four longitudinal field studies. Management science, 46(2):186-204, 2000.

34. Lex van Velsen, Mirka Evers, Cristian-Dan Bara, Harm Op den Akker, Simone Boerema, and Hermie Hermens. Understanding the acceptance of an ehealth technology in the early stages of development: An enduser walkthrough approach and two case studies. JMIR Formative Research, 2(1):e10474, 2018.

35. Paul Legris, John Ingham, and Pierre Collerette. Why do people use information technology? a critical review of the technology acceptance model. Information and management, 40(3):191-204, 2003.

36. Claudia Pagliari. Design and evaluation in eHealth: challenges and implications for an interdisciplinary field. Journal of medical Internet research, 9(2), 2007.

37. Jeppe Agger Nielsen and Lars Mathiassen. Interpretive flexibility in mobile health: Lessons from a government-sponsored home care program. Journal of medical Internet research, 15(10), 2013.

38. Birgitta Bergvall-Kåreborn and Anna Ståhlbröst. User expressions translated into requirements. Human Technology. An Interdisciplinary Journal on Humans in ICT Environments, 2010.

39. Trisha Greenhalgh, Joseph Wherton, Chrysanthi Papoutsi, Jennifer Lynch, Gemma Hughes, Christine A'Court, Susan Hinder, Nick Fahy, Rob Procter, and Sara Shaw. Beyond adoption: a new framework for theorizing and evaluating nonadoption, abandonment, and challenges to the scale-up, spread, and sustainability of health and care technologies. Journal of medical Internet research, 19(11), 2017.

40. Xueni Pan and Antonia F de C Hamilton. Why and how to use virtual reality to study human social interaction: The challenges of exploring a new research landscape. British Journal of Psychology, 2018.

41. Vinoba Vinayagamoorthy, Andrea Brogni, Marco Gillies, Mel Slater, and Anthony Steed. An investigation of presence response across variations in 
visual realism. In The 7th Annual International Presence Workshop, pages 148-155. 



\title{
Chapter 6
}

The importance of systematically reporting and reflecting on eHealth development: Participatory development process of a virtual reality application for forensic mental health

\author{
Hanneke Kip, Saskia M. Kelders, Yvonne H. A. Bouman, \\ and Lisette J.E.W.C. van Gemert-Pijnen
}

Journal of Medical Internet Research, 21(8), DOI: 10.2196/12972 


\begin{abstract}
Background: The use of electronic health (eHealth) technologies in practice often is lower than expected, mostly because there is no optimal fit among a technology, the characteristics of prospective users, and their context. To improve this fit, a thorough systematic development process is recommended. However, more knowledge about suitable development methods is necessary to create a tool kit that guides researchers in choosing development methods that are appropriate for their context and users. In addition, there is a need for reflection on the existing frameworks for eHealth development to be able to constantly improve them.
\end{abstract}

Objective: The two main objectives of this case study were to present and reflect on the (1) methods used in the development process of a virtual reality application for forensic mental health care and (2) development model that was used: the CeHRes Roadmap (the Centre for eHealth Research Roadmap).

Methods: In the development process, multiple methods were used to operationalize the first 2 phases of the CeHRes Roadmap: the contextual inquiry and value specification. To summarize the most relevant information for the goals of this study, the following information was extracted per method: (1) research goal, (2) explanation of the method used, (3) main results, (4) main conclusions, and (5) lessons learned about the method.

Results: Information on 10 methods used is presented in a structured manner. These 10 methods were stakeholder identification, project team composition, focus groups, literature study, semi-structured interviews, idea generation with scenarios, Webbased questionnaire, value specification, idea generation with prototyping, and a second round of interviews. The lessons learned showed that although each method added new insights to the development process, not every method appeared to be the most appropriate for each research goal.

Conclusions: Reflection on the methods used pointed out that brief methods with concrete examples or scenarios fit the forensic psychiatric patients the best, among other things, because of difficulties with abstract reasoning and low motivation to invest much time in participating in research. Formulating clear research questions based on a model's underlying principles and composing a multidisciplinary project team with prospective end users appeared to be important in this study. The research questions supported the project team in keeping the complex development processes structured and prevented tunnel vision. With regard to the CeHRes Roadmap, continuous stakeholder involvement and formative evaluations were evaluated as strong points. A suggestion to further improve the Roadmap is to explicitly integrate 
the use of domain-specific theories and models. To create a tool kit with a broad range of methods for eHealth development and further improve development models, studies that report and reflect on development processes in a consistent and structured manner are needed. 


\section{Introduction}

Electronic health (eHealth) - a technology to support health, well-being, and health care-can offer many benefits, such as increased quality of care, easily accessible health care, and increased self-management [1]. However, these benefits are often not fully realized in practice [2]. A possible explanation for this is that technology does not optimally fit the needs, wishes, and characteristics of the involved end users and their context [3-5]. A way to improve this fit is thorough participatory eHealth development in which potential end users are structurally involved in the development process [1,6-8]. Consequently, many efforts have been made to create models, approaches, and guidelines for development of eHealth technologies. Examples are the CeHRes Roadmap (the Centre for eHealth Research Roadmap) [9], the person-based approach [10], the accelerated creation-to-sustainment model [11], intervention mapping [12], the persuasive system design model [13], and the agile science approach [14]. Most of these models and approaches do not offer concrete prescriptions for ready-to-use research methods that fit specific contexts and people. Instead, they present abstract guidelines for development to support researchers in shaping their development process. Although a step-by-step, detailed prescription of a specific development process does not seem feasible because of different characteristics of contexts, people, and technologies, there does seem to be a need for more knowledge and guidelines on how to apply these models in practice [14]. To support researchers in operationalizing development models, we propose that a general tool kit with a broad range of eHealth development methods might be developed. Such a tool kit can provide an overview of broad-range development methods and guidelines on when and how to apply them. In this way, it can support researchers in choosing appropriate methods for the context and end users with which they are working and different phases of their development process. Using a tool kit can prevent other researchers from having to reinvent the wheel and result in more efficient and better substantiated development processes.

To create a tool kit, more generalizable knowledge on eHealth development methods is necessary. To build this knowledge base, more case studies that explain and reflect on specific development methods used seem to be necessary [15]. On top of that, there also should be more critical reflection on eHealth development models $[2,10]$, mostly to be able to constantly improve these models to keep them in line with the most recent insights. Although there are several studies that describe development processes of eHealth technologies [16-20], there seems to be no standardized way of reporting and reflecting on the methods used. Also, an in-depth 
critical reflection on the development model used is often lacking. To fill these gaps in the literature, this case study presents and reflects on the development process of a virtual reality (VR) application for forensic mental health care. This study had 2 main goals. First, it aimed to increase knowledge on suitable methods for participatory eHealth development. This contributes to creating the aforementioned tool kit. Second, it aimed to reflect on the development model used to guide the process: the CeHRes Roadmap. Combined with other studies that reflect on this model, this can result in further improvement of the Roadmap.

\section{Methods}

\section{The CeHRes Roadmap}

In this study, the aforementioned CeHRes Roadmap [9] was applied to shape the development process of the VR application. This development model specifically focuses on eHealth development, implementation, and evaluation with structural stakeholder involvement $[1,6,9]$. The Roadmap has been proven useful for eHealth development in multiple settings $[16,18,21]$ and seems to be suitable for development in complex contexts [9], such as forensic mental health care. The Roadmap is based on 5 principles that are also acknowledged by other studies on eHealth development:

- eHealth development should be a participatory process-structurally and actively involving stakeholders during development is important $[7,10,12,21]$.

- eHealth should not be seen as a separate, stand-alone tool but has to be integrated in a health care context, which also implies changes in the way health care is delivered $[5,22,23]$.

- eHealth development and implementation should be intertwined; implementation is a very complex activity that should be accounted for from the start of the development process [24,25].

- eHealth technologies should be based on theories from persuasive design, which can be used to support behaviour and attitude change via technology [13].

- Continuous, formative evaluation in eHealth development is important to enable creating by evaluation $[7,8,14,26]$. 
Figure 1. The CeHRes Roadmap (the Centre for eHealth Research Roadmap) [9].

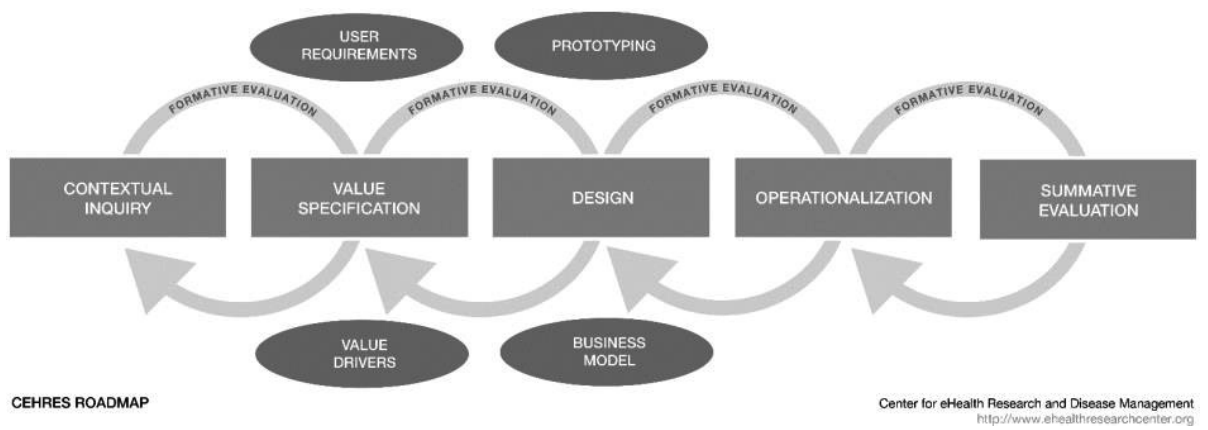

These principles are translated into a model with 5 phases with accompanying goals, which are presented in Figure 1 [9]. This model can be used by developers to shape their development approach $[3,6,9]$. As the aim of this paper is to describe the development of eHealth technology and not the implementation or evaluation, the focus lies on the first 2 phases of the Roadmap: the contextual inquiry and value specification. These phases aim to create a thorough foundation for a technology and account for the interrelationship among the context, the people involved, and the technology. In the contextual inquiry, relevant stakeholders are identified, their roles, tasks, and opinions are analysed, and the current situation and its weak and strong points are described to determine if and in what way technology can contribute. In the value specification, the values of the key stakeholders have to be identified and prioritized to determine what the added value of a technology should be. These values have to be translated into specific requirements that state what the technology should be able to do and look like [6].

\section{Case}

Due to the involvement of 2 of the researchers in the development process, this research can be labelled as an action study. In this study, the development process of a VR application for the treatment of forensic psychiatric patients is presented. This project was initiated and mostly took place at Transfore, a forensic hospital in the east of the Netherlands, which offers forensic mental health care to both in- and outpatients. Forensic mental health care is a complex branch of mental health care, which is situated at the intersect between mental health care and the law because it deals with the combination of mental illness and delinquent behaviour. In forensic mental health care, inpatients who reside in a closed setting and outpatients who are living at home are treated for sexual or aggressive criminal behaviour [20,21]. A 
primary goal is to prevent criminal recidivism by means of treatment of offenserelated factors, such as antisocial behaviour or coping skills. Owing to their low motivation for treatment, low educational levels, and comorbid psychiatric disorders [22-24], forensic psychiatric patients can be characterized as a vulnerable patient population [25,26], which can be hard to include in research [27].

Multiple studies have pointed out the potential of VR for the assessment and treatment of forensic psychiatric patients [27-29]. VR offers the possibility to practice coping skills instead of talking about them, can be used to overcome practical issues for inpatients residing in clinics, and can enable therapists to observe patients' reactions to offense-related stimuli or situations, such as children, drugs, or aggressive persons [29-31]. In VR, users enter computer-generated worlds that substitute their real-world sensory experiences with virtual ones [32], resulting in a feeling of presence: a sense of actually being in a virtual place [33]. Although VR applications have been used in mental health care, especially in exposure therapy for phobias [34], not much is known about its application in the treatment of forensic psychiatric patients [27]. Furthermore, little attention has been paid to how VR interventions should be developed for mental health care in general [32]. In our recent systematic review, we found that there are hardly any studies that discuss the development of technologies for forensic mental health [28]. However, especially in such a complex context in which there is little experience with the application of VR, thorough development is important $[10,27]$. Consequently, a thorough contextual inquiry and value specification to provide a good foundation for the application were especially important.

\section{Materials and Procedures}

In this study, multiple methods were used to operationalize the first 2 phases of the CeHRes Roadmap. The development process started with the contextual inquiry. In this phase, the stakeholders were identified, a literature review was conducted, and a multidisciplinary project team to coordinate the project was constituted. Also, focus groups and interviews with forensic patients and therapists were held. In the value

specification phase, 6 scenarios with concepts for VR applications were generated by the multidisciplinary project team. These concepts were presented to the patients, therapists, and stakeholders in a Web-based questionnaire. Next, values were formulated and used to create a concept for a VR app. This concept was visualized in a low-fidelity prototype and presented to the patients and therapists in an interview to examine their opinions and preferences. These activities were not performed 
sequentially: several methods were conducted alongside each other or were updated throughout the process [18]. Figure 2 provides an overview of the methods used in the development process. The arrows represent the iterative nature of the process and show that the methods and results of the contextual inquiry and value specification are not strictly separated but overlap. For more in-depth information about the results of the interviews and questionnaire, we refer readers to 2 other papers $[29,30]$ that focus more on the content of the results and potential of $V R$ for forensic mental health instead of a reflection on the methods and overall development process.

Figure 2. An overview of the used methods in the contextual inquiry and value specification phases of this study.

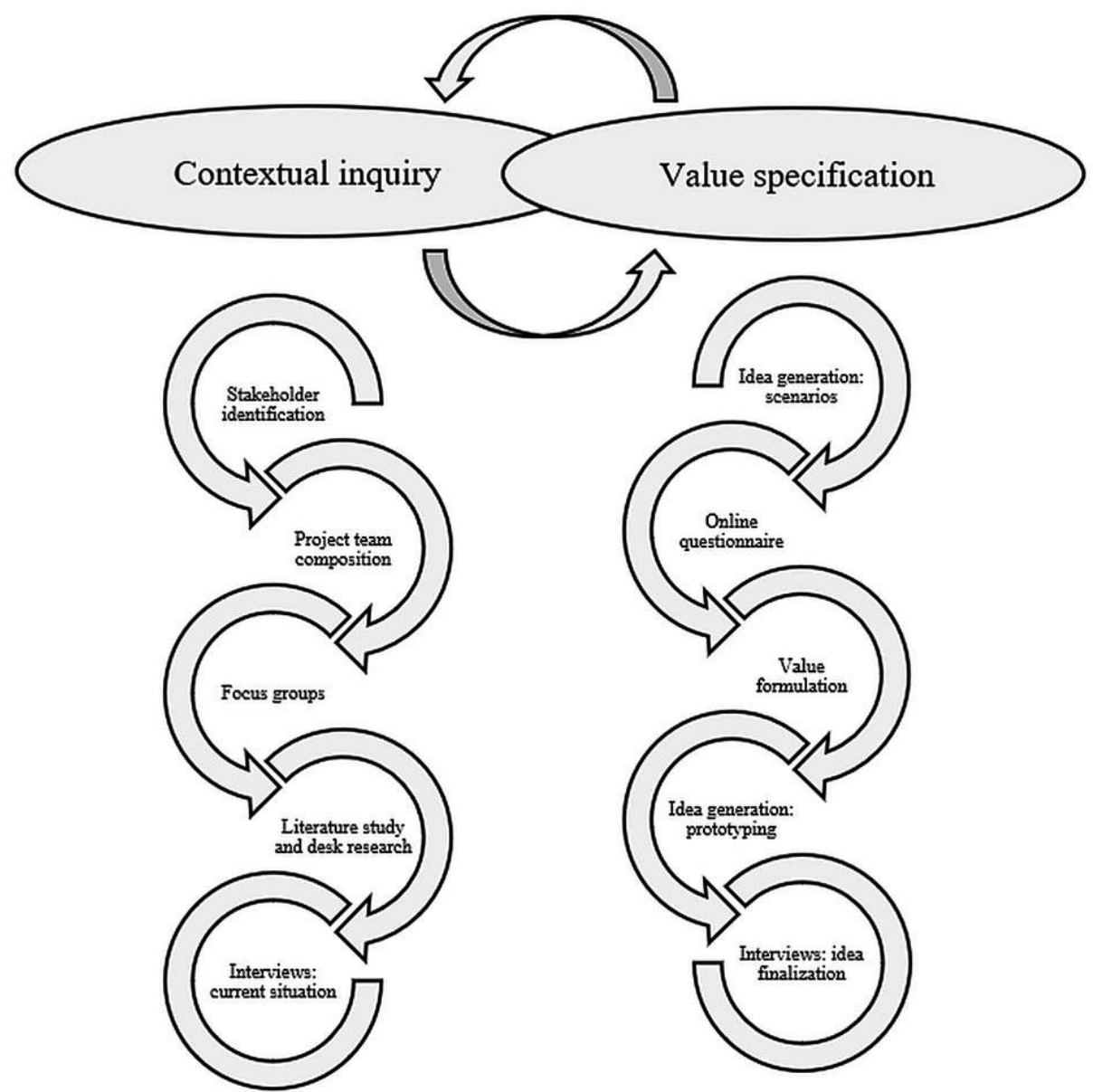




\section{Analysis}

To reflect on the suitability of the methods and overall development process, we provided the most relevant information about each research method in a comprehensive table. The aim of this table is to present the goals, methods, results, and experiences with each method as clearly and concisely as possible. For each development method, the following information is reported:

- Research question: The research question for the development activity.

- Method: The name of the method, including the most relevant methodological information.

- Target group: If applicable, a description of the target group of which the data were collected and characteristics of the participants.

- Main results: A summary of the most important results and, if necessary, a reference to a Multimedia Appendix with further information about these results.

- Conclusions: The main conclusions and recommendations for further steps of the development process, which were drawn based on the results.

- Lessons learned: A reflection on the suitability of the method for the specific development phase, target group, and research question. 


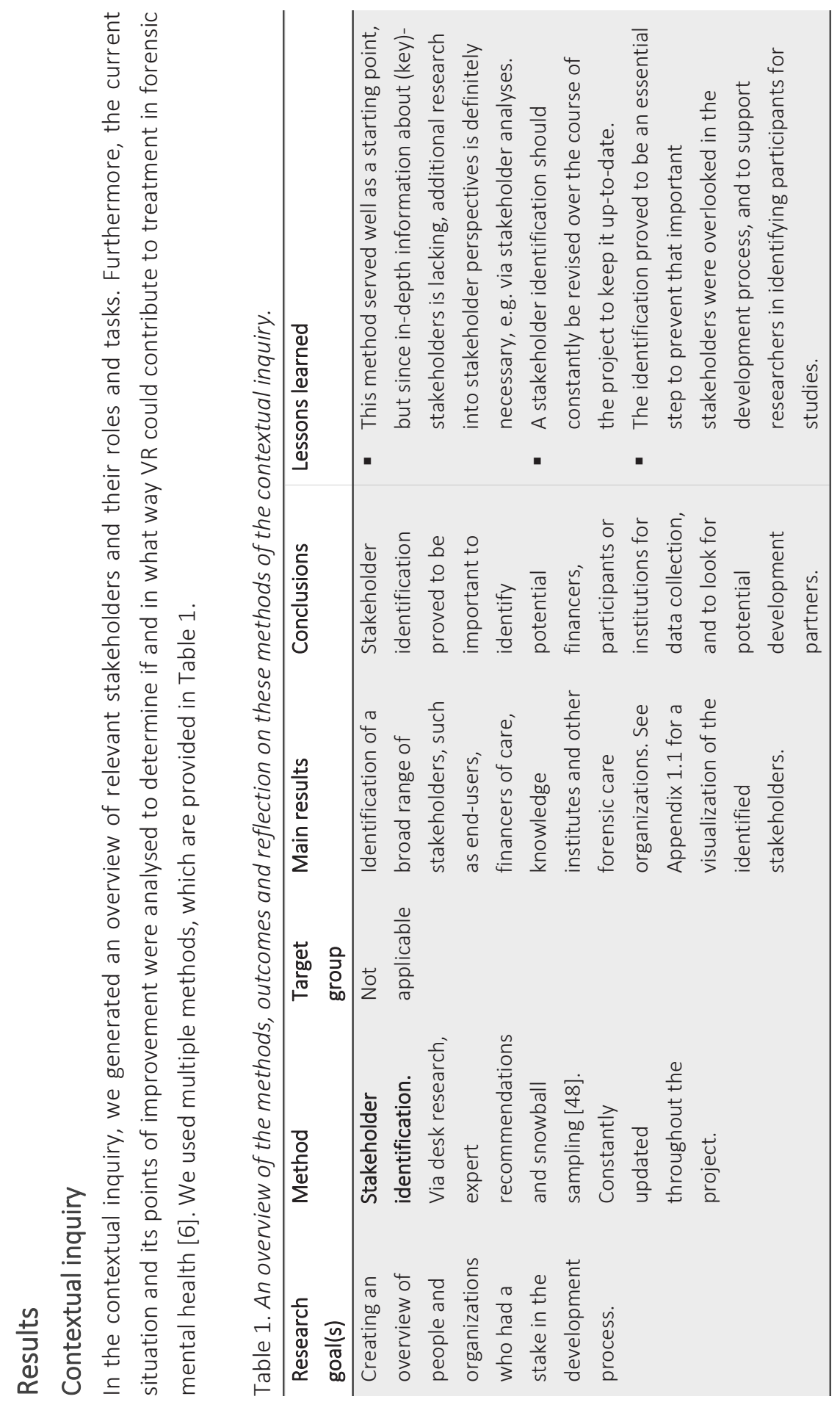




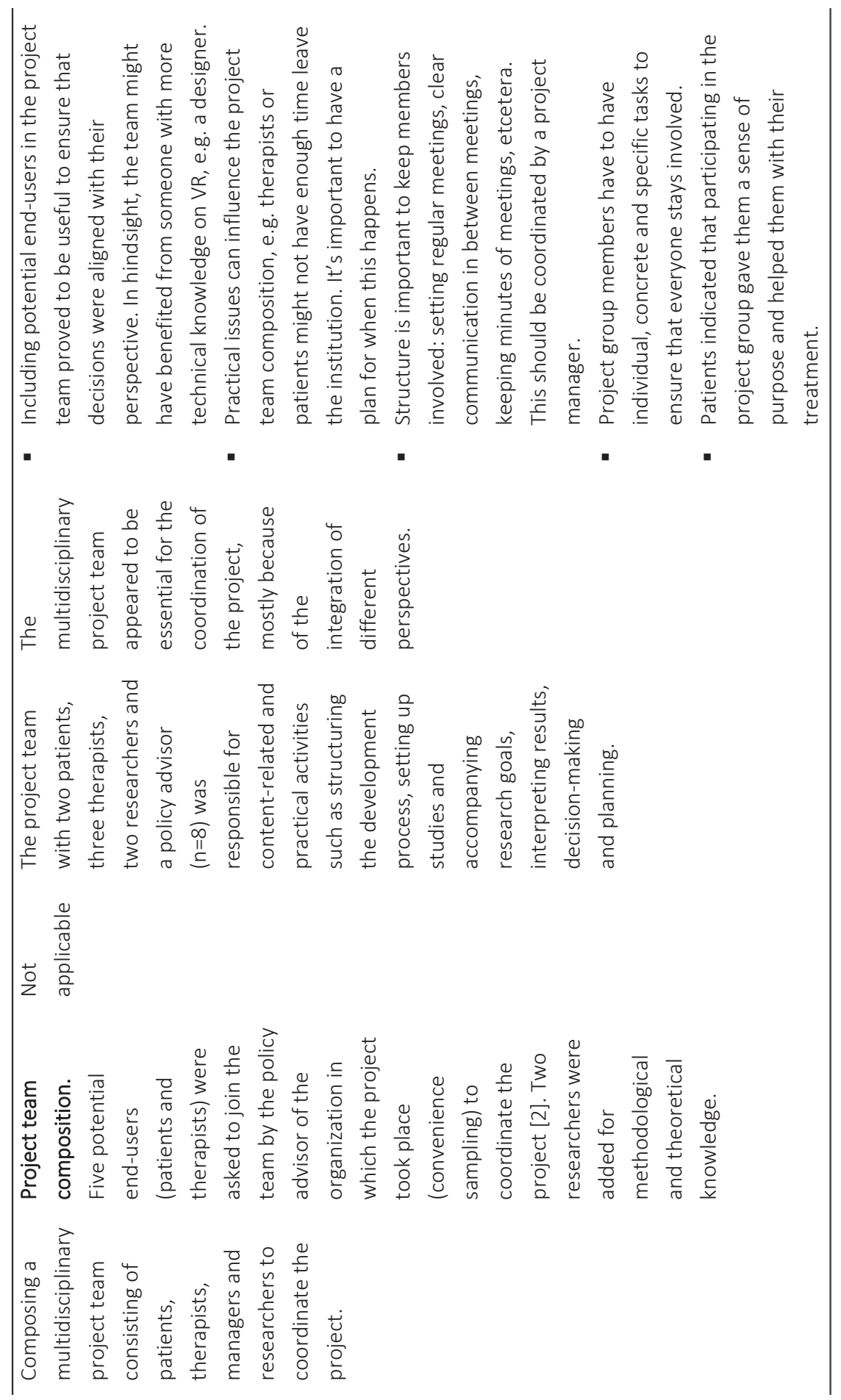




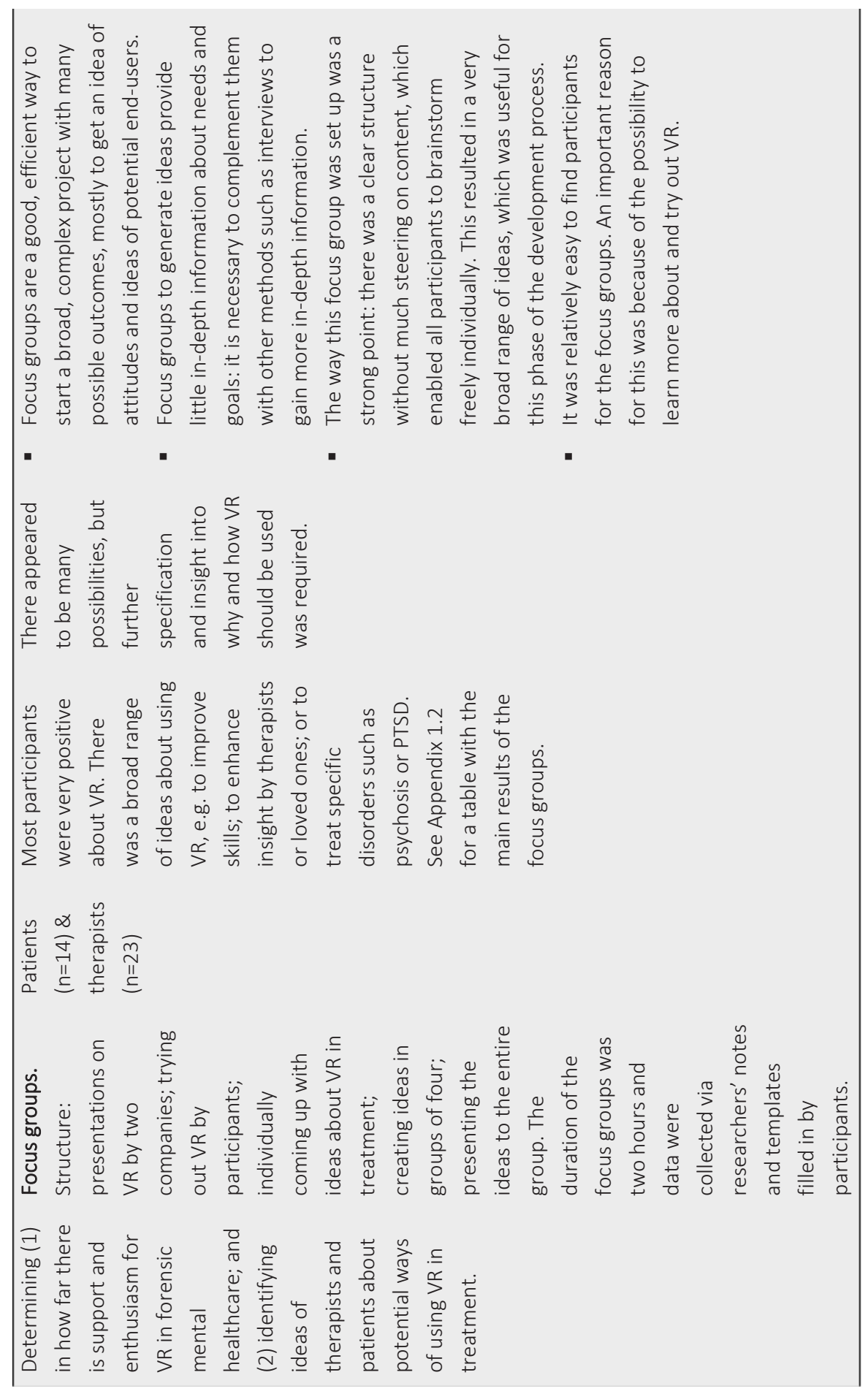




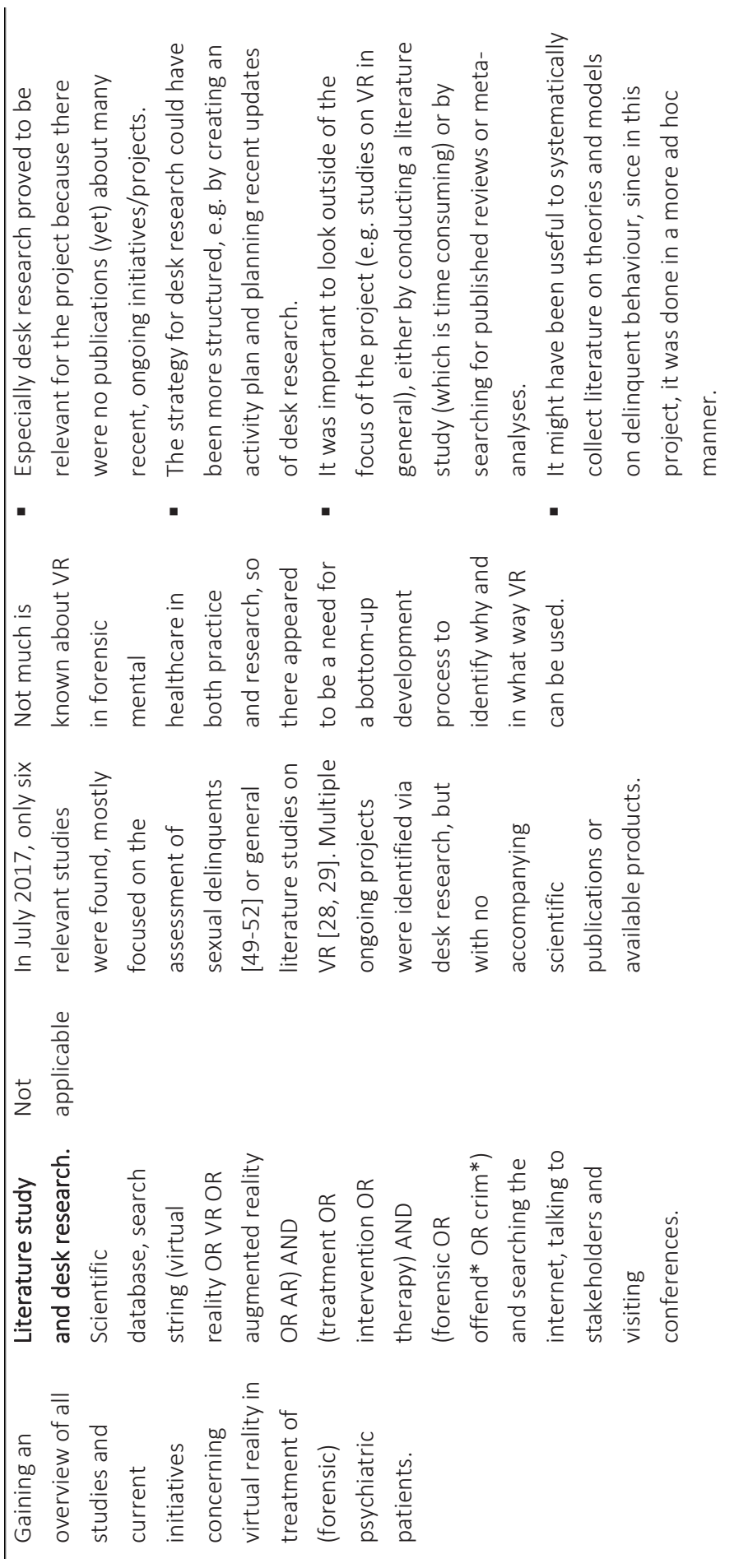




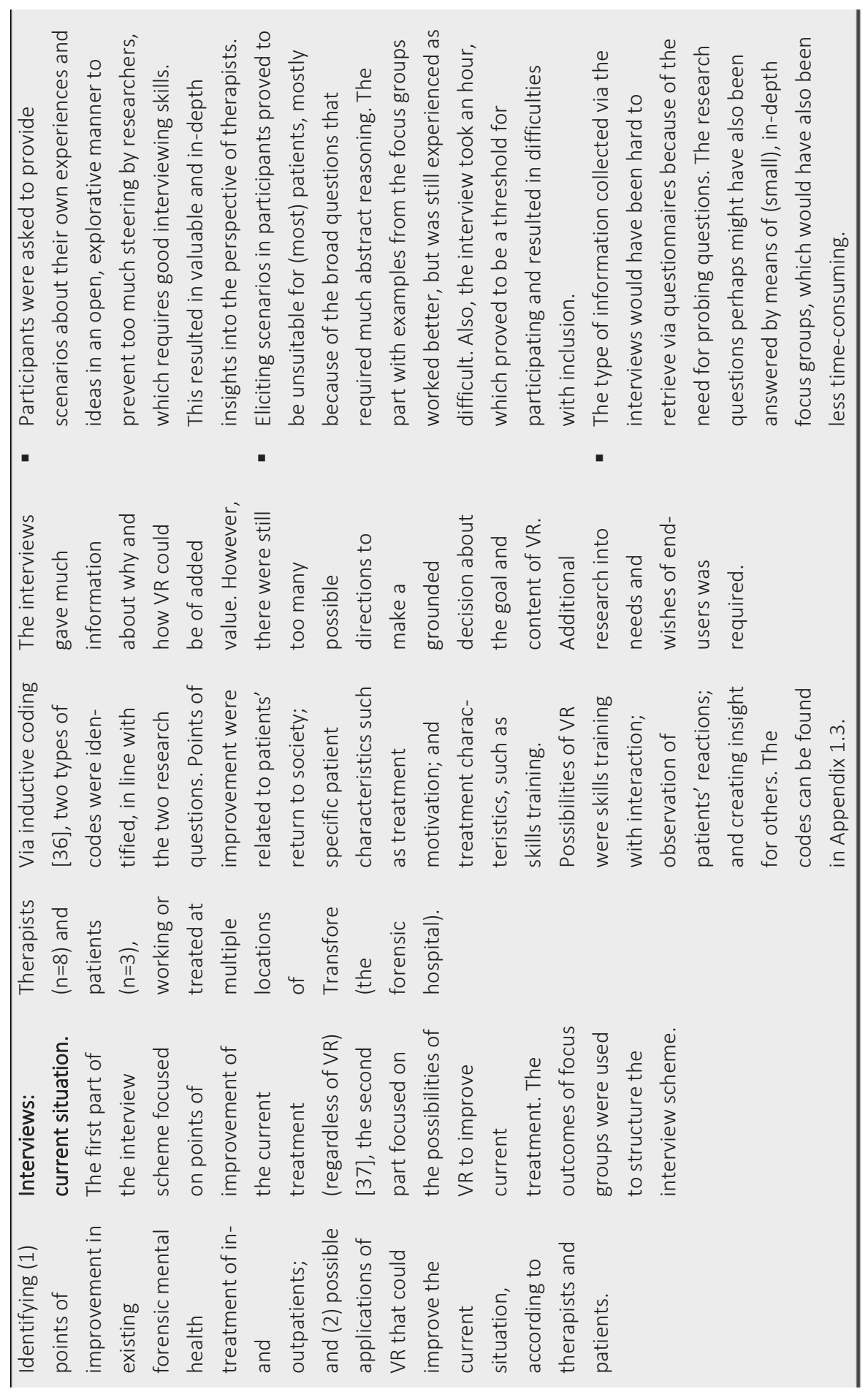




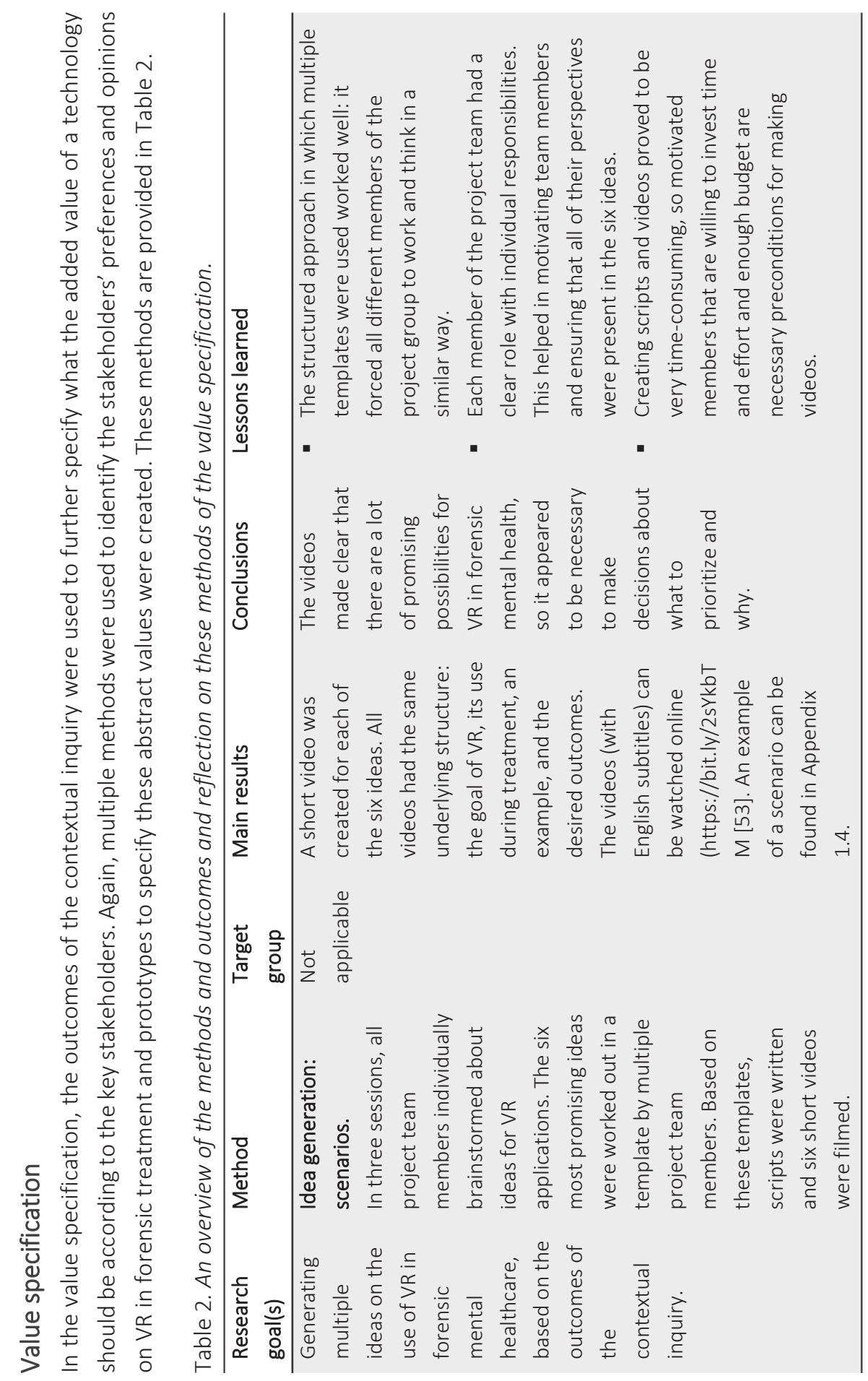




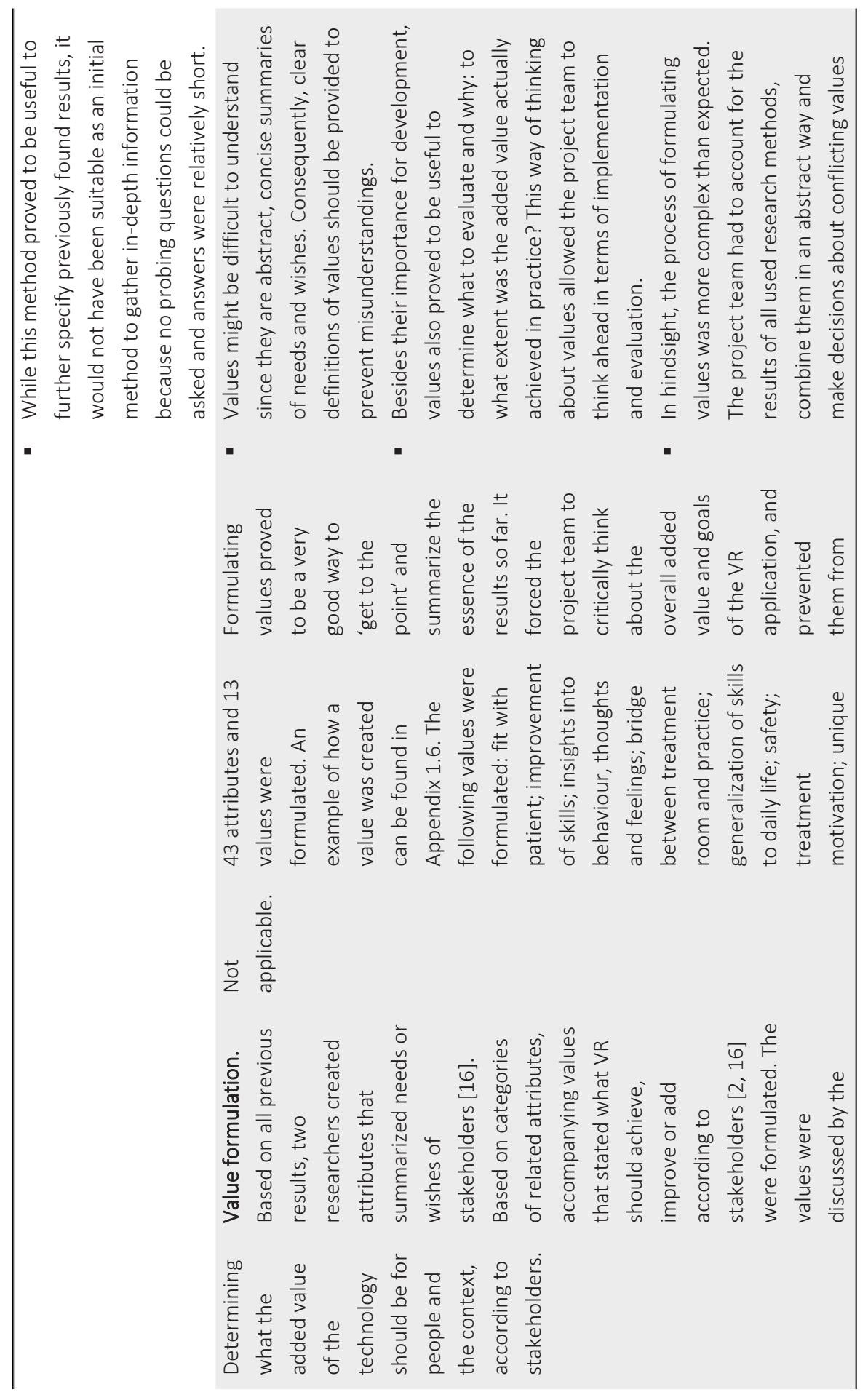




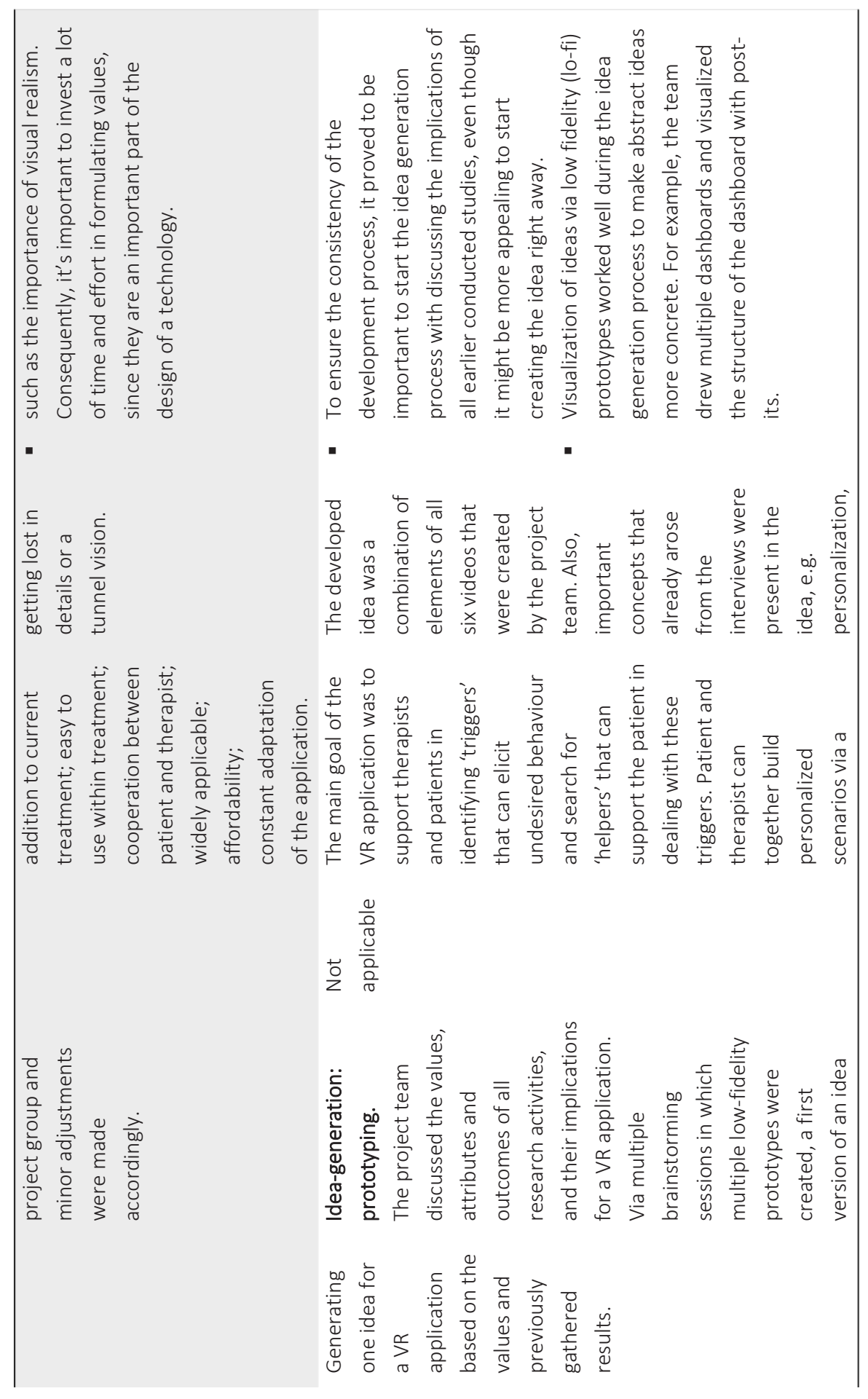




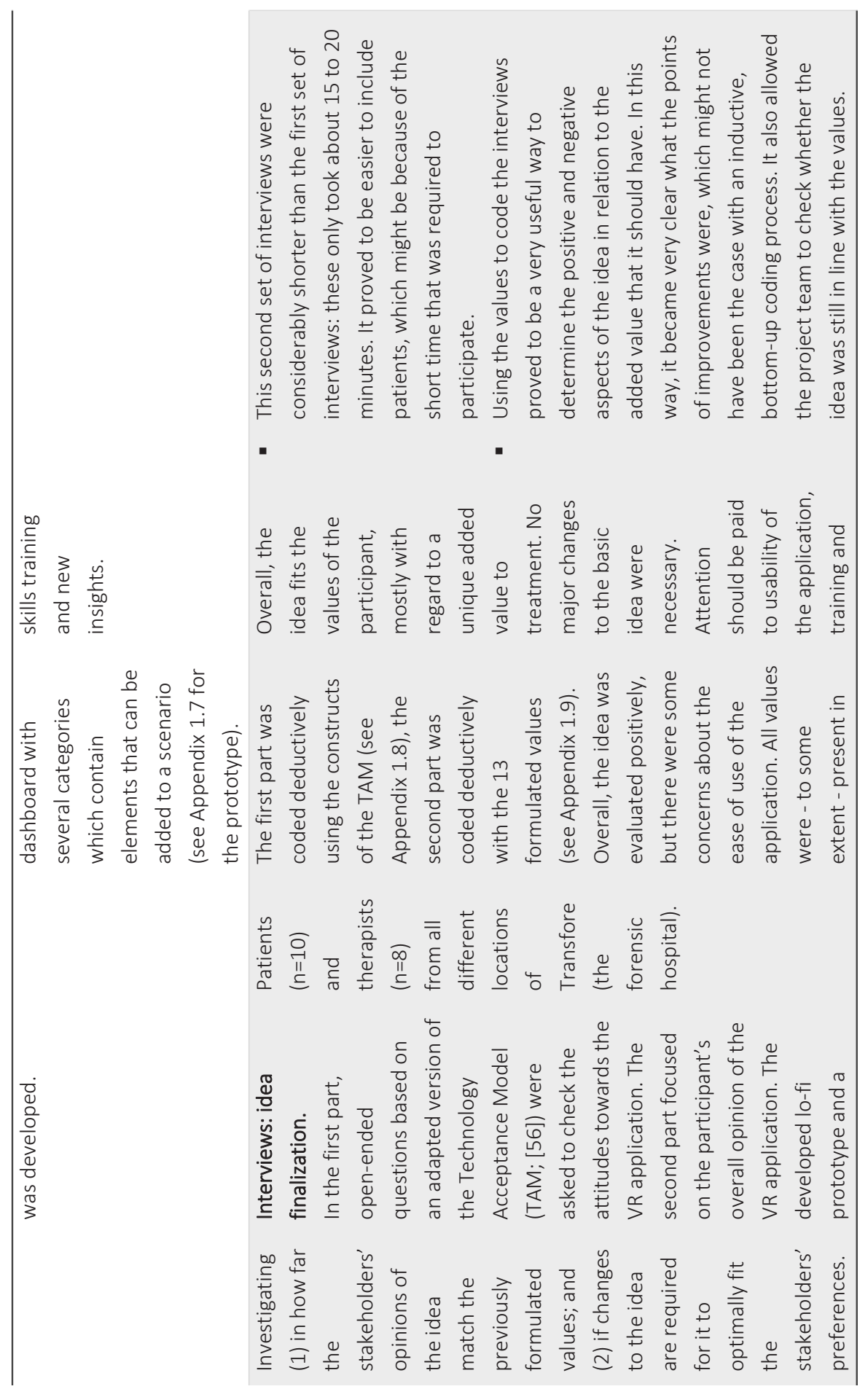




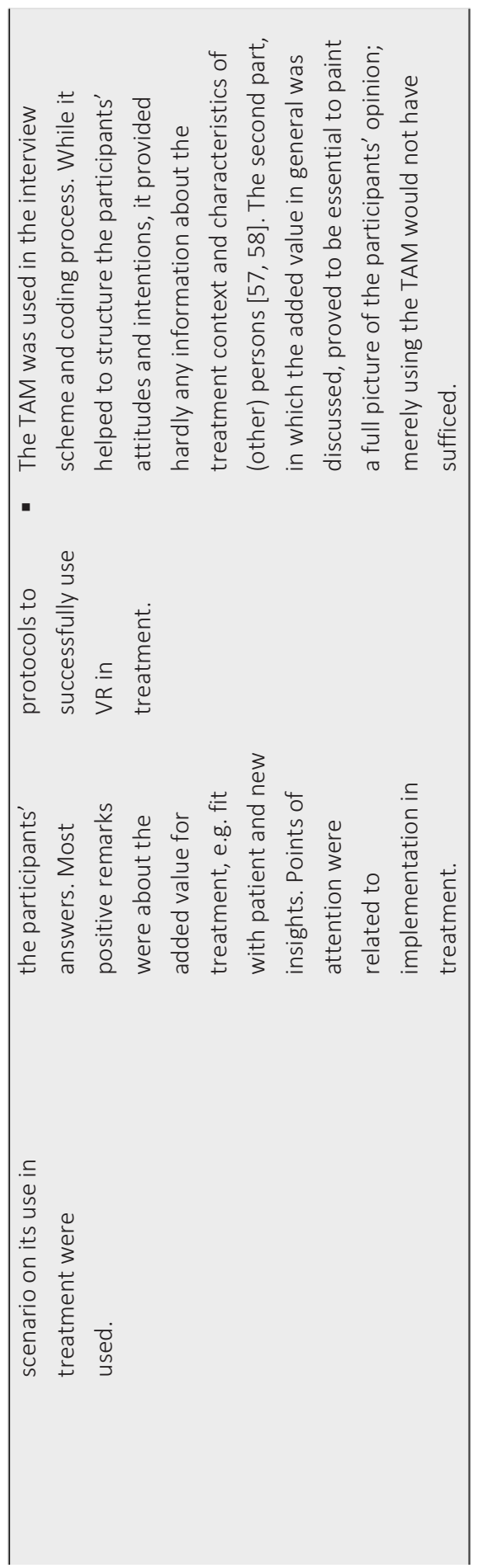




\section{Discussion}

\section{Reflection on development methods}

The main goals of this study were to analyse the suitability of the development methods for participatory eHealth development in a complex context and reflect on the development model used: the CeHRes Roadmap. This study can contribute to the development of a broad tool kit from which researchers can choose appropriate methods for the stage of their development process, participants, and context. In hindsight, this study would have benefited from such a tool kit, as the results showed that all methods generated valuable information, but not each method proved to be very suitable for the target group and their context. Besides generating knowledge on suitable methods, this type of study can also facilitate reflection and accompanying improvements of the development model used. Although this study offers a contribution, more studies that pay attention to development methods and models are required to make generalizable statements about methods and models.

The first goal of this study was to reflect on the suitability of different development methods. The relevance of this goal became clear from the experiences of the project team, as a major challenge was to identify the suitable methods for the forensic psychiatric patient population. These types of vulnerable patient populations are often difficult to involve in research, and not much is known about the suitable methods for these types of population $[27,44]$. On the basis of the experiences with methods used in this study, several conclusions and recommendations can be drawn on the suitability of methods.

A first set of recommendations focuses on involving patients in research. First of all, working with concrete examples seemed to work better than merely asking patients for their opinion or ideas without much guidance or input [4]. Using existing or potential examples is also possible in the earliest stages of the process, when not much is known yet, and can be done by using methods derived from a human-centred design, such as scenarios, personas, or prototypes $[45,46]$. A second recommendation based on the findings of this study is to keep data collection as short as possible, because patients might have difficulties with concentration or are not motivated to invest a lot of time. This recommendation is also relevant for health care professionals, because although researchers often want to collect as much data as possible, the professionals often not have a lot of time to participate [17]. The balance between how much in-depth information should be collected and the duration of data collection was experienced as difficult, so more research on this topic is needed. Finally, participating in research should be perceived as personally relevant or 
rewarding [47]. Although we used rewards such as VR goggles in the questionnaire and interviews, including participants for the focus groups proved to be easier. A reason for this might have been that participants could experience VR during the focus groups, which was perceived as new and exciting by both patients and therapists. Consequently, it appears to be worthwhile to spend time on identifying personally relevant rewards for participants.

The second set of recommendations is focused on combining multiple methods and perspectives to paint a clear and complete picture of the context and stakeholder perspective. First, although involving patients proved to be very valuable, the development process also benefited from the perspectives of other types of stakeholders, such as therapists, managers, researchers, and technology developers, as they might have different needs or a more overarching view $[28,48]$. For example, the analysis of the first set of interviews showed that patients mostly mentioned the use of VR to observe situations and stimuli, whereas therapists also pointed out the importance of other possibilities, such as skill training, which was not mentioned by the patients. Second, involving participants via multiple methods enabled the project team to gain different types of information that supported them in getting a good grasp of all perspectives on VR in forensic mental health care. Finally, it can be concluded that more knowledge on suitable methods for involving patients, therapists, and other stakeholders in eHealth development is needed to be able to make more generalizable statements and create a tool kit [47].

\section{Operationalization of the Development Model}

Besides reflections on development methods, this study also aimed to reflect on the application of the development model that was used: the CeHRes Roadmap. It is of course not possible to conclude whether the development process guided by the CeHRes Roadmap resulted in better outcomes than another development method, partly because that would require 2 parallel development processes in identical settings [18], which is difficult both practically and conceptually. Nevertheless, based on the experiences of the project team, it can be concluded that the CeHRes Roadmap provided a valuable guidance for the development process. This process resulted in a concept for a VR application that is based on the wishes and preferences of the therapists and patients. The fit with their wishes became especially clear in the second round of interviews that showed that participants were enthusiastic about the concept and their opinions closely matched the previously formulated values. 
On the basis of the experiences of this study, several recommendations can be made on how to operationalize the CeHRes Roadmap and similar development models. First of all, an important principle of eHealth development is that it should comprise multiple formative evaluation cycles. The experiences of this study confirmed that the Roadmap should not be used as a linear, sequential approach with a fixed order of phases and accompanying activities [18]. To illustrate, the first set of interviews and focus groups provided information that was relevant for both the contextual inquiry and value specification phase. Also, during the value specification, activities from the design phase, such as prototyping and scenarios, were used to elicit opinions. Consequently, although the phases of the Roadmap are visualized as separate blocks (see Figure 1), they should be used as overlapping, interwoven sets of principles and methodologies. A thorough understanding of the principles of the Roadmap appeared to be more important than strictly following the order of separate phases.

A second important finding was that the formulation of clear, specific research goals was pivotal in structuring this development process. A pitfall of an elaborate development process in a complex setting is that it might become unstructured or vague $[6,14]$. We tried to prevent this by formulating multiple clear, specific research questions that were based on the goals of the Roadmap's phases and its 5 underlying principles [6]. To keep the process coherent, the project team carefully thought about how these research questions related to the outcomes of the previous development activities. Also, we added multiple formative evaluations to check whether the outcomes of different activities remained consistent with each other. This process is visualized in Figure 3. 
Figure 3. The structure of the goal-driven development process with multiple formative evaluation cycles.

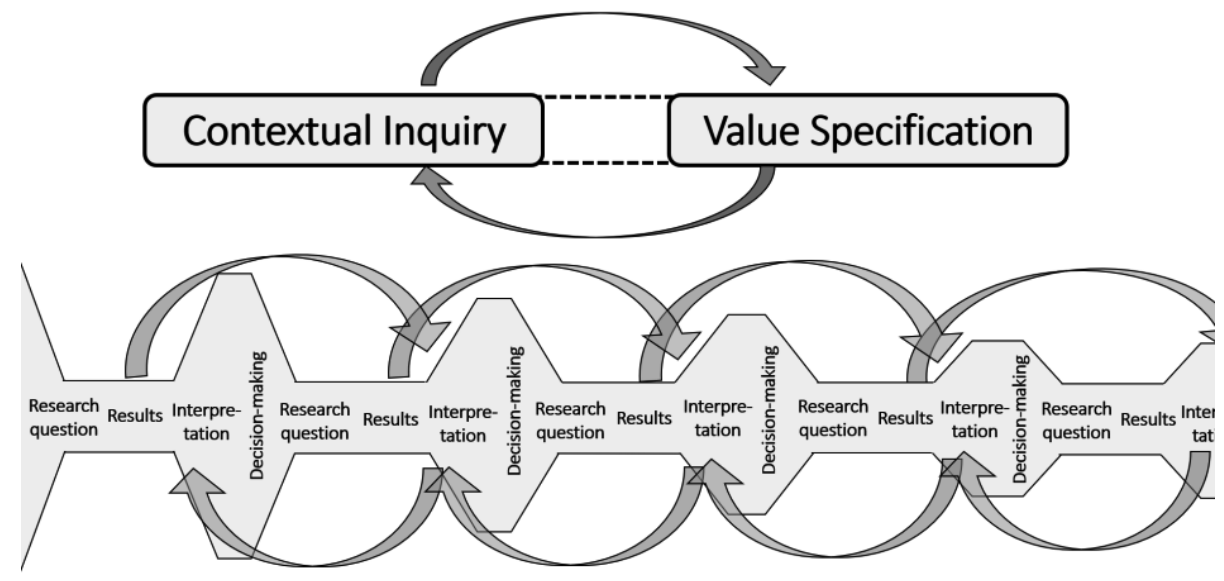

Third, although constituting and managing an interdisciplinary project team was complex and time-consuming, the team was found to be an important part of the development process as it facilitated decision making from multiple perspectives $[22,49,50]$. Multidisciplinary teamwork in health care is often complex [51], so several measures were taken to increase the chances on a successful collaboration. Among other things, patients and therapists that participated in the project team were involved as active co-designers instead of passive informants [52,53] and thus took part in activities, such as designing studies, interpreting results, and creating and adapting ideas. To achieve this, the project leader ensured that each project team member had a clear task, as was, for example, done in the creation of scenarios, where each member actively participated in creating an idea and writing the script for 2 of the videos. Fourth, much attention was paid to the functioning of the team. Among other things, roles and tasks of all team members were made clear; regular, bimonthly meetings were held and there was ample communication in between meetings; individual members got the opportunity to be involved in activities of their own choice; there was a mix of skills and interests of members; there was a positive climate of trust and common respect; and, importantly, the team had a common, clear goal [51]. However, as these findings are based on only 1 development process, they are not generalizable. As the functioning of a project team seems to be a relevant topic in eHealth development, more studies on how to compose and organize multidisciplinary project teams should be conducted to be able to draw generalizable 
conclusions and recommendations. Finally, when operationalizing the CeHRes Roadmap-or any other development model-a thorough understanding of the model's underlying principles, continuous formative evaluations to prevent tunnel vision, clear research questions with suitable methods, and a well-functioning multidisciplinary team were found to be important.

\section{Reflection on the CeHRes Roadmap}

While using the CeHRes Roadmap to shape the development process, we identified several strong points but also some points of improvement. First of all, the participatory development principle was used to determine what the main goal of the VR application should be in a bottom-up manner. According to this principle, it is important to involve users from the start to ensure that a technology addresses actual problems or points of improvement and is of added value for them [54]. However, in many cases, the goal of an eHealth technology is determined by researchers and/or developers, and stakeholders are involved as mere informants in later stages to provide feedback on concepts that were created in a top-down manner [55]. In this project, we tried to prevent this by actively involving stakeholders from the start, among other things, by asking them about points of improvement of the current situation and enabling them to come up with their own ideas about VR. Further along the process, values were formulated to specify the goal of the VR application. These values forced the project team to explicitly state the added value that a technology should have for patients and therapists. However, during the value specification, we noticed that there was a lack of clear guidelines on how to formulate these values and what topics they should cover. Although this value-driven approach was experienced as useful to keep an eye on people and their context, there is still much uncharted territory. We recommend that more studies using values in their development process should be conducted to be able to create clear guidelines.

Second, the Roadmap emphasizes the importance of formative evaluation and use of multiple methods. This indeed proved to be essential in this development process, especially because at the start of the project, there was no knowledge about the use of VR in forensic treatment. Consequently, much information had to be generated to make substantiated choices for the goal and content of the VR app. Just using 1 or 2 research methods would not have sufficed. This can be illustrated by the following example on personalization of VR. The first interviews and literature study indeed pointed out that personalization was important [35-37] but did not provide indepth information about this topic. The results of the questionnaire offered more 
insights into what stakeholders wanted to be able to personalize: virtual people, environments, and scenarios. Throughout the process, the project team further specified these preferences and translated them into concepts for personalized VR applications via low-fidelity prototypes that were evaluated with stakeholders and fine-tuned accordingly. If only 1 interview study would have been conducted, the project team would not have had enough input to create a personalized VR application. A disadvantage of the multimethod, iterative approach was that it was very time-consuming. It might be possible that, if more would have been known about VR in forensic mental health care or suitable development methods, less research would have been required, which might have resulted in a shorter and more efficient development process. But again, more research on different types of development methods is required to draw more conclusions on this topic.

Finally, when reflecting on the development process, a more systematic approach toward involving domain-specific theories and models could have been used. Owing to the involvement of researchers and professionals with much knowledge on existing treatment models and theories on offending, this information was included but in an ad hoc manner. As other studies and models such as intervention mapping point out, it is important to incorporate theories that explain and change behaviour in eHealth interventions $[7,12,56,57]$. In this project, this relates to models that explain delinquent behaviour or theories that underpin treatment of forensic psychiatric patients, such as the general theory of crime [58] or the risk-need-responsivity model [59]. Consequently, we recommend that the use of domain-specific theories and models to explain behaviour and treatment can be explicitly integrated in the Roadmap. To do this, the pillar on persuasive design could be adapted. In its current state, it focuses on behaviour change via persuasive design. We suggest a change to this pillar, so that, besides persuasive theory, it also entails the use of domain-specific theories and models throughout the entire development process. Goals and activities derived from this adapted principle could be added to the contextual inquiry and value specification phases to add more focus on domainspecific theories at the beginning of the development process.

\section{Conclusions}

This study described and reflected on the methods and development model used in a development process of a VR application for a complex setting: forensic mental health care. To take the domain of eHealth development to the next level, more studies need to report and reflect on the development processes in a standardized 
way to generate more knowledge on suitable methods. This might result in a tool kit that researchers can use to choose and operationalize methods. Based on this study, we conclude that eHealth development is much more than programming a technology or just going with the flow; it requires thorough research via methods that fit the participants, stage in the development process and context, structured project coordination by a multidisciplinary project team, a flexible and open mind-set, and the inclusion of multiple perspectives in every decision.

\section{Acknowledgments}

Funding for this study was provided by Stichting Vrienden van Oldenkotte. The authors would like to thank the members of the VooRuit met VR project team for their valuable contributions to this project: Dirk Dijkslag, Kirby Weerink, Ron Voorhuis, Jakob Visser, Kevin Krimmel, and Anne Marike Halma. A special thanks to Ankie Kuiper and Ines Brünninghoff for their work in analysing the questionnaire and conducting the second set of interviews and to Kirby Weerink for conducting the first round of interviews. 


\section{References}

1. van Gemert-Pijnen L, Kip H, Kelders SM, Sanderman R. Introducing ehealth. In: van Gemert-Pijnen L, Kelders SM, Kip H, Sanderman R, editors. eHealth Research, Theory and Development: A Multi-Disciplinary Approach. London: Routledge; 2018:23-46.

2. Mohr DC, Schueller SM, Montague E, Burns MN, Rashidi P. The behavioral intervention technology model: an integrated conceptual and technological framework for ehealth and mhealth interventions. J Med Internet Res 2014 Jun 5;16(6):e146

3. van Gemert-Pijnen L, Peters O, Ossebaard HC, editors. Improving eHealth. The Netherlands: Eleven International Publishing; 2013.

4. Beerlage-de Jong N. eHealth vs Infection: Participatory Development of Persuasive eHealth to Support Safe Care. The Netherlands: University Library/University of Twente; 2016.

5. Pieterse ME, Kip H, Cruz-Martínez RR. The complexity of eHealth implementation: a theoretical and practical perspective. In: van GemertPijnen L, Kelders SM, Kip H, Sanderman R, editors. eHealth Research, Theory and Development: A Multi-Disciplinary Approach. London: Routledge; 2018:247-270.

6. Kip H, van Gemert-Pijnen L. Holistic development of eHealth technology. In: van Gemert-Pijnen L, Kelders SM, Kip H, Sanderman R, editors. eHealth Research, Theory and Development: A Multi-Disciplinary Approach. London: Routledge; 2018:151-186.

7. Michie S, Yardley L, West R, Patrick K, Greaves F. Developing and evaluating digital interventions to promote behavior change in health and health care: recommendations resulting from an international workshop. J Med Internet Res 2017 Dec 29;19(6):e232

8. Patrick K, Hekler EB, Estrin D, Mohr DC, Riper H, Crane D, et al. The pace of technologic change: implications for digital health behavior intervention research. Am J Prev Med 2016 Dec;51(5):816-824.

9. van Gemert-Pijnen JE, Nijland N, van Limburg M, Ossebaard HC, Kelders SM, Eysenbach G, et al. A holistic framework to improve the uptake and impact of ehealth technologies. J Med Internet Res 2011 Dec 5;13(4):e111.

10. Yardley L, Morrison L, Bradbury K, Muller I. The person-based approach to intervention development: application to digital health-related behavior change interventions. J Med Internet Res 2015 Jan 30;17(1):e30. 
11. Mohr DC, Lyon AR, Lattie EG, Reddy M, Schueller SM. Accelerating digital mental health research from early design and creation to successful implementation and sustainment. J Med Internet Res 2017 Dec 10;19(5):e153.

12. Eldredge LK, Markham CM, Ruiter RA, Fernández ME, Kok G, Parcel GS. Planning Health Promotion Programs: An Intervention Mapping Approach. Hoboken, New Jersey: John Wiley \& Sons; 2016.

13. Oinas-Kukkonen $\mathrm{H}$, Harjumaa M. Persuasive systems design: key issues, process model, and system features. Commun Assoc Inf Syst 2009;24(1):28.

14. Hekler EB, Klasnja P, Riley WT, Buman MP, Huberty J, Rivera DE, et al. Agile science: creating useful products for behavior change in the real world. Transl Behav Med 2016 Dec;6(2):317-328.

15. van Gemert-Pijnen L, Kelders SM, Kip H, Sanderman R, editors. eHealth Research, Theory and Development: A Multi-Disciplinary Approach. London: Routledge; 2018.

16. Wentzel J, van Velsen L, van Limburg M, de Jong N, Karreman J, Hendrix R, et al. Participatory ehealth development to support nurses in antimicrobial stewardship. BMC Med Inform Decis Mak 2014 Jun 5;14:45.

17. van Velsen L, Wentzel J, van Gemert-Pijnen JE. Designing ehealth that matters via a multidisciplinary requirements development approach. JMIR Res Protoc 2013 Jun 24;2(1):e21.

18. Kelders SM, Pots WT, Oskam MJ, Bohlmeijer ET, van Gemert-Pijnen JE. Development of a web-based intervention for the indicated prevention of depression. BMC Med Inform Decis Mak 2013 Feb 20;13:26.

19. van der Weegen S, Verwey R, Spreeuwenberg M, Tange $H$, van der Weijden $\mathrm{T}$, de Witte $\mathrm{L}$. The development of a mobile monitoring and feedback tool to stimulate physical activity of people with a chronic disease in primary care: a user-centered design. JMIR Mhealth Uhealth 2013 Jul 2;1(2):e8.

20. Wolpin SE, Halpenny B, Whitman G, McReynolds J, Stewart M, Lober WB, et al. Development and usability testing of a web-based cancer symptom and quality-of-life support intervention. Health Informatics J 2015 Mar;21(1):1023.

21. Beerlage-de Jong N, van Gemert-Pijnen L, Wentzel J, Hendrix R, Siemons L. Technology to support integrated antimicrobial stewardship programs: a user centered and stakeholder driven development approach. Infect Dis Rep 2017 Mar 30;9(1):6829. 
22. Geissbuhler A. Lessons learned implementing a regional health information exchange in Geneva as a pilot for the Swiss national ehealth strategy. Int J Med Inform 2013 May;82(5):e118-e124.

23. Covvey HD. Healthcare as a complex adaptive system. In: van Gemert-Pijnen L, Kelders SM, Kip H, Sanderman R, editors. eHealth Research, Theory and Development: A Multi-Disciplinary Approach. London: Routledge; 2018:89110.

24. Greenhalgh T, Wherton J, Papoutsi C, Lynch J, Hughes G, A'Court C, et al. Beyond adoption: a new framework for theorizing and evaluating nonadoption, abandonment, and challenges to the scale-up, spread, and sustainability of health and care technologies. J Med Internet Res 2017 Dec 1;19(11):e367.

25. Ross J, Stevenson F, Lau R, Murray E. Factors that influence the implementation of e-health: a systematic review of systematic reviews (an update). Implement Sci 2016 Dec 26;11(1):146.

26. Sieverink F, Köhle N, Cheung K, Roefs A, Trompetter H, Keizer J, et al. Evaluating ehealth. In: van Gemert-Pijnen L, Kelders SM, Kip H, Sanderman $\mathrm{R}$, editors. eHealth Research, Theory and Development: A Multi-Disciplinary Approach. London: Routledge; 2018.

27. Flaskerud JH, Winslow BJ. Conceptualizing vulnerable populations healthrelated research. Nurs Res 1998;47(2):69-78.

28. Kip H, Bouman YH, Kelders SM, van Gemert-Pijnen LJ. eHealth in treatment of offenders in forensic mental health: a review of the current state. Front Psychiatry 2018;9:42.

29. Kip H, Kelders SM, Weerink K, Kuiper A, Brüninghoff I, Bouman YH, et al. Identifying the added value of virtual reality for treatment in forensic mental health: a scenario-based, qualitative approach. Front Psychol 2019;10:406.

30. Kip H, Kelders SM, van Gemert-Pijnen LJ. Putting the Value in VR: How to Systematically and Iteratively Develop a Value-Based VR Application with a Complex Target Group. In: Proceedings of the $2019 \mathrm{CHI}$ Conference on Human Factors in Computing Systems. 2019 Presented at: CHI'19; May 4-9, 2019; Glasgow, Scotland UK.

31. van Woezik AF, Braakman-Jansen LM, Kulyk O, Siemons L, van Gemert-Pijnen JE. Tackling wicked problems in infection prevention and control: a guideline for co-creation with stakeholders. Antimicrob Resist Infect Control 2016;5:20. 
32. Renaud P, Trottier D, Rouleau J, Goyette M, Saumur C, Boukhalfi T, et al. Using immersive virtual reality and anatomically correct computergenerated characters in the forensic assessment of deviant sexual preferences. Virtual Real 2013 Oct 30;18(1):37-47.

33. Fromberger $\mathrm{P}$, Meyer S, Kempf $\mathrm{C}$, Jordan K, Müller JL. Virtual viewing time: the relationship between presence and sexual interest in androphilic and gynephilic men. PLoS One 2015;10(5):e0127156.

34. Renaud P, Chartier S, Rouleau J, Proulx J, Goyette M, Trottier D, et al. Using immersive virtual reality and ecological psychology to probe into child molesters' phenomenology. J Sex Aggress 2011 Nov 8;19(1):102-120.

35. Renaud P, Rouleau JL, Proulx J, Trottier D, Goyette M, Bradford JP, et al. Virtual characters designed for forensic assessment and rehabilitation of sex offenders: standardized and made-to-measure. J Virtual Real Broadcast 2010;7(5):1-9.

36. Fromberger $\mathrm{P}$, Jordan K, Müller JL. [Use of virtual reality in forensic psychiatry. A new paradigm?]. Nervenarzt 2014 Mar;85(3):298-303.

37. Benbouriche M, Nolet K, Trottier D, Renaud P. Virtual Reality Applications in Forensic Psychiatry. In: Proceedings of the 2014 Virtual Reality International Conference. 2014 Presented at: VRIC'14; April 9-11, 2014; Laval, France.

38. YouTube. 2018. Vooruit met VR URL: https://www.youtube.com/playlist?list=PLPPQsPUGLUhmgEKfTArOwJ6Uem osnAsis [accessed 2018-01-04].

39. Kelders SM. Involvement as a Working Mechanism for Persuasive Technology. In: Proceedings of the International Conference on Persuasive Technology. 2015 Presented at: PERSUASIVE'15; June 3-5, 2015; Chicago, IL, USA p. 3-14.

40. Zaichkowsky JL. The personal involvement inventory: reduction, revision, and application to advertising. J Advert 1994 Dec;23(4):59-70.

41. Venkatesh V, Davis FD. A theoretical extension of the technology acceptance model: four longitudinal field studies. Manage Sci 2000 Feb;46(2):186-204.

42. van Velsen L, Evers M, Bara CD, den Akker HO, Boerema S, Hermens $\mathrm{H}$. Manage sciunderstanding the acceptance of an ehealth technology in the early stages of development: an end-user walkthrough approach and two case studies. JMIR Form Res 2018 Jun 15;2(1):e10474. 
43. Legris $\mathrm{P}$, Ingham J, Collerette P. Why do people use information technology? A critical review of the technology acceptance model. Inform Manage 2003 Jan;40(3):191-204.

44. Emergency Preparedness and Response | CDC. 2010. Public Health Workbook: To Define, Locate, and Reach Special, Vulnerable, and At-Risk Populations in an Emergency URL: https://emergency.cdc.gov/workbook/pdf/ph_workbookfinal.pdf

45. Beerlage-de Jong N, Wentzel J, Hendrix R, van Gemert-Pijnen L. The value of participatory development to support antimicrobial stewardship with a clinical decision support system. Am J Infect Control 2017 Apr 1;45(4):365371.

46. Burns C. Human-centred design. In: van Gemert-Pijnen L, Kelders SM, Kip H, Sanderman R, editors. eHealth Research, Theory and Development: A MultiDisciplinary Approach. London: Routledge; 2018.

47. Dugas M, Trottier ME, Dansokho SC, Vaisson G, Provencher T, Colquhoun H, et al. Involving members of vulnerable populations in the development of patient decision aids: a mixed methods sequential explanatory study. BMC Med Inform Decis Mak 2017 Jan 19;17(1):12.

48. van der Vaart R, Witting M, Riper H, Kooistra L, Bohlmeijer ET, van GemertPijnen LJ. Blending online therapy into regular face-to-face therapy for depression: content, ratio and preconditions according to patients and therapists using a Delphi study. BMC Psychiatry 2014 Dec 14;14:355.

49. Feldman SS, Schooley BL, Bhavsar GP. Health information exchange implementation: lessons learned and critical success factors from a case study. JMIR Med Inform 2014 Aug 15;2(2):e19.

50. Nielsen JA, Mathiassen L. Interpretive flexibility in mobile health: lessons from a government-sponsored home care program. J Med Internet Res 2013 Oct 30;15(10):e236.

51. Nancarrow SA, Booth A, Ariss S, Smith T, Enderby P, Roots A. Ten principles of good interdisciplinary team work. Hum Resour Health 2013 May 10;11:19.

52. DeSmet A, Thompson D, Baranowski T, Palmeira A, Verloigne $M$, de Bourdeaudhuij I. Is participatory design associated with the effectiveness of serious digital games for healthy lifestyle promotion? A meta-analysis. J Med Internet Res 2016 Apr 29;18(4):e94.

53. Yip J, Clegg T, Bonsignore E, Gelderblom H, Rhodes E, Druin A. Brownies or Bags-of-Stuff?: Domain Expertise in Cooperative Inquiry With Children. In: 
Proceedings of the 12th International Conference on Interaction Design and Children. 2013 Presented at: IDC'13; June 24-27, 2013; New York, USA p. 201-210.

54. Kip H, Beerlage-de Jong N, Wentzel J. The contextual inquiry. In: van GemertPijnen JE, Kelders SM, Kip H, Sanderman R, editors. eHealth Research, Theory and Development: A Multi-Disciplinary Approach. London: Routledge; 2018:187-206.

55. Scaife M, Rogers $Y$, Aldrich F, Davies M. Designing for or Designing With? Informant Design for Interactive Learning Environments. In: Proceedings of the ACM SIGCHI Conference on Human Factors in Computing Systems. 1997 Presented at: CHI'97; March 22-27, 1997; Atlanta, Georgia, USA p. 343-350.

56. Moller AC, Merchant G, Conroy DE, West R, Hekler E, Kugler KC, et al. Applying and advancing behavior change theories and techniques in the context of a digital health revolution: proposals for more effectively realizing untapped potential. J Behav Med 2017 Feb;40(1):85-98.

57. Webb TL, Joseph J, Yardley L, Michie S. Using the internet to promote health behavior change: a systematic review and meta-analysis of the impact of theoretical basis, use of behavior change techniques, and mode of delivery on efficacy. J Med Internet Res 2010 Feb 17;12(1):e4.

58. Gottfredson MR. A General Theory Of Crime. Stanford: Stanford University Press; 1990.

59. Bonta J, Andrews DA. Risk-Need-Responsivity Model for Offender Assessment and Rehabilitation. Canada: Public Safety Canada; 2007. 

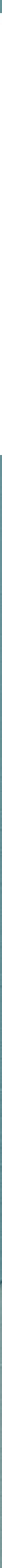


\section{॥NTERMEZZZ}

VR application

Triggers \& Helpers
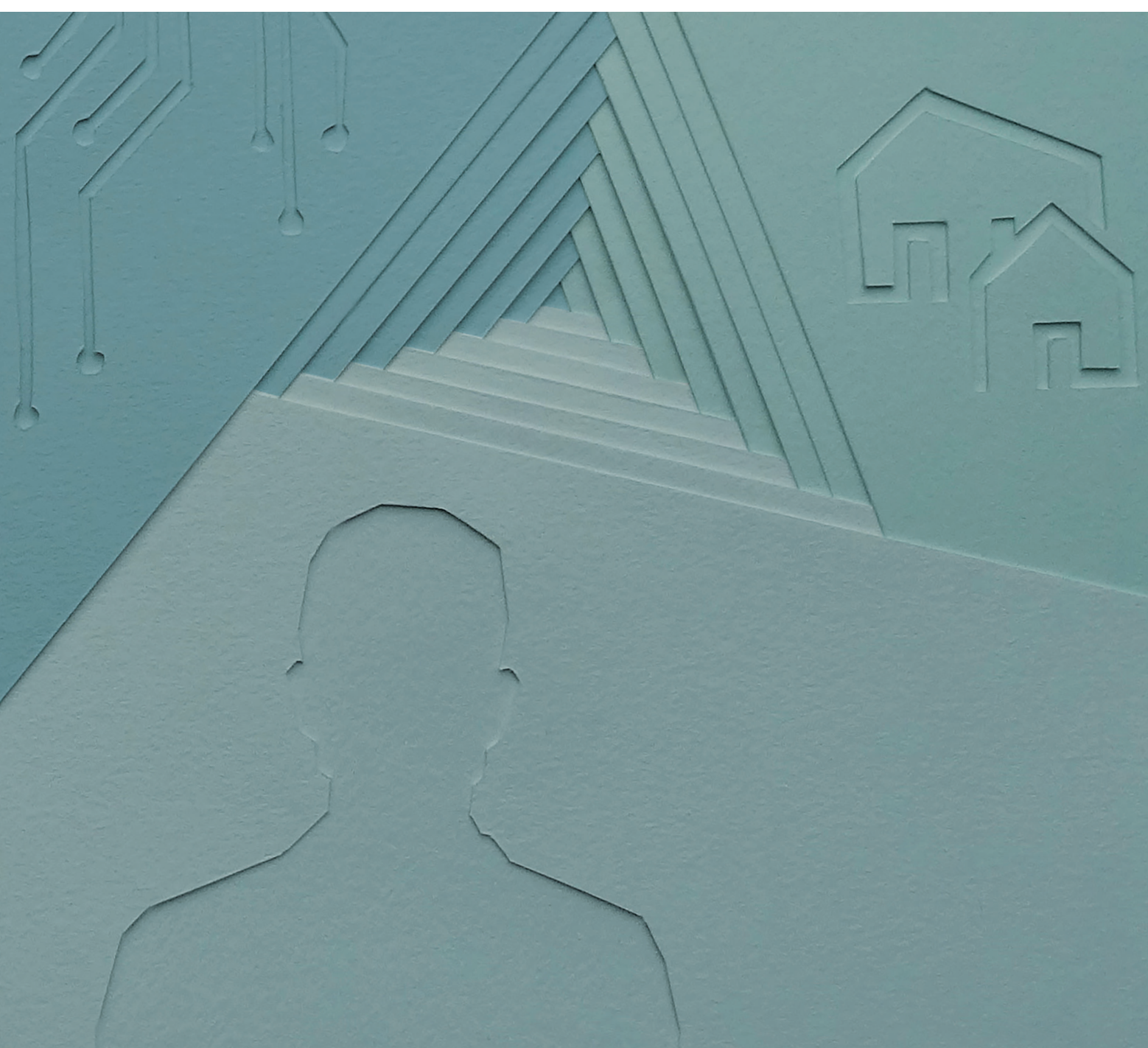


\section{Intermezzo - Explanation of the VR application 'Triggers \& Helpers'}

\section{What are triggers and helpers?}

Regardless of a forensic psychiatric patient's offense, diagnosis, or type of treatment, forensic mental healthcare always focuses on what 'triggers' a patient. In other words: what are the circumstances, situations and/or persons that increase the chances of someone (re)committing an offense? Triggers can be viewed as risk factors, which refer to variables that are associated with a higher chance of undesired, criminal behaviour. Risk factors are an important concept in treatment of offenders. To illustrate; the Risk-Need-Responsivity (RNR) model [1], which is viewed as the most influential and predominant model in forensic mental healthcare, prescribes that assessment should result in an overview of evidence-based risk factors that are relevant for an individual patient. Once identified, these specific risk factors should be targeted by means of responsive interventions in order to decrease the chance of reoffending. In general, a distinction can be made between three types of risk factors: static, stable dynamic, and acute dynamic risk factors. Static risk factors can be identified in assessment, but cannot be changed (anymore). Examples are prior offenses or job history [2]. Dynamic risk factors can be influenced, for example using cognitive behavioural therapy or social skills training. Two different types of dynamic risk factors can be identified: stable and acute dynamic risk factors. Stable dynamic risk factors can be assessed by means of risk assessment instruments and do not change on a regular (i.e. daily or hourly) basis. Examples are antisocial attitudes, substance abuse, financial problems and antisocial associates [2, 3]. Acute dynamic risk factors, on the other hand, are highly dependent on the context and state of the offender and are thus harder to assess due to their highly contextual and temporal nature. Example are a fit of rage, the access an offender has to a potential victim, intoxication, or stress $[4,5]$. Since these factors are only relevant during short periods of time and in specific situations, they are harder to target in treatment. Generally speaking, these acute dynamic risk factors can be viewed as triggers: changeable circumstances, situations and/or (behaviour of) other persons that can result in a loss of self-control and thus increase the chances on (re)offending. As opposed to static and stable dynamic risk factors, triggers do not have a predictive value for the long term, but can predict behaviour on the short term (12-48 hours) and serve as warnings of acute danger for loss of self-control and undesired behaviour. 


\section{Triggers and helpers in current treatment of offenders}

Assessment and treatment of forensic psychiatric patients are mainly focused on stable dynamic risk factors. However, it is also important to identify and intervene on triggers (or acute dynamic risk factors) in order to provide skills to the patient to deal with these challenging situations. Examples of these skills - which can be referred to as 'helpers' - are relaxation exercises, listening to soothing music, distracting oneself by playing games on a smartphone, or acquiring specific conversation skills to better deal with anger. By means of not only focusing on triggers, but also on helpers, a patient can acquire the right tools to deal with challenging situations. If, for example, a patient with aggression-regulation problems gets especially wound up by large, broad men wearing soccer shirts from a specific club who talk to them in a demeaning way, it can be very helpful to teach them to remain calm in these types of situations. Furthermore, if a patient with sensory processing issues tends to lose control in busy environments with a lot of loud noises and people, such as bars or train stations, patient and therapist can figure out ways to better cope with the overload of stimuli.

Because of the broad and diverse nature of the forensic psychiatric patient populations, there are a lot of different types of triggers and combinations of triggers. The more insight therapist and patient have in the specific triggers that are relevant for an individual, the better treatment can be tailored to the specific needs of a patient. However, it can be quite challenging to identify these triggers in standard inperson treatment sessions, which mostly consist of conversations. Amongst other things because patients can have difficulties with remembering and reflecting on their own behaviour, which can make it hard for them to identify the factors that triggered them in a specific situation. Additionally, triggers are often very context-depended and not always consciously experienced as such by patient, making it hard to pinpoint what caused an outburst. Furthermore, patients are not always entirely honest, amongst other things because they might be embarrassed, or they are afraid that specific information can incriminate them. Another challenge of current treatment is that, while patient and therapist can talk about possible ways to deal with triggers, they often cannot actually practice with the suggested coping skills (helpers) in realistic situations. All of this highlights the need for novel ways to identify triggers that contribute to undesired behaviour in an individual patient, and to help the patient in dealing with these triggers. 


\section{The possibilities of virtual reality for identifying triggers and helpers}

Virtual reality (VR) can be used to support therapist and patient in identifying relevant acute dynamic risk factors and providing patients with tools to deal with these triggers. In VR, patients can enter computer-generated environments in which realworld sensory visual and auditory perceptions are substituted with virtual ones [6]. Ideally, this will elicit a sense of presence, which is the illusion of actually being in a place, while one is physically situated in another $[7,8]$. Due to this sense of presence, patients can be virtually transferred to environments that are related to offending, such as pubs, living rooms or primary schools. An advantage of this is that, even though the virtual environment is not real, the emotions they experience are [7]. Consequently, patients can be 'triggered' in VR which results in more insights, but without endangering others. For example, different types of loud noises such as police sirens can be added to a virtual scenario, small children can walk by to see how the patient responds to this, or a therapist can try to provoke a patient in a virtual roleplay with an officer. Actually observing how a patient responds to specific triggers can be considered as a more valid approach than identifying them in retrospect in a conversation $[9,10]$. In VR, the patient and therapist gain more insight into how the patient responds to challenging situations, conversations and/or stimuli, which is expected to result in a better, more comprehensive and clearer overview of triggers.

When looking at the helpers, an important advantage of VR is that it allows the patient to practice with new behaviour [11]. Talking about coping skills such as counting to ten or walking away from a situation is 'easier said than done'; generalization of such skills to real life is often experienced as difficult [9]. In VR, a patient can continuously practice with new behaviour in a controlled setting: similar situations can be repeated, such as a conversation with a significant other in a living room, but changes can be added as well, for example screaming children in the background. This emphasis on doing instead of talking is not only beneficial for the patient; the therapist can also gain more insight into how the patient behaves and has the opportunity to give specific and relevant feedback and tips [9, 12]. A final advantage of practicing with coping with triggers in VR is related to safety. There is a paradox in treatment of offenders: on the one hand, they learn most from making mistakes and putting themselves in difficult situations, but on the other hand, this is not desirable in the real world due to the dangers this might pose for society and the offender. However, VR offers ample opportunity to practice with behaviour and make mistakes without harming anyone. 


\section{The VR application Triggers \& Helpers}

Because of the good fit between the opportunities of VR and the current challenges in identifying and improving triggers and helpers, a new intervention is being developed, called 'Triggers \& Helpers'. For this intervention, the software of CleVR is used. In this application, the patient wears a head-mounted display and noisecancelling headphones. During VR-sessions, the patient can walk through virtual environments such as a shopping street by means of a controller. Furthermore, virtual role-playing is possible by means of a voice-morphing microphone which can be used by a therapist. This makes it possible for the therapist to 'play' a broad range of virtual characters with different types of voices. Furthermore, the therapist can control the movements, facial expressions and body language of the virtual avatars by means of a 'control panel' on a laptop, and can also enable changes within virtual environments, such as adding passers-by on the street or children that enter a room. By means of this, a personalized VR scenario can be created for different types of patients. In Figures 1 and 2, screenshots of two virtual environments of CleVR are provided.

Figure 1. A screenshot of a living room in which a patient can talk to the virtual characters (C CleVR).

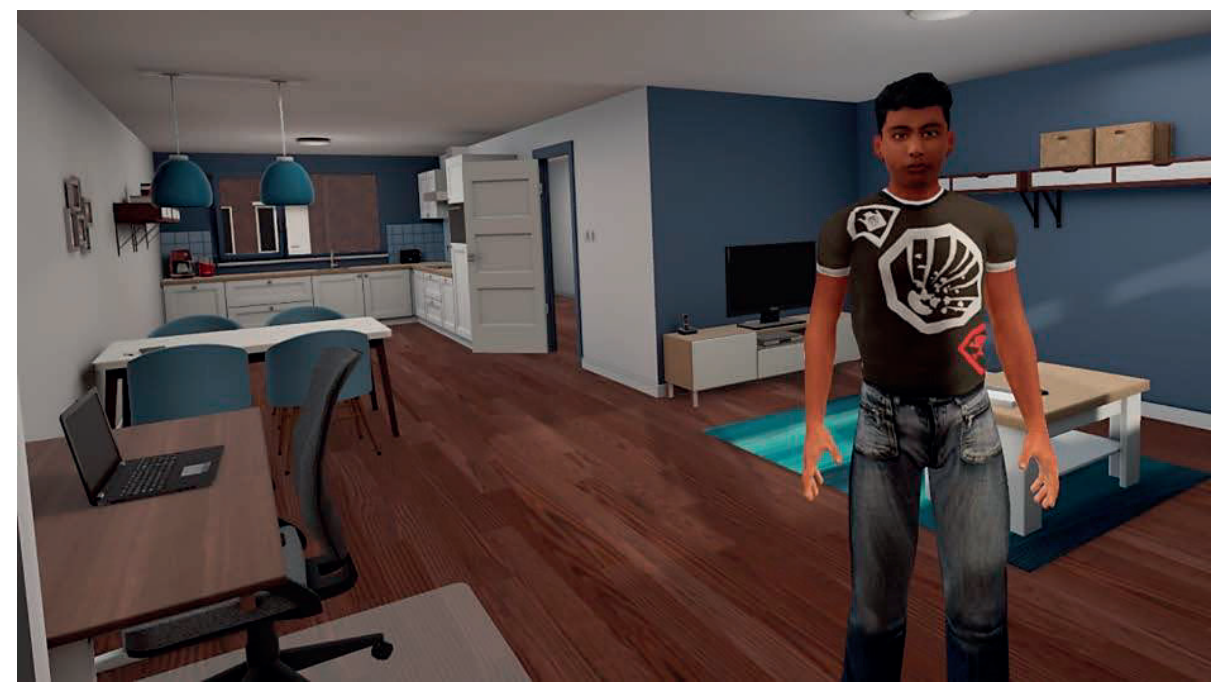


Figure 2. A screenshot of a street where patients can walk by means of a joystick and talk to virtual characters (C CleVR).

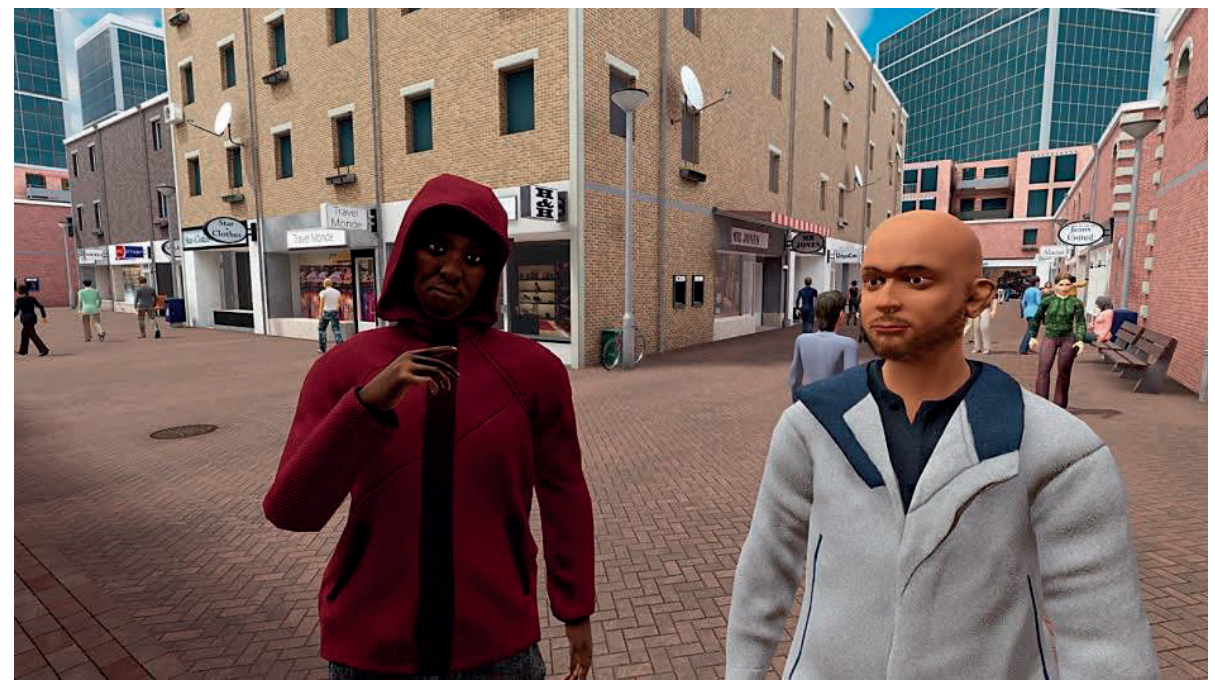

The VR application Triggers \& Helpers uses the software of CleVR. The idea for this application is developed by the interdisciplinary 'VooRuit met VR' project team, which consists of two patients, a therapist, an occupational therapist, a forensic nurse, two researchers and a policy advisor. By means of an iterative participatory development process, during which the project team continuously collected input from healthcare professionals, patients and other stakeholders such as VR designers and managers, the idea for the Triggers \& Helpers application was created $[9,12,13]$. This application is focused on creating highly personalized and flexible scenarios that can be integrated in in-person treatment sessions. Since identifying these triggers is already a part of standard treatment of all forensic psychiatric patients, the VR application has to be embedded within standard care and thus has to be used in a 'blended' way. Because of the many opportunities for personalization and the central role of triggers in treatment of all forensic psychiatric patients, this VR application can in principle be used in treatment of all patients, ranging from people with aggression regulation problems to paedophiles. Despite the major differences between patients, there still needs to be some standardization in the way in which the VR application is used, highlighting the need for a protocol that is structured yet allows for enough flexibility. For example, all therapists and patients first have to discuss the problems of a patient and possible triggers in order to collect input for a first version of a virtual scenario. 
Based on these conversations, the therapist and patient can together come up with hypotheses about a patient's triggers that later on can be tested in VR.

When the patient and therapist feel that they have enough input to start with VR, they can start building a personalized scenario via a laptop-based dashboard that guides them through the process via multiple screens in which virtual 'building blocks' can be selected. Here, shared-decision making is seen as essential, which means that the patient has to actively participate in building the scenario. Consequently, this process is not viewed as a necessary precondition for starting with $V R$, but as a part of treatment itself. First, the therapist and patient together have to decide on a virtual environment, for example a shopping street or a bar. After that, they can select virtual avatars with which the patient can converse (e.g. two broadly built men or an attractive woman), background effects (e.g. people talking loudly in the background or background music), and triggers and helpers (e.g. police sirens or a phone for distraction). In Figure 3, a prototype of the screen in which triggers and helpers can be selected is shown. Once the patient and therapist have selected all virtual building blocks and are satisfied with the scenario they built, they can start with the session. During the VR session, the therapist controls the voices and movements of one (or more) virtual avatars and can also introduce or remove specific, predetermined triggers to the scenario via the control panel. If a certain trigger is missing in this control panel, the therapist can also quickly go back to the dashboard with the virtual building blocks to make minor changes to the scenario. This highlights the highly flexible nature of the VR application: constant changes to the scenario can be made to make sure it optimally fits the triggers (and helpers) of an individual patient. Furthermore, the therapist can save a scenario, either to fully re-use it, or to be able to quickly make minor adaptations to a scenario that has been proven to be useful, such as changing the looks of a virtual avatar or adding different background music. In this way, the VR application offers the therapist and patient many tools to identify personally relevant triggers in realistic context and to practice with helpers in a controlled setting. 
Figure 3. A prototype of the screen of the dashboard in which triggers and helpers can be selected, with on the left an overview of the screens in which other virtual building blocks can be selected.

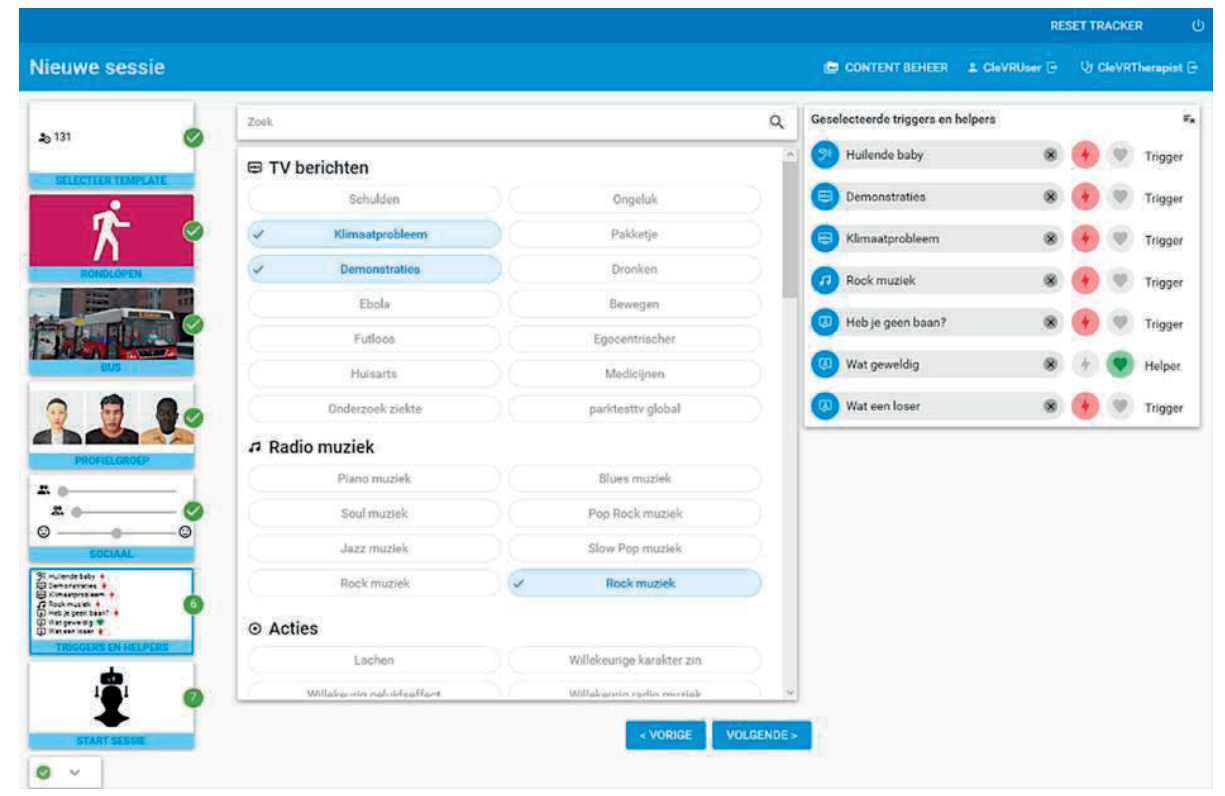




\section{References}

1. Bonta J, Andrews DA. Risk-need-responsivity model for offender assessment and rehabilitation. Rehabilitation. 2007;6(1):1-22.

2. Capaldi DM, Knoble NB, Shortt JW, Kim HK. A systematic review of risk factors for intimate partner violence. Partner abuse. 2012;3(2):231-80.

3. Ward T, Fortune C-A. The role of dynamic risk factors in the explanation of offending. Aggression and violent behavior. 2016;29:79-88.

4. Hanson RK, Harris AJ. Where should we intervene? Dynamic predictors of sexual offense recidivism. Criminal Justice and behavior. 2000;27(1):6-35.

5. Hanson RK. Stability and change: Dynamic risk factors for sexual offenders. Sexual offender treatment: Controversial issues. 2006:17-31.

6. Freeman D, Reeve S, Robinson A, Ehlers A, Clark D, Spanlang B, et al. Virtual reality in the assessment, understanding, and treatment of mental health disorders. Psychological medicine. 2017;47(14):2393-400.

7. Diemer J, Alpers GW, Peperkorn HM, Shiban Y, Mühlberger A. The impact of perception and presence on emotional reactions: a review of research in virtual reality. Frontiers in psychology. 2015;6:26.

8. Riva G, Davide F, IJsselsteijn WA. Being there: The experience of presence in mediated environments. Being there: Concepts, effects and measurement of user presence in synthetic environments. 2003;5.

9. Kip H, Kelders SM, Weerink K, Kuiper A, Brüninghoff I, Bouman YH, et al. Identifying the added value of virtual reality for treatment in forensic mental health: a scenario-based, qualitative approach. Frontiers in psychology. 2019;10:406.

10. Cornet LJ, Van Gelder J-L. Virtual reality: a use case for criminal justice practice. Psychology, Crime \& Law. 2020:1-17.

11. Klein Tuente S, Bogaerts S, Bulten E, Keulen-de Vos M, Vos M, Bokern H, et al. Virtual reality aggression prevention therapy (VRAPT) versus waiting list control for forensic psychiatric inpatients: a multicenter randomized controlled trial. Journal of Clinical Medicine. 2020;9(7):2258.

12. Kip H, Kelders SM, Van Gemert-Pijnen LJ, editors. Putting the Value in VR: How to Systematically and Iteratively Develop a Value-Based VR Application with a Complex Target Group. Proceedings of the 2019 CHI Conference on Human Factors in Computing Systems; 2019.

13. Kip H, Kelders SM, Bouman YHA, van Gemert-Pijnen LJ. The importance of systematically reporting and reflecting on eHealth development: 
Participatory development process of a virtual reality application for forensic mental health care. Journal of medical internet research. 2019;21(8):e12972. 

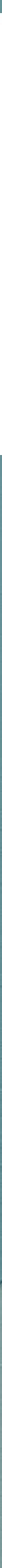


\section{PART 3}

Novel methods to evaluate eHealth

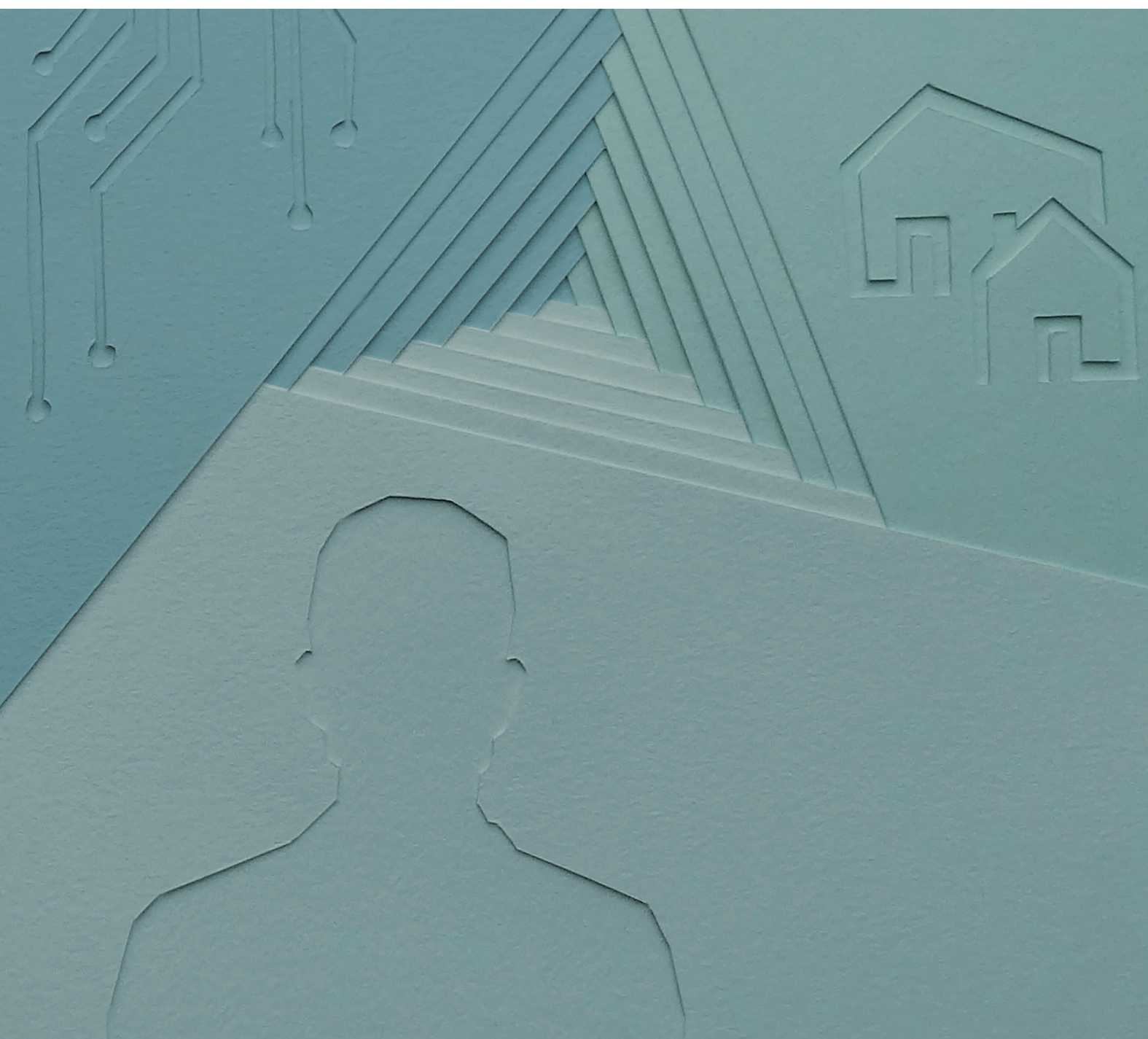





\section{Chapter 7}

Can self-control training (SCT) increase self-control and decrease aggression? Two evaluation studies to optimize a SCT app

Hanneke Kip, Marcia C. da Silva, Yvonne H.A. Bouman, Lisette van Gemert-Pijnen and Saskia M. Kelders 


\begin{abstract}
Background. Despite its potential, self-control training (SCT) has not been studied much in the context of reactive aggression. To overcome practical issues and to support users in sticking to the SCT-assignments, an app that offers SCT by asking users to use their non-dominant hand for daily tasks was developed. Based on the optimization phase of the multiphase optimization strategy (MOST) framework, two evaluation studies were conducted to optimize the app. The goal of the first study was to determine whether there was a significant increase in participants' self-control and decrease in their aggression during and after receiving SCT, either via app or email. The goal of the second study was to determine whether participants that received SCT via app or e-mail, and received either one daily task or five tasks at once, improved more in self-control and aggression compared to each other and the control group.
\end{abstract}

Methods. The first study applied a pretest-posttest design without control group ( $\mathrm{N}=$ 19), in which university students received both an app- and e-mail-based version of SCT. The second study used a $2 \times 2$ full factorial design $(N=204)$, with a control group $(N=69)$ and four experimental groups, with delivery via e-mail versus app and receiving 1 daily task versus 5 at once as factors. During respectively five and four measuring points, self-control was assessed via the Brief Self-Control Scale (BSCS) and in the second study also via the Go/No-Go task, and aggression was assessed using the Brief Aggression Questionnaire (BAQ). In both studies, open-ended questions were asked to gain insight into the interventions' points of improvement. Quantitative data were analysed using repeated measures linear mixed models. Qualitative data were analysed by means of inductive coding.

Results. In the first study, self-control and aggression improved after using the SCT intervention, but since no control group was used, no robust conclusions could be drawn. Results of the second study showed no interaction effects, but only selfcontrol of app-users improved over time; no improvements were observed in the email and control condition. No differences in aggression, and no differences between the 1 - and 5 -task conditions and control groups were found on all outcome measures. Qualitative data showed that while the opinions on the SCT-tasks differed, participants were overall satisfied with the intervention, but wanted more reminders. Conclusions. The results of both studies show that an SCT app might bolster selfcontrol, while no convincing effects on aggression were found in this student sample. Future research in populations with aggression regulation problems, such as forensic psychiatric patients, is necessary. 


\section{Introduction}

\section{Aggression and self-control}

Aggression is a complex societal problem that can take on many forms [1] that all result in a broad range of personal and societal consequences [2, 3]. Aggression can be either proactive or reactive. Proactive aggression is purposeful, non-provoked and used to gain a resource, such as power or an object, while reactive aggression refers to impulsive and uncontrolled outbursts of anger as a rection to a threat, provocation or frustration $[4,5]$. Reactive aggression is a common form of aggression that causes problems in a broad range of domains, amongst which violence against public servants; hooliganism; bullying in schools; bar fights; domestic violence; or violence within psychiatry $[3,6-8]$. Reducing reactive aggression is important yet difficult. Compared to how much research has been conducted on causes and consequences of aggression, relatively little is known about effective interventions [9]. The predominant approach in treating aggression regulation problems is the cognitive model $[10,11]$. However, while it has been helpful, meta-analyses show that effect sizes for type of treatment, based on cognitive models such as cognitive behavioural therapy, lag somewhat behind on those of other types of disorders such as anxiety and depression [12, 13]. Consequently, there is a need for more effective interventions that decrease reactive aggression [11, 14].

\section{Self-control training}

A large body of research has shown that self-control is related to reactive aggression $[15,16]$, making it into a promising focal point of aggression regulation interventions. Nevertheless, self-control is underrepresented in interventions used in clinical practice [15]. Self-control refers to the ability to prevent or override unwanted thoughts or behaviour [17]. Many studies have shown that self-control training (SCT) can strengthen self-control [18-20]. SCT is a straightforward intervention in which participants are asked to perform tasks that require self-control in order to override an impulse and replace it with a preferred response for a pre-specified period of time, often two weeks $[18,21]$. A well-studied example is the use of one's non-dominant hand for daily tasks such as brushing teeth, opening doors, or picking up items [18, 22]. The proposed working mechanism is that participants practice in repressing an automatic response and replacing it with a non-automatic response in one domain (e.g. using one's non-dominant hand), which improves self-control, and by practicing this behaviour, the effects of improved self-control can be generalized to other domains, such as aggression regulation. 
SCT has been applied to improve a broad range of behaviours driven by selfcontrol such as physical activity, school performance or quitting smoking, and proves to be an effective way to bolster self-control and reduce accompanying undesired behaviour [18-20]. Despite its potential for targeting aggression, SCT has not been studied much in context of aggression regulation. Two experimental studies that did focus on aggression applied the non-dominant hand paradigm and showed very promising results $[22,23]$. In the first study, 40 undergraduates were assigned to either SCT or a no intervention control condition for two weeks [22]. Self-control was first depleted via an attention control task. Results showed that participants reported a decrease in physical inclinations to harm their romantic partners in an experimental set-up, while no decreases in these aggressive inclinations of the control group were observed. In the second study, 70 undergraduates were included, and SCT was delivered to them in the same way as the previous study [23]. Compared to a control group, participants that followed SCT were less aggressive than participants in the control condition, which was especially true for those high in trait aggressiveness. This was assessed in a lab by means of a task in which they were given the opportunity to retaliate an actor that insulted them by blasting loud blasts of white noise. While both studies showed promising results, more research is required: not merely to replicate the effects, but also to study SCT in a larger sample, measure outcomes outside of a lab setting, and to gain more insight into how SCT works by measuring effectiveness throughout the process, as opposed to only after SCT is finished.

\section{The potential of SCT for clinical practice}

SCT has multiple relevant advantages for clinical practice. Amongst other things, it does not require a high level of cognitive skills in its users, its content is straightforward, and it is easy to administer due to its simple instructions. However, in current studies, SCT is delivered face-to-face by researchers [22, 23], implying that if it is used in practice, (healthcare) professionals should deliver SCT to patients or other participants, taking up precious time of that can also be used for other purposes. An app seems like a good solution to implement SCT in clinical practice for multiple reasons. First, an app is scalable and easy to implement since it can be accessed by many people [24] without requiring sparse time from already overworked healthcare staff. Second, technology design principles can be applied in order to support people who are not that motivated to use SCT. This is especially relevant in populations that are not motivated to participate in treatment, such as forensic psychiatric patients whose treatment is often obligatory $[25,26]$. To involve these 
types of target groups, persuasive design can be used to increase adherence and engagement to eHealth interventions [27, 28]. By adding persuasive features such as rewards, reminders and personalization to a to-be-developed SCT app, users can be supported in using the intervention as intended, resulting in more positive outcomes. Because an SCT app can increase motivation and does not require a high level of cognitive effort, it can be a suitable way to bolster self-control and thus decrease reactive aggression in hard-to-reach target groups that, amongst other things, have difficulties with reflecting on their own behaviour due to externalization such as blaming others for their aggression, and have cognitive deficits such as problems with memory and attention $[25,26]$. Since this is a novel approach towards SCT, research should determine whether using a persuasive app is indeed of added value compared to delivering SCT via written instructions.

\section{The need for further research}

To summarize, there is an obvious need for more research into SCT. First of all, studies that replicate the design used in previous studies are necessary in order to be able to draw more robust conclusions [22, 23]. Second, these types of evaluation studies should be conducted in the real world, assessing self-control during real-life instead of in a laboratory setting [18]. Third, merely determining if SCT works does not suffice: research should determine how SCT works in the most optimal way [18]. For example, in what way should the tasks of the non-dominant hand paradigm be delivered to the participants? And which tasks are most suitable for SCT? Fourth, delivering SCT via an app seems to be a feasible and effective way, but research needs to investigate whether using an app is of added value and why this is the case.

Ideally, an SCT app should be tested with the most suitable target groups such as prisoners or psychiatric patients. However, in line with recent insights on eHealth evaluation, it is important to first identify the most optimal way of delivering the intervention before putting in a lot of resources that are required for large scale evaluations in clinical practice [29]. In case of SCT, before a large-scale study can be conducted in clinical practice, it is necessary to identify the most optimal way of delivering SCT via an app. In order to answer these types of questions and to create the most optimal version of an SCT app, the aim of this current study is to evaluate the intervention and to optimize it based on the outcomes, to ensure that SCT is as efficient and effective as possible. This approach is based on the multiphase optimization strategy (MOST) framework, which is used to optimize and evaluate multicomponent behavioural interventions and contains a preparation, optimization 
and evaluation phase [29]. Before conducting a large randomized controlled trial in the third phase, the most optimal version of an intervention is designed based on an optimization criterion, based on empirical information collected by using suitable research designs such as factorial designs [30]. In order to create the most efficient and effective version of SCT in an efficient way, it is evaluated with university students, who are easier to involve in research and for whom the working mechanisms of SCT are expected to be the same as for other groups such as forensic psychiatric patients [31]. The optimized version that will result from these evaluation studies can be implemented and thoroughly evaluated in clinical practice.

\section{The current study}

This paper reports on two studies on the evaluation and optimization of an SCT app to increase self-control and reduce reactive aggression. The first study is a pilot study with a pretest-posttest design without control group. Its main goal was to identify whether there was a significant increase in participants' self-control and decrease in their aggression during and after SCT. Also, the content and way of delivering SCT, via app or e-mail, was evaluated by means of quantitative and qualitative data. The second study is a full factorial design with a control group, and was inspired by the outcomes from the first pilot study. In this second study, comparisons were made between participants that received SCT via an app or via e-mail, and between those that received one task per day or five tasks at once. The main objective was to identify whether these experimental groups improved more in self-control and aggression compared to each other and the control group. Also, points of improvement for the SCT intervention were identified using these quantitative outcomes in combination with qualitative data. Based on the findings of both studies, an optimized version of SCT can be developed which can be used and evaluated in clinical practice.

\section{Methods - study 1 Design}

The overall goal of the pretest-posttest study without control group was to identify whether there was a significant increase in participants' self-control and decrease in their aggression during and after the self-control training (SCT) using the nondominant hand paradigm. In the design of this first study, participants were randomized into two different groups to study the added value of delivering the tasks via an app (phase A) versus e-mail (phase B). In phase A, each day a new task was presented to the user via the app, and in phase $B$, an e-mail was sent with five tasks 
at once to replicate the set-up from previous studies on SCT and aggression [22, 23]. The first group was assigned to an ABA condition (i.e. app - e-mail - app), and the second group was assigned to the BAB condition. Two groups were made to account for order effects. Each phase lasted 5 days, resulting in a total of 15 intervention days. In order to gain insight into after how long SCT results in changes in self-control and aggression, participants were assessed every five days. The study design is visualized in Figure 1. Furthermore, to explore how the tasks were experienced, participants were asked to rate their performance on each task. Finally, to assess points of improvement of the app, additional qualitative data were collected by means of semistructured interviews with 10 randomly selected participants who finished the intervention. Overall, this design was used to answer the following four research questions:

1. Are there significant increases in self-control within and between the two groups over time?

2. Are there significant decreases in aggression within and between the two groups over time?

3. To what extent did participants successfully complete the tasks of the selfcontrol training?

4. What are the points of improvement of the SCT app according to the participants? 
Figure 1. Overview of the pretest-posttest study design of Study 1.

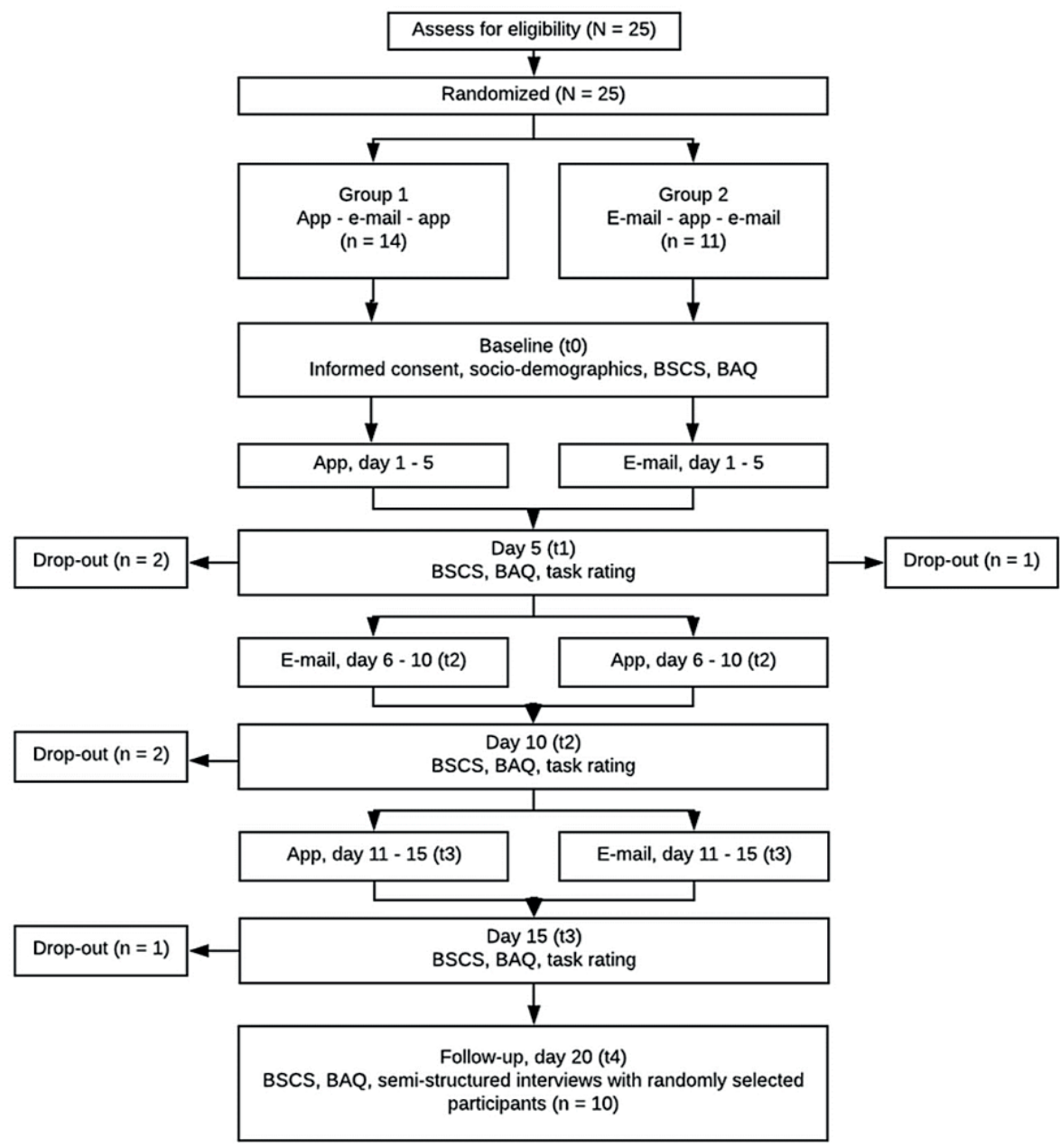

\section{Participants}

University students were invited via Sona, a test subject pool of the University of Twente where students can participate in studies in an exchange for course credits. Also, a convenience sample of students from other universities was invited via e-mail. The participants had to be at least 18 years old and had to be able to use the selfcontrol training (SCT) app for 15 consecutive days. Participants were excluded if they were unable to use their hands for daily tasks or if they were ambidextrous. This 
convenience sample resulted in 25 participants, of which 19 completed the study and were included in the analyses; six dropped out for personal reasons. Out of these 19 participants, 11 were female, all of them were right-handed and the average age was 23 years $(S D=2.50)$. Participants were mainly from the Netherlands $(n=12)$, followed by Brazil $(n=6)$ and Germany $(n=1)$. Participants were randomized to the ABA $(n=$ $9)$ and $B A B(n=10)$ condition. For the interviews that took place after the intervention period, 10 participants ( 5 from each group) were selected at random.

\section{Materials}

\section{The Hands-ON app}

For this first evaluation study, a new app that contained the self-control training via the non-dominant hand paradigm was developed [32], based on earlier studies on self-control training [18]. The app called Hands-ON was developed using methods from human-centred design: prototyping and expert-based usability tests [33]. First, a paper prototype was created based on the descriptions of the SCT in the two previous studies that applied the non-dominant hand paradigm to reduce aggression $[22,23]$. Based on this paper prototype, a functioning prototype was created on a platform designated to develop apps for research of the BMS Lab of the University of Twente (The Incredible Intervention Machine; TIIM). In the Hands-ON app, users were presented with a daily mundane task such as opening doors or picking up items, and were asked to perform it that day using their non-dominant hand. In total, there were 15 daily tasks. These tasks were partly based on the previous studies [22, 23], and partly created by the researchers. In order to support users in following the SCT as intended, persuasive elements were added [34]: reminders by sending notifications to the users twice a day to support them in remembering to perform the task; personalization by mentioning the user's name; and praise by complimenting users when they indicated they completed a task.

A think-aloud usability test with the first version of the app was conducted with six experts on eHealth design of the University of Twente: four from the Department of Psychology, Health \& Technology, and two from the Biomedical Signals and Systems. Experts were asked to think aloud while navigating through the app and afterwards answered several questions on the app's content and design. Experts evaluated the app's usability as fairly high and perceived the persuasive elements as intended. The visual design was seen as appealing, but there were minor remarks regarding the size of text and buttons. Furthermore, experts understood most of the tasks but indicated that some were too difficult or could benefit from clearer phrasing. 
Based on the outcomes of the usability test, small changes were made to the app's design; several tasks were removed; others were rephrased; and several new tasks that were suggested by the experts were added. All of this resulted in the first version of the app, of which several screenshots are presented in Figure 2 [32].

Figure 2. Screenshots of the Hands-ON app, used in Study 1.

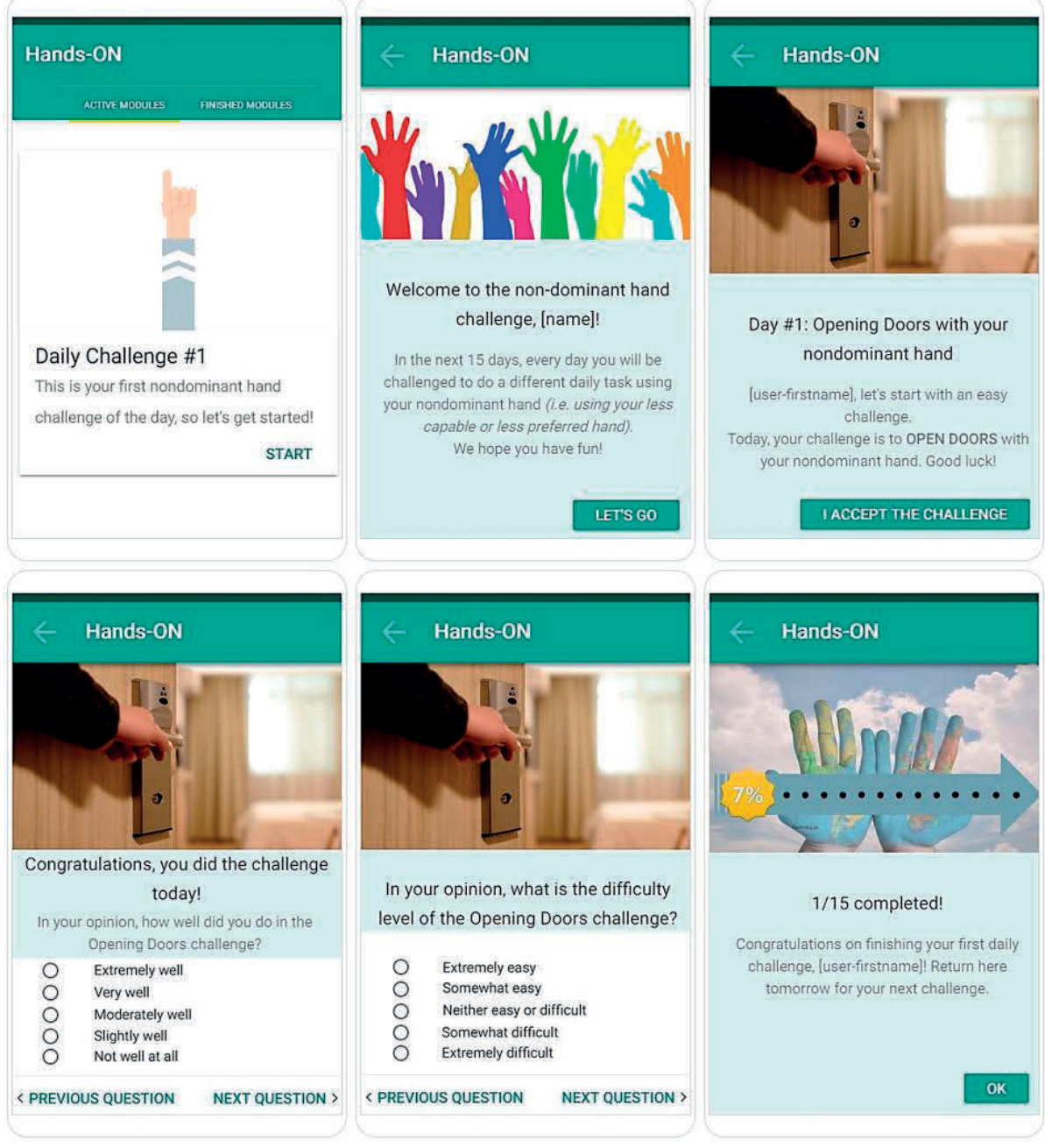

\section{E-mail self-control training}

Besides the app, self-control training was also delivered to the participants via e-mail. In this phase, participants received one e-mail with five tasks at the start of each 5day block. The e-mail contained similar instructions as the app. 


\section{Brief Self-Control Scale (BSCS)}

In order to measure self-control, the Brief Self-Control Scale (BSCS; [35]) was selected because it is a widely used and well-validated measure of self-control [36-38]. Furthermore, the BSCS is a brief self-report questionnaire that consists of 13 items [35], which means that it is easily administrable. The BSCS measures trait self-control via items with a 5-point Likert scale, where 1 refers to 'not at all' and 5 to 'extremely', so higher scores represent higher levels of self-control. Examples of items are 'I am good at resisting temptation' and 'Pleasure and fun sometimes keep me from getting work done'. At $\mathrm{t} 1$, the original version of the scale was used while at $\mathrm{t} 2, \mathrm{t} 3$, $\mathrm{t} 4$ and $\mathrm{t} 5$, slight adaptations in phrasing were added to ensure that the BSCS covered selfcontrol over the past five days. In the current study, the Cronbach's alpha of the BSCS at the five measuring moments ranged between .786 and .911, showing an overall high reliability.

\section{Brief Aggression Questionnaire (BAQ)}

Aggression was measured by the Brief Aggression Questionnaire (BAQ), a 12-item validated scale to measure trait aggression [39]. The BAQ was selected because it is validated and was used in a previous study on aggression and self-control training [23]. The BAQ measures four dimensions: physical aggression, anger, verbal aggression, and hostility. Examples of items are 'I have trouble controlling my temper' and 'Given enough provocation, I could hit another person'. Participants score the extent to which an item applies to them on a 5-point Likert scale, where 1 represents 'extremely uncharacteristic of me' and 5 'extremely characteristic of me', meaning that higher scores represent higher levels of aggression. In the current study, the Cronbach's alpha of the BAQ at the five measurement points ranged between .712 and .894 , showing an overall good reliability.

\section{Task rating}

In order to gain insight into how the tasks were perceived, participants were asked to rate their performance on all 15 tasks on a 5-points Likert-scale, in which 1 represented 'not well at all' and 5 'very well'. App-users were asked to rate the difficulty of tasks and their performance on the task on a daily basis, while participants that received the e-mails - in which all five tasks were sent at once - rated their performance on all tasks after these five days.

\section{Interview scheme}

Finally, to gain insight into experiences and points of improvements, semi-structured interviews with seven open-ended questions were conducted with 10 participants. In these interviews, general impressions and experiences with the app, differences 
between the intervention via app and e-mail, and points of improvement for the app were discussed using a predetermined interview scheme and probing questions.

\section{Procedure}

The BSCS and BAQ were assessed every five days via Qualtrics, an online survey system (see Figure 1). After filling out the baseline survey at to - including the informed consent, socio-demographic questions and the BSCS and BAQ - participants started with the intervention. They were again assessed after 5 days of using the intervention (t1), after 10 days (t2), and after 15 days (t3), as can be seen in Figure 1. Also, 5 days after completing the 15-day SCT, a post-intervention assessment was conducted (t4). Furthermore, participants were asked to rate the difficulty of the task in the app and had to indicate how well they did in the app. The one-on-one interviews with the 10 participants took approximately 30 minutes and were conducted in person $(n=5)$ or via videoconferencing $(n=5)$.

\section{Analysis}

Shapiro-Wilk and Kolmogorov-Smirnov tests showed that all scores were normally distributed. To check for differences at baseline independent sample t-tests were conducted. In order to answer the first two research questions and identify changes within and between groups over time, a repeated measures linear mixed model with time and group as a fixed factors and participants as a random factor were used, using compound symmetry as the repeated covariance structure. Scores on the BSCS and $\mathrm{BAQ}$ on $\mathrm{t} 0, \mathrm{t} 1, \mathrm{t} 2, \mathrm{t} 3$ and $\mathrm{t} 4$ were used as the dependent variable. Interaction effects showed whether the changes over time differed between groups, and main effects for time showed whether the scores of all groups changed over time. Least Significant Difference (LSD) post-hoc analyses were run to provide more insight into the outcomes by identifying significant differences between groups or measurement points. To investigate the effects of self-control training on self-control and aggression for the two separate groups, repeated measures linear mixed models with time as the only fixed factor were used for each group separately, again using compound symmetry as the repeated covariance structure. To answer the third research question, descriptive statistics of the participants' evaluation of the tasks were calculated. Finally, to answer the fourth research question, data from the semistructured interviews were coded inductively by two researchers, using the method of constant comparison [40]. 


\section{Results - study 1 \\ Self-control}

The first research question of this first study aimed to determine if changes in selfcontrol occurred over time and whether the changes in self-control differed between the two groups. The total scores and scores per group are provided in Table 1 . The BSCS scores of the two groups did not differ at baseline $(t[18]=-.902, p=.397)$.

Table 1. Means and standard deviation of the BSCS scores of Group 1 (app, e-mail, app), Group 2 (e-mail, app, e-mail) and all participants combined.

\begin{tabular}{llll}
\hline & $\begin{array}{l}\text { Group 1 ( }=9) ; M \\
\text { (SD) }\end{array}$ & $\begin{array}{l}\text { Group 2 (N = 10); } \\
(\mathrm{SD})\end{array}$ & $\begin{array}{l}\text { Total (N = 19); } \\
(\mathrm{SD})\end{array}$ \\
\hline $\begin{array}{l}\text { Baseline } \\
\text { (t0) }\end{array}$ & $39.11(10.62)$ & $42.10(10.34)$ & $40.68(10.30)$ \\
5 days (t1) & $44.78(8.48)$ & $43.10(6.06)$ & $43.90(7.15)$ \\
10 days (t2) & $45.44(8.90)$ & $49.50(5.93)$ & $47.58(7.56)$ \\
15 days (t3) & $44.00(11.10)$ & $49.40(8.02)$ & $46.84(9.73)$ \\
Post (t4) & $43.00(9.19)$ & $49.50(10.50)$ & $46.42(10.19)$ \\
\hline
\end{tabular}

The repeated measures linear mixed model showed no significant interaction effect between time and group $(F[4,68,000]=.928, p=.349)$, meaning that the changes over time did not differ between the two groups. A main effect for time was identified $(F[4,68,000]=5.606, p=.001)$, which shows that the BSCS scores of all participants increased over time. No main effect for group was found $(F[1,17]=.928, p=.001)$, which means that there were no differences between both groups on all BSCS scores. LSD post hoc analyses showed a significant increase of self-control scores between t0 and all four other measuring points, with mean differences ranging between 3.33 and 6.87, and $p$-values ranging between .049 and $<.001$. Furthermore, a significant increase was identified between t1 and t2 ( $M=3.53$ [Cl95 . 215, 6.85), $p=.037$ ).

When zooming in on changes over time in the two separate groups, Figure 3 shows that the increase of the scores of Group 2 (e-mail, app, e-mail) seems to be somewhat higher than those of Group 1 (app, e-mail, app). To further investigate this, a repeated linear mixed model with only time as a fixed factor was performed for each group separately. For Group 1 (app, e-mail, app), no main effect of time was found $(F[4,32.000]=1.849, p=.144)$, but for Group 2 (e-mail, app, e-mail), a main effect of time was identified $(F[4,36.000]=6.331, p=.001)$. This shows that the self-control scores of Group 2 improved significantly over time, but not for Group 1. 
Figure 3. The BSCS scores of Group 1 (app, e-mail, app) and Group 2 (e-mail, app, email) over time.

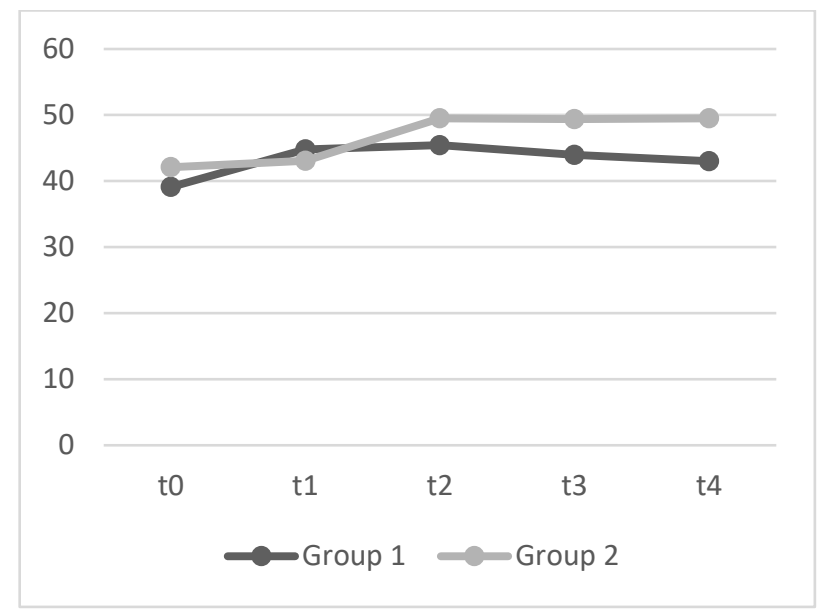

\section{Aggression}

Research question 2 aimed to identify differences within and between groups over time on aggression as measured by the BAQ. The average scores per group and for all participants are provided below in Table 2. The scores at baseline did not differ per group $(t[18]=.087, p=.932)$.

Table 2. Means and standard deviation of the BAQ scores of Group 1 (app, e-mail, app), Group 2 (e-mail, app, e-mail) and all participants combined.

\begin{tabular}{llll}
\hline & $\begin{array}{l}\text { Group 1 }(\mathrm{n}=\text { 9); } \mathrm{M} \\
(\mathrm{SD})\end{array}$ & $\begin{array}{l}\text { Group 2 }(\mathrm{n}=10) ; \mathrm{M} \\
(\mathrm{SD})\end{array}$ & $\begin{array}{l}\text { Total } \\
(\mathrm{SD})\end{array}$ \\
\hline $\begin{array}{l}\text { Baseline } \\
\text { (t0) }\end{array}$ & $28.56(7.23)$ & $28.60(7.56)$ & $28.58(7.20)$ \\
5 days (t1) & $25.44(6.50)$ & $22.80(5.39)$ & $24.05(5.93)$ \\
10 days (t2) & $26.33(7.68)$ & $23.50(7.77)$ & $24.84(7.65)$ \\
15 days (t3) & $25.89(9.29)$ & $21.50(7.56)$ & $23.58(8.49)$ \\
Post (t4) & $26.44(9.33)$ & $20.90(7.75)$ & $23.53(10.19)$ \\
\hline
\end{tabular}

A repeated measures linear mixed model showed no significant interaction effects between time and group $(F[4,68.000]=.864, p=.490)$, meaning that there were no differences between groups in changes in aggression over time. A significant main effect for time was identified $(F[4,68.000]=3.311, p=.015)$, which means that the 
BAQ scores of all participants decreased significantly over time. No significant main effect for group was found $(F[1,17], p=.300)$, meaning that all BSCS scores did not differ between groups. LSD post-hoc tests showed that the BAQ scores on t0 were significantly higher than those of all other four measurement moments, with a mean difference ranging between 3.661 and 4.09, and p-values ranging between .003 and .026. No other differences were observed, which indicates that the scores on baseline were significantly higher than all other scores.

As can be seen in Figure 4, the decrease of BAQ scores of Group 2 (e-mail, app, e-mail) seems to be somewhat larger than the decrease of Group 1 (app, e-mail, app). Post hoc analyses in which a linear mixed model with only time as a fixed factors were used for each group separately indeed showed no significant main effect of time for Group $1(F[4,32.000]=.560, p=.693)$, while a significant main effect for time was found for Group $2(F[4,36.000]=3.642, p=.014)$.

Figure 4. The BAQ scores of Group 1 (app, e-mail, app) and Group 2 (e-mail, app, email) over time.

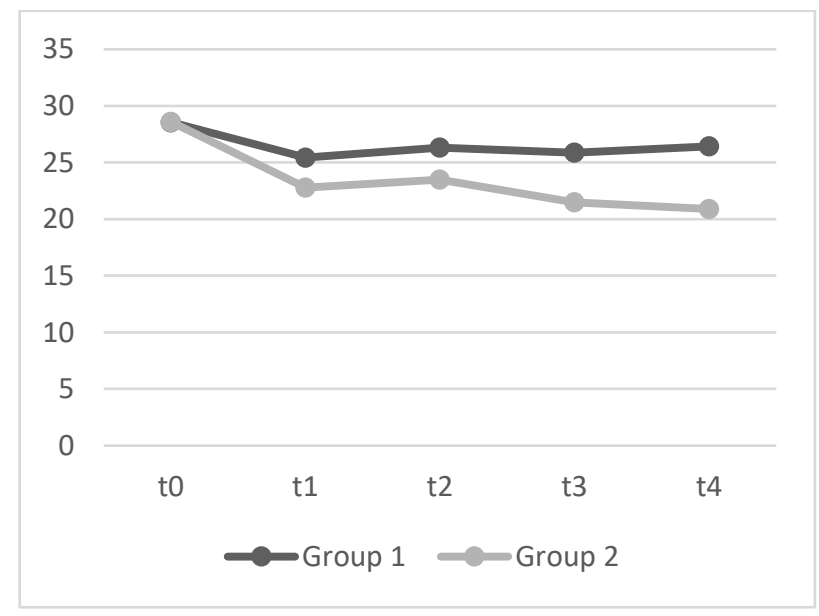

\section{Performance on tasks}

The third research question aimed to determine the extent to which participants successfully completed the tasks that they had to perform with their non-dominant hand. A broad range of scores on performance on the 15 tasks was observed, in which the task on which participants performed worst was rated with an average score of 2.0, and the highest with a 4.25. The average score for all tasks was 3.22, indicating that on average, participants indicated that they did fairly well in performing the tasks. 
In Table 3, the average scores for each condition per group are provided. For these groups, the tasks were the same at each point in time, but the way of delivering them differed (app or e-mail). While the average scores in the three app phases $(M=3.26$, $S D=.80)$ were slightly higher than those of the three e-mail phases $(M=3.02, S D=$ $.16)$, this difference was not significant ( $t[49], p=.811$ ).

Table 3. The average rating participants gave to how well they did in a task per phase.

\begin{tabular}{llll}
\hline & Day 0 - Day 5; & Day 6-Day 10; & Day 11-Day 15; \\
& $\mathrm{M}(\mathrm{SD})$ & $\mathrm{M}(\mathrm{SD})$ & $\mathrm{M}(\mathrm{SD})$ \\
\hline Group 1 & $3.66(.75)$ & $2.95(.78)$ & $3.53(1.07)$ \\
& App & E-mail & App \\
Group 2 & $3.50(1.00)$ & $3.14(.65)$ & $2.46(.62)$ \\
& E-mail & App & E-mail \\
\hline
\end{tabular}

\section{Suggestions from users}

The fourth and final research question of this first study aimed to provide insight into points of improvement. Inductive analysis resulted in four main codes, which are briefly explained below.

\section{Perceptions of the intervention}

Most of the 10 interviewed participants $(n=6)$ noticed changes in their cognitions during the intervention. They indicated that they had to be more conscious about their daily tasks to remember and perform them with the non-dominant hand. One participant said: "I had to use other functions of my brain that I felt like they were asleep. I had to pay more attention to the things I did in my daily life (pp. 6)".

\section{Comparison between the app and e-mail instructions}

In general, participants preferred the app over the e-mail instructions ( $n=8)$, mainly because the app sent them reminders to support the use of the non-dominant hand. One participant said the following about it: "I prefer the app because I use my phone every day (...) the app is more convenient (pp. 9)". Two participants reported not having a preference.

\section{Bugs in the app}

Four participants experienced different bugs while using the app. The errors varied from unusable (one participant could not log in temporarily), moderate (on the evaluation page of the activity of the day, one participant had problems with the keyboard that did not appear), and annoying, i.e. only an intermittent bug (for one user, the app stopped working and closed automatically once or twice). Overall, 
participants considered the bugs not severe, as stated: "Only once it bugged (...), I could not type. But otherwise, everything was normal. I really enjoyed it (pp. 2)".

Points of improvement

All in all, participants considered the app easy to use and well designed. The instructions to perform the tasks were easy to understand and they liked participating in the intervention. However, there were several points of improvement. Most participants $(n=6)$ said they would like to have at least one more reminder during the day. Also, in their opinion, the app could be more visually attractive. Another point raised was the need for more personalization: users wanted to choose how many and which tasks to accomplish each day, and they also wanted to follow their personal progress better, as one participant stated: "I'd definitely make sure it tracks progress (...) so you'd see which tasks you've done and if you're doing great or not (pp. 4)". 


\section{Methods - study 2 \\ Design}

The first study showed slight differences between the group that used the e-mail version two times instead of one. Besides the difference of the delivery mode between app and e-mail, another difference was that participants in the e-mail condition received the five tasks at once, while app-users received daily tasks. Consequently, the second study aimed to investigate differences between receiving training through app or e-mail, and between receiving one daily task or all five tasks at once to determine the most optimal way of delivering SCT. Finally, the first study did not have a control group, so we cannot ascribe the improvements in self-control and aggression directly to the intervention. The main goal of this second study was to determine whether SCT is more effective for groups using the app or e-mail compared to a control group, and for groups that receive daily tasks or five tasks at once, again compared to a control group. A 2x2 full factorial design was used to compare the effects of the app versus e-mail, and one daily task versus five tasks at once. The research questions were:

1. Are there differences between the improvements over time on self-control and aggression between the group that received SCT via an app, via e-mail, and the control group?

2. Are there differences between the improvements over time on self-control and aggression between the group that received one daily task, five tasks at once, and the control group?

3. What are the experiences with and points of improvement of the SCT intervention according to the participants?

In order to answer these research questions, four experimental conditions and one control group were used. The levels of the factors were app versus e-mail, and daily tasks versus five tasks at once. The structure of this design is provided in Figure 5. In order to answer the third research question, all participants were asked to answer several open-ended questions in the final questionnaire at post-intervention assessment. 
Figure 5. An overview of the $2 \times 2$ full factorial design of Study 2.

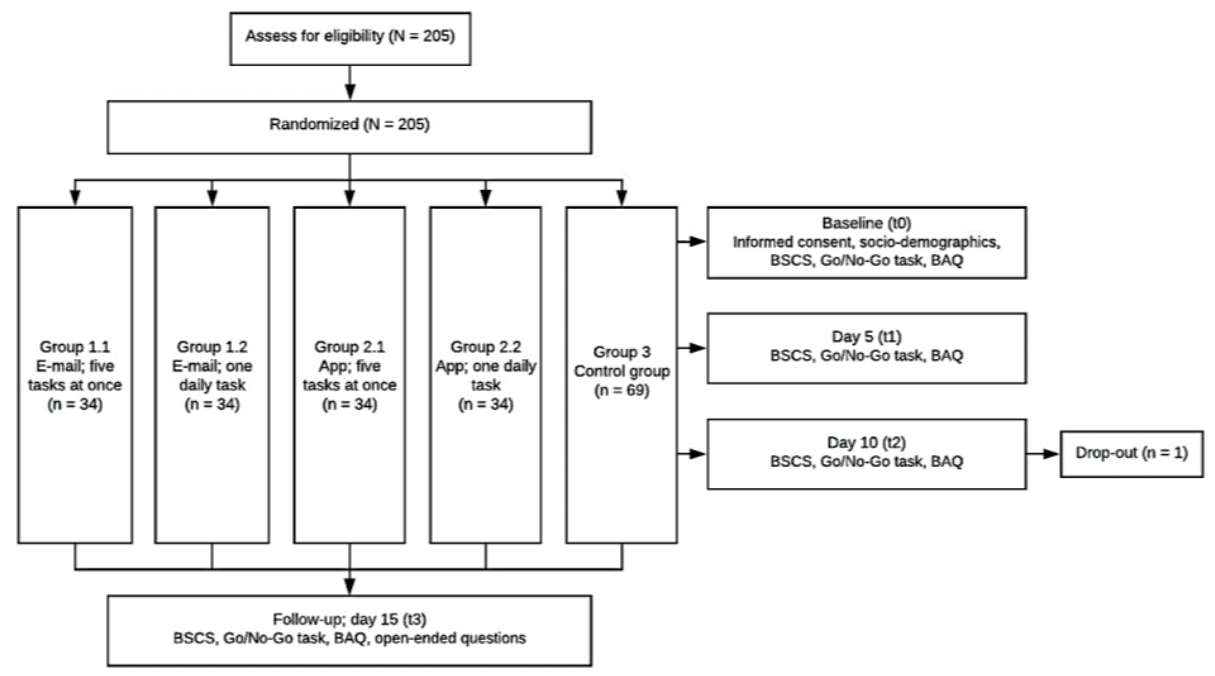

\section{Participants}

For Study 2, recruitment took place via Sona, a test subject pool of the University of Twente, via which students from social sciences can participate in studies in an exchange for course credits. As was the case in Study 1, the participants had to be at least 18 years old and had to be able to use the self-control training (SCT) app for 10 consecutive days. Participants were excluded if they were unable to use their hands for daily tasks or if they were ambidextrous. This convenience sample resulted in a total of 205 participants who started the study, of which 204 filled out the questionnaires in the follow-up measurement at $\mathrm{t} 3$ and were included in the analyses. However, not all participants filled out all questionnaires. Most of the participants were psychology students (85.80\%), the remaining 27 students studied communication science (13.20\%). Out of these 204 students, whose mean age was 20.33 (SD = 2.35), $143(70.10 \%)$ were female, 59 male $(28.90 \%)$ and 2 preferred not to answer (1\%). Most students (77.50\%) were German, $16.70 \%$ was Dutch, and $5.90 \%$ had a different nationality. Finally, for most participants, the right hand was their dominant hand (89.70\%). 


\section{Materials}

\section{The HandSwitch app}

Based on the outcomes of the first study, several minor changes were made to the design and content of the app. This adapted version was again developed in the TIIM. The most apparent change was the name of the app, based on advice of experts in forensic psychiatry where the app might be used after its optimization, because the term 'hands on' has different associations in that domain. Consequently, its name was changed into HandSwitch. This gave rise to changes in design, which can be seen in Figure 6. Besides changes to the app's design, several adaptations to its content were made based on the findings of the first study. Two reminders a day were added ( 8 a.m. and 8 p.m.). Tasks that were too hard to execute were removed based on scores of participants and outcomes of the semi-structured interviews. Furthermore, because in Study 1, changes in self-control were observed already after five days, it was decided to shorten the SCT's duration to only 10 days to make it as efficient as possible. Finally, because of the factorial design, two different versions of the app were made: one in which one daily task was provided, and one in which all five tasks were presented at once.

\section{E-mail self-control training}

As was the case in study 1, an e-mail version of SCT was used as well. There were two different e-mail conditions. In one condition, participants received an e-mail with all five tasks at once. In the other condition, they received five daily e-mails, each containing a new task. As soon as the participant was allocated to one of the two conditions, the e-mails were scheduled to be sent automatically at the correct days and times. It was explicitly mentioned that, if necessary, participants could contact the researcher with questions about the intervention. Furthermore, several images that were used in the app were added to the e-mail as well (e.g. the witch). 
Figure 6. Screenshots of the HandSwitch app, used in Study 2.

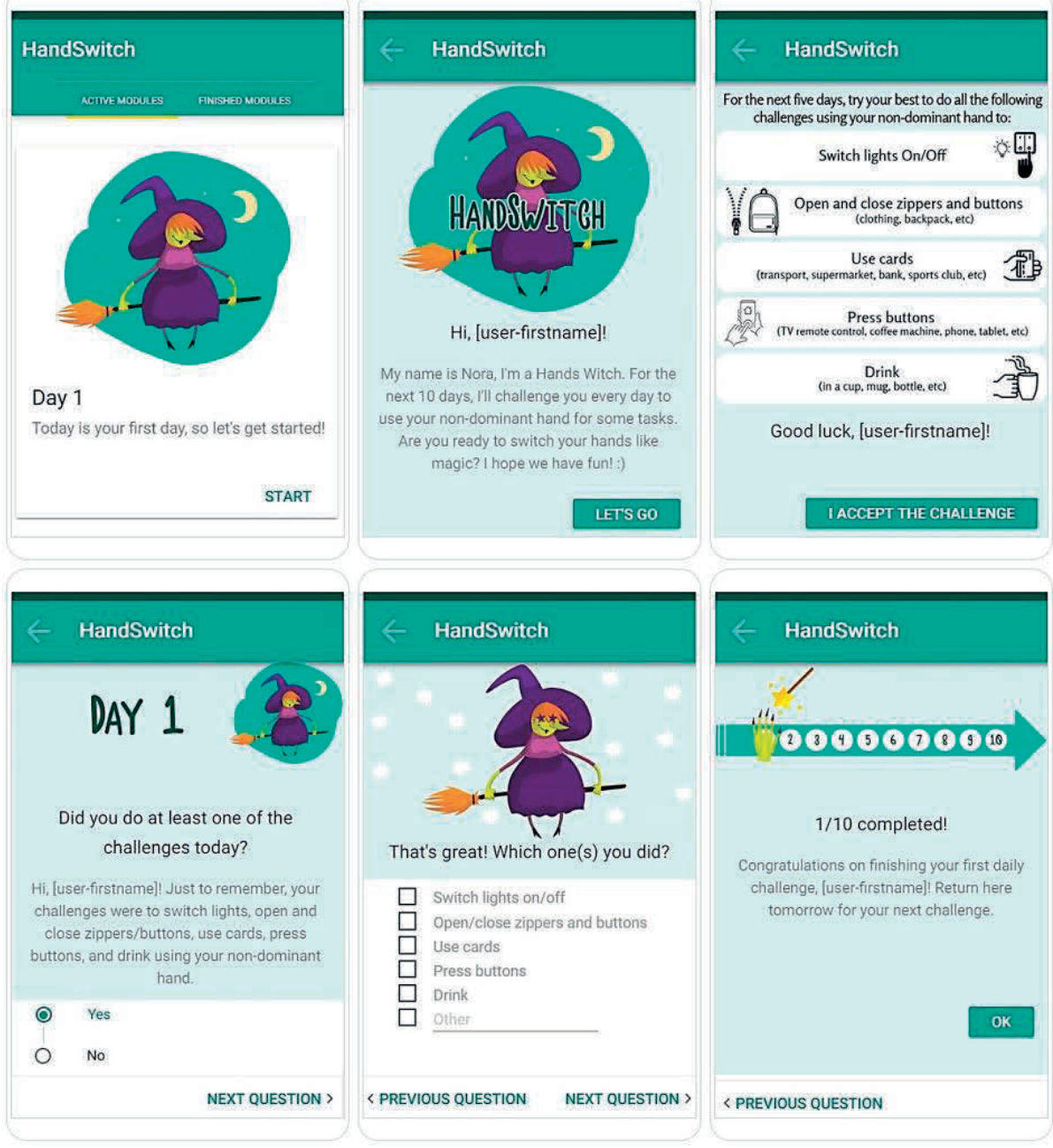

\section{Brief Self-Control Scale (BSCS) and Brief Aggression Questionnaire (BAQ)}

In this second study, the BSCS and BAQ were again used. In this study, the Cronbach's alpha of the four measurements of the BSCS ranged between .790 and .852, showing a good internal consistency at all measuring moments. The Cronbach's alpha of all four BAQ measurements ranged between .661 and .773. Only at t0 the alpha of .661 was considered low, while at the other three moments it can be considered as good.

\section{Go/No-Go task}

A large meta-analysis on self-control measures indicated that self-control is best assessed using multiple methods since it is a complex, multidimensional construct 
[36]. In line with these recommendations, self-control was also measured with an executive function task. The Go/No-Go task is a well-studied measure of cognitive control and has been used in previous research to assess self-control [36]. In the Go/No-Go task, participants are instructed to respond to target stimuli, but have to refrain from responding to non-target stimuli, which requires suppressing a behavioural response. In the current study, the average reaction time was calculated, in which shorter reaction times represent higher levels self-control.

\section{Experiences and task performance}

To gain insight into the experiences of the participants, three open-ended questions were asked in the final assessment at t3. Participants were asked to (1) explain whether they experienced any effects on self-control; (2) what their opinion of the intervention was; and (3) what points of improvements they identified. Furthermore, participants indicated for all 10 tasks whether it should be removed and - if they wished to remove it - why this was the case. For each task, they were asked to rate on a 5-point Likert scale how well they did on the task, where 1 represented very bad and very difficult respectively, and 5 very good and very easy. Finally, participants were asked to suggest other tasks that could be incorporated in the intervention.

\section{Procedure}

Participants were informed about the goal of the study in general terms; self-control was not explicitly mentioned to prevent bias. As can be seen in Figure 5, after providing informed consent, participants were assessed four times: once directly before starting with SCT (t0), twice during SCT (t1 \& t2), and once five days after completing SCT (t3). At all measuring points, the BSCS, Go/No-Go task and BAQ were completed via Qualtrics. Filling out the questionnaires took on average 15 minutes. Also, app users were asked to rate their performance and tasks in the app itself, while participants who received e-mails were asked to rate these via Qualtrics. Participants in the control conditions only received e-mails with an invitation to fill out the questionnaires. In the final questionnaire at $\mathrm{t} 3$, participants in the e-mail and app conditions were asked to answer three open-ended questions on the intervention in Qualtrics.

\section{Analysis}

An a priori power analysis was conducted with $G^{*}$ Power, with a medium effect size ( $d$ $=.40$ ), a ß-power of 0.8, an alpha of .05 and an independent two-sided t-test to evaluate the main outcome. Results showed that a total sample of 176 participants 
with each main condition requiring 59 participants. Data were analysed using IBM SPSS software (version 24.0) and significance was accepted at .05. In order to check for differences at baseline on outcomes of the three measures, one-way betweensubjects ANOVAs were used.

Due to the full factorial design of this study, the same analyses were conducted twice: once comparing the control group with participants receiving the SCT via app versus the participants that received SCT via e-mail, and once comparing the control group with the participants that received 1 task per day or 5 tasks at once. To account for autocorrelation within participants, repeated measures linear mixed models were used. Compound symmetry was used as the repeated covariance structure as this structure showed the best fit for the data across different models. Scores on the BSCS and BAQ and average reaction times of the Go/No-Go tasks on t0, t1, t2 and t3 were used as the dependent variable. Time and group were used as fixed factors, along with their interactions, and participants were modelled as random factor. Interaction effects showed whether the changes over time differed between groups, and main effects for time showed whether the scores of all participants changed over time. LSD post-hoc analyses were run to provide more insight into the outcomes by identifying significant differences between groups and changes over time. To investigate the effects of SCT on self-control and aggression for each separate group, repeated measures linear mixed models with time as the only fixed factor were used for each group, again using compound symmetry as the repeated covariance structure.

In order to answer the third research question on points of improvement, the written answers to the open-ended questions were analyzed inductively by two researchers, using the method of constant comparison [40]. Descriptive statistics were used to provide an overview of how many participants wanted to remove a task from the intervention. 


\section{Results}

\section{Descriptive statistics and baseline assessment}

In Table 4 the average scores and standard deviations for all groups are provided for the three measures. No significant differences on baseline (t0) of the scores of the $\operatorname{BSCS}(F[2,201]=1.359, p=.259)$ and $\operatorname{BAQ}[F(2,199)=.070, p=.932]$ were found for app, e-mail and control group, meaning that all groups showed comparable baseline levels of self-control and aggression. A significant difference was found on the baseline scores of the mean reaction times of the Go/No-Go task $(F[2,202]=3.283$, $p=.04)$. LSD post hoc analyses showed that the mean difference of the scores of the app group in milliseconds was significantly lower than that of the e-mail group $(M=-$ 44.26 [Cl95 -78.37, -10.13], $p=.011$ ). However, the used repeated measure linear mixed model corrects for these differences at baseline by using the group to which the participants were assigned as a fixed factor. Furthermore, for the 1 task, 5 tasks and control group, no significant differences on baseline (t0) were found for the scores on the $\operatorname{BSCS}(F[2,202]=1.417, p=.245]$; the average reaction times on the Go/No-Go task $(F[2,202]=.064, p=.938)$; and the BAQ scores $(F[2,200]=.010, p=$ .990). This shows that these groups had similar baseline levels of self-control and aggression.

Table 4. Descriptive statistics of the scores on the Brief Self-Control Scale (BSCS), the Go/No-Go task and Brief Aggression Questionnaire (BAQ) for all groups.

\begin{tabular}{|c|c|c|c|c|c|c|}
\hline $\begin{array}{l}\text { Main } \\
\text { group }\end{array}$ & $\mathrm{n}$ & $\begin{array}{l}\text { to (M; } \\
\text { SD) }\end{array}$ & $\mathrm{t1}(\mathrm{M} ; \mathrm{SD})$ & $\begin{array}{l}\text { t2 (M; } \\
\mathrm{SD})\end{array}$ & $\begin{array}{l}\text { t3 (M; } \\
S D)\end{array}$ & $\begin{array}{l}\text { Difference } \\
\text { t3 - to (M; } \\
S D)\end{array}$ \\
\hline \multicolumn{7}{|c|}{ Brief Self-control Scale (BSCS) } \\
\hline E-mail & 68 & $\begin{array}{l}\text { 41.38; } \\
6.32\end{array}$ & $\begin{array}{l}\text { 41.71; } \\
6.98\end{array}$ & $\begin{array}{l}\text { 42.04; } \\
7.73\end{array}$ & $\begin{array}{l}\text { 41.62; } \\
6.77\end{array}$ & $.24 ; 6.17$ \\
\hline App & 67 & $\begin{array}{l}\text { 41.78; } \\
8.22\end{array}$ & $\begin{array}{l}42.85 \\
6.93\end{array}$ & $\begin{array}{l}\text { 44.07; } \\
8.04\end{array}$ & $\begin{array}{l}\text { 44.18; } \\
7.92\end{array}$ & $2.39 ; 6.33$ \\
\hline 5 tasks & 66 & $\begin{array}{l}42.12 ; \\
6.99\end{array}$ & $\begin{array}{l}42.70 \\
6.49\end{array}$ & $\begin{array}{l}43.33 ; \\
8.27\end{array}$ & $\begin{array}{l}43.41 ; \\
7.32\end{array}$ & $1.28 ; 6.23$ \\
\hline 1 task & 68 & $\begin{array}{l}41.07 \\
7.73\end{array}$ & $\begin{array}{l}41.75 \\
7.46\end{array}$ & $\begin{array}{l}42.69 ; \\
7.65\end{array}$ & $\begin{array}{l}42.37 ; \\
7.65\end{array}$ & $1.29 ; 6.51$ \\
\hline Control & 69 & $\begin{array}{l}40.07 ; \\
6.76\end{array}$ & $\begin{array}{l}39.68 \\
7.06\end{array}$ & $\begin{array}{l}40.56 ; \\
7.93\end{array}$ & $\begin{array}{l}41.51 ; \\
7.51\end{array}$ & $1.43 ; 6.81$ \\
\hline
\end{tabular}




\begin{tabular}{|c|c|c|c|c|c|c|}
\hline Total & 204 & $\begin{array}{l}41.07 ; \\
7.15\end{array}$ & $\begin{array}{l}\text { 41.40; } \\
7.08\end{array}$ & $\begin{array}{l}42.21 ; \\
8.0\end{array}$ & $\begin{array}{l}42.42 ; \\
7.51\end{array}$ & $1.35 ; 6.47$ \\
\hline \multicolumn{7}{|c|}{$\begin{array}{l}\text { Go/No-Go } \\
\text { milliseconds) }\end{array}$} \\
\hline E-mail & 68 & $\begin{array}{l}241.56 \\
115.48\end{array}$ & $\begin{array}{l}202.59 \\
112.68\end{array}$ & $\begin{array}{l}\text { 165.76; } \\
76.24\end{array}$ & $\begin{array}{l}166.64 ; \\
102.50\end{array}$ & $\begin{array}{l}-74.92 \\
107.40\end{array}$ \\
\hline App & 67 & $\begin{array}{l}\text { 197.30; } \\
89.07\end{array}$ & $\begin{array}{l}143.33 ; \\
70.60\end{array}$ & $\begin{array}{l}149.55 \\
78.71\end{array}$ & $\begin{array}{l}\text { 138.25; } \\
79.31\end{array}$ & $\begin{array}{l}-57.09 \\
82.79\end{array}$ \\
\hline 5 tasks & 65 & $\begin{array}{l}221.83 ; \\
96.35\end{array}$ & $\begin{array}{l}\text { 185.36; } \\
98.90\end{array}$ & $\begin{array}{l}\text { 197.06; } \\
112.46\end{array}$ & $\begin{array}{l}167.93 \\
109.16\end{array}$ & $\begin{array}{l}-58.45 \\
95.23\end{array}$ \\
\hline 1 task & 68 & $\begin{array}{l}216.64 ; \\
103.76\end{array}$ & $\begin{array}{l}\text { 156.68; } \\
82.64\end{array}$ & $\begin{array}{l}150.22 \\
79.70\end{array}$ & $\begin{array}{l}\text { 143.12; } \\
91.32\end{array}$ & $\begin{array}{l}-73.52 ; \\
97.73\end{array}$ \\
\hline Control & 69 & $\begin{array}{l}221.83 ; \\
96.35\end{array}$ & $\begin{array}{l}\text { 185.36; } \\
98.90\end{array}$ & $\begin{array}{l}\text { 197.06; } \\
112.46\end{array}$ & $\begin{array}{l}167.92 \\
109.16\end{array}$ & $\begin{array}{l}-53.91 ; \\
109.05\end{array}$ \\
\hline Total & 204 & $\begin{array}{l}220.24 ; \\
102.02\end{array}$ & $\begin{array}{l}\text { 177.13; } \\
98.42\end{array}$ & $\begin{array}{l}\text { 171.02; } \\
92.53\end{array}$ & $\begin{array}{l}157.75 \\
98.44\end{array}$ & $\begin{array}{l}-61.96 \\
100.52\end{array}$ \\
\hline \multicolumn{7}{|c|}{ Brief Aggression Questionnaire (BAQ) } \\
\hline E-mail & 68 & $\begin{array}{l}30.19 ; \\
5.60\end{array}$ & $\begin{array}{l}26.31 ; \\
6.08\end{array}$ & $\begin{array}{l}26.28 ; \\
6.27\end{array}$ & $\begin{array}{l}25.78 \\
6.29\end{array}$ & $-4.41 ; 6.53$ \\
\hline App & 67 & $\begin{array}{l}29.99 ; \\
5.27\end{array}$ & $\begin{array}{l}27.79 \\
5.32\end{array}$ & $\begin{array}{l}26.75 \\
5.92\end{array}$ & $\begin{array}{l}26.45 \\
5.66\end{array}$ & $-3.64 ; 4.94$ \\
\hline 5 tasks & 65 & $\begin{array}{l}29.94 ; \\
5.66\end{array}$ & $\begin{array}{l}27.52 \\
5.82\end{array}$ & $\begin{array}{l}27.38 \\
6.58\end{array}$ & $\begin{array}{l}26.80 \\
6.10\end{array}$ & $-3.22 ; 6.03$ \\
\hline 1 task & 65 & $\begin{array}{l}30.25 \\
5.29\end{array}$ & $\begin{array}{l}26.71 ; \\
5.71\end{array}$ & $\begin{array}{l}25.87 ; \\
5.46\end{array}$ & $\begin{array}{l}25.67 \\
5.77\end{array}$ & $-4.63 ; 5.43$ \\
\hline Control & 69 & $\begin{array}{l}30.12 ; \\
5.87\end{array}$ & $\begin{array}{l}26.33 ; \\
6.67\end{array}$ & $\begin{array}{l}26.75 \\
6.77\end{array}$ & $\begin{array}{l}27.22 \\
7.29\end{array}$ & $-2.88 ; 6.32$ \\
\hline Total & 204 & $\begin{array}{l}30.10 \\
5.56\end{array}$ & $\begin{array}{l}26.81 ; \\
6.06\end{array}$ & $\begin{array}{l}26.59 \\
6.30\end{array}$ & $\begin{array}{l}26.49 \\
6.45\end{array}$ & $-3.64 ; 5.98$ \\
\hline
\end{tabular}

\section{App versus e-mail versus control group}

\section{Self-control: BSCS}

A repeated measure linear mixed model showed no significant overall interaction effects between time and group $(F[2,807.713]=8.75, p=.417)$. However, a significant main effect of time was observed $(F[1,807.714]=4.525, p=.034)$, which shows that for all participants, the BSCS scores improved over time. No significant main effect of 
group was found $(F(2,597.578)=1.027, p=.359)$, meaning that there were no significant differences between all BSCS scores between all three groups. Post hoc LSD tests showed a significant difference between self-control scores of the app and control group. As can be seen in the mean difference between groups, the scores of participants in the app group were higher $(M=2.627[95 \mathrm{Cl}+.689,+4.566], p=.008)$. This shows that all self-control scores of the app group were on average higher than those of the control group. To illustrate these findings, a plot of the means of all three conditions was created (see Figure 7). To further explore differences within the three groups, additional post hoc analyses were performed.

Figure 7. The means of the score on the BSCS of the app, e-mail and control group at the four measurement moments.

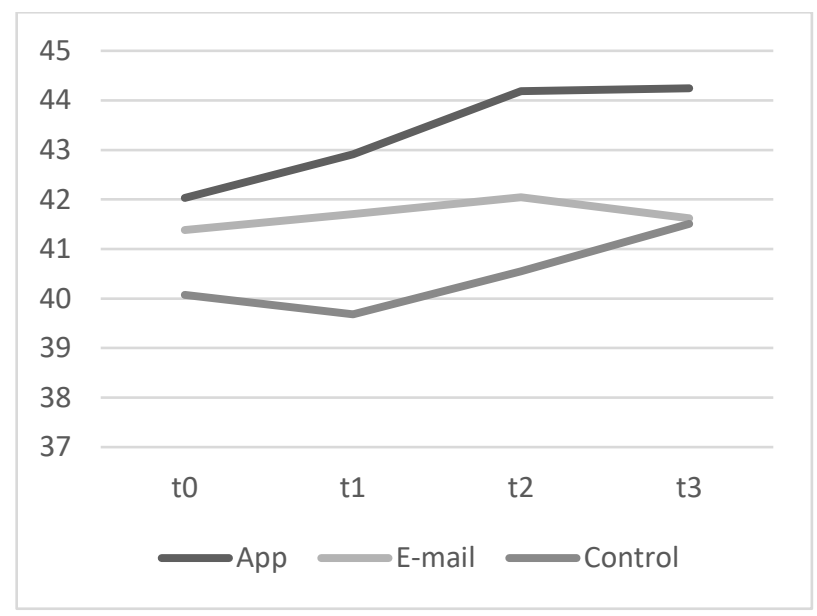

To zoom in on the changes over time within the three conditions, a linear mixed model using compound symmetry with only time as a fixed factor was used for each group separately. For the app condition, significant improvements in self-control over time were identified by a main effect of time $(F[3,196.315]=4.090, p=.008)$. However, for the e-mail condition $(F[3,201,000]=.251, p=.861)$ and the control group $(F[3$, $210.000]=1.953, p=.122$ ), no significant differences between scores over time were found. These results show that only in the app condition, self-control increased significantly over time. 


\section{Self-control: Go/No-Go}

A significant interaction effect was observed for the reaction times on the Go/No-Go task over time for all three groups $(F[6,604.172]=2.630, p=.016)$, meaning that changes in reaction time differed between the three groups over time. As can be seen in Figure 8, the reaction time of the control group increased at $t 2$, while the score of the e-mail group, which was higher at $t 1$, is lower at $t 2$, which explains the interaction effect. A main effect for time was identified $(F[3,604.174]=33.178, p<.001)$, meaning that all reaction times significantly decreased over time. Also, a significant main effect was identified for groups $(F[2,201,854]=4.944, p=.008)$. LSD post hoc analyses show that the reaction times of the app group for all measurements were lower than those of the control group $(M=-35.42[\mathrm{Cl}-61.41,-9.44], p=.008)$ and the e-mail group ( $M=-36.51[\mathrm{Cl}-62.59,-10.44], p=.006)$.

Figure 8. The mean reaction time for the Go/No-Go tasks in milliseconds for the app, e-mail and control groups.

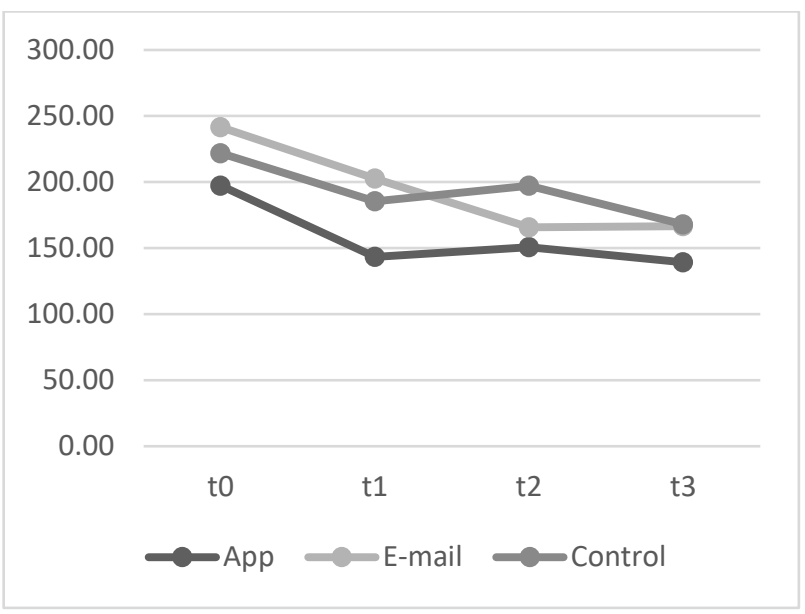

To identify whether significant decreases in reaction time took place in each separate group, three linear mixed model analyses with only time as a fixed factor were conducted. A main effect for time was found in the app group $(F[3,198,984]=16.391$, $p<.001)$, the e-mail group $(F[3,201,000]=14.322, p<.001)$ and the control group $(F[3,204,000]=8.188, p<.001)$. In line with Figure 8 , LSD post hoc analyses showed that for all groups, the decreases between the baseline measure at to and the three following measures ( $\mathrm{t} 1, \mathrm{t} 2$ and $\mathrm{t} 3$ ) were significant ( $p$-values ranged between $<.001$ and .004). 


\section{Aggression - app, e-mail and control group}

$A$ repeated measures linear mixed model using BAQ scores showed no significant interaction effects between time and all three groups, $(F[6,602.594]=1.525, p=$ .168). A significant main effect of time was observed $(F[3,602.597]=46.663, p<.001)$, showing that the self-reported aggression of all groups decreased over time. The LSD post-hoc analyses showed no significant differences between the scores of all groups. As can be seen in Figure 9, the BAQ scores on t0 seem to be substantially higher than the other three measuring moments. Additional analyses were conducted to investigate changes within and between groups.

Figure 9. The means of the score on the BAQ of the app, e-mail and control group at the four measurement moments.

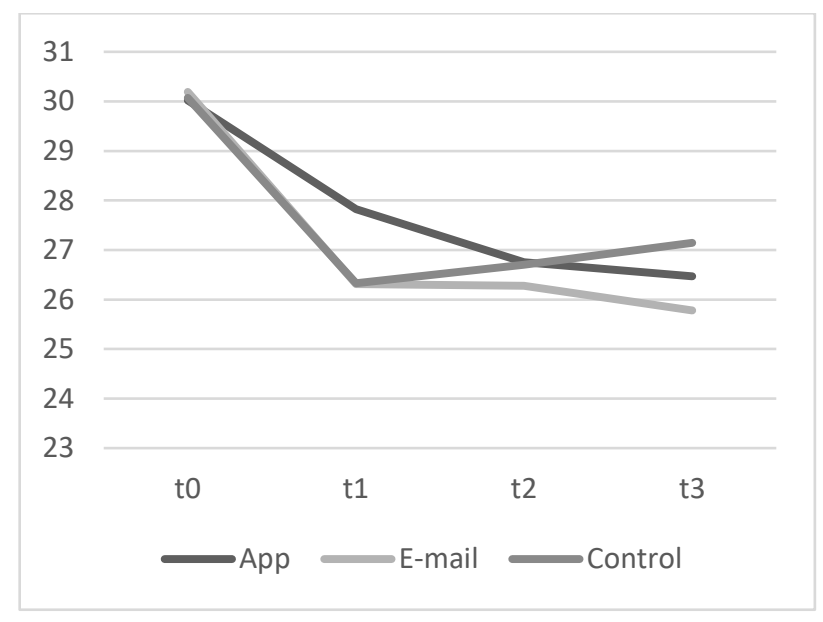

To investigate whether this difference over time was significant for each separate group, a linear mixed model with only time as a fixed factor was used for each group. For all three conditions, respectively app $(F[3,195,447]=14.753, p<.001)$, e-mail $(F[3,201,000]=19.267 ; p<.001)$ and control condition $(F[3,209.120]=16.318, p<$ .001 ), significant changes over time were observed. In line with Figure 9, post-hoc LSD analyses showed only significant ( $p$-values all <.001) differences between t0 and $t 1$, t2 and t3 for all three groups, indicating that scores remained relatively stable after the drop between t0 and $\mathrm{t} 1$. 


\section{5 tasks versus 1 task versus control group}

\section{Self-control: BSCS}

A repeated measure linear mixed model showed no significant interaction effects between time and all three groups on self-control $(F[6,604.393]=0.400, p=.879)$. A significant main effect was identified for time $(F[3,604.397]=4.109, p=.007)$, so for all participants, self-control increased over time. Post hoc analyses showed a significant difference between the means of the group that received 5 tasks at once and the control group ( $M=2.311$, [CI95 +.183, +4.438], $p=.033)$. The average BSCS scores for all three groups are plotted in Figure 10.

Figure 10. The means of the score on the BSCS of the group that received 5 tasks at once, the group that received one daily task, and the control group.

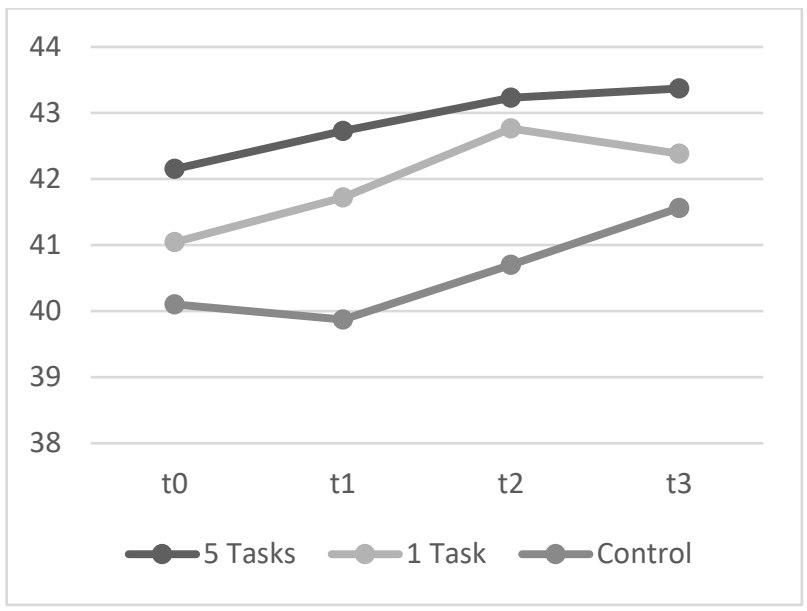

To further explore the results, a linear mixed model with only time as a fixed factor was used for each group separately. No significant effects of time were found for the group that received 5 tasks at once $(F[3,193.418]=.937, p=.424)$, the group that received 1 task per day, $(F[3,201.000]=2.124, p=.098)$, and the control group $(F[3$, $210.000]=1.953, p=.122$ ). This means that the improvement of self-control within each separate group was not significant.

\section{Self-control: Go/No-Go}

No significant interaction effect between time and group was found $(F[6,604.403]=$ $1.661, p=.128)$. A main effect for time was found $(F[3,604.409]=32.967, p<.001)$, showing that reaction time for all participants significantly decreased over time. LSD post hoc analyses showed that the mean reaction times of the group that received 1 
task were overall lower than those of the control group ( $M=-26.36$ [Cl95 -52.51, .22), $p=.048)$, which can also be observed in Figure 11.

Figure 11. The mean reaction time for the Go/No-Go tasks in milliseconds for the group that received 5 tasks at once, the group that received one daily task, and the control group.

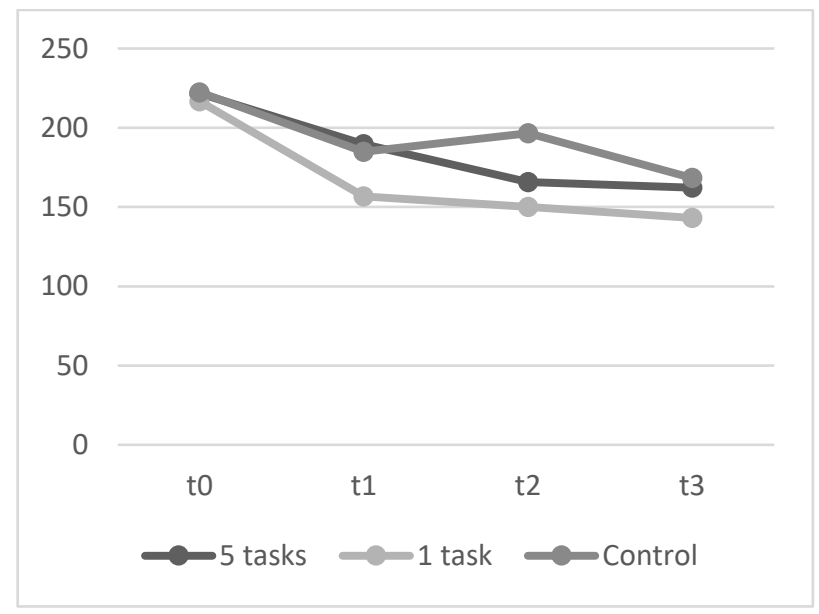

To further investigate the effect of time for the three separate groups, repeated measures linear mixed model with only time as a fixed factor were used for each group. A significant main effect of time was found for the group that received 5 tasks at once $(F[3,193.471] 3=8.885, p<.001), 1$ task per day $(F[3,201,000]=20.330, p<$ $.001)$ and the control group $(F[3,210,000]=8.614, p<.001)$. Post hoc analyses showed that for all groups, the decrease between t0 and the next three measures ( 1 , t2 and t3) were all significant, and all had a significance level of $p<.001$.

\section{Aggression - 5 tasks, 1 task and control group}

For the scores on the $\mathrm{BAQ}$, no significant interaction effect between time and group was found $(F[6,602.592)=1.551, p=.159)$. Post hoc tests showed no differences between groups. A significant main effect of time was found $(F[3,602.595)=46.579$, $p<.001)$, indicating that the scores for all groups together decreased over time. 
Figure 12. The means of the score on the BAQ of the group that received 5 tasks at once, the group that received one daily task, and the control group.

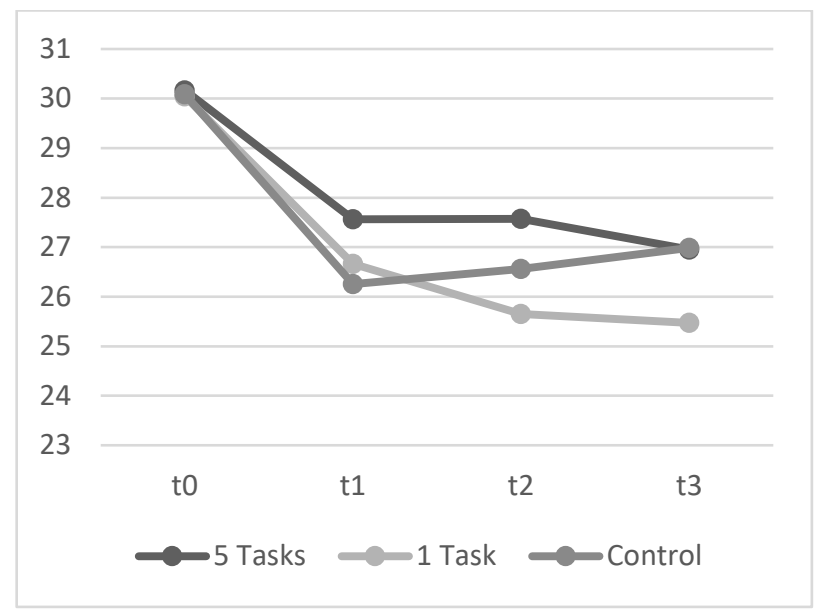

Linear mixed models for each separate group with only time as a fixed factor showed a significant main effect of time for the group that received 5 tasks at once $(F[3$, $193.338]=9.305, p<.001)$, the group that received 1 task per day $(F[3,200.151]=$ $25.834, p<.001)$, and the control group $(F[3,209.120]=16.318, p<.001)$. As can also be observed in Figure 12, post hoc analyses again showed that these decreases were only significant between t0 and the other three measurement moments.

\section{Experiences and points of improvement}

The codes show that most participants did not have any points of improvements and were satisfied with the intervention. The full coding schemes can be found in Appendix $A$ and $B$. The most-mentioned point of improvement was to add more reminders since participants indicated they often forgot about the tasks during the day. Also, participants indicated that some tasks were too difficult and needed to be either removed or adapted. As can be seen in Appendix C, almost two thirds (62.22\%) of the participants indicated that task 10 (writing with the non-dominant hand) should be removed, mostly due to its negative impact on daily life, such as making notes during lectures or signing official documents. For the other nine tasks, less than a quarter (range of $1.48 \%$ to $24.44 \%$ ) of the participants indicated that it should be removed.

Another point that arose from the answers was that several participants experienced minor bugs in answering questions about how well the task went in the 
app. They noted that this did not affect the intervention itself. Also, some participants who received five tasks at once indicated that they would have preferred to receive less tasks, while several participants who received a daily task would rather have received more tasks at once. Furthermore, multiple other recommendations were made by relatively few participants, for example, four participants expressed the need to know more about the reason for using one's non-dominant hand since they did not see the relevance. Finally, 24 participants had suggestions that did not pertain to the intervention, but targeted the study design, e.g. remarks on the used questionnaires.

\section{Discussion}

\section{Summary and interpretation of results}

The goal of this study was to provide insight into the effectiveness and points of improvement of a self-control training (SCT) intervention to increase self-control and reduce aggression. The first study showed that self-control and aggression both improved after using the SCT intervention, but since no control group was used, no robust conclusions could be drawn. The second study was inspired by the outcomes and points of improvements identified in this first pilot study. In order to investigate potential differences between delivering SCT via app or e-mail, and between receiving one task per day or five at once, a full factorial design was used. While no showed interaction effects were found, analyses showed that only self-reported self-control of participants that used the app improved over time; no improvements over time were observed in the e-mail and control condition. While further research with target groups with lower self-control is warranted, this outcome shows the potential added value that a mobile app might have for the delivery of SCT $[18,19,22,23]$. An explanation for this, underlined by the qualitative results, is that an app can send reminders to support users in remembering to perform the tasks.

Furthermore, while the participants that used the app performed overall better on the Go/No-Go tasks, there was no interaction effect, which means that the differences might be explained by existing differences at baseline. It is not fully clear yet whether the Go/No-Go is a valid way to assess self-control. Additionally, no meaningful differences between groups were found on self-reported aggression. There are multiple possible explanations for this. First, aggression levels might already have been relatively low due in the university student sample, which leaves little room for improvement. Second, it is considered difficult to measure aggression using a selfreport questionnaire, which might have influenced the validity of the results. Third, SCT might simply not be able to target reactive aggression, but this is considered 
unlikely due to the positive findings of earlier research [22, 23]. In these previous studies, aggression was measured by means of fictional scenarios and lab tasks, which again underlines the importance of identifying other ways to assess aggression.

No differences between the control group and groups that received one and five tasks were found, which implies that the number of tasks is not a component that adds to the effectiveness of SCT. An explanation for this is that regardless of the type and number of tasks, participants always have to suppress a dominant response on a daily basis, which is considered as the main working mechanism of SCT. Together, these results show that an SCT app is the most effective way to improve self-control, regardless of how many tasks are presented per day. Finally, qualitative results showed that participants were satisfied with the design and content of both app and e-mail SCT, but they preferred to receive more reminders to perform the nondominant hand tasks. In general, the results of this study indicate that app-based SCT, a straightforward and easy-to-implement intervention, might increase self-control, but not aggression in a student sample. Further research into these results is warranted to draw more robust conclusions.

\section{Personalization of the SCT app}

The quantitative and qualitative results of this study show multiple ways to further improve the app. However, there seemed to be little consensus on aspects that might improve the app for all users, which points into the direction of creating multiple versions of the app. For example, analyses showed that the number of tasks that is received over a period of five days is not related to effectiveness of SCT. However, several participants who received one task indicated that they would have preferred to receive more tasks at once, and vice versa, indicating that individual differences might exist and therefore posing an opportunity for personalization. Another point of improvement was related to the suitability of the tasks of SCT. The participants' ratings per task showed that there was much difference between the their opinions on tasks. They gave a broad range of reasons: amongst other things, tasks were found too difficult, too easy, too inconvenient, or they were said not to occur enough during daily life. Since personalization of eHealth technologies can positively influence adherence, engagement and thus effectiveness [28, 41], it might be beneficial to create a more personalized version of the app in which the content and number of the tasks can be adapted to the preferences of a broad range of users. For example, technology can offer users the possibility to compile their own intervention [42], which means that participants can be offered the possibility to select the number and 
type of the non-dominant hand tasks they want to perform, resulting in a personalized set of tasks that are not too difficult, practical or unchallenging, and thus might provide the best opportunity to practice self-control for an individual.

Another option to personalize the SCT app is by offering different types of SCT-tasks. This study used the non-dominant hand paradigm, in line with previous studies on SCT and aggression [22, 23]. Most participants found the interventions fun to perform, but - as qualitative data showed - doing these types of tasks might become repetitive and boring. However, there are more ways to shape SCT; amongst other things by asking participants to refrain from using common slang words [22]. Therefore, participants might be given the opportunity to switch between nondominant hand and word-related tasks to allow for more diversity. On the other hand, selecting tasks might require too much effort or too many options might result in overwhelmed participants. Consequently, while all of these options to further personalize the app in order to adapt it to users' preferences sound promising, further research is necessary to investigate whether these ways of personalization actually result in increased effectiveness.

\section{Design of the SCT app}

This study has shown that the app is an effective way to bolster self-control. In general, participants appreciated the app and were positive about its usability and visual design. This positive assessment can partly be explained by the involvement of the users in the app's development process, since participatory development methods can lead to a better fit between the technology and the needs and wishes of the user $[43,44]$. Good design of eHealth technologies has the potential to increase engagement with and adherence to an intervention, which in its turn can improve its effectiveness [28]. In line with this presumption, almost all participants in this study were adherent. However, this might be due to the credits that participating students received, and not all participants were very enthusiastic about the app and its tasks on the long term. Furthermore, it might be more challenging to engage hard-to-reach target groups such as prisoners or forensic psychiatric patients. Consequently, a next version of the app can benefit more from the possibilities of technology to further engage users. A possible way to achieve this is by means of gamification, in which elements from game-design such as social comparison, mastery or rewards are added [45].

The most important point of improvement mentioned by all participants was that more reminders should be sent to support users in remembering to perform the 
tasks of SCT. Participants in the e-mail condition did not receive daily reminders, which might explain why no significant improvements in self-control in this condition were found. Further research could focus on how adherent participants need to be in order for SCT to be effective: is the extent to which it is used related to increases in self-control? Future research can use log data to gain objective insight into the use of the app. While app-users received reminders, this was not perceived as enough by multiple participants, which means that in a next version of the app, more reminders could be sent. However, since reminders can be experienced as annoying by users [46], participants can be offered the option to adapt the number, timing and content of reminders to their own preferences, again highlighting the importance of a personalized SCT app.

\section{Future research}

\section{Evaluation}

Since this is, to the best of our knowledge, the first study that evaluated a self-control training app, we aimed to not just gain insight into if the app works, but also into which elements contributed to the effectiveness by means of a $2 \times 2$ full factorial design, which is in line with the optimization phase of the Multiphase Optimization Strategy (MOST) framework [29, 30]. While promising results were found, additional research is needed to further investigate and replicate these findings. Consequently, in line with the next and final evaluation phase of the MOST framework, a fully powered randomized controlled trial with the most optimal version of the app should be conducted to draw more robust conclusions about its effectiveness. Based on the findings of this study, the SCT app can be optimized by adding more opportunities for personalization, allowing individual users to adapt its content and design. This implies that different versions of the SCT app can be created, for example with differences in tasks or the number of reminders. This might raise questions about how to evaluate the effectiveness of all of these different versions. However, while the content and design are not completely identical, the underlying intervention principles are the same [47]. Consequently, in order to establish whether a personalized version of the app is more effective than a non-personalized 'locked-down' version, a three-armed randomized controlled trial can be conducted, according to the aforementioned 'trial of intervention principles' [47]. Additionally, to identify which components of an improved version - such as reminders or gamification - add to the effectiveness, other fractional or full factorial designs can be employed [29, 30]. 
Besides gaining more insight into how the design of a mobile app can contribute to effectiveness, more insight into how SCT works is required as well. For example, what are the crucial elements that make it effective [18]? While the current study already provided some answers - for example on whether the number of tasks influences effectiveness - there are more questions that need to be addressed. For example, more insight is required into how long the effects of SCT remain since they might wash out fairly quickly after finishing the intervention, and for how long SCT should ideally be administered [18]. Innovative evaluation methods are required to further open the black box of the SCT app. An example of a suitable evaluation method for these types of questions is an introduction/withdrawal single-case experimental design $[48,49]$, which can provide more insight into how SCT works, and what the added value of technology is in further bolstering its effectiveness.

\section{New applications of SCT}

In this study, we included students since this target group is easy to involve in research, and working mechanisms behind SCT are expected to be the same, regardless of the target group [18]. Our results were fairly promising, but we found no interaction effects. An explanation for this is that in our student sample, selfcontrol was already relatively high, and aggression relatively low, leaving not much room for improvement. Other target groups with more problems with self-control might benefit more from the SCT-app. Examples of hard-to-reach populations that might especially benefit from such a straightforward and non-language driven intervention, are forensic psychiatric patients, delinquent youth or prisoners. Since assessing aggression in these types of target groups via self-report measures might be prone to multiple types of biases such as memory or social desirability bias, these types of measures might not be sufficiently reliable and, to overcome these results, they can be combined with other types of measures, such as reports or questionnaires on aggressive behaviour filled out by staff [50]. Also, measures that do not require reading, such as the Go/No-Go task that was used in this study, might be very suitable for these types of target groups, who often are semi-illiterate or have other cognitive deficits [51,52]. However, further research is needed to ensure the suitability and validity of these types of measures for assessing evaluating the SCT-app.

SCT cannot just be applied to different target groups, but also to other target behaviours. Many existing (eHealth) interventions that aim to improve goal-driven behaviour such as a lack of physical activity, smoking or unhealthy eating suffer from the intention-behaviour gap [53]. This means that participants have trouble sticking 
to their goals, which might be explained by a lack of self-control $[54,55]$. Therefore, SCT can be used as an addition to these types of interventions to bridge the intentionbehaviour gap and thus increase their effectiveness. SCT has indeed been shown to improve a broad range of health-related behaviours [35], so it would be interesting to study the potential of an SCT app to bolster the effectiveness of existing, goal-driven eHealth interventions in a relatively cheap, scalable and easy way.

\section{Limitations}

In this paper, we combined two studies in order to efficiently evaluate if and how an SCT app works. The approach we used can be viewed as agile eHealth evaluation, in which multiple evaluation cycles are combined to be able to quickly yield results [56]. While this efficient and innovative approach resulted in useful input for an optimized version of the intervention, there are some limitations of both designs that were used. In the first study, no control group was used, which means that the observed improvement in self-control might be a mere-measurement effect [57]. However, the goal of the first study was to quickly provide insight into the potential of the SCT app with a relatively small sample and to identify points of improvements for a larger study with a control group. The first study illustrates that, when optimizing interventions via evaluation studies, designs without control groups can yield useful results for shaping future evaluation studies, especially if they are combined with other methods.

Regarding the second study, no interaction effects were identified. When calculating the power of the $2 \times 2$ full factorial design, we assumed a medium effect size, but since no comparable studies were available on which we could base the effect size, this estimation might have been too high. This might have resulted in a study with not enough power to identify interaction effects. Regardless, we were still able to gain some initial insights into effectiveness of the app and identify useful recommendations for improvement of SCT. Also, an explanation might be found in the characteristics of the university student sample: their levels of self-control might have already been quite high, and their aggression levels low, leaving not much room for improvement. Furthermore, as opposed to most evaluation studies on SCT [18], we used a follow-up measure. However, this was only after five days. It is possible that the effects of SCT 'wash out' fairly quickly after completing the intervention, so in future research, more follow-up measures should be used over a longer period of time to gain insight into how long the effects of the SCT app remain.

A main limitation of this study was the measurement of aggression. As mentioned before, using self-report questionnaires to measure this behaviour is 
suboptimal. Furthermore, the analyses showed a strong drop in BAQ-scores after the baseline measure and a low Cronbach's alpha of the BAQ on baseline. This can be explained by the way questions were phrased: at the baseline measurement, the BAQ focused on aggression in general, and after that, the focus was on the past five days, which might have influenced the scores. For example, if no aggressive incidents occurred in the five days before filling out the questionnaire, the scores might have been lower than if the questions were focused on a longer time-frame, as was the case in the BAQ that was administered at baseline. However, the repeated measures linear mixed models we used accounted for these differences and showed no differences in changes in aggression between groups, which means that this measurement error did not affect the conclusions of this study.

Finally, the rewards that were received by participants might have influenced the results. In the second study, participating students received credits for their education if they finished the study and thus had to use the app for 10 days. This situation is not representative for real-life, in which more users might drop out due to a lack of rewards: non-adherence is indeed a big issue for eHealth interventions [58]. Regardless, participants indicated that they liked the intervention and reminders were included, which might positively impact adherence in real life.

\section{Conclusion}

This study showed that self-control of students who used a self-control training (SCT) app increased over time, as opposed to students that received SCT via e-mail and a control-group. No effects on aggression were found, which might be explained by the limitations of the measure used or the extent to which aggression was a problem of the target group. Regardless, the SCT app has the potential to increase self-control. Based on the findings of this study, an improved, personalized version of the app should be developed in which content and design can be adapted to fit individual users. Further research with participants lower in self-control should provide more insight into if and how SCT works, and how the possibilities of mobile apps can be used to further bolster its effectiveness.

\section{Disclosure statement}

This study was funded by Stichting Vrienden van Oldenkotte. The authors have no conflict of interest. 


\section{References}

1. Krug, E.G., et al., The world report on violence and health. The lancet, 2002. 360(9339): p. 1083-1088.

2. Rutherford, A., et al., Violence: a priority for public health?(part 2). Journal of Epidemiology \& Community Health, 2007. 61(9): p. 764-770.

3. Dijk, J.v., J.v. Kesteren, and P. Smit, Criminal victimisation in international perspective. 2007: Boom Juridische Uitgevers.

4. Poulin, F. and M. Boivin, Reactive and proactive aggression: evidence of a two-factor model. Psychological assessment, 2000. 12(2): p. 115.

5. Dodge, K.A. and J.D. Coie, Social-information-processing factors in reactive and proactive aggression in children's peer groups. Journal of personality and social psychology, 1987. 53(6): p. 1146.

6. Geoffrion, S., et al., Workplace aggression against health care workers, law enforcement officials, and bus drivers: Differences in prevalence, perceptions, and psychological consequences. Journal of Workplace Behavioral Health, 2017. 32(3): p. 172-189.

7. Van Dijk, J., et al., The burden of crime in the EU: A comparative analysis of the European Survey of Crime and Safety (EU ICS 2005). 2007.

8. Pekurinen, V., et al., Patient aggression and the wellbeing of nurses: a crosssectional survey study in psychiatric and non-psychiatric settings. International journal of environmental research and public health, 2017. 14(10): p. 1245.

9. Denson, T.F., Four promising psychological interventions for reducing reactive aggression. Current Opinion in Behavioral Sciences, 2015. 3: p. 136141.

10. Polaschek, D.L., et al., Cognitive-behavioral rehabilitation for high-risk violent offenders: An outcome evaluation of the violence prevention unit. Journal of interpersonal violence, 2005. 20(12): p. 1611-1627.

11. Ross, J., et al., The impact of psychological therapies on violent behaviour in clinical and forensic settings: A systematic review. Aggression and Violent Behavior, 2013. 18(6): p. 761-773.

12. Del Vecchio, T. and K.D. O'Leary, Effectiveness of anger treatments for specific anger problems: A meta-analytic review. Clinical psychology review, 2004. 24(1): p. 15-34. 
13. Saini, M., A meta-analysis of the psychological treatment of anger: Developing guidelines for evidence-based practice. Journal of the American Academy of Psychiatry and the Law Online, 2009. 37(4): p. 473-488.

14. Gaynes, B.N., et al., Preventing and de-escalating aggressive behavior among adult psychiatric patients: a systematic review of the evidence. Psychiatric services, 2017. 68(8): p. 819-831.

15. Denson, T.F., C.N. DeWall, and E.J. Finkel, Self-Control and Aggression. Current Directions in Psychological Science, 2012. 21(1): p. 20-25.

16. Gottfredson, M.R. and T. Hirschi, A general theory of crime. 1990: Stanford University Press.

17. Muraven, M., R.F. Baumeister, and D.M. Tice, Longitudinal improvement of self-regulation through practice: Building self-control strength through repeated exercise. The Journal of social psychology, 1999. 139(4): p. 446-457.

18. Friese, M., et al., Does self-control training improve self-control? A metaanalysis. Perspectives on Psychological Science, 2017. 12(6): p. 1077-1099.

19. Beames, J., T.P. Schofield, and T.F. Denson, A meta-analysis of improving selfcontrol with practice. DT de Ridder, M. Adriaanse, K. Fujita (red.) International Handbook of Self-control in Health and Well-being. Abingdon Oxford: Routledge, 2017.

20. Hagger, M.S., et al., Ego depletion and the strength model of self-control: a meta-analysis. Psychological bulletin, 2010. 136(4): p. 495.

21. Berkman, E.T., Self-regulation training. Handbook of self-regulation: Research, theory, and applications, 2016: p. 440-457.

22. Finkel, E.J., et al., Self-regulatory failure and intimate partner violence perpetration. Journal of personality and social psychology, 2009. 97(3): p. 483.

23. Denson, T.F., et al., Self-control training decreases aggression in response to provocation in aggressive individuals. Journal of Research in Personality, 2011. 45(2): p. 252-256.

24. van Gemert-Pijnen, L.J., et al., Introducing ehealth, in eHealth Research, Theory and Development. 2018, Routledge. p. 3-26.

25. Deenik, J., et al., Implementation barriers and facilitators of an integrated multidisciplinary lifestyle enhancing treatment for inpatients with severe mental illness: the MULTI study IV. BMC health services research, 2019. 19(1): p. 740. 
26. Drieschner, K.H. and A. Boomsma, The treatment motivation scales for forensic outpatient treatment (tms-f) construction and psychometric evaluation. Assessment, 2008. 15(2): p. 224-241.

27. Kelders, S.M., et al., Persuasive system design does matter: a systematic review of adherence to web-based interventions. Journal of medical Internet research, 2012. 14(6): p. e152.

28. Ludden, G.D., et al., How to increase reach and adherence of web-based interventions: a design research viewpoint. Journal of medical Internet research, 2015. 17(7): p. e172.

29. Collins, L.M. and K.C. Kugler, Optimization of Behavioral, Biobehavioral, and Biomedical Interventions. 2018.

30. Collins, L.M., et al., Factorial experiments: efficient tools for evaluation of intervention components. American journal of preventive medicine, 2014. 47(4): p. 498-504.

31. De Ridder, D.T., et al., Taking stock of self-control: A meta-analysis of how trait self-control relates to a wide range of behaviors. Personality and Social Psychology Review, 2012. 16(1): p. 76-99.

32. da Silva, M.C., A mobile app-based intervention for self-control (Hands-ON): usability and feasibility evaluations. 2019, University of Twente.

33. Burns, C., Human-centred design, in eHealth Research, Theory and Development. 2018, Routledge. p. 207-227.

34. Oinas-Kukkonen, H. and M. Harjumaa, Persuasive systems design: Key issues, process model, and system features. Communications of the Association for Information Systems, 2009. 24(1): p. 28.

35. Tangney, J.P., R.F. Baumeister, and A.L. Boone, High self-control predicts good adjustment, less pathology, better grades, and interpersonal success. Journal of personality, 2004. 72(2): p. 271-324.

36. Duckworth, A.L. and M.L. Kern, A meta-analysis of the convergent validity of self-control measures. Journal of research in personality, 2011. 45(3): p. 259268.

37. Fung, S.-f., C.Y.W. Kong, and Q. Huang, Evaluating the dimensionality and psychometric properties of the Brief Self-Control Scale amongst Chinese university students. Frontiers in Psychology, 2019. 10.

38. Lindner, C., G. Nagy, and J. Retelsdorf, The dimensionality of the Brief SelfControl Scale-An evaluation of unidimensional and multidimensional applications. Personality and Individual Differences, 2015. 86: p. 465-473. 
39. Webster, G.D., et al., The brief aggression questionnaire: Structure, validity, reliability, and generalizability. Journal of personality assessment, 2015. 97(6): p. 638-649.

40. Boeije, H., A purposeful approach to the constant comparative method in the analysis of qualitative interviews. Quality and quantity, 2002. 36(4): p. 391409.

41. Brouwer, W., et al., Which intervention characteristics are related to more exposure to internet-delivered healthy lifestyle promotion interventions? A systematic review. Journal of medical Internet research, 2011. 13(1): p. e2.

42. Andersson, G., et al., Can the patient decide which modules to endorse? An open trial of tailored internet treatment of anxiety disorders. Cognitive behaviour therapy, 2011. 40(1): p. 57-64.

43. van Gemert-Pijnen, J.E., et al., A holistic framework to improve the uptake and impact of eHealth technologies. Journal of medical Internet research, 2011. 13(4): p. e111.

44. Michie, S., et al., Developing and evaluating digital interventions to promote behavior change in health and health care: recommendations resulting from an international workshop. Journal of medical Internet research, 2017. 19(6): p. e232.

45. Sailer, M., et al., Psychological perspectives on motivation through gamification. Interaction Design and Architecture Journal, 2014(19): p. 2837.

46. Westermann, T., S. Möller, and I. Wechsung. Assessing the relationship between technical affinity, stress and notifications on smartphones. in Proceedings of the 17th International Conference on Human-Computer Interaction with Mobile Devices and Services Adjunct. 2015.

47. Mohr, D.C., et al., Trials of intervention principles: evaluation methods for evolving behavioral intervention technologies. Journal of Medical Internet Research, 2015. 17(7): p. e166.

48. Krasny-Pacini, A. and J. Evans, Single-case experimental designs to assess intervention effectiveness in rehabilitation: A practical guide. Annals of physical and rehabilitation medicine, 2018. 61(3): p. 164-179.

49. Dallery, J., R.N. Cassidy, and B.R. Raiff, Single-case experimental designs to evaluate novel technology-based health interventions. Journal of medical Internet research, 2013. 15(2): p. e22. 
50. Kobes, M.H., H.H. Nijman, and E.B. Bulten, Assessing aggressive behavior in forensic psychiatric patients: Validity and clinical utility of combining two instruments. Archives of psychiatric nursing, 2012. 26(6): p. 487-494.

51. Greenberg, E., E. Dunleavy, and M. Kutner, Literacy Behind Bars: Results from the 2003 National Assessment of Adult Literacy Prison Survey. NCES 2007473. National Center for Education Statistics, 2007.

52. Clausen, W., et al., Health literacy among people with serious mental illness. Community mental health journal, 2016. 52(4): p. 399-405.

53. Sniehotta, F., J. Presseau, and V. Araújo-Soares, Time to retire the theory of planned behaviour. Health psychology review, 2014. 8(1): p. 1.

54. Pfeffer, I. and T. Strobach, Executive functions, trait self-control, and the intention-behavior gap in physical activity behavior. Journal of Sport and Exercise Psychology, 2017. 39(4): p. 277-292.

55. Sniehotta, F.F., U. Scholz, and R. Schwarzer, Bridging the intention-behaviour gap: Planning, self-efficacy, and action control in the adoption and maintenance of physical exercise. Psychology \& health, 2005. 20(2): p. 143160.

56. Patrick, K., et al., The pace of technologic change: implications for digital health behavior intervention research. 2016, Elsevier.

57. Godin, G., et al., Which survey questions change behavior? Randomized controlled trial of mere measurement interventions. Health Psychology, 2010. 29(6): p. 636.

58. Brown, M., et al., Gamification and adherence to web-based mental health interventions: a systematic review. JMIR mental health, 2016. 3(3): p. e39. 


\section{Appendices}

\section{Appendix A - Opinion on app}

Table A.1. The codes of the opinions of the participants and number of times they were mentioned by all participants that received the app $(n=68)$ and e-mail $(n=68)$, and received either one or five tasks within that condition.

\begin{tabular}{llll}
\hline Codes & Total & $\begin{array}{l}1 \text { task } \\
(n=34)\end{array}$ & $\begin{array}{l}5 \text { tasks } \\
(n=34)\end{array}$ \\
\hline
\end{tabular}

\section{App $(n=68)$}

\section{Positive}

App was easy to use and clear

$\begin{array}{lll}26 & 12 & 14 \\ 13 & 4 & 9 \\ 11 & 9 & 2 \\ 10 & 5 & 5 \\ 9 & 6 & 3 \\ 4 & 1 & 3 \\ 1 & 1 & 0\end{array}$

Design of the app was appealing 14

Positive evaluation, without further explanation

The app was a good reminder of the tasks

The app functioned as it should/no bugs

App was fun to use

Nice that the app mentions your name

\section{Negative}

Bugs in answering questions

$\begin{array}{lll}34 & 18 & 16 \\ 9 & 3 & 6 \\ 5 & 2 & 3 \\ 4 & 2 & 2 \\ 2 & 1 & 1 \\ 1 & 0 & 1\end{array}$

E-mail $(n=68)$

\section{Positive}

The content of the e-mails was easy to understand

$\begin{array}{lll}40 & 18 & 22 \\ 11 & 3 & 8 \\ 8 & 6 & 2 \\ 8 & 6 & 2 \\ 6 & 2 & 4 \\ 4 & 0 & 4 \\ 4 & 3 & 1 \\ 2 & 0 & 2 \\ 1 & 0 & 1\end{array}$

\section{Negative}

Not enough reminders were sent

Small elements of the e-mails were unclear

$\begin{array}{lll}8 & 5 & 3 \\ 4 & 1 & 3 \\ 3 & 2 & 1 \\ 3 & 3 & 0 \\ 2 & 1 & 1\end{array}$




\section{Appendix B - Points of improvement}

Table B.1. The points of improvement and number of times they were mentioned by all participants that received SCT $(N=134)$ and for the e-mail and app group, and the 1 and 5 task group (each $n=68$ ).

\begin{tabular}{|c|c|c|c|c|c|}
\hline \multirow[t]{2}{*}{ Code } & \multirow[t]{2}{*}{ Total } & App & E-mail & 5 tasks & 1 task \\
\hline & & $\begin{array}{l}(\% \text { of } \\
\text { total) }\end{array}$ & $\begin{array}{l}(\% \text { of } \\
\text { total) }\end{array}$ & $\begin{array}{l}(\% \text { of } \\
\text { total) }\end{array}$ & $\begin{array}{l}\text { (\% of } \\
\text { total) }\end{array}$ \\
\hline \multirow{2}{*}{ No points of improvement } & \multirow[t]{2}{*}{40} & 19 & 21 & 15 & 25 \\
\hline & & $(47.5 \%)$ & $(52.5 \%)$ & $(37.5 \%)$ & $(62.5 \%)$ \\
\hline \multirow{2}{*}{$\begin{array}{l}\text { Add more reminders to perform the } \\
\text { tasks }\end{array}$} & \multirow[t]{2}{*}{32} & 14 & 18 & 20 & 12 \\
\hline & & $(43.8 \%)$ & $(56.2 \%)$ & $(62.5 \%)$ & $(37.5 \%)$ \\
\hline \multirow[t]{2}{*}{ Change one or more of the tasks } & \multirow[t]{2}{*}{19} & 13 & 6 & 14 & 5 \\
\hline & & $(68.4 \%)$ & $(31.6 \%)$ & $(73.7 \%)$ & $(26.3 \%)$ \\
\hline \multirow[t]{2}{*}{ Fix the bugs in the app } & \multirow[t]{2}{*}{7} & 7 & 0 & 3 & 4 \\
\hline & & $(100 \%)$ & $(0 \%)$ & $(42.9 \%)$ & $(57.1 \%)$ \\
\hline \multirow{2}{*}{$\begin{array}{l}\text { Add a validation/way to prevent } \\
\text { 'cheating' }\end{array}$} & \multirow[t]{2}{*}{6} & 2 & 4 & 1 & 5 \\
\hline & & $(33.3 \%)$ & $(66.7 \%)$ & $(16.7 \%)$ & $(83.3 \%)$ \\
\hline \multirow[t]{2}{*}{ Provide only one task per day } & \multirow[t]{2}{*}{5} & 3 & 2 & 5 & 0 \\
\hline & & $(60 \%)$ & $(40 \%)$ & $(100 \%)$ & $(0 \%)$ \\
\hline \multirow[t]{2}{*}{ Provide more than one task per day } & \multirow[t]{2}{*}{4} & 2 & 2 & 0 & 4 \\
\hline & & $(50 \%)$ & $(50 \%)$ & $(0 \%)$ & $(100 \%)$ \\
\hline \multirow{2}{*}{$\begin{array}{l}\text { More explanation on the goal of the } \\
\text { intervention }\end{array}$} & \multirow[t]{2}{*}{4} & 2 & 2 & 1 & 3 \\
\hline & & $(50 \%)$ & $(50 \%)$ & $(25 \%)$ & $(75 \%)$ \\
\hline \multirow{2}{*}{$\begin{array}{l}\text { Make it easier to see the tasks in the } \\
\text { app }\end{array}$} & \multirow[t]{2}{*}{2} & 1 & 1 & 1 & 1 \\
\hline & & $(50 \%)$ & $(50 \%)$ & $(50 \%)$ & $(50 \%)$ \\
\hline \multirow{2}{*}{$\begin{array}{l}\text { Change the time when the e-mail was } \\
\text { sent }\end{array}$} & \multirow[t]{2}{*}{2} & 0 & 2 & 0 & 2 \\
\hline & & $(0 \%)$ & $(100 \%)$ & $(0 \%)$ & $(100 \%)$ \\
\hline \multirow{2}{*}{$\begin{array}{l}\text { Suggestions for changes to the study } \\
\text { design }\end{array}$} & \multirow[t]{2}{*}{24} & 10 & 14 & 12 & 12 \\
\hline & & $(41.7 \%)$ & $(58.3 \%)$ & $(50 \%)$ & $(50 \%)$ \\
\hline
\end{tabular}




\section{Appendix C - Task assessment}

Table C.1. Participants' assessment of the ten tasks and the codes for the reasons for removal.

\begin{tabular}{|c|c|c|c|c|c|}
\hline $\begin{array}{l}\text { Task } \\
\#\end{array}$ & Content & $\begin{array}{l}\text { How } \\
\text { well? } \\
\text { M; } \\
\text { SD } \\
\text { (n=68 } \\
\text { ) }\end{array}$ & $\begin{array}{l}\text { Diffi- } \\
\text { culty } \\
? \\
M ; \\
\text { SD } \\
\text { (n=68 } \\
\text { ) }\end{array}$ & $\begin{array}{l}\text { \# remove } \\
(\mathrm{N}=135)\end{array}$ & Reason for removal \\
\hline 10 & Write & $\begin{array}{l}1.87 ; \\
1.56\end{array}$ & $\begin{array}{l}3.34 \\
1.97\end{array}$ & $\begin{array}{l}84 \\
(62.22 \%)\end{array}$ & $\begin{array}{l}\text { Inconvenient for daily life }(N=54) \text {; Too } \\
\text { difficult/hard to maintain }(N=26) \text {; Task } \\
\text { not very common }(N=4) \text {. }\end{array}$ \\
\hline 3 & Use cards & $\begin{array}{l}3.30 \\
1.19\end{array}$ & $\begin{array}{l}2.85 \\
1.28\end{array}$ & $\begin{array}{l}33 \\
(24.44 \%)\end{array}$ & $\begin{array}{l}\text { Task not very common }(n=12) \text {; Too } \\
\text { difficult/hard to maintain }(n=7) \text {; } \\
\text { Inconvenient for daily life }(n=7) \text {; Using } \\
\text { non-dominant hand or both hands } \\
\text { anyway }(n=3) \text {; Too easy }(n=2) \text {; Task } \\
\text { description unclear }(n=1) \text {. }\end{array}$ \\
\hline 8 & $\begin{array}{l}\text { Use } \\
\text { mobile } \\
\text { phone }\end{array}$ & $\begin{array}{l}2.75 \\
1.18\end{array}$ & $\begin{array}{l}3.52 \\
1.15\end{array}$ & $\begin{array}{l}32 \\
(23.70 \%)\end{array}$ & $\begin{array}{l}\text { Too difficult/hard to maintain }(n=20) \text {; } \\
\text { Task not very common }(n=7) \text {; Using } \\
\text { non-dominant hand or both hands } \\
\text { anyway }(n=5) \text {. }\end{array}$ \\
\hline 1 & $\begin{array}{l}\text { Switch } \\
\text { lights } \\
\text { on/off }\end{array}$ & $\begin{array}{l}3.78 \\
1.19\end{array}$ & $\begin{array}{l}3.07 ; \\
1.42\end{array}$ & $\begin{array}{l}22 \\
(16.30 \%)\end{array}$ & $\begin{array}{l}\text { Too easy }(n=11) \text {; Task description } \\
\text { unclear }(n=6) \text {; Using non-dominant } \\
\text { hand or both hands anyway }(n=5) \text {; Too } \\
\text { difficult/hard to maintain }(n=3) \text {; Task } \\
\text { not very common }(n=2) \text {. }\end{array}$ \\
\hline 7 & $\begin{array}{l}\text { Pick-up } \\
\text { and carry } \\
\text { items }\end{array}$ & $\begin{array}{l}3.22 \\
0.96\end{array}$ & $\begin{array}{l}3.43 \\
1.00\end{array}$ & $\begin{array}{l}22 \\
(16.30 \%)\end{array}$ & $\begin{array}{l}\text { Task not very common }(n=7) \text {; Too } \\
\text { difficult/hard to maintain }(n=6) \text {; Using } \\
\text { non-dominant hand or both hands } \\
\text { anyway }(n=6) \text {; Task description unclear } \\
(n=3) \text {. }\end{array}$ \\
\hline 9 & Eat & $\begin{array}{l}2.69 \\
0.85\end{array}$ & $\begin{array}{l}2.96 \\
1.22\end{array}$ & $\begin{array}{l}19 \\
(14.07 \%)\end{array}$ & $\begin{array}{l}\text { Too difficult/hard to maintain }(n=11) \text {; } \\
\text { Inconvenient for daily life }(n=5) \text {; Using } \\
\text { non-dominant hand or both hands } \\
\text { anyway }(n=3) \text {. }\end{array}$ \\
\hline 2 & $\begin{array}{l}\text { Open/ } \\
\text { close }\end{array}$ & $\begin{array}{l}3.02 ; \\
1.16\end{array}$ & $\begin{array}{l}3.05 \\
1.07\end{array}$ & $\begin{array}{l}17 \\
(12.59 \%)\end{array}$ & $\begin{array}{l}\text { Using non-dominant hand or both hands } \\
\text { anyway }(n=9) \text {; Too difficult/hard to }\end{array}$ \\
\hline
\end{tabular}




\begin{tabular}{|c|c|c|c|c|c|}
\hline & $\begin{array}{l}\text { zippers } \\
\text { and } \\
\text { buttons }\end{array}$ & & & & $\begin{array}{l}\text { maintain }(n=4) \text {; too easy }(n=2) \text {; Task } \\
\text { not very common }(n=2) \text {; Task } \\
\text { description unclear }(n=1) \text {. }\end{array}$ \\
\hline 4 & $\begin{array}{l}\text { Press } \\
\text { buttons }\end{array}$ & $\begin{array}{l}3.32 \\
1.11\end{array}$ & $\begin{array}{l}3.47 \\
1.13\end{array}$ & $\begin{array}{l}15 \\
(11.11 \%)\end{array}$ & $\begin{array}{l}\text { Too easy }(n=6) \text {; Task description } \\
\text { unclear }(n=5) \text {; Task not very common } \\
(n=2) \text {; Using non-dominant hand or } \\
\text { both hands anyway }(n=2) \text {. }\end{array}$ \\
\hline 6 & $\begin{array}{l}\text { Open } \\
\text { doors }\end{array}$ & $\begin{array}{l}3.37 \\
1.07\end{array}$ & $\begin{array}{l}3.20 \\
1.21\end{array}$ & $\begin{array}{l}15 \\
(11.11 \%)\end{array}$ & $\begin{array}{l}\text { Using non-dominant hand or both hands } \\
\text { anyway }(n=9) \text {; Too easy }(n=4) \text {; Too } \\
\text { difficult/hard to maintain }(n=2) \text {. }\end{array}$ \\
\hline 5 & $\begin{array}{l}\text { Drink } \\
\text { using a } \\
\text { cup or a } \\
\text { mug, } \\
\text { bottle }\end{array}$ & $\begin{array}{l}3.61 ; \\
0.95\end{array}$ & $\begin{array}{l}2.80 \\
1.18\end{array}$ & $\begin{array}{l}2 \\
(1.48 \%)\end{array}$ & $\begin{array}{l}\text { Inconvenient for daily life }(n=1) \text {; Using } \\
\text { non-dominant hand or both hands } \\
\text { anyway }(n=1) \text {. }\end{array}$ \\
\hline
\end{tabular}





\section{Chapter 8}

General discussion

Partially based on:

Kip, H., Oberschmidt, K., \& Bierbooms, J. J. (2020). eHealth Technology in Forensic Mental Healthcare: Recommendations for Achieving Benefits and Overcoming Barriers. International Journal of Forensic Mental Health, 1-17.

Kip, H. \& Bouman, Y.H.A. (2020). Van denken en praten naar doen en ervaren: op zoek naar de toegevoegde waarde van technologie voor de forensische psychiatrie.

Sancties, 56(4),249-260. 


\section{Summary}

In the introduction of this thesis (Chapter 1), it became clear that while eHealth has a lot of potential to improve forensic mental healthcare, there is much unchartered territory, mostly related to the ways in which this added value can be achieved. This resulted in the two main goals of this thesis: one more concrete, and the other more abstract. The first goal was to determine how and why eHealth interventions can be of added value for forensic mental healthcare. The second goal was to provide more insight into how eHealth interventions can optimally be developed, implemented and evaluated in complex contexts. In order to reach these goals, the thesis was divided into three parts. The first part was focused on the current state of affairs of eHealth in forensic mental healthcare. It contained a systematic review on the use of technology in treatment of offenders (Chapter 2) and a mixed-methods evaluation of the implementation of a web-based intervention that was already being used in clinical practice (Chapter 3). The second part of this thesis was focused on the participatory development of virtual reality (VR) - a technology that seemed to be especially promising for forensic mental healthcare due to its unique characteristics. In Chapter 4, the points of improvement of the current in-person treatment and ways in which VR could address those were analysed. Chapter 5 elaborated on this by describing the development of values that specified what the added value of VR for treatment of forensic psychiatric patients should be. In Chapter 6, the entire participatory development process that led to the development of the 'Triggers \& Helpers' application was described and analysed. Finally, the third part of this thesis was focused on the evaluation of eHealth. In Chapter 7, another type of eHealth intervention that could add something new to treatment - a self-control training app - was optimized using two research designs that are suitable for eHealth evaluation.

In this thesis' final part, the general discussion, the main findings regarding the added value, adaptiveness and development, implementation and evaluation of eHealth are presented. Next, the main implications of these findings for research and practice are discussed in light of other research. In the following section, several points of improvement of the CeHRes Roadmap - the backbone of this thesis - are presented. Furthermore, several promising directions for future research that arise from this thesis are provided. Following that, the major strengths and limitations of the methods used in this thesis are considered. All of this results in the main conclusions that are drawn based on the work that is presented in this thesis. 


\section{Main findings}

\section{1 eHealth has to be of added value to improve quality of care}

"eHealth interventions have to offer something new and unique that cannot be achieved in regular, in-person treatment."

Based on the findings of this thesis it can be concluded that, to truly be of added value and thus to meaningfully increase the quality of care, technologies need to offer something new and unique that cannot be achieved by means of the existing, inperson treatment approach. The systematic review (Chapter 2 ) and the evaluation of implementation of a web-based intervention (Chapter 3) made clear that currently, mostly language-based interventions are used. These types of technologies are often based on or replace specific parts of existing treatment, such as psycho-education or assignments from cognitive behavioural therapy (CBT). While we identified multiple mostly potential - advantages of these types of eHealth interventions, such as increased efficiency, increased accessibility of treatment and an increased feeling of independence and ownership in patients $[1,2]$, these interventions do not seem to have a large, positive impact on the quality of care of forensic psychiatric patients. A technology that does have potential to change forensic mental healthcare is virtual reality (VR). We showed that, according to stakeholders, interactive, highly personalized VR does indeed have much potential to overcome current points of improvement of forensic mental healthcare since VR can offer many new possibilities for patients and therapists [3-5]. Amongst other things, by means of VR skill training in realistic virtual environments can take place, and both therapists and patients can gain more insight into how a patient responds to challenging situations or stimuli. Furthermore, we have introduced another type of intervention that can have a major impact on treatment of forensic psychiatric patients is a self-control training (SCT) app. This intervention targets the automatic processes that underlie self-control in a way that does not require a high level of cognitive skills [6]. These types of technologies can be used to deliver novel types of interventions that can influence risk factors that are difficult to target with existing treatment - which often requires deliberate reflection on behaviours, emotions and cognitions. Especially due to the complex nature of treatment of forensic psychiatric patients, eHealth should be used in a blended way, which means that technology and in-person care should be merged in order to combine the best of both worlds. In general, this thesis showed that eHealth interventions can offer many new possibilities to deliver and further improve interventions that do not require high levels of literacy and can overcome problems with treatment motivation and reflective abilities. 


\subsection{Adaptiveness of technology, people and context}

"In order for eHealth to be of added value, technology, people and context should all be flexible and adaptive to ensure a good fit."

Another main finding of this thesis is that in order for eHealth to reach its potential added value, it is important that technology, people and context are flexible and can be adapted to each other. First, the content and design of a technology should be adaptable in order to seamlessly fit the characteristics, points of improvement and values of a specific treatment setting. To illustrate, in Chapter 2 we concluded that a one-size-fits-all approach is not suitable for the broad and complex forensic psychiatric patient population [1]. Additionally, Chapters 4 and 5 on the added value of VR underlined the importance of personalization of virtual scenarios to ensure that they are aligned with the stable and dynamic risk factors of a specific patient $[3,4]$. Finally, the evaluation of the SCT app showed that participants required more possibilities for personalization of the intervention [6]. According to our systematic review, personalization is indeed considered to be a major point of improvement of most existing eHealth interventions in treatment intervention [1]. Consequently, more and more researchers and practitioners agree on the importance of adaptive eHealth interventions. However, while this topic has been receiving an increasing amount of attention, the adaptiveness of the context and people involved remains quite underexposed. Consequently, based on this thesis, it can also be concluded that in order to ensure that an adaptive eHealth intervention is fully integrated in an organization, the context in which it is used should also be adaptive. For example, in Chapter 3 we concluded that an important reason for the low uptake of the eHealth intervention was the lack of its integration in existing procedures, habits of the therapists and systems [2]. Additionally, in Chapter 4 and 5 it became clear that in order for VR to reach its added value, a necessary precondition is that it should not be used as a separate addition, but should become an integrated part of existing inperson treatment, which required much practical and content-related support from the organization [3, 4]. All of this implies that organizations have to make major changes to the way care is delivered in order to optimally benefit from the possibilities of eHealth and that it should not be viewed as a stand-alone tool. Finally, besides the technology and context, the participants and patients that use an eHealth intervention need to be adaptive. In Chapter 2 it was shown that many, but not all therapists had the required technical skills to use the web-based intervention. However, more important factors seemed to be a willingness to just start with experimenting with different parts of the intervention and the ability to integrate the 
eHealth intervention in treatment, as opposed to viewing it as a separate addition. The studies on the potential of VR also underlined the importance of skills, which surpassed merely technical skills: therapists require a flexible state of mind and new way of thinking about blended treatment in which eHealth and in-person care are merged. Embedding an eHealth intervention within an organization requires changes in the way in which care is organized, and because eHealth enables new ways of working, this also has implications for the roles and tasks of therapists. To conclude, this thesis has shown that technology should be able to be adapted to fit the specific characteristics and requirements from its users and the context, that the context in which eHealth is used should be adapted to fit the characteristics of a technology and needs of the people involved, and that the people that use eHealth should be able to adapt a technology in such a way that it seamlessly fits with a context and the needs of the users.

\subsection{Adaptiveness of eHealth development, implementation and}

\section{evaluation}

"eHealth development, implementation and evaluation should be seen as flexible, iterative processes in which research methods are adapted to the context and people."

Throughout this entire thesis, attention is paid to the holistic development [3-5], implementation [2] and evaluation [6] of eHealth. An important finding that arose from these studies is that research methods and the development, implementation and evaluation processes themselves should be flexible and adaptive in order to fit the practical requirements from the context, the preferences and skills of the participants, and the characteristics of technologies. These processes should not be too structured and rigid, but also not too flexible and ad hoc, which demonstrates the importance of finding a balance between a systematic yet flexible approach. An agile approach and a flexible yet systematic mindset of eHealth developers are advised to find and maintain this balance. To illustrate, Chapters 4 and 6 illustrated that in order to collect data that is as valuable as possible for future development activities, it is important to select research methods based on three different elements: the specific goal of a phase, the characteristics of the participants, and practical requirements from the context $[4,5]$. Additionally, in Chapter 5 we have shown that while a development process should be systematic and structured, it still can be very flexible and adaptive, meaning that decisions for next activities are made based on findings, new insights and experiences that arose from previous activities [5]. Adaptivity is not 
only an essential concept for development, but also for implementation. In Chapters 2 and 3 of this thesis, we concluded that implementation of eHealth is an activity of which the importance and complexity is often underestimated and is still often viewed as a post-design activity [1, 2]. To overcome implementation issues in research and practice, more attention should be paid to the complex interrelationships between the multiple levels and perspectives that are intertwined within implementation processes, already from the start of the development process. Consequently, implementation strategies should be adapted to fit the perspective of the therapists and patients involved, the organization in which an eHealth intervention is used, requirements from the wider context such as government or health insurers, and the characteristics of the technology used [2]. Finally, regarding the adaptiveness of eHealth evaluation, research designs should be selected that do justice to its holistic nature and again practical requirements from practice and characteristics of the participants. To illustrate, in Chapter 3 , in which the implementation of a web-based intervention was evaluated, we showed that a mixed-methods approach in which qualitative interview and desk research data were merged with quantitative log data, does justice to the holistic, multi-level nature of implementation. Additionally, in Chapter 7 we showed the importance of using multiple evaluation designs that account for the characteristics of a technology. The full factorial design and overall approach that was based on the MOST design did not only provide insight in effectiveness, but also resulted in outcomes that were useful for the further optimization of the SCT app. To conclude, this thesis has shown that eHealth development, implementation and evaluation should all be viewed as flexible, dynamic processes that should be adapted based on recent insights, characteristics from participants and requirements from practice.

\section{Implications for research and practice}

\subsection{The added value of eHealth for forensic mental healthcare}

By means of the studies in this thesis, it has become clear that eHealth has the potential to enable major changes in the way mental healthcare is delivered: not only for forensic, but also other types of psychiatric patients [1, 7]. In Chapter 4, multiple points of improvement of current forensic mental healthcare were identified [4]. Technology can offer multiple ways in which to overcome some of these issues. A first point of improvement is that, while specific skills, such as social and emotion regulation skills, are essential for patients to deal with 'triggering' situations, it is often not possible to train these skills in a realistic context during in-person treatment, 
which mostly takes place in treatment rooms. VR offers multiple ways to improve this skills in context by means of its ability to elicit a sense of presence in the users, meaning that users have the sense of actually being in a virtual environment and experiencing the accompanying emotions. From a practical point of view, the main advantage of $V R$ is that patients can be transferred to environments that would otherwise have been hard to access [4, 8-12]. Because of this possibility, VR interventions do not only have an enormous potential for treatment of offenders, but also for many other types of mental healthcare such as treatment of specific phobias, psychosis or eating disorders [13-17].

A second point of improvement is the cognitive focus of most existing treatment sessions. These types of 'talking therapies' are not only challenging for many patients who have trouble with deliberate reflection, but are also not very suitable to address the automatic aspects of behaviour, such as biases. An example of an eHealth intervention that addresses this topic is the SCT app that we developed and evaluated [6]. Another example from other research is an app that targets cognitive approach biases towards alcohol by means of alcohol avoidance training (AAT), in which the user has to push away pictures of alcoholic beverages and pull non-alcoholic beverages towards themselves, which can result in changes in the reaction and thinking patterns in one's brain, and has shown to be able to reduce alcohol intake $[18,19]$. This approach has recently been extended to influence biases towards angry faces in a gamified VR intervention [20]. Consequently, these types of interventions can cause a paradigm shift in mental healthcare by enabling treatment of the more automatic components of behaviour.

A third point of improvement we identified is that therapists are often dependent on the information that patients provide during treatment, but this is not always fully reliable due to for example memory or social desirability biases. Technology offers multiple ways to gather contextual, continuous data that can be valuable for treatment. Examples are mobile apps that allows experience sampling on emotions or specific risk factors throughout the day, or wearables that collect physiological data [7, 21, 22]. To further illustrate, research has shown that heart rate and skin conductance rise in the 20 minutes preceding aggressive outbursts in forensic psychiatric inpatients [23]. A possible application of this finding is that by means of these data, individual prediction models can be generated that allow for just-in-time coaching in order to prevent reactive aggression. Based on all of the above it can be concluded that there are multiple types of innovative eHealth interventions that can increase the quality of care by unlocking new possibilities for 
treatment. However, more research is needed to gain more insight into the relationships between the possibilities of a technology and the types of advantages it can have for healthcare.

\subsection{Cognitive and experiential eHealth}

In order to gain more insight into what type of advantages different types of eHealth interventions can offer, a distinction can be roughly made between two different types of eHealth interventions. On the one hand, there are interventions that are mostly reliant on deliberate cognitive skills such as reading, writing or talking about behaviours, feelings and cognitions. Examples are web-based interventions or apps that are based on cognitive behavioural therapy, or the delivery of standard treatment via videoconferencing. These types of technologies are mostly used to replace specific parts of therapy that are usually delivered in-person and have the potential to increase efficiency and might even improve a patient's sense of ownership for treatment. Because of the important role that deliberate cognitive processes such as attention, memory and reflection play in these types of interventions, they can be viewed as 'cognitive eHealth'. On the other hand, this thesis has shown that there also are eHealth interventions that can offer new possibilities that cannot be achieved in in-person treatment. Examples are practicing with behaviour in context and observing realistic situations in VR, the use of wearables to monitor and coach behaviour based on physiological or experience sampling data, and the use of apps that target automatic processes, such as the self-control training app. While there are many differences, these types of technologies are connected by an emphasis on doing and experiencing in relevant contexts, and they do not require much deliberate cognitive reflection via reading, talking or writing. Consequently, these types of interventions can be referred to as 'experiential eHealth', because this term refers to the process in which knowledge and meaning are created by grasping and transforming real-life experiences $[24,25]$. The studies in this thesis have shown that both cognitive and experiential eHealth interventions can be of added value for mental healthcare, with the former offering more practical benefits, and the latter enabling new ways of treatment.

While these novel experiential eHealth interventions have much potential, a pitfall is that they follow Gartner's hype cycle: after an initial peak of inflated expectations, a technology ends up in the trough of disillusionment [26]. Indeed, many new eHealth interventions are introduced in healthcare, without carefully considering why and how they should be used; it is not clear what problems or points 
of improvements they address [7, 27]. In order to ensure that these problems don't occur with these types of innovative eHealth interventions, it is important to prevent that eHealth is viewed as a separate element: we should always carefully consider what new possibilities an intervention should bring to an existing situation, and how it should be used in a blended way in order to fully integrate eHealth in-person treatment [28].

\subsection{Integrating eHealth in forensic mental healthcare}

In order to optimally benefit from the benefits of technology, eHealth interventions should be integrated within treatment. In Chapter 1 of this thesis, it was explained that the Risk-Need-Responsivity (RNR) model is currently one of the most, if not the most predominant approach to reduce reoffending in forensic psychiatric patients $[29,30]$. The need-principle of the RNR-model states that treatment should focus on reducing the specific dynamic risk factors of individual patients [30]. eHealth interventions offer novel ways to address multiple types of risk factors. For example, when looking at stable dynamic risk factors, eHealth interventions such as web-based modules or apps can be used to teach patients about generic skills that can support them in improving their functioning at work or building a healthier social network [1]. Furthermore, role-playing in VR can be used to address more acute dynamic risk factors such as impulse control [8,31]. The VR intervention that was developed in this thesis, Triggers \& Helpers, can be used to address a broad range of (acute) dynamic risk factors because of its high level of adaptiveness and almost endless possibilities for personalization.

Because eHealth interventions can be used to make healthcare more efficient and to-the-point, they can also support the operationalization of the riskprinciple of the RNR model, which prescribes that the intensity of treatment should be adapted to the risk that a specific patient poses. This means that high-risk patients require more intensive and frequent treatment than patients that show lower risk of re-offending and committing severe crimes. However, this is easier said than done, especially considering the increasing number of forensic psychiatric patients, combined with a shortage of staff and budget cuts in forensic mental healthcare [3234]. As our review and other work has stated, technologies such as web-based modules and mobile apps offer the opportunity to deliver treatment to patients regardless of time, place and availability of staff $[1,7,33,35]$, and can thus address the risk-element of the RNR-model. 
Finally, by means of the studies in this thesis we have shown that eHealth interventions should be adaptive, which is in line with the responsivity-principle of the RNR-model. According to this principle, treatment should be adapted to the needs and characteristics of an individual forensic psychiatric patient [30]. This implies that existing and new eHealth interventions should be highly personalized in order to make them more responsive. Additionally, in order to work in a responsive way, therapists can also use different types of eHealth interventions, such as a combination of VR, biofeedback and an experience sampling app. While the advantages of combining technologies are clear, this is again easier said than done since this requires much expertise, which highlights the need for fitting education and training [7, 36]. It has become clear that eHealth interventions seem to fit well within the RNR model, but more research is necessary in order to determine in what way this should be achieved. In general, we recommend that eHealth interventions should be embedded within current, evidence-based treatment approaches in order to be of added value for patient and therapist. In forensic mental healthcare, the RNR-model or possibly the Good Lives Model offer fitting frameworks for the integration of eHealth in treatment $[30,37]$. In other domains, researchers should identify frameworks or models that are suitable for that specific domain and investigate how technology fits within these approaches.

\subsection{Bolstering self-control with eHealth}

The previous implications have made clear that in forensic mental healthcare, eHealth interventions can be connected to risk factors, and also have to bring something new to the table in order to be of added value. The SCT-app that was developed and evaluated in this thesis is an example of this since it targets self-control, an important risk factor for offending. A meta-analysis has identified an effect size over .20 of low self-control on criminal behaviour, which shows that self-control - the ability to prevent or override unwanted thoughts or behaviours [38] - is one of the strongest correlates of crime [39]. Since the exertion of self-control is not just related to conscious or effortful processes $[40,41]$; it can partly be seen as an automatic process, which is hard to target with the currently predominant 'talking therapies' such as cognitive behavioural therapy [42]. Consequently, in order to search for new ways to target self-control via technology, we found that an SCT-app - an evidencebased, 'experiential eHealth'-intervention - can be used to bolster self-control and thus has the potential to reduce reactive aggression [42-46]. Additionally, self-control is not only a major predictor for crime $[47,48]$, but also for a broad range of goal- 
driven behaviour [49]. A review on self-control in general has identified five broad domains in which it is related to positive outcomes: achievement and task performance (for example grades or school performance), impulse control (for example in reactive aggression), psychosocial adjustment (for example depression or anxiety), interpersonal functioning (for example relationship satisfaction) and moral emotions (for example shame or guilt) $[40,49]$. On the one hand, this shows the relevance of self-control interventions for forensic mental healthcare, since these five domains encompass many different dynamic risk factors and increased self-control can help offenders in increasing their behaviour in those five domains [50,51]. On the other hand, it also shows the huge potential of eHealth interventions that target the more impulsive, automatic part of self-control for many other settings, such as treatment of specific disorders such as depression or addiction, or more general positive behaviours related to for example school performance, healthy eating or physical activity. It is important to note that SCT should not be viewed as a standalone intervention, mostly because self-control is only relevant when a patient wants to reach specific goals. This means that it can be combined with existing, goal-driven interventions that target the reflective part of behaviour, and thus resulting in a more comprehensive way of changing behaviour [43, 52].

While the SCT app offers novel ways to increase self-control that are not possible in in-person treatment, more research is needed in order to make more robust claims about the SCT's app added value. For example, to unravel its benefits for forensic mental healthcare, it needs to be studied in a sample of forensic psychiatric patients by means of suitable research designs. Additionally, using our work as a foundation, further research is needed to study the effects of the design of a technology on this app, answering questions about whether gamification or additional reminders can further bolster its effects by increasing engagement and adherence to these types of interventions [53]. Finally, the SCT app should be studied in other target groups to investigate whether it can for example increase academic performance in students, dieting in people with obesity, or physical activity in people with mental illness. However, if the SCT app is used in other samples, it is important to initiate a new development process in order to ensure that the version of the app fits the needs and preferences of a new target group: adaptivity is again an important concept when using these types of eHealth interventions in practice. 


\subsection{The adaptiveness of eHealth}

Throughout this thesis it has become clear that one of the main advantages of eHealth interventions is that they can be adapted to fit the individual use. Unfortunately this is not common practice yet, making personalization one of the most important challenges in eHealth research [1]. While general consensus seems to be that personalization is important for eHealth $[35,53,54]$, it currently is used as an umbrella term. For example, when looking at VR, different types of VR have different possibilities of personalization. To illustrate, an intervention in which users can select different types of non-interactive 360-videos to expose inpatients to daily life outside of closed settings; and role-playing in a virtual world in which the environment, virtual actors and stimuli can all be adapted to an individual patient can both be referred to as personalized VR, while the extent of personalization is clearly very different and they can be of added value in very different ways $[7,10]$. In order to prevent confusion about what is meant with personalization and to make it easier to clarify the potential of these types of interventions, it might be sensible to create different terminologies. A distinction might be made between fixed, personalized and adaptive VR. Fixed VR can refer to for example pre-recorded 360-videos in which no changes can be made to the content and design of VR. While participants can choose which non-interactive VR video they want to use, all users receive the same version of these videos. In personalized VR, the general framework of an intervention is fixed, but parts can be adapted to fit individual patients. An example is a virtual roleplaying intervention with a predetermined environment, topic and behaviour, but elements, such as minor events within this environment and the content of the conversation in VR can be adapted to individual patients [8]. Finally, adaptive VR can be viewed as an intervention with no predetermined framework: all elements can be adapted to fit individual patients. The highly flexible 'Triggers and Helpers' VR-application that was developed by means of the work in this thesis is an example of this: by means of virtual 'building blocks', unique VR scenarios can be generated that seamlessly fit the risk factors and characteristics of a broad range of patients. Finally, it is important to note that thorough development in which end-users are actively involved is required to identify the way in which eHealth should be personalized, for example, to gain insight into the factors that should be adaptable. To illustrate, in the development of our highly adaptive VR application, we determined that the type of virtual environment, the appearance of the virtual avatars, their verbal and non-verbal behaviour, and the triggers and helpers should all be adaptable in order to optimally fit the needs from practice and we discussed the specific options extensively with therapists, patients 
and VR designers. This shows the importance of participatory, interdisciplinary development in the creation of personalized eHealth interventions.

\subsection{Adaptive development with vulnerable target groups}

By means of our research we have concluded that, in order to create eHealth interventions in which there is a good fit between technology, people and context, actively involving users in development processes is challenging but very valuable. Participatory development with vulnerable target groups such as forensic psychiatric patients is especially important, since their skills and characteristics are very different from those of developers, who often mostly reason from their own perspectives. Despite its importance, not much is known about how to best involve vulnerable target groups $[1,7,55]$. In order to prevent a top-down approach in our development process, we actively involved forensic psychiatric patients from the start, as part of the development team and by means of asking for their input via multiple research methods [3-5]. While this resulted in very valuable insights and a personalized VR application that fits the predetermined values of the stakeholders, this approach was both time-consuming and challenging. It appeared to be difficult to select methods that yielded valuable information from patients and that fit their characteristics. To illustrate, while semi-structured interviews on points of improvements fit the contextual inquiry and specific research questions, it was challenging to involve patients, which can partly be explained by their low motivation to participate or difficulties with reading, writing and abstract reasoning [4, 5]. Research methods in which we used prototypes, scenarios or existing examples resulted in outcomes that were more valuable for the development process [5]. This example shows that in cocreation, especially with vulnerable target groups, it is beneficial to use concrete examples as opposed to merely asking patients about their needs and wishes $[4,56]$. Furthermore, it can also be concluded that selecting fitting research methods in development is important. In our development process, experiences of researchers, therapists and patients in the team that coordinated the project team proved to be helpful, which shows the importance of an interdisciplinary project team. Additionally, there is a need for more knowledge on how to design novel eHealth interventions for and with complex, hard-to-reach vulnerable patient populations such as forensic psychiatric patients [57]. 


\subsection{Adaptive, mixed-methods evaluation processes to evaluate eHealth}

In this thesis we illustrated the importance of determining the added value of eHealth for a specific context. The formulation of values is a way to provide an overview of what an eHealth intervention should add or change within an existing situation [3]. In order to determine whether an eHealth intervention actually resulted in these improvements and changes, evaluation should ideally be based on these values. Since there are multiple types of values, for example related to generalization of acquired skills in VR to 'real life', increased treatment motivation in patients, good fit within existing treatment and financial benefits for the organization [3], multiple methods are required to gain insight into the extent to which these values are realized in practice. Recent insights into eHealth research emphasize the importance of pragmatic approaches that emphasize usefulness, acceptability and feasibility of new technologies $[58,59]$. However, currently, eHealth evaluation is focused mostly on quantitative evaluation of effectiveness on patient-related outcomes using RCTs [59, 60]. Consequently, to show a different approach towards eHealth evaluation, we used a pre-post-design without control group, a full factorial design and qualitative research to evaluate optimize the SCT app in a pragmatic way. Our approach illustrates that in evaluation, eHealth interventions should not be viewed as fixed, 'locked-down' tools, but as adaptive, flexible means to an end that can and should continuously be adapted based on new insights, using pragmatic methods that fit the characteristics of a technology [59]. Besides factorial designs, there are of course many other evaluation designs that can be used to evaluate eHealth in context and can overcome the limitations of RCTs. An example of a design that is viewed as suitable for eHealth is a single-case experimental design (SCED) [61]. SCEDs can be used to follow an individual in-depth by using themselves as their own control condition, while also accounting for practical difficulties such as problems with acquiring a large sample of homogeneous participants and differences or changes in the design and content of interventions $[61,62]$. While these types of quantitative designs can offer many relevant insights, this thesis has also shown the value of qualitative research by means of the evaluation of the SCT app and implementation of the web-based intervention. In order to paint a complete picture of the added value of an eHealth intervention, we recommend a mixed-methods approach in which different types of data are merged $[63,64]$. To conclude, this thesis has shown the importance of an iterative approach towards eHealth evaluation in which multiple suitable and pragmatic research designs are combined in order to evaluate its added value in context. 


\section{Suggestions for improvement for the CeHRes Roadmap}

This thesis was based on the principles and phases of the CeHRes Roadmap $[65,66]$. In general, we can conclude that the Roadmap offered valuable guidelines for the participatory and iterative development, implementation and evaluation of eHealth. It was especially useful in ensuring that we constantly kept an eye on the context, selected suitable research methods from different disciplines such as psychology and human-centred design, and applied an iterative approach during which constant changes were made, while still maintaining a clear structure and focus [5]. However, by means of the work presented in this thesis, several points of improvement for the CeHRes Roadmap and other similar development models and approaches can be identified.

\subsection{Contextual inquiry, value specification and design}

Despite several differences on an abstract level, we noticed that there was much overlap between the research and development activities of the contextual inquiry, value specification and design phases. Amongst other things, the interviews and questionnaires that were focused on the points of improvement and possibilities of VR were relevant for both the contextual inquiry and value specification [4]. Additionally, in the value specification, multiple methods from the design phase were used, for example prototyping to gain insight into values, and requirement formulation in the design phase instead of value specification [3]. Consequently, elements of the value specification might either be integrated in the contextual inquiry and design phase, or the focus and perhaps name of the value specification phase might be adapted to clarify the main conceptual differences with the other two development phases. In line with this, several changes can be made to the way the Roadmap is visualized. Currently, it is comprised of separate blocks which are connected by arrows that represent formative evaluation cycles. While the interrelationships are quite clear, this visualization might still suggest a sequential approach due to the separate blocks. This thesis has shown that there is much overlap between development, implementation and evaluation activities, so an updated design of the Roadmap without separate blocks but with intertwined elements might be able to better show these interrelationships.

The main point of improvements that was identified for the design phase is related to the integration of behaviour change theories and domain-specific theories and frameworks in eHealth interventions. While we did consider the fit of our VR intervention with existing frameworks such as the RNR-model and the $I^{3}$ model [30, 
67], the CeHRes Roadmap did not explicitly 'force' us to do this, as opposed activities such as a stakeholder identification or the integration of persuasive elements. Consequently, a separate goal or activity could be added to the design phase to further support developers in better connecting domain-specific theories to eHealth interventions. Finally, the current version of the Roadmap explicitly encourages persuasive design, but more attention should be paid to the integration of evidencebased behaviour change techniques in eHealth interventions, since they offer a broad range of ways to support behaviour change $[68,69]$. More research is needed to determine if and how persuasive features can be combined or complemented with behaviour change techniques [70].

\subsection{Operationalization}

Currently, the operationalization phase of the Roadmap mostly focuses on completing and rolling out a business model. However, as we showed in the evaluation of the implementation of a web-based intervention, much more than only a business model is required [2]. Consequently, the goals of this phase can be expanded by adding the formulation of value-based implementation outcomes and implementation strategies that are adapted to the relevant context and people $[2,71,72]$. Also, more attention can be paid to the operationalization of (parts of) existing implementation frameworks into an implementation plan. Examples of frameworks that account for the holistic nature of eHealth are the NASSS or CFIR frameworks, since they account for the many different types and levels of factors related to the people, context and (eHealth) intervention $[73,74]$. Finally, it might be worth considering to change the name of this phase to 'Implementation', since this term might better fit the predominant terminology used in the domain of eHealth. On the other hand, a pitfall of this term is that it might imply that implementation is a post-design activity instead of a process that is intertwined with development and is relevant from the start [27]. This shows the importance of a good definition of this phase and an adapted design of the Roadmap that illustrates the interrelationship of development and implementation to do justice to the complex, multi-level and essential nature of this phase. 


\subsection{Summative evaluation}

While the current summative evaluation phase of the CeHRes Roadmap contains a broad range of research topics that might be considered, several additions and a clearer underlying approach and vision might be useful. First of all, a more processoriented approach towards evaluation can be emphasized, for example in line with the MOST design. Just as eHealth development, evaluation should be viewed as an iterative process with constant adaptations to process and product. This implies that the Roadmap's current distinction between formative and summative evaluation is too strict and does not do justice to the iterative nature of the summative evaluation process. The term summative evaluation might even imply that it is merely a postdesign activity, as opposed to a way to continuously optimize an eHealth intervention. Consequently, the design of the Roadmap and terminology used might be updated to better reflect the iterative and continuous nature of eHealth evaluation. Perhaps the mere removal of the term 'summative' could prevent any misunderstandings about the post-design and -implementation nature of eHealth evaluation. Furthermore, the connection between values, evaluation objectives and accompanying research methods can be further elaborated to ensure that by means of thorough, iterative, mixed-method evaluation in the intended situation, conclusions can be drawn about the added value of eHealth interventions.

\section{Future research}

While this thesis provided new insights into why and how experiential eHealth interventions such as VR can be of added value for forensic mental healthcare, we are still at the beginning of unravelling if and how VR works for these types of complex target groups [31]. More research on the effectiveness and implementation of VR in forensic mental healthcare is required, using the values that were determined in this thesis as foundation [3]. Another interesting possibility for future research is to focus on the potential of VR to influence predictors of offending, such as self-control. To illustrate, a recent study on VR aggression regulation therapy in forensic psychiatric inpatients showed that, while no direct effects on aggression were found in patients that received the VR intervention, self-reported non-planning impulsiveness was increased directly after the intervention compared to a control group [31]. Even though aggression did not decrease, this study shows the potential of VR to target these types of dynamic risk factors. Furthermore, VR might be combined with technologies that can monitor physiological signals such as heart rate variability and skin conductance, because they might be able to provide more insight into the 
process of losing and maintaining self-control [7, 22]. Future research can also further unravel the working mechanisms of $V R$ in for example treatment of aggression. Amongst other things, it would be interesting to determine the extent to which presence - the feeling of actually being present in a virtual environment - is related to the effectiveness of VR in decreasing reactive aggression [4, 75, 76]. Finally, to further investigate the relationship between arousal, experienced emotions, presence and effectiveness, biofeedback can be used to measure physiological arousal and connect it to experienced emotions and effectiveness [31, 76].

By means of the results of this thesis it has become clear that there are many existing and unexplored ways in which eHealth interventions can target different types of dynamic risk factors that contribute to offending. However, not much is known about how to achieve this. One way to integrate eHealth in treatment guided by the RNR-model is by means of connecting eHealth interventions to risk assessment instruments $[50,51]$, since these instruments provide an overview of the extent to which evidence-based static and dynamic risk factors are expected to contribute to offending in an individual patient. To further integrate the use of eHealth in forensic mental healthcare, an overview of interventions that are considered to be suitable for influencing specific risk factors can be generated. In that way therapists can be supported in selecting the most appropriate interventions for a patient's individual set of risk factors, resulting in a responsive blended treatment [2, 7]. Additionally, since the Good Lives Model, which applies a more positive psychology-approach, has been gaining ground $[37,77]$, it would also be interesting to determine how eHealth fits within this model, for example by determining how eHealth interventions can support offenders in reaching their 'primary goods'. However, it is important to note that merely selecting an eHealth intervention based on risk factors does not suffice: the intervention has to fit the preferences and skills of the therapists and patient. Finally, when evaluating and selecting eHealth interventions, it is important to consider that the effectiveness of treatment is not only a consequence of the specific intervention; it is also influenced by nonspecific factors such as therapeutic alliance, therapist competence and patient's treatment motivation [78]. Future research could also focus on the relationship between these factors and the effectiveness of an eHealth intervention.

A necessary precondition for the integration of eHealth in existing treatment is the active involvement and competence of therapists. Up until now, this topic has been mostly addressed by means of skills training, often only related to technical know-how. However, as was illustrated by our implementation study, merely skills 
training does not suffice for successful implementation, partly because the use of eHealth interventions requires changes in the role of a therapist in treatment $[2,7]$. A potentially relevant concept for this changing role of the therapist is adaptive expertise: the extent to which employees are able to successfully deal with tasks or problems that are new and uncommon to their work domain which requires domainspecific, metacognitive and innovative skills [79,80]. Perhaps such a mindset or personality trait results in a sense of ownership for independently acquiring skills and trying out new eHealth interventions. Consequently, adaptive expertise might be a better predictor of a therapist's competence to use Health than top-down skills trainings. Future research can investigate to what extent adaptive expertise in healthcare professionals predicts successful usage of eHealth interventions, and if and how it can be improved [81].

Finally, an important conclusion of this thesis is that development, implementation and evaluation processes have to be adapted to the phase in the process, the specific research questions, and the characteristics of the participants and research context. While we provided multiple recommendations, it is difficult to empirically test these since this would require multiple parallel development processes for similar technologies in identical settings, which is difficult from both a practical and conceptual point of view $[5,82]$. In order to make more substantiated claims about development processes, more studies that include a critical reflection on the methods used for development, implementation and evaluation are required, using a similar approach as our paper on the development process of VR [5]. If more of these studies are published, a systematic review combined with qualitative research on experiences of researchers can be conducted in order to create a toolkit that can support researchers in selecting the most appropriate and fitting methods for their process, as opposed to choosing the method that they are most familiar with. Such a toolkit can include an overview of advantages, barriers, and recommendations about how to optimally use these methods in practice, and should also contain guidelines on how to approach specific parts of the development process, such as the formulation of values and requirements, and the ways in which they can be used to shape evaluation $[3,83]$. 


\section{Strengths \& limitations}

The work in this thesis has multiple strengths and limitations. One of its main strengths is the use of different types of methods and technologies in order to gather various new insights into the possibilities of eHealth for forensic mental healthcare from multiple perspectives. However, while we used elements from all five phases of the CeHRes Roadmap, it was not possible to apply the entire Roadmap to one eHealth intervention, mostly because developing an eHealth intervention from scratch is very time-consuming $[56,84]$. To illustrate, in the development process of VR, we were not able to conduct usability tests on a next-to-final version of the technology since at the moment of writing this thesis, it is still being programmed by a commercial company. This also means that it was unfortunately not possible to go through the implementation and evaluation process. Regardless, relevant insights into implementation and evaluation were collected by studies on other types of technologies. These findings can serve as a foundation for further implementation and evaluation of the developed VR technology, guided by the CeHRes Roadmap.

Several limitations are related to the generalizability of the findings of this thesis. While in some of our studies data were collected on a national level, most studies were conducted in one organization that offers multiple types of forensic mental healthcare. Because forensic mental healthcare is organized in a similar way in the Netherlands, this probably has not affected the validity of our results. However, a self-selection bias could have influenced the results: people with a negative attitude towards eHealth might not have participated in for example interviews or online questionnaires. To account for this in studies on VR development, we asked participants to provide a broader perspective than merely their own experiences, for example by asking about the opinions and preferences of other patients or therapists. Also, in the implementation study, all therapists working at one clinic participated, so no self-selection bias could have occurred. Finally, it is worth noting that most of our findings were confirmed by other studies from the Netherlands, for example by a large national study we conducted about the current state of affairs and promising directions, and two Dutch reports on VR and wearables [7, 10, 22]. This suggests that our findings are representative for Dutch forensic mental healthcare. Nevertheless, it might be difficult to directly translate all of our findings to other countries. On the one hand because treatment of offenders is organized differently in other countries [85], and on the other hand because the eHealth-climate differs per country [86]. Many countries might not be as far as the Netherlands in their readiness to use novel types of technologies in treatment, or have different requirements, legislation or practical 
preconditions. Regardless, the findings of this thesis are relevant for treatment of offenders on a more general level and the principles and recommendations on eHealth development, implementation and evaluation are provided in an abstract way, which means that they can be operationalized in different countries and settings.

While this study focused on eHealth in forensic mental healthcare, many of our recommendations address eHealth development, implementation and evaluation in general. One might wonder whether the conclusions we drew are just relevant for this specific setting. However, in this thesis, forensic mental healthcare should be viewed as a specific case to which principles and methods are applied in order to be able to draw more general conclusions. Especially because this is such a complex context with hard-to-involve patients, multiple types of stakeholders and many types of undesired behaviour and accompanying treatment, it provides a valuable context to further specify and improve models such as the CeHRes Roadmap. Additionally, we used generic models and frameworks such as human-centred design, the NASSS Framework, and MOST design to guide study designs and interpret our results. Regardless, the results should of course be interpreted with care and more research in which the methods used are applied in different settings is necessary to draw more robust conclusions about eHealth development, implementation and evaluation in context.

\section{Conclusion}

This thesis provided insight into the development, implementation and evaluation of eHealth interventions that can be of added value for forensic mental healthcare. First, we showed that eHealth interventions have much potential to increase efficiency and quality of care, but that there is a big gap between this potential and the current situation. Especially experiential eHealth interventions in which technologies such as VR or wearables are used to monitor and influence subjective experiences in realistic, relevant contexts without requiring much deliberate, cognitive reflection are seen as promising. Since these types of technologies can provide therapists and patients with new possibilities that cannot be achieved in in-person treatment, they have the potential to enable a paradigm shift towards a more biopsychosocial approach towards behaviour change. More cognitively focused interventions such as webbased interventions or videoconferencing appear to be especially suitable for digitalizing parts of existing care in order to increase the efficiency of care and to improve ownership in patients. Generally, these types of interventions are based on existing approaches, which shows that they are an addition to existing care instead of 
a new way of delivering care. Regardless of the type of technology that is used, eHealth can create a shift in the way in which treatment is viewed: by means of technology, patients can be more actively involved in their own treatment and the therapist can - at times - take on a more supporting role instead of always being in the lead. This shift is in line with a positive psychology approach, in which the patient is viewed as a person with agency and not merely an offender.

Second, we concluded that in order for eHealth to be of added value, technology, people and the context should all be adaptive. An important recommendation that arose from this thesis is the possibility to adapt the content and design of eHealth interventions to the needs and characteristics of individual patients, which is especially relevant in the very broad, mixed forensic psychiatric patient population. Additionally, eHealth should not only be implemented in such a way that it fits the intended context, but organizations itself should also be adaptive in order to ensure that eHealth is integrated in their healthcare systems. Ideally, users such as therapists and patients also need to have a flexible mindset in order to get the most out of eHealth. Unfortunately, when looking at the current state of affairs - not just in forensic, but also in many other domains in mental healthcare - much of the potential of eHealth isn't reached yet. This can be explained by means of the focus on adaptive technology: often, the implicit expectation seems to be that an eHealth intervention should automatically fit the organization and therapists, and if this is not the case, it is viewed as unsuitable. More emphasis on the required adaptiveness of healthcare professionals, patients and organizations to integrate adaptive eHealth interventions might overcome many existing problems.

Third, this thesis has shown the importance of holistic and adaptive development, implementation and evaluation processes. In all these processes, the methods used need to fit the phase in the process, the specific research question, the practical requirements that arise from the context and the characteristics of the participants. Furthermore, a holistic approach in which attention is paid to the technology, context and people involved did indeed prove to be valuable in development, implementation and evaluation, underlining the inseparable relationship between these three elements. Finally, this thesis has pointed out that it is crucial to always carefully consider what the added value of an eHealth intervention is for the people involved. Merely using eHealth for the sake of innovating often does not result in improvements. To ensure that eHealth interventions that are of added value for people and healthcare, they should fit the needs, characteristic and wishes that arise from the context and people involved. Based on our work, we can conclude 
that adaptiveness is an essential concept in eHealth: the technology, the people involved, the context in which it is used, and the development, implementation and evaluation processes all have to be adaptive and flexible in order for eHealth to be of added value. 


\section{References}

1. Kip H, Bouman YH, Kelders SM, van Gemert-Pijnen LJ. eHealth in treatment of offenders in forensic mental health: a review of the current state. Frontiers in psychiatry. 2018;9:42.

2. Kip H, Sieverink F, van Gemert-Pijnen LJ, Bouman YH, Kelders SM. Integrating People, Context, and Technology in the Implementation of a Web-Based Intervention in Forensic Mental Health Care: Mixed-Methods Study. Journal of Medical Internet Research. 2020;22(5):e16906.

3. Kip H, Kelders SM, Van Gemert-Pijnen LJ, editors. Putting the Value in VR: How to Systematically and Iteratively Develop a Value-Based VR Application with a Complex Target Group. Proceedings of the 2019 CHI Conference on Human Factors in Computing Systems; 2019.

4. Kip H, Kelders SM, Weerink K, Kuiper A, Brüninghoff I, Bouman YH, et al. Identifying the added value of virtual reality for treatment in forensic mental health: a scenario-based, qualitative approach. Frontiers in psychology. 2019;10:406.

5. Kip H, Kelders SM, Bouman YH, van Gemert-Pijnen LJ. The importance of systematically reporting and reflecting on eHealth development: Participatory development process of a virtual reality application for forensic mental health care. Journal of medical internet research. 2019;21(8):e12972.

6. Kip H, Da Silva, M.C., Bouman, Y.H.A., Gemert-Pijnen, J.E.W.C. van, Kelders, S.M. Can self-control training (SCT) increase self-control and decrease aggression? Two evaluation studies to optimize a SCT app. . Submitted.

7. Kip H, Oberschmidt K, Bierbooms J, Dijkslag D, Kelders S, Roelofsen B. Technologie in de forensische zorg-Crossing borders. Kwaliteit Forensische Zorg. 2019;1.

8. Tuente SK, Bogaerts S, Van Ijzendoorn S, Veling W. Effect of virtual reality aggression prevention training for forensic psychiatric patients (VRAPT): study protocol of a multi-center RCT. BMC psychiatry. 2018;18(1):1-9.

9. Cornet LJ, Van Gelder J-L. Virtual reality: a use case for criminal justice practice. Psychology, Crime \& Law. 2020:1-17.

10. Cornet LJM, Den Besten AL, Van Gelder J-L. Virtual Reality en Augmented Reality in justitiële context. 2019. 
11. Fromberger P, Jordan K, Müller JL. Virtual reality applications for diagnosis, risk assessment and therapy of child abusers. Behavioral sciences \& the law. 2018;36(2):235-44.

12. Trottier D, Goyette M, Benbouriche M, Renaud P, Rouleau J-L, Bouchard S. Using Virtual Reality with Child Sexual Offenders: Assessing Deviant Sexual Interests. Virtual Reality for Psychological and Neurocognitive Interventions: Springer; 2019. p. 209-25.

13. Freeman D, Reeve S, Robinson A, Ehlers A, Clark D, Spanlang B, et al. Virtual reality in the assessment, understanding, and treatment of mental health disorders. Psychological medicine. 2017;47(14):2393-400.

14. Pot-Kolder RM, Geraets CN, Veling W, van Beilen M, Staring AB, Gijsman HJ, et al. Virtual-reality-based cognitive behavioural therapy versus waiting list control for paranoid ideation and social avoidance in patients with psychotic disorders: a single-blind randomised controlled trial. The Lancet Psychiatry. 2018;5(3):217-26.

15. Veling W, Moritz S, Van Der Gaag M. Brave new worlds-review and update on virtual reality assessment and treatment in psychosis. Schizophrenia bulletin. 2014;40(6):1194-7.

16. Botella C, Fernández-Álvarez J, Guillén V, García-Palacios A, Baños R. Recent progress in virtual reality exposure therapy for phobias: a systematic review. Current psychiatry reports. 2017;19(7):42.

17. Ferrer-Garcia M, Pla-Sanjuanelo J, Dakanalis A, Vilalta-Abella F, Riva G, Fernandez-Aranda $F$, et al. A randomized trial of virtual reality-based cue exposure second-level therapy and cognitive behavior second-level therapy for bulimia nervosa and binge-eating disorder: Outcome at six-month followup. Cyberpsychology, Behavior, and Social Networking. 2019;22(1):608.

18. Wiers RW, Rinck M, Kordts R, Houben K, Strack F. Retraining automatic action-tendencies to approach alcohol in hazardous drinkers. Addiction. 2010;105(2):279-87.

19. Laurens MC, Pieterse ME, Brusse-Keizer M, Salemink E, Allouch SB, Bohlmeijer ET, et al. Alcohol Avoidance Training as a Mobile App for Problem Drinkers: Longitudinal Feasibility Study. JMIR mHealth and uHealth. 2020;8(4):e16217. 
20. Smeijers D, Koole SL. Testing the effects of a virtual reality game for aggressive impulse management (VR-GAIME): study protocol. Frontiers in psychiatry. 2019;10:83.

21. Derks YP, Klaassen R, Westerhof GJ, Bohlmeijer ET, Noordzij ML. Development of an Ambulatory Biofeedback App to Enhance Emotional Awareness in Patients with Borderline Personality Disorder: Multicycle Usability Testing Study. JMIR mHealth and uHealth. 2019;7(10):e13479.

22. Cornet LJM, Mandersloot $\mathrm{M}$, Pool $\mathrm{R}$, De Kogel CH. De'zelfmetende'justitiabele: Een verkennend onderzoek naar technologische zelfmeetmethoden binnen justitiële context. Cahiers 2017. 2017(17).

23. de Looff P, Noordzij ML, Moerbeek M, Nijman H, Didden R, Embregts P. Changes in heart rate and skin conductance in the 30 min preceding aggressive behavior. Psychophysiology. 2019;56(10):e13420.

24. Kolb DA, Boyatzis RE, Mainemelis C. Experiential learning theory: Previous research and new directions. Perspectives on thinking, learning, and cognitive styles. 2001;1(8):227-47.

25. Yardley S, Teunissen PW, Dornan T. Experiential learning: transforming theory into practice. Medical teacher. 2012;34(2):161-4.

26. Almario CV. The effect of digital health technology on patient care and research. Gastroenterology \& hepatology. 2017;13(7):437.

27. Pieterse $M$, Kip $H$, Cruz-Martinez RR. The complexity of ehealth implementation: a theoretical and practical perspective. eHealth Research, Theory and Development: A Multi-Disciplinary Approach: Routledge; 2018. p. 247-70.

28. Wentzel J, van der Vaart R, Bohlmeijer ET, van Gemert-Pijnen JE. Mixing online and face-to-face therapy: how to benefit from blended care in mental health care. JMIR mental health. 2016;3(1):e9.

29. Polaschek DL. An appraisal of the risk-need-responsivity (RNR) model of offender rehabilitation and its application in correctional treatment. Legal and criminological Psychology. 2012;17(1):1-17.

30. Bonta J, Andrews DA. Risk-need-responsivity model for offender assessment and rehabilitation. Rehabilitation. 2007;6(1):1-22.

31. Klein Tuente S, Bogaerts S, Bulten E, Keulen-de Vos M, Vos M, Bokern H, et al. Virtual reality aggression prevention therapy (VRAPT) versus waiting list 
control for forensic psychiatric inpatients: a multicenter randomized controlled trial. Journal of Clinical Medicine. 2020;9(7):2258.

32. Jansman-Hart EM, Seto MC, Crocker AG, Nicholls TL, Côté G. International trends in demand for forensic mental health services. International Journal of Forensic Mental Health. 2011;10(4):326-36.

33. Wild TS, Fromberger P, Jordan K, Müller I, Müller JL. Web-based health services in forensic psychiatry: a review of the use of the internet in the treatment of child sexual abusers and child sexual exploitation material offenders. Frontiers in Psychiatry. 2019;9:763.

34. Kuosmanen A, Tiihonen J, Repo-Tiihonen E, Eronen M, Turunen H. Nurses' Views Highlight a Need for the Systematic Development of Patient Safety Culture in Forensic Psychiatry Nursing. Journal of Patient Safety. 2017.

35. van Gemert-Pijnen LJ, Kip H, Kelders SM, Sanderman R. Introducing ehealth. eHealth research, theory and development: a multi-disciplinary approach: Routledge; 2018. p. 3-26.

36. Bierbooms J, Feijt M, IJsselsteijn W, Sluis-Thiescheffer W, Weijmans M, van der Burg E, et al., editors. Serious Games for Professional Skills: The Design of an Escape Room to Explore the Possibilities of eMental Health. Companion Publication of the 2020 ACM on Designing Interactive Systems Conference; 2020.

37. Ward T, Mann RE, Gannon TA. The good lives model of offender rehabilitation: Clinical implications. Aggression and violent behavior. 2007;12(1):87-107.

38. Muraven M, Baumeister RF, Tice DM. Longitudinal improvement of selfregulation through practice: Building self-control strength through repeated exercise. The Journal of social psychology. 1999;139(4):446-57.

39. Pratt TC, Cullen FT. The empirical status of Gottfredson and Hirschi's general theory of crime: A meta-analysis. Criminology. 2000;38(3):931-64.

40. De Ridder DT, Lensvelt-Mulders G, Finkenauer C, Stok FM, Baumeister RF. Taking stock of self-control: A meta-analysis of how trait self-control relates to a wide range of behaviors. Personality and Social Psychology Review. 2012;16(1):76-99.

41. Alberts HJ, Martijn C, Greb J, Merckelbach H, de Vries NK. Carrying on or giving in: The role of automatic processes in overcoming ego depletion. British Journal of Social Psychology. 2007;46(2):383-99. 
42. Denson TF. Four promising psychological interventions for reducing reactive aggression. Current Opinion in Behavioral Sciences. 2015;3:136-41.

43. Friese M, Frankenbach J, Job V, Loschelder DD. Does self-control training improve self-control? A meta-analysis. Perspectives on Psychological Science. 2017;12(6):1077-99.

44. Beames J, Schofield TP, Denson TF. A meta-analysis of improving self-control with practice. DT de Ridder, M Adriaanse, K Fujita (red) International Handbook of Self-control in Health and Well-being Abingdon Oxford: Routledge. 2017.

45. Hagger MS, Wood C, Stiff C, Chatzisarantis NL. Ego depletion and the strength model of self-control: a meta-analysis. Psychological bulletin. 2010;136(4):495.

46. Denson TF, Capper MM, Oaten M, Friese M, Schofield TP. Self-control training decreases aggression in response to provocation in aggressive individuals. Journal of Research in Personality. 2011;45(2):252-6.

47. Denson TF, DeWall CN, Finkel EJ. Self-Control and Aggression. Current Directions in Psychological Science. 2012;21(1):20-5.

48. Gottfredson MR, Hirschi T. A general theory of crime: Stanford University Press; 1990.

49. Tangney JP, Baumeister RF, Boone AL. High self-control predicts good adjustment, less pathology, better grades, and interpersonal success. Journal of personality. 2004;72(2):271-324.

50. Van Horn J, Eisenberg M, Bouman Y, Van den Hanenberg F, Van der Put C, Bogaerts S. Forensisch Ambulante Risico Evaluatie (FARE). Utrecht: Kwaliteit Forensische Zorg; 2016.

51. Spreen M, Brand E, Ter Horst P, Bogaerts S. Handleiding en methodologische verantwoording HKT-R, Historisch, Klinische en Toekomstige-Revisie. 2014.

52. Friese $M$, Hofmann W, Wiers RW. On taming horses and strengthening riders: Recent developments in research on interventions to improve selfcontrol in health behaviors. Self and Identity. 2011;10(3):336-51.

53. Ludden GD, van Rompay TJ, Kelders SM, van Gemert-Pijnen JE. How to Increase Reach and Adherence of Web-Based Interventions: A Design Research Viewpoint. J Med Internet Res. 2015;17(7):e172.

54. Michie S, Yardley L, West R, Patrick K, Greaves F. Developing and evaluating digital interventions to promote behavior change in health and health care: 
recommendations resulting from an international workshop. Journal of medical Internet research. 2017;19(6):e232.

55. Bierbooms J, Bouman Y, Dijkslag D, Kimpen R, Muller J, Wieske R. Do's en don'ts van e-health in de forensische ggz. Kwaliteit Forensische Zorg (KFZ). 2015.

56. Beerlage-de Jong N. eHealth vs. infection: Participatory development of persuasive eHealth to support safe care. 2016.

57. Dugas M, Trottier M-È, Dansokho SC, Vaisson G, Provencher T, Colquhoun H, et al. Involving members of vulnerable populations in the development of patient decision aids: a mixed methods sequential explanatory study. BMC medical informatics and decision making. 2017;17(1):12.

58. Glasgow RE. What does it mean to be pragmatic? Pragmatic methods, measures, and models to facilitate research translation. Health Education \& Behavior. 2013;40(3):257-65.

59. Mohr DC, Weingardt KR, Reddy M, Schueller SM. Three problems with current digital mental health research... and three things we can do about them. Psychiatric services. 2017;68(5):427-9.

60. Sieverink F, Köhle N, Cheung K, Roefs A, Trompetter H, Keizer J, et al. Evaluating ehealth. eHealth Research, Theory and Development: A MultiDisciplinary Approach: Routledge; 2018.

61. Dallery J, Cassidy RN, Raiff BR. Single-case experimental designs to evaluate novel technology-based health interventions. Journal of medical Internet research. 2013;15(2):e22.

62. Krasny-Pacini A, Evans J. Single-case experimental designs to assess intervention effectiveness in rehabilitation: A practical guide. Annals of physical and rehabilitation medicine. 2018;61(3):164-79.

63. Sieverink F. Opening the Black Box of eHealth. Twente: Universiteit van Twente. 2017.

64. Venkatesh V, Brown SA, Sullivan YW. Guidelines for conducting mixedmethods research: An extension and illustration. Journal of the Association for Information Systems. 2016;17(7):2.

65. Kip H, van Gemert-Pijnen LJ. Holistic development of ehealth technology. eHealth Research, Theory and Development: A Multi-Disciplinary Approach: Routledge; 2018. p. 131-66.

66. van Gemert-Pijnen JE, Nijland N, van Limburg M, Ossebaard HC, Kelders SM, Eysenbach $\mathrm{G}$, et al. A holistic framework to improve the uptake and impact 
of eHealth technologies. Journal of medical Internet research. 2011;13(4):e111.

67. Finkel EJ. The 13 model: Metatheory, theory, and evidence. Advances in experimental social psychology. 49: Elsevier; 2014. p. 1-104.

68. Moller AC, Merchant G, Conroy DE, West R, Hekler E, Kugler KC, et al. Applying and advancing behavior change theories and techniques in the context of a digital health revolution: proposals for more effectively realizing untapped potential. Journal of behavioral medicine. 2017;40(1):85-98.

69. Michie S, Richardson M, Johnston M, Abraham C, Francis J, Hardeman W, et al. The behavior change technique taxonomy (v1) of 93 hierarchically clustered techniques: building an international consensus for the reporting of behavior change interventions. Annals of behavioral medicine. 2013;46(1):81-95.

70. Asbjørnsen RA, Smedsrød ML, Nes LS, Wentzel J, Varsi C, Hjelmesæth J, et al. Persuasive system design principles and behavior change techniques to stimulate motivation and adherence in electronic health interventions to support weight loss maintenance: Scoping review. Journal of medical internet research. 2019;21(6):e14265.

71. Proctor E, Silmere H, Raghavan R, Hovmand P, Aarons G, Bunger A, et al. Outcomes for implementation research: conceptual distinctions, measurement challenges, and research agenda. Administration and Policy in Mental Health and Mental Health Services Research. 2011;38(2):65-76.

72. Powell BJ, McMillen JC, Proctor EK, Carpenter CR, Griffey RT, Bunger AC, et al. A compilation of strategies for implementing clinical innovations in health and mental health. Medical care research and review. 2012;69(2):123-57.

73. Greenhalgh T, Wherton J, Papoutsi C, Lynch J, Hughes G, Hinder S, et al. Beyond adoption: a new framework for theorizing and evaluating nonadoption, abandonment, and challenges to the scale-up, spread, and sustainability of health and care technologies. Journal of medical Internet research. 2017;19(11):e367.

74. Damschroder LJ, Aron DC, Keith RE, Kirsh SR, Alexander JA, Lowery JC. Fostering implementation of health services research findings into practice: a consolidated framework for advancing implementation science. Implementation science. 2009;4(1):1-15. 
75. Riva G, Davide F, IJsselsteijn WA. Being there: The experience of presence in mediated environments. Being there: Concepts, effects and measurement of user presence in synthetic environments. 2003;5.

76. Diemer J, Alpers GW, Peperkorn HM, Shiban Y, Mühlberger A. The impact of perception and presence on emotional reactions: a review of research in virtual reality. Frontiers in psychology. 2015;6:26.

77. Willis GM, Ward T. The good lives model: Does it work? Preliminary evidence. L Craig, L Dixon, \& TA Gannon (2013), What Works in Offender Rehabilitation: An evidence based approach to assessment and Treatment. 2013:305.

78. Chatoor I, Kurpnick J. The role of non-specific factors in treatment outcome of psychotherapy studies. European Child \& Adolescent Psychiatry. 2001;10(1):S19.

79. Carbonell KB, Stalmeijer RE, Könings KD, Segers M, van Merriënboer JJ. How experts deal with novel situations: A review of adaptive expertise. Educational Research Review. 2014;12:14-29.

80. Crawford VM, Schlager M, Toyama Y, Riel M, Vahey P, editors. Characterizing adaptive expertise in science teaching. annual meeting of the American Educational Research Association, Montreal, Quebec, Canada; 2005.

81. Bohle Carbonell K, Könings KD, Segers M, van Merriënboer JJ. Measuring adaptive expertise: development and validation of an instrument. European Journal of Work and Organizational Psychology. 2016;25(2):167-80.

82. Kelders SM, Pots WT, Oskam MJ, Bohlmeijer ET, van Gemert-Pijnen JE. Development of a web-based intervention for the indicated prevention of depression. BMC medical informatics and decision making. 2013;13(1):26.

83. Van Velsen L, Wentzel J, Van Gemert-Pijnen JE. Designing eHealth that matters via a multidisciplinary requirements development approach. JMIR research protocols. 2013;2(1):e21.

84. Wentzel MJ. Keeping an eye on the context: participatory development of eHealth to support clinical practice. 2015.

85. Sampson S, Edworthy R, Völlm B, Bulten E. Long-term forensic mental health services: an exploratory comparison of 18 European countries. International Journal of Forensic Mental Health. 2016;15(4):333-51.

86. Wilkowsk W, Ziefle M, Alagoez F. How user diversity and country of origin impact the readiness to adopt E-health technologies: an intercultural comparison. Work. 2012;41(Supplement 1):2072-80. 

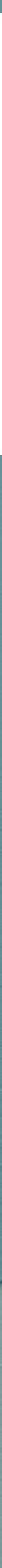


\section{SUMMARY IN DUTCH (Samenvatting)}

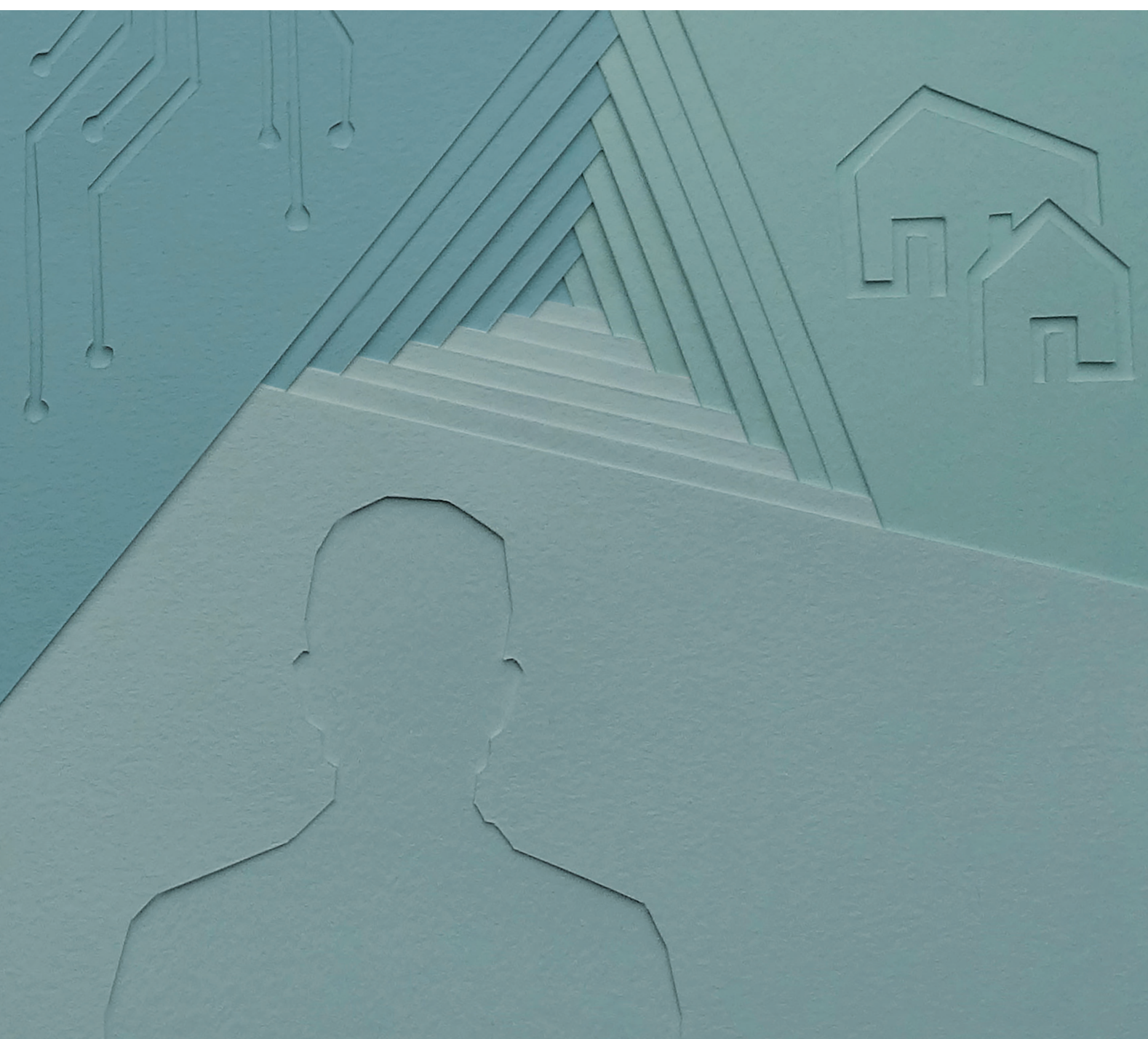




\section{Samenvatting}

\section{Introductie}

In Hoofdstuk 1 worden de achtergrond en de aanleiding van dit proefschrift geschetst aan de hand van wetenschappelijke literatuur. Allereerst wordt de context waarin het onderzoek is uitgevoerd geschetst: de forensische geestelijke gezondheidszorg (fggz). De fggz bevindt zich op het snijvlak van de psychiatrie en rechtspraak en is gericht op de behandeling van mensen die agressief of seksueel grensoverschrijdend gedrag hebben vertoond of dreigen te vertonen, deels of volledig vanwege een psychiatrische stoornis. Een voorbeeld van een patiënt is een man die vanwege alcoholverslaving, een licht verstandelijke beperking en autisme moeite heeft om zijn agressie onder controle te houden en daardoor zijn partner meerdere keren heeft mishandeld. Een belangrijk doel van de fggz is het voorkomen dat een patiënt recidiveert, oftewel opnieuw de fout in gaat. $\mathrm{Er}$ zijn behandelmodellen waarvan bekend is dat ze de kans op recidive enigszins verkleinen. Het meest gebruikte en onderzochte model in de fggz is het Risk-Need-Responsivity (RNR) Model. Het risk principe van dit model voorschrijft dat de intensiviteit van de behandeling moet aansluiten bij de hoogte van de kans op het plegen van een nieuw, ernstig delict. Volgens het need principe moet de behandeling gericht moet zijn op dynamische risicofactoren die volgens risicotaxatie de kans op een delict bij een individuele patiënt vergroten, zoals middelenmisbruik, antisociale attitudes en financiële problemen. Volgens het responsivity principe moet de behandeling zo goed mogelijk aansluiten op de eigenschappen en problematiek van een individuele patiënt, wat laat zien dat een one-size-fits-all benadering niet past bij de brede, diverse forensische patiëntenpopulatie. Aangezien het RNR-model erg breed is, moet het ingevuld worden met specifiekere interventies. Een veelgebruikte behandelvorm is cognitieve gedragstherapie, waarin behandelgesprekken en huiswerkoefeningen gericht zijn op het beïnvloeden van gedachten en gedragingen die bijdragen aan het grensoverschrijdende gedrag.

Meerdere onderzoeken tonen aan dat behandeling van forensisch psychiatrische patiënten, met name door cognitieve gedragstherapie, leidt tot ietwat lagere recidivecijfers dan geen behandeling. Om de recidive verder te verlagen, zijn er enkele verbeterpunten die aangepakt zouden kunnen worden. Zo zijn forensisch psychiatrische patiënten meestal niet gemotiveerd voor hun (vaak verplichte) behandeling en is er vaak spraak van complexe problematiek en co-morbiditeit, wat inhoudt dat patiënten meerdere psychiatrische stoornissen hebben. Daarnaast zijn 
veel patiënten laaggeletterd en laagopgeleid waardoor het lastig voor ze kan zijn om in behandelgesprekken te reflecteren op hun gedachten en gedrag en huiswerkopdrachten te maken. Verder is de fggz, in tegenstelling tot veel vormen van reguliere ggz, niet gericht op specifieke stoornissen, maar op het voorkomen van recidive, waardoor de forensische patiëntenpopulatie erg breed en complex is: er is sprake van veel verschillende stoornissen, delicten, en typen patiënten. Om deze problemen aan te pakken kunnen bestaande behandelingen verbeterd worden, en is er ook behoefte aan nieuwe vormen behandeling die in kunnen grijpen op de verbeterpunten.

eHealth-interventies bieden mogelijkheden om de hiervoor genoemde verbeterpunten aan te pakken. eHealth verwijst naar de inzet van technologie, met name informatie- en communicatietechnologie om gezondheid, welzijn en de gezondheidszorg te ondersteunen. In de ggz wordt eHealth vaak blended ingezet, wat inhoudt dat face-to-face behandeling en eHealth interventies met elkaar worden gecombineerd. Er zijn verschillende technologieën die ingezet kunnen worden in de (f)ggz, waarvan web-based modules op dit moment het meest gebruikt worden. In dit soort modules worden onderdelen van een behandeling, zoals psycho-educatie waarin uitleg wordt gegeven over een bepaalde stoornis, online aangeboden door middel van geschreven en gesproken tekst, video's en opdrachten die zelfstandig gemaakt moeten worden. Hoewel er binnen de fggz nog niet veel bekend is, blijkt uit effectonderzoek uit andere vormen van ggz dat dit soort modules effectief zijn; zo kunnen ze bijvoorbeeld leiden tot een verlaging van depressieve of angstklachten. Andere technologieën die momenteel worden gebruikt zijn beeldbellen, waarin (een deel van) de behandeling digitaal wordt gegeven, mobiele apps die een patiënt kan gebruiken om buiten de behandeling zelfstandig oefeningen te doen, of wearables die fysiologische data zoals hartslag kunnen verzamelen om inzicht te geven in spanning gedurende de dag. Een technologie die de laatste jaren wat meer in opkomst is, is virtual reality (VR). Door een VR-bril op te zetten krijgen gebruikers het gevoel dat ze zich daadwerkelijk in een virtuele omgeving bevinden. In deze virtuele omgevingen kunnen patiënten blootgesteld worden aan situaties die ze spannend vinden en kunnen ze oefenen met nieuw gedrag, terwijl de behandelaar mee kan kijken en zo meer inzicht krijgt in het gedrag van een patiënt. Hoewel dit soort technologieën veelbelovend lijken te zijn voor de fggz, is er nog weinig bekend over wat de toegevoegde waarde precies is, en blijft het gebruik achter op de verwachtingen, waardoor het potentieel van eHealth interventies vaak niet wordt behaald. 
Om de kloof tussen de huidige situatie en het potentieel van eHealth te verkleinen is het van belang om eHealth-interventies op een goede manier te ontwikkelen, implementeren en evalueren. Er zijn verschillende modellen en frameworks die hierbij kunnen helpen. In dit proefschrift wordt voornamelijk gebruik gemaakt van de principes en richtlijnen van de CeHRes Roadmap. De Roadmap maakt, net als veel andere frameworks, gebruik van participatory development, wat inhoudt dat eindgebruikers en andere betrokken stakeholders actief betrokken worden bij ontwikkeling, implementatie en evaluatie zodat de eHealth-interventie goed aansluit op hun eigenschappen en wensen. Daarnaast wordt eHealth ontwikkeling gezien als agile en wordt gebruik gemaakt van meerdere formatieve evaluatiecycli, wat betekent dat gedurende het proces er continu nieuwe ideeën en producten worden ontwikkeld en aangepast op basis van snelle evaluaties met gebruikers of andere stakeholders. Ook is de Roadmap gebaseerd op een holistische benadering van ontwikkeling, implementatie en evaluatie: in elke fase wordt er uitgebreid aandacht besteed aan de samenhang tussen de eigenschappen van een eHealth-technologie, de wensen en eisen van de betrokken personen, en de eigenschappen en praktische randvoorwaarden vanuit de context waarin de technologie gebruikt zal worden. Om zo'n holistische aanpak vorm te geven, wordt gebruik gemaakt van theorieën en frameworks vanuit verschillende disciplines, zoals bijvoorbeeld prototypingmethoden vanuit human-centred design, gedragsveranderingstheorieën vanuit de psychologie, of implementatie-aanpakken vanuit business modeling.

In de Roadmap zijn wat abstractere principes vertaald naar vijf fases voor de ontwikkeling, implementatie en evaluatie van eHealth, die aan elkaar verbonden zijn door middel van formatieve evaluatiecycli. In de contextual inquiry worden de betrokken stakeholders, de huidige situatie en de verbeterpunten van de context waar de technologie gebruikt zal gaan worden in kaart gebracht. In de value specification worden de uitkomsten van de vorige fase verder gespecificeerd, onder andere door middel van values die aangeven wat e toegevoegde waarde van een eHealth interventie moet zijn, en op basis daarvan moeten requirements en een business model opgesteld worden. In de design fase wordt op basis van de requirements meerdere prototypes - visualisaties van de te-ontwikkelen eHealthinterventies - ontwikkeld en geëvalueerd met gebruikers. Daarnaast worden in deze fase persuasieve elementen of gedragsveranderingstheorieën toegevoegd aan het design om de kans op gedragsverandering te vergroten. In de operationalization fase wordt de technologie uitgerold in de context aan de hand van het eerder ontwikkelde business model en een plan met implementatie-activiteiten. In de summative 
evaluation fase wordt het gebruik van de eHealth interventie en de impact op de gebruikers en de organisatie geëvalueerd. Gedurende al deze fases worden formatieve evaluaties uitgevoerd om te kijken of ideeën en producten aansluiten op de wensen en eisen vanuit gebruikers en context, en of ze nog steeds gebaseerd zijn op bevindingen vanuit eerdere fases. Alhoewel de Roadmap al meerdere keren succesvol is toegepast, zijn er meerdere verbeterpunten. Zo kan het lastig te zijn om uit te zoeken welke methoden het beste passen binnen de brede fases, is nog niet veel bekend over welke implementatie-modellen en -theorieën goed passen en hoe die in het proces ingebed kunnen worden, en wordt eHealth nog vaak ontwikkeld en geëvalueerd met methoden die niet goed passen bij de technologie en de context waarin de technologie gebruikt wordt.

Om de verbeterpunten die in dit eerste hoofdstuk geschetst zijn aan te pakken, heeft dit proefschrift twee hoofddoelen. Het eerste doel is in kaart brengen in hoe en waarom verschillende soorten eHealth interventies van toegevoegde waarde kunnen zijn voor de fggz. Het tweede doel is het verkrijgen van meer inzicht in hoe eHealth interventies zo optimaal mogelijk ontwikkeld, geïmplementeerd en geëvalueerd kunnen worden in complexe contexten.

\section{Deel 1: De huidige stand van zaken van eHealth in de forensische ggz}

Zoals hiervoor is geschetst is er nog weinig bekend over onderzoek naar en het gebruik van eHealth-interventies in de behandeling van forensisch psychiatrische patiënten. Om meer inzicht te krijgen in de huidige stand van zaken, richt het eerste deel van dit proefschrift zich op een inventarisatie van wetenschappelijk onderzoek naar eHealth, en wordt het gebruik van een bestaande web-based interventie in de ambulante fggz geëvalueerd.

In Hoofdstuk 2 wordt in kaart gebracht welk onderzoek er is uitgevoerd naar technologie in de behandeling van delinquenten. Door middel van een systematisch literatuuronderzoek zijn er in totaal 50 onderzoeken geanalyseerd om inzicht te krijgen in de voordelen en beperkingen van eHealth voor de behandeling van forensisch psychiatrische patiënten. Op basis van deze inventarisatie bleek dat het meeste onderzoek uit was gevoerd naar beeldbellen en web-based modules. Met name naar web-based modules is wat effectonderzoek uitgevoerd, en over het algemeen bleken deze even effectief als face-to-face behandeling te zijn. Daarnaast bleken er ook wat technologieën in opkomst te zijn waar nog geen effectonderzoek naar uit was gevoerd, waaronder VR en serious games. Uit dit onderzoek kwamen meerdere, voornamelijk potentiële voordelen van eHealth naar voren, waaronder de 
mogelijkheden om nieuwe, unieke informatie over een patiënt te verzamelen, een efficiëntere manier van behandelen aan te bieden, en de eHealth-interventie aan te passen (tailoren) zodat deze qua inhoud en design goed aansluit op de eigenschappen van een patiënt. De voornaamste barrières hadden betrekking op een gebrek aan bewijs voor effectiviteit, problemen met implementatie in de praktijk, en veel onbekendheid over hoe eHealth ontwikkeld, geïmplementeerd en geëvalueerd kan worden in een forensische context. Er werd geconcludeerd dat eHealth-interventies goed aan moeten sluiten bij de patiënten en context om de barrières te doorbreken en de voordelen te behalen: het moet gezien worden als een geïntegreerd onderdeel van bestaande zorg in plaats van als opzichzelfstaande toevoeging. Om dit te bereiken, is het van belang om te investeren in goede ontwikkeling, implementatie en evaluatie.

Aangezien uit hoofdstuk 2 bleek dat web-based modules relatief veel worden gebruikt, wordt in Hoofdstuk 3 het implementatieproces van een web-based interventie in de ambulante fggz geëvalueerd. Deze interventie bestaat uit meer dan 200 opzichzelfstaande modules die gericht zijn op onder andere delict-analyses, autisme of sociale vaardigheden. Om recht te doen aan de holistische, dynamische aard van implementatie - waarin factoren gerelateerd aan de context, technologie en mensen met elkaar verbonden zijn - is gebruik gemaakt van een mixed-methods benadering, waarin interviews met alle 18 behandelaren werkzaam op één polikliniek werden gecombineerd met desk research met bestaande documentatie over het implementatieproces en log data analyses met data van 721 patiënten en 172 behandelaren om het daadwerkelijke gebruik van de modules in kaart te brengen. Deze log data-analyses lieten zien dat het gebruik van de interventie inderdaad te wensen overliet: slechts $18 \%$ van de patiënten van de organisatie startte een module, waarvan ook weer $18 \%$ de module helemaal afrondde. Ook bleek maar de helft van alle behandelaren minimaal één keer gebruik te hebben gemaakt van de interventie, en hiervan was het grootste deel geen actief gebruiker. Uit de interviews kwam naar voren dat behandelaren de voordelen van de interventie wel zagen, maar hem vaak niet introduceerden aan de patiënt, voornamelijk omdat het geen onderdeel was van hun routine. Daarnaast gaven ze ook dat de modules een relatief hoog niveau van lees-, schrijf- en reflectieve vaardigheden vereisen, wat niet goed aan bleek te sluiten op de vaardigheden van de meeste forensische patiënten. Uit desk research en de interviews bleek dat er behoefte was aan meer steun vanuit de organisatie, dat de interventie beter ingebed moest worden in bestaande structuren, en dat de vaardighedentraining voor behandelaren aan het begin niet voldoende was voor 
succesvolle implementatie. De resultaten van Hoofdstuk 3 onderstrepen het belang van een holistische benadering: er kwam naar voren dat er voor goede implementatie aandacht besteed moet worden aan veranderingen in de organisatie, de kennis en vaardigheden van de behandelaar en patiënt, en de vormgeving en inhoud van de technologie. Adaptiviteit lijkt hier een belangrijk concept in te zijn: er wordt dan ook aanbevolen dat een technologie aangepast moet kunnen worden aan individuele patiënten, dat behandelaren flexibel om moeten kunnen gaan met eHealthinterventies, en dat organisaties hun implementatiestrategieën en bestaande structuren aanpassen zodat ze aansluiten bij een nieuwe eHealth-interventie.

\section{Deel 2: De toegevoegde waarde van virtual reality}

Uit Hoofdstuk 3 bleek dat, hoewel web-based interventies voordelen kunnen hebben, ze niet optimaal aan lijken te sluiten op de eigenschappen van forensische patiënten. Omdat uit de literatuurreview van Hoofdstuk 2 naar voren kwam dat VR een relatief onbekende maar zeer veelbelovende technologie voor de fggz is, is het tweede deel van dit proefschrift gericht op de ontwikkeling van een nieuwe VR-applicatie, gericht op de behandeling van ambulante en klinische forensisch psychiatrische patiënten. Met name omdat hier nog weinig over bekend is, was het van belang om een grondig ontwikkelproces uit te voeren om de verschillende mogelijkheden te onderzoeken en tot een interventie te komen die zo veel mogelijk toegevoegde waarde heeft voor de bestaande behandeling. Om dit te bereiken, is in het tweede deel van dit proefschrift gebruik gemaakt van de eerste drie fases van de CeHRes Roadmap, waarbij de nadruk vooral ligt op nauwe samenwerking met patiënten en behandelaren.

Allereerst werd in Hoofdstuk 4 op zoek gegaan naar verbeterpunten van de huidige behandeling en de manieren waarop VR daarvoor van toegevoegde waarde kon zijn volgens behandelaren en patiënten. Om dit te bereiken zijn eerst interviews gehouden met acht behandelaren en drie patiënten, waarin ze werden gevraagd naar verbeterpunten en ideeën voor VR. Op basis van de uitkomsten van die interviews zijn zes video's met scenario's voor mogelijke VR-toepassingen ontwikkeld om concrete voorbeelden te kunnen geven. Via open vragen in een online vragenlijst hebben 89 behandelaren en 19 patiënten hun mening gegeven over deze zes video's. Op basis van alle verzamelde data kwamen meerdere verbeterpunten van de huidige behandeling naar voren. Zo bleek dat het lastig was om patiënten te helpen met het ontwikkelen van en realistisch oefenen met bepaald gedrag zoals emotieregulatie- of sociale vaardigheden, kwam naar voren dat de lage behandelmotivatie van patiënten belemmerend kon werken, en werd aangegeven dat er een grote kloof tussen 'binnen 
en buiten' werd ervaren, met name in klinische settingen. Behandelaren en patiënten konden veel verschillende mogelijkheden van VR bedenken, waaronder de mogelijkheid om in een realistische, virtuele setting te oefenen met bijvoorbeeld agressieregulatie-vaardigheden, het observeren van het gedrag van de patiënt in context door de behandelaar; en de mogelijkheid om patiënten bloot te stellen aan lastige situaties zoals drugs bij verslaving of jonge kinderen bij pedofilie. Hoewel deze mogelijkheden hypothetisch zijn, blijkt dat er veel manieren zijn waarop VR iets nieuws toe kan voegen aan de bestaande behandeling en kunnen deze bevindingen als fundering voor de ontwikkeling van nieuwe VR-toepassingen dienen. Hierbij is het wel van belang om altijd kritisch te blijven op de mate waarin VR echt van toegevoegde waarde is om te voorkomen dat het hype-gedreven in wordt gezet.

In Hoofdstuk 5 wordt verder ingegaan op de resultaten uit Hoofdstuk 4, maar wordt er meer nadruk gelegd op het ontwikkelproces en minder nadruk op de mogelijkheden van VR. In dit vijfde hoofdstuk wordt namelijk getoond hoe values geformuleerd kunnen worden aan de hand van activiteiten uit het VRontwikkelproces, met name omdat hier nog niet veel over bekend is. Values zijn begrippen die beschrijven wat een technologie volgens stakeholders moet bereiken of verbeteren, en vatten in principe de beoogde toegevoegde waarde van een eHealth-interventie samen. Door values op te stellen, kunnen de opvattingen en perspectieven van verschillende stakeholders op een overzichtelijke wijze gecombineerd en samengevat worden. Om tot values te komen, zijn allereerst de resultaten van de online vragenlijst geanalyseerd. In deze vragenlijst hebben in totaal 146 patiënten, behandelaren en andere stakeholders zoals managers, onderzoekers en technologie-ontwikkelaars hun mening over zes video's met mogelijke VRtoepassingen gegeven door middel van gesloten en open vragen. Op basis van de uitkomsten is één scenario ontwikkeld, dat door middel van korte semigestructureerde interviews geëvalueerd werd met in totaal 18 patiënten en behandelaren. De resultaten hiervan werden geanalyseerd met behulp van een eerste versie van de values, die daarna weer werden aangepast op basis van de uitkomsten van die interviews. Op basis van de resultaten van die interviews en de vragenlijst wordt getoond hoe een interdisciplinair projectteam bestaande uit zorgverleners, patiënten, onderzoekers en managers een set van 13 values heeft opgesteld. Enkele values zijn 'fit met patiënt', wat inhoudt dat de inhoud en vormgeving van de VR aangepast moet kunnen worden op individuele patiënten; 'generalisatie van vaardigheden naar het dagelijks leven', wat betekent dat het oefenen in VR moet leiden tot daadwerkelijke gedragsverandering, en 
'behandelmotivatie', wat duidt op het voordeel dat patiënten door middel van VR meer betrokken kunnen worden bij hun eigen behandeling. Op basis van de procedure die in dit hoofdstuk is geschetst wordt het makkelijker voor andere eHealth-ontwikkelaars om values op te stellen. Meer onderzoek is nodig om inzicht te bieden in hoe values vertaald kunnen worden naar andere ontwikkelactiviteiten zoals requirements en prototypes, en op welke manier ze als fundering voor implementatiestrategieën en evaluatieplannen kunnen dienen.

In Hoofdstuk 6, wordt aandacht besteed aan het ontwikkelproces dat heeft geleid tot de VR-toepassing 'Triggers \& Helpers'. Dit proces, dat is geïnspireerd door de contextual inquiry, value specification en design fases van de CeHRes Roadmap, heeft niet alleen geleid tot een idee voor een VR-toepassing die aansluit op de forensische context, maar ook tot nieuwe inzichten in de manier waarop eHealth ontwikkeld kan worden in complexe contexten en met kwetsbare, lastig te betrekken patiëntpopulaties zoals forensisch psychiatrische patiënten. In totaal zijn tien verschillende activiteiten gebruikt in het ontwikkelproces: een stakeholder identificatie; samenstelling van een interdisciplinaire projectgroep; focusgroepen met patiënten en behandelaren over de mogelijkheden van VR; een literatuurstudie naar VR; semigestructureerde interviews met drie patiënten en acht behandelaren over verbeterpunten van de huidige situatie; idee-generatie met scenario's waarin zes video's met mogelijke VR-toepassingen werden ontwikkeld; een online vragenlijst waarin de mening van 146 behandelaren, patiënten en stakeholders over die zes video's werd gevraagd; formulering van in totaal 13 values; prototyping om één specifiek idee voor een VR-toepassing uit te werken; en een tweede ronde semigestructureerde interviews met 18 behandelaren en patiënten om uit te zoeken in hoeverre het prototype in lijn is met de hiervoor geformuleerde values. Voor elke activiteit werden het doel, een uitleg van de methode, de belangrijkste resultaten en conclusies, en de geleerde lessen weergegeven op een gestructureerde manier om kennis te delen met andere eHealth-onderzoekers. Uit deze lessen bleek onder andere dat, hoewel elke activiteit iets toevoegde, niet elke gehanteerde methode even passend was voor de onderzoeksvraag en de eigenschappen van de participanten. Zo bleken lange interviews met weinig concrete voorbeelden niet goed aan te sluiten bij de voorkeuren en vaardigheden van forensisch psychiatrische patiënten. Daarnaast kwam het belang van een interdisciplinair projectteam met onder andere patiënten, behandelaren, managers en onderzoekers naar voren om het project te structureren en een focus op de context te houden. De resultaten van dit onderzoek kunnen gebruikt worden om sterke punten van de CeHRes Roadmap, 
zoals de continue betrokkenheid van stakeholders en formatieve evaluaties, sterker aan te zetten. Ook zijn enkele verbeterpunten naar voren gekomen. Zo kan de integratie van domein-specifieke theorieën zoals bijvoorbeeld het RNR-model wat sterker, en is er nog veel onduidelijkheid over welke methode goed aansluit bij welke soort onderzoeksvraag. Dit alles pleit voor de ontwikkeling van een eHealth-toolkit die ontwikkelaars kan ondersteunen in het selecteren van de methode die het beste past bij hun onderzoeksvraag, in plaats van het toepassen van een methode waar ze het meest bekend mee zijn. De activiteiten van het tweede deel van dit proefschrift hebben geleid tot de specifieke VR-toepassing 'Triggers \& Helpers'.

\section{Deel 3: Evaluatie van eHealth}

Hoewel VR erg veelbelovend lijkt te zijn voor de forensische zorg, blijkt uit de literatuurreview uit Hoofdstuk 2 en uit ander onderzoek dat er meerdere technologieën zijn die iets nieuws toe kunnen voegen aan de behandeling van forensisch psychiatrische patiënten. Daarnaast kwam het belang van goede evaluatie door middel van passende methoden uit dit hoofdstuk naar voren, waarbij het van belang is om verder te kijken dan alleen de standaard 'randomized controlled trial' (RCT). Nieuwe methoden zijn nodig om de toegevoegde waarde van eHealth in kaart te brengen en om de zogenaamde black box van eHealth te openen, zodat inzicht gekregen kan worden in hoe de technologie bijdraagt aan de effectiviteit. Om die reden richt het derde deel van dit proefschrift zich op de evaluatie van een mobiele app.

In Hoofdstuk 7 van worden een app- en e-mail-versie van zelfcontroletraining (ZCT) op twee verschillende manieren geëvalueerd. Uit eerder onderzoek is namelijk gebleken dat ZCT een relatief simpele manier is om zelfcontrole te verbeteren, wat een positieve invloed kan hebben op gedrag waar zelfcontrole voor nodig is, zoals bijvoorbeeld gezond eten, fysieke activiteit en, in het geval van deze studie, reactieve agressie. In ZCT worden gebruikers gevraagd om hun niet-dominante hand te gebruiken voor alledaagse taken zoals het oppakken van spullen en het openen van deuren. Het idee hierachter is dat doordat deze impulsen onderdrukt worden, zelfcontrole als een algemene vaardigheid wordt getraind. In dit onderzoek zijn een app- en e-mailversie van ZCT ontwikkeld en geoptimaliseerd door middel van twee evaluatiestudies. Deze aanpak is gebaseerd op de optimization fase van het multiphase optimization strategy (MOST) framework, waarin een optimale versie van een interventie wordt ontwikkeld door middel van onderzoeksresultaten. 
Het eerste onderzoek maakte gebruik van een kleinschalig pretest-posttestdesign zonder controlegroep waarin 19 studenten de app-en e-mailversie van ZCT gebruikten. Uit dit onderzoek bleek dat gedurende en na gebruik van ZCT scores op een zelfcontroleschaal toenamen (Brief Self-Control Scale; BSCS), terwijl de scores op een agressieschaal (Brief Aggression Questionnaire; BAQ) afnamen. Daarnaast werd data verzameld over de geschiktheid van de ZCT-taken en het design van de app via een gesloten vragen in de laatste vragenlijst en semigestructureerde interviews met 10 gebruikers. Op basis van deze studie werd de app verder verbeterd, en werd een nieuw onderzoek opgezet: een $2 \times 2$ full factorial design, waarin app versus e-mail, en één dagelijkse taak versus vijf taken in één keer de factoren waren. In totaal namen 204 studenten deel, waarvan 69 werden toegewezen aan de controlegroep. Gedurende een periode van 15 dagen werden zelfcontrole en agressie gemeten door middel van de twee vragenlijsten (BSCS \& BAQ) en een Go/No-Go taak. Ook werden participanten gevraagd om de haalbaarheid van taken te beoordelen, en in de vragenlijst werden open vragen gesteld om inzicht te krijgen in verbeterpunten. Uit dit tweede onderzoek kwamen geen interactie-effecten naar voren, maar bleek wel dat gedurende de interventieperiode zelfcontrole zoals gemeten door de BSCS alleen verbeterde in de groep die de app gebruikte; binnen de controle- en e-mailgroepen werden geen betekenisvolle verbeteringen waargenomen. Er werden geen relevante resultaten gevonden voor agressie en de Go/No-Go taak. Daarnaast werden er ook geen verschillen gevonden tussen zelfcontrole en agressie bij participanten die één dagelijkse taak en vijf taken in één keer ontvingen. Uit de kwalitatieve data bleek dat gebruikers over het algemeen tevreden waren, maar dat er verschil zat in hoe de taken werden beoordeeld, dat participanten aangaven dat ze meer reminders wilden ontvangen, en er meer mogelijkheden zouden moeten zijn voor het aanpassen van bijvoorbeeld het aantal taken. Op basis van alle resultaten kan geconcludeerd worden dat de ZCT-app een veelbelovende technologie om het automatische aspect van zelfcontrole te verbeteren lijkt te zijn, maar dat meer onderzoek nodig is en de app meer mogelijkheden voor personalisatie moet bevatten. Het niet verbeteren van agressie zou verklaard kunnen worden door het gebruik van studenten in plaats van een populatie met agressieregulatie-problemen, zoals forensisch psychiatrische patiënten. Vervolgonderzoek met innovatieve evaluatiedesigns kan aantonen of ZCTapps van toegevoegde waarde zijn voor dit soort moeilijk te bereiken doelgroepen. 


\section{Deel 4 - Discussie}

Op basis van het werk in dit proefschrift kunnen enkele belangrijke conclusies worden getrokken en aanbevelingen worden gedaan, gericht op de toegevoegde waarde van eHealth voor de forensische zorg en op de ontwikkeling, implementatie en evaluatie van eHealth in complexe contexten.

\section{Belangrijkste bevindingen}

Ten eerste kan op basis van dit proefschrift worden geconcludeerd dat eHealth met name van toegevoegde waarde kan zijn voor de kwaliteit van zorg als het echt iets nieuws toevoegt wat niet of erg lastig bereikt kan worden zonder technologie. Voorbeelden zijn het gebruik van VR om rollenspellen in een realistische context mogelijk te maken, of een zelfcontrole-app die het automatische aspect van zelfcontrole kan beïnvloeden. Binnen de forensische zorg blijkt het wel van belang te zijn om deze technologieën in een 'blended' manier te gebruiken, wat inhoudt dat ze gecombineerd worden met face-to-face behandeling. Een tweede belangrijke bevinding is dat, om ervoor te zorgen dat eHealth-interventies van toegevoegde waarde zijn, de technologie, mensen en context flexibel zijn en adaptief zijn, wat inhoudt dat ze aan elkaar aangepast kunnen worden. Uit onderzoek naar VR en de zelfcontroleapp kwam het belang van personalisatie naar voren: de inhoud en vormgeving van een eHealth-interventie moeten aansluiten bij de behoeften en eigenschappen van gebruikers en hun context. Hoewel dit vaak een impliciete verwachting is, blijkt alleen een adaptieve technologie niet voldoende te zijn voor succesvolle implementatie: ook gebruikers zoals behandelaren moeten op een flexibele manier met eHealth om kunnen gaan, waarbij een adaptieve mindset en de benodigde vaardigheden belangrijk zijn vanwege de nieuwe elementen die eHealth toe kan voegen. Ook moet de context aangepast worden om eHealth-interventies in te bedden; zo zijn bijvoorbeeld veranderingen nodig in zorgstructuren en bestaande systemen van organisaties. Een derde conclusie is dat het van belang is om eHealth ontwikkeling, implementatie en evaluatie als adaptieve processen vorm te geven. Bij ontwikkeling is het van belang dat de onderzoeksmethoden aansluiten bij de vaardigheden van de gebruikers, en dat het ontwikkelproces continu aangepast en bijgestuurd kan worden op basis van nieuwe inzichten en resultaten. In het geval van implementatie moet in de selectie van implementatiestrategieën en onderzoeksmethoden rekening gehouden worden met de meerdere niveaus waarop implementatie plaatsvindt en de complexe onderlinge relaties. Bij de evaluatie van eHealth blijkt het belangrijk te zijn dat methoden aansluiten op de eigenschappen van 
technologie: eHealth-interventies kunnen niet gezien worden als vaststaande tools, maar als flexibele processen met meerdere componenten die continu verbeterd moeten worden aan de hand van inzichten die worden verkregen door middel van innovatieve onderzoeksdesigns zoals factorial of single-case experimental designs. Daarnaast kwam naar voren dat evaluatie geen post-design activiteit is, maar een continu proces zonder vaststaand einde.

\section{De toegevoegde waarde van eHealth voor de forensische ggz}

Door middel van de verschillende studies in dit proefschrift is naar voren gekomen dat, hoewel er nog veel moet gebeuren om dit in de praktijk te realiseren, eHealth een enorm potentieel heeft om de manier waarop geestelijke gezondheidszorg wordt geleverd te verbeteren. Dit geldt niet alleen voor de forensische, maar ook voor andere vormen van zorg. Een eerste voorbeeld van een technologie waarmee verbeterpunten aangepakt kunnen worden is VR, waarin gebruikers gedrag kunnen oefenen en observeren in realistische omgevingen die aangepast kunnen worden aan de eigenschappen van de patiënt. Een tweede mogelijkheid van technologie is het op een laagdrempelige manier beïnvloeden van automatische processen zoals biases, bijvoorbeeld door middel van apps of web-based games waarvoor weinig cognitieve vaardigheden nodig zijn. Hierbij kan gedacht worden aan de ZCT-app uit dit proefschrift, maar ook het gebruik van bijvoorbeeld approach-avoidance trainingen om biases gerelateerd aan alcohol of agressie te beïnvloeden. Een derde mogelijkheid is om continue en betrouwbare data te verzamelen die meer inzicht geeft in de patiënt. Voorbeelden zijn wearables of apps die 24 uur per dag informatie over bijvoorbeeld hartslag of ervaren emoties kunnen verzamelen. Een valkuil bij dit soort nieuwe, veelbelovende technologieën is dat gebruik vooral hype-gedreven is, wat inhoudt dat ze, na een eerste piek, in de vergetelheid belanden. Om dit te voorkomen is het van belang om eHealth-interventies goed in te bedden. Het RNR-model dat kort is uitgelegd in de introductie van dit proefschrift zou hiervoor als basis kunnen dienen. eHealth-interventies zouden gekoppeld kunnen worden aan risicofactoren die uit risicotaxatie naar voren komen, bijvoorbeeld het gebruik van VR om gebrekkige sociale vaardigheden te verbeteren of web-based modules die gericht zijn op overmatig drugsgebruik. Om uit te zoeken hoe eHealth op een responsieve wijze gebruikt kan worden om risicofactoren bij individuele patiënten aan te pakken is echter meer onderzoek nodig. 


\section{Zelfcontrole en eHealth}

De zelfcontrole-app uit dit proefschrift is een voorbeeld van een eHealth-interventie die aan risicofactoren gekoppeld worden. Zelfcontrole is namelijk een belangrijke voorspeller van reactieve agressie blijkt. De ZCT-app blijkt zelfcontrole te kunnen verbeteren door middel van een simpele taak: het gebruiken van de non-dominante hand. Gezien zelfcontrole een relevant construct is voor agressie, maar ook voor veel andere doelgerichte gedragingen zoals gezond eten en bewegen, is het de moeite waard om verder te onderzoeken of en hoe technologie gebruikt kan worden om zelfcontrole te meten en verbeteren. Daarnaast is uit recent onderzoek gebleken dat een VR-interventie gericht op reactieve agressie emotieregulatie kan verbeteren bij tbs'ers, wat inhoudt dat VR ook mogelijkheden biedt om zelfcontrole op een andere wijze te verbeteren. Ten slotte blijkt uit ander onderzoek met forensische patiënten dat 20 minuten voorafgaand aan agressieve uitbarstingen veranderingen in fysiologische signalen zoals huidgeleiding waarneembaar zijn. Dit biedt mogelijkheden om het verlies van zelfcontrole te voorspellen en op tijd in te grijpen door middel van technologie. Er is echter veel meer onderzoek nodig om de mogelijkheden van dit soort eHealth-interventies verder in kaart te brengen.

\section{Het ontrafelen van de toegevoegde waarde van eHealth}

Aangezien eHealth niet alleen voordelen heeft voor de forensische ggz, maar voor de zorg in zijn algemeenheid, is het ook op conceptueel niveau van belang om te kijken naar de manieren waarop eHealth waarde toe kan voegen. Een belangrijke bevinding die niet alleen uit dit proefschrift, maar ook uit ander werk over eHealth naar voren komt, is het belang van personalisatie. Dit blijkt echter als een erg overkoepelende term gehanteerd te worden, wat impliceert dat er meer behoefte is aan inzicht in de verschillende vormen van personalisatie omdat, afhankelijk van de mate van personalisatie, eHealth verschillende soorten voordelen kan hebben. Om dit verder te illustreren, kan gekeken worden naar de eigenschappen van VR. Er zou bijvoorbeeld onderscheid gemaakt kunnen worden tussen drie vormen: ten eerste 'fixed' VR waarin er geen aanpassingen aan de inhoud van VR gemaakt kunnen worden, ten tweede gepersonaliseerde VR, waarin bepaalde onderdelen zoals het onderwerp van gesprek en bewegingen van een virtuele tegenspeler aangepast kunnen worden, en ten derde adaptieve VR, waarin alle onderdelen aangepast kunnen worden aan de individuele gebruiker, zoals het geval is bij de 'Triggers \& Helpers' toepassing uit dit proefschrift. Meer onderzoek is nodig om dit soort categorisaties te onderzoeken en te koppelen aan de toegevoegde waarde van 
eHealth. Een andere belangrijke implicatie van dit proefschrift is het onderscheid tussen eHealth-interventies die relatief veel cognitieve vaardigheden zoals aandacht, lezen en schrijven vereisen, en eHealth-interventies die meer gericht zijn op het aanbieden en in kaart brengen van subjectieve ervaringen in een realistische context, zonder nadruk op geschreven taal. Dit onderscheid zou aangeduid kunnen worden door 'cognitieve eHealth' zoals web-based interventies of apps gebaseerd op cognitieve gedragstherapie, en zogenaamde 'experiëntiële eHealth', zoals VR, wearables die data verzamelen of apps die ingrijpen op automatische processen. $\mathrm{Om}$ ervoor te zorgen dat dit soort experiëntiële eHealth-interventies van toegevoegde waarde zijn, is het van belang om via ontwikkeling, implementatie en evaluatie voor een goede fit tussen de gebruikers, de context en de technologie te zorgen.

\section{Adaptieve ontwikkeling, implementatie en evaluatie van eHealth}

Hoewel steeds meer onderzoekers het belang van het actief betrekken van eindgebruikers bij eHealth-ontwikkeling, -implementatie en -evaluatie onderkennen, is dit nog niet vanzelfsprekend. Met name bij kwetsbare patiënten die lastig te betrekken zijn bij onderzoek wordt eHealth vaak nog top-down wordt ontwikkeld, waarbij ontwikkelaars de meeste keuzes maken en patiënten vaak slechts laat in het proces en zijdelings betrekken. Op basis van onze ervaringen met het betrekken van patiënten blijkt onder andere dat het gebruik van concrete voorbeelden goed werkt: interviews waarin we vroegen naar verbeterpunten in het algemeen werkten minder goed dan interviews waarin patiënten werden gevraagd naar hun mening over een concreet prototype. Er is echter nog meer behoefte aan inzicht in welke methoden goed aansluiten bij de eigenschappen van kwetsbare patiëntpopulaties. Door middel van vervolgonderzoek zou een toolkit met methoden voor eHealth-ontwikkeling gegenereerd kunnen worden om andere onderzoekers te ondersteunen in het selecteren van methodes die goed aansluiten bij de onderzoeksvraag, context en doelgroep.

Naast ontwikkeling en implementatie, blijkt dat ook evaluatie van eHealth om adaptiviteit vraagt. eHealth-interventies zijn flexibele producten met meerdere componenten die continu aangepast kunnen worden op basis van nieuwe inzichten. Om hier recht aan te doen, is er behoefte aan verschillende innovatieve en passende onderzoeksdesigns die goed aansluiten op specifieke onderzoeksvragen, values of eigenschappen van technologie. Een voorbeeld hiervan is het in dit proefschrift toegepaste full factorial design, maar ook andere aanpakken zoals single-case experimental designs lijken goed aan te sluiten. Om een goed beeld te krijgen van de 
toegevoegde waarde van een eHealth-interventie voor de praktijk, is het van belang om evaluatie te baseren op eerder vastgestelde values. Doordat deze niet altijd kwantitatief gemeten kunnen worden, is mixed-methods onderzoek waarin kwantitatief en kwalitatief onderzoek gecombineerd worden passend. Om de black box van eHealth te openen wordt dus aanbevolen om gebruik te maken van meerdere onderzoeksmethoden, eHealth als een flexibel middel te zien dat continu aangepast kan worden, en evaluatie als een proces in plaats van een post-design activiteit te zien.

\section{Verbeterpunten voor de CeHRes Roadmap}

De CeHRes Roadmap diende als de ruggengraat van dit proefschrift. Door dit framework toe te passen op ontwikkeling, implementatie en evaluatie in de praktijk kunnen enkele sterke en verbeterpunten geïdentificeerd worden. Allereerst bleek de Roadmap behulpzaam te zijn in het houden van een focus op de context en stakeholders, en werd het continu evalueren en bijstellen van producten en processen ondersteund, waardoor er sprake was van een iteratief en flexibel maar toch gestructureerd en systematisch proces. Als gekeken wordt naar eHealthontwikkeling, bleek dat er relatief weinig aandacht was voor de integratie van domeinspecifieke theorieën en modellen zoals bijvoorbeeld het RNR-model in het ontwerp van een interventie: de focus ligt nu vooral op persuasieve elementen. In de huidige operationalization fase ligt de nadruk met name op het uitrollen van een business model, maar dit zou verder verbreed kunnen worden door de implementatie outcomes en strategieën die in ons implementatieonderzoek zijn gebruikt toe te voegen, ondersteund door holistische implementatie-frameworks zoals het NASSS Framework en het CFIR. Ten slotte zou in de summative evaluation-fase evaluatie wat meer als een proces weergegeven kunnen worden in plaats van een set activiteiten, met een wat sterkere koppeling aan de values als fundering van een breed evaluatieplan.

\section{Conclusie}

Alhoewel de resultaten voorzichtig geïnterpreteerd moeten worden, onder andere doordat de meeste data in één instelling is verzameld, de situatie in andere landen anders kan zijn waardoor bepaalde aanbevelingen niet te generaliseren zijn, en doordat veel deelnemers zichzelf aan konden melden en er zo sprake zou kunnen zijn van een zelfselectie-bias, heeft dit proefschrift meerdere waardevolle inzichten opgeleverd. Ten eerste is aangetoond dat, hoewel er nog veel onontgonnen terrein 
is, eHealth-interventies veel potentieel hebben om de kwaliteit van zorg te verbeteren. Met name 'experiëntiële' eHealth-interventies zoals VR of wearables kunnen door hun focus op ervaringen in realistische contexten iets nieuws toevoegen aan de zorg. Ten tweede kan geconcludeerd worden dat adaptiviteit van de technologie, mensen en context van belang is om ervoor te zorgen dat eHealth van toegevoegde waarde is: flexibiliteit op meerdere niveaus is essentieel. Ten derde is het belang van adaptieve ontwikkel-, implementatie- en evaluatieprocessen uit dit proefschrift naar voren gekomen, waarbij de onderzoeksmethoden en processen zo goed mogelijk aan moeten sluiten bij de eigenschappen van de participanten, de praktische voorwaarden vanuit de context, en de onderzoeksvragen. Een noodzakelijke voorwaarde voor eHealth die van toegevoegde waarde is, is dus een goede 'fit' tussen de technologie, mensen en de context. 

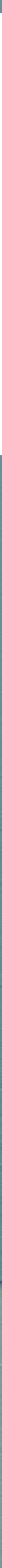


\section{PUBLICAT\|ONS AND OTHER OUTPUT}

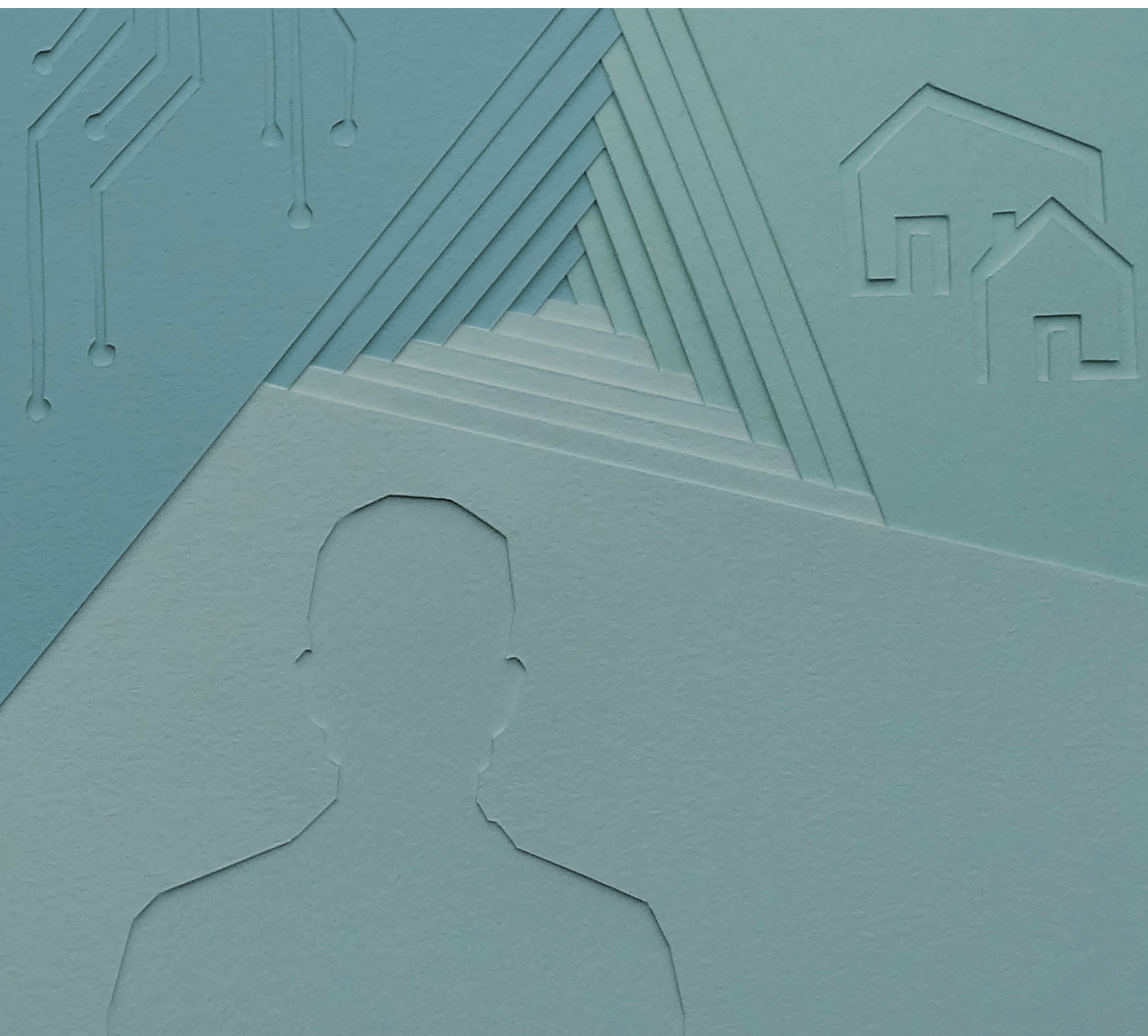




\section{Publications in peer-reviewed journals}

Kip, H., Sieverink, F., van Gemert-Pijnen, J.E.W.C., Bouman, Y.H.A. \& Kelders, S.M. (2020). Integrating people, context, and technology in the implementation of a webbased intervention in forensic mental health care: mixed-methods study. Journal of Medical Internet research, 22(4), e16906.

Kip, H. \& Bouman, Y.H.A. (2020). Van denken en praten naar doen en ervaren: Op zoek naar de toegevoegde waarde van technologie voor de forensische psychiatrie. Sancties, 2020(4), 249-260.

Kip, H., Oberschmidt, K. \& Bierbooms, J. (2020). eHealth Technology in Forensic Mental Healthcare: Recommendations for Achieving Benefits and Overcoming Barriers. International Journal of Forensic Mental Health, 1-17.

Beerlage-de Jong, N., Kip, H. \& Kelders, S.M. (2020). Evaluation of the Perceived Persuasiveness Questionnaire: a user-centered card-sort study. Journal of medical Internet Research, 22(10), e20404.

Kelders, S.M., Kip, H. \& Greeff, J. (2020). Psychometric evaluation of the TWente Engagement with Ehealth Technologies Scale (TWEETS): Evaluation study. Journal of Medical Internet Research, 22(10), e17757.

Kip, H., Wentzel, J. \& Kelders, S.M. (2020). Shaping blended care: adapting an instrument to support therapists in using eMental health. JMIR Mental Health, 7(11), e24245.

Kip, H., Kelders, S.M., Weerink, K., Bouman, Y.H.A, Dijkslag, D., \& van Gemert-Pijnen, J.E.W.C. (2019). Identifying the added value of virtual reality for treatment in forensic mental health: a scenario-based, qualitative approach. Frontiers in Psychology, 10, 406.

Kip, H., Kelders, S.M., Bouman, Y.H.A., \& van Gemert-Pijnen, J.E.W.C. (2019). The importance of systematically reporting and reflecting on eHealth development: Participatory development process of a virtual reality application for forensic mental health care. Journal of Medical Internet research, 21(8), e12972. 
Kip, H., Kelders, S. M., \& van Gemert-Pijnen, J.E.W.C. (2019). Putting the Value in VR: How to systematically and iteratively develop a value-based VR application with a complex target group. In: Proceedings of the 2019 CHI Conference on Human Factors in Computing Systems (pp. 1-12).

Kelders, S.M. \& Kip, H. (2019). Development and initial validation of a scale to measure engagement with eHealth technologies. In: CHI EA 2019 - Extended Abstracts of the 2019 CHI Conference on Human Factors in Computing Systems [3312917] Association for Computing Machinery (ACM).

Kip, H., Bouman, Y.H., Kelders, S. M., \& van Gemert-Pijnen, J.E.W.C. van (2018). eHealth in treatment of offenders in forensic mental health: a review of the current state. Frontiers in psychiatry, 9, 42.

Kip, H., Da Silva, M.C., Bouman, Y.H., van Gemert-Pijnen, J.E.W.C. \& Kelders, S.M. A self-control training app to increase self-control and reduce aggression - A full factorial design. Manuscript under review at Internet interventions.

\section{Books, chapters \& reports}

Kip, H., Oberschmidt, K., Bierbooms, J., Dijkslag, D., Kelders, S., \& Roelofsen, B. (2019). Technologie in de forensische zorg - Crossing borders. Utrecht: KFZ.

Gemert-Pijnen, J.E.W.C. van \& Kip, H. (2019). E-health: Zinvol toegepast in de praktijk. In: J.A.M. Vandermeulen, M.M.A. Derix, \& A. van Dijke (Eds.), De rol van neuropsychologie bij psychotherapie (pp. 117-126). Houten: Bohn Stafleu Van Loghum.

Gemert-Pijnen, J.E.W.C. van, Kelders, S.M., Kip, H., \& Sanderman, R. (Eds.) (2018). eHealth research, theory and development: a multi-disciplinary approach. London: Routledge. 
Gemert-Pijnen, J.E.W.C. van., Kip, H., Kelders, S.M., \& Sanderman, R. (2018). Introducing eHealth. In: eHealth Research, Theory and Development (pp. 3-26). London: Routledge.

Kip, H. \& van Gemert-Pijnen, J.E.W.C. (2018). Holistic development of eHealth technology. In: eHealth Research, Theory and Development (pp. 131-166). London: Routledge.

Kip, H., Beerlage-de Jong, N., \& Wentzel, J. (2018). The contextual inquiry. In: eHealth Research, Theory and Development (pp. 167-186). London: Routledge.

Pieterse, M., Kip, H., \& Cruz-Martínez, R. R. (2018). The complexity of eHealth implementation: a theoretical and practical perspective. In: eHealth Research, Theory and Development (pp. 247-270). London: Routledge.

Kelders, S.M., Kip, H., Sieverink, F. \& van Gemert-Pijnen, J.E.W.C. (2016). eHealth: combining psychology, technology \& health. Retrieved from: www.futurelearn.com/courses/ehealth.

\section{Conference contributions}

Kip, H., Dekkers, T., da Silva, M.C., Bouman, Y.H.A., van Gemert-Pijnen, J.E.W.C \& Kelders, S.M. Bolstering self-control via an app: a factorial design. Oral presentation at Association for researchers in psychology and health (ARPH) conference. 28 January 2021, online.

Kip, H. De mogelijkheden van technologie voor de behandeling van delinquenten. Oral presentation at 'Justitiële interventies en nieuwe technologie'. 1 October 2020, online.

Kip, H. (accepted, delayed due to corona). Using the non-dominant hand-paradigm to increase self-control: a pilot study of the Handswitch app. Oral presentation in symposium 'Innovating forensic mental healthcare: from theory to technology' at: International Association of Forensic Mental Health Services (IAFMHS) conference. 22-25 June 2021, Krakow, Poland. 
Kip, H., Keizer, J. \& Kelders, S.M. (accepted, delayed due to corona). Development methods for eHealth technologies: an initial overview. Oral presentation at Supporting Health by Technology X conference. 10-11 June 2021, Enschede.

Kip, H. \& Roelofsen, B. (2020). Technologie in de forensische zorg: grensverleggend. Oral presentation at Festival Forensische Zorg (FFZ) conference. 23 January, Utrecht.

Kip, H. \& Wentzel, M.J. (2019). The adaptation of the 'Fit for blended care' instrument to support therapists in using eHealth. Oral presentation at Supporting Health by Technology IX conference. 16-17 May, Groningen.

Kip, H., Kelders, S.M. \& van Gemert-Pijnen, J.E.W.C. (2019). Putting the value in VR: how to systematically and iteratively develop a value-based VR application with a complex target group. Oral presentation at $2019 \mathrm{CHI}$ Conference on Human Factors in Computing Systems: Weaving the threads of CHI. 4-9 May, Glasgow, United Kingdom.

Kelders, S.M. \& Kip, H. (2019). Development and initial validation of a scale to measure engagement with eHealth technologies. Poster presentation at $\mathrm{CHI}$ Conference on Human Factors in Computing Systems: Weaving the threads of CHI. 4-9 May, Glasgow, United Kingdom.

Kip, H., Oberschmidt, K., Kelders, S.M. \& Roelofsen, B. (2019). Technologie in de forensische zorg: crossing borders. Oral presentation at Festival Forensische Zorg (FFZ) conference. 22 January, Utrecht.

Kip, H., van den Boogert, F. (2018). Monitoring and coaching of reactive intimate partner violence: a systematic development approach. Oral presentation in symposium 'FoReTech Study: Longitudinal research, technology and forensic treatment: a university and hospital-based project' at: International Association of Forensic Mental Health Services (IAFMHS) conference. 12-14 June, Antwerpen, Belgium. 
Kip, H. (2018). FoReTech: eHealth technology development in forensic mental health. Oral presentation in symposium 'FoReTech Study: Longitudinal research, technology and forensic treatment: a university and hospital-based project' at International Association of Forensic Mental Health Services (IAFMHS) conference. 12-14 June, Antwerpen, Belgium.

Kip, H., Dijkslag, D., Voorhuis, R. \& Bouman, Y.H.A. (2018). Samen VooRuit met virtual reality. Oral presentation at Festival Forensische Zorg (FFZ) conference. 23 January, Utrecht.

Kip, H. (2017). Evidence-based eHealth: wat werkt voor wie? Oral presentation at VGCT (Vereniging voor Gedragstherapie en Cognitieve Therapie) Najaarscongres. 10 November, Veldhoven.

Kip, H., Bouman, Y.H.A., Halma, A.M. \& van Gemert-Pijnen, J.E.W.C. (2017). eHealth and Forensic Mental Health - What are the benefits, barriers and possibilities? Oral presentation at International Association of Forensic Mental Health Services (IAFMHS) conference. 13-15 June, Split, Croatia.

Kip, H., Kelders, S.M., Bouman, Y.H.A., Dijkslag, D. \& van Gemert-Pijnen, J.E.W.C. (2017). Participatory development of Virtual Reality to coach forensic psychiatric patients. Poster presentation at 12th International Conference on Persuasive Technology. 3-4 April, Amsterdam.

Kip, H. \& Bouman, Y.H.A. (2017). eHealth ontwikkelen met gebruikers. Workshop at Festival Forensische Zorg (FFZ). 24 January, Utrecht.

Kip, H. (2016). eHealth MOOC: combining psychology, health \& technology. Oral presentation at Association for researchers in psychology and health (ARPH) conference. 29 September, Leiden. 


\section{Invited talks and workshops}

Kip, H. (2020). De mogelijkheden van VR voor een forensisch psychiatrische context. Invited talk at INNOvember. 16 November, online.

Kip, H. (2020). Development \& implementation of VR in forensic mental health care settings. Invited talk at the first invitational research meeting on VR in forensic mental health settings (FOReVR). 4 November, online.

Kip, H. (2020). Guest lecture: Technology in forensic mental healthcare. Guest lecture in master Clinical Psychology, Leiden University. 3 March, Leiden.

Kip, H. (2019). Technologie in de forensische zorg: crossing borders. Invited talk at $4^{\mathrm{e}}$ KFZ Symposium, 19 September, Amersfoort.

Kip, H. (2019). Virtual reality in de forensische psychologie. Invited talk at De Waag. 11 July, Utrecht.

Kip, H. \& Bouman, Y.H.A. (2019). Forensic psychology \& technology. Invited talk at Invitational conference on virtual reality, Pompestichting \& Radboud University. 21 June, Nijmegen.

Kip, H. \& Bouman, Y.H.A. (2019). Technologie in de forensische ggz. Invited workshop on Technology for psychologists \& management team of Transfore. 16 May \& 5 December, Zwolle \& Deventer.

Kip, H. \& Bouman, Y.H.A. (2019). Participatory development of virtual reality for forensic mental healthcare. Invited talk, at the Virtual Reality Mental Health Lab of University Medical Centre Groningen (UMCG). 3 May, Groningen.

Kip, H. (2019). Virtual reality in de praktijk: ervaringen en ideeën. Invited talk in Werkatelier Technologie in de kliniek: VR \& Robotica, Dimence Groep. 9 April, Deventer. 
Weerink, K. \& Kip, H. (2019). De verpleegkundige in de forensische zorg van de toekomst. Guest lecture at Saxion University of Applied Sciences, 1 April, Deventer.

Kip, H. (2019). Minddistrict in de behandeling. De rol van de behandelaar, cliënt, technologie en organisatie. Invited talk in Werkatelier Technologie in de kliniek: Compassievolle technologie, Dimence Groep. 12 February, Deventer.

Kip, H. \& Weerink, K (2018). Virtual reality in de forensische zorg: welke kansen zie jij? Invited talk at Transfore Draait Door University (TDDU). November 22, Zwolle.

Kip, H. (2018). Virtual reality. Toepassingsmogelijkheden voor de forensische patiënt. Invited talk at symposium Reclassering Overijssel \& Transfore. 31 October, Deventer.

Kip, H. \& Voorhuis, R. (2018). VooRuit met VR. Invited talk at ICT \& Health conference, 24 January, Utrecht.

Kip, H. \& Sieverink, F (2017). eHealth MOOC. Invited talk at Nictiz. 4 May, Den Haag.

Kip, H. \& Verschuur, J. (2017). Referaat: the Good Lives Model. Invited symposium at Transfore. 11 April, Deventer.

Van Gemert-Pijnen, J.E.W.C., Kip, H. \& Kelders, S.M. (2017). Workshop eHealth. Invited workshop for medical psychologists at Jeroen Bosch Ziekenhuis. 8 February, Den Bosch.

Van Gemert-Pijnen, J.E.W.C., Kip, H. \& Altena, M. (2017). eHealth voor bedrijfs- en verzekeringsartsen. Invited workshop. 9 January, Arnhem

Kip, H. \& Kelders, S.M. (2017). Persuasieve technologie \& eHealth. Invited talk at Research group of Medical Psychology, Radboud UMC. 9 January, Nijmegen.

Kip, H. (2016). Hoe ontwikkel je eHealth met patiënten? Van theorie naar praktijk. Invited talk at Nictiz Symposium at Zorg \& ICT. 27 January, Utrecht. 

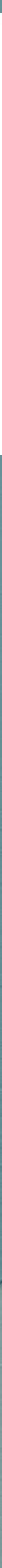
DANIKOORD

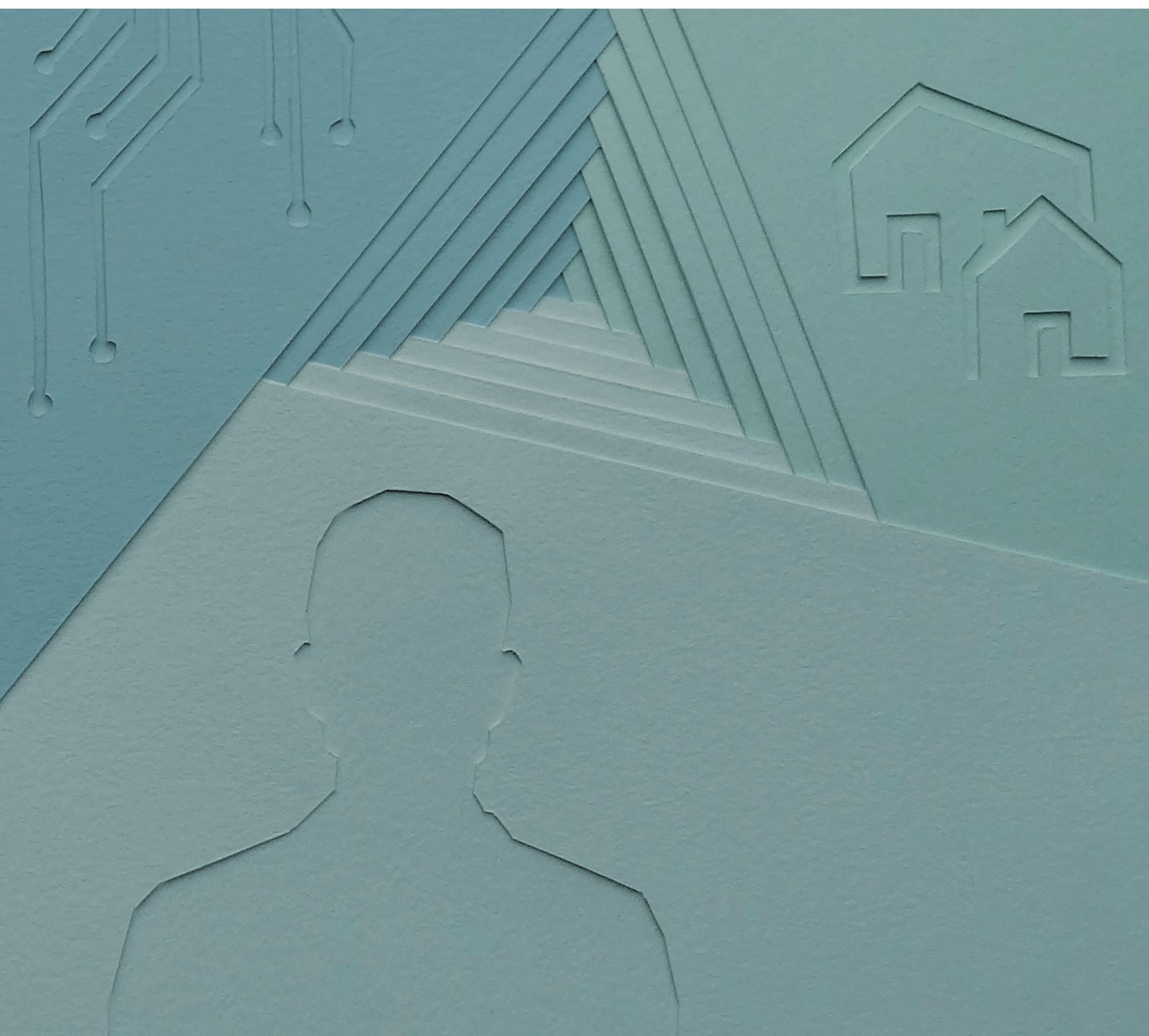




\section{Dankwoord}

Het schrijven van een proefschrift kan behoorlijk ingewikkeld en intimiderend zijn, maar dat is niks in vergelijking met het schrijven van het dankwoord; toch het eerste (en misschien wel het enige) onderdeel van een proefschrift dat gelezen wordt. Nu zijn er veel mensen die ik enorm wil bedanken voor hun hulp tijdens mijn promotietraject, en zoals jullie weten ben ik niet echt kort van stof, dus brace yourselves, mijn dankwoord is coming!

Het begon allemaal vijf jaar geleden, toen Lisette in een overleg met een student en Yvonne en mij tussen neus en lippen door meedeelde dat ik wel bij Transfore zou kunnen promoveren. Met een zeer brede opdrachtomschrijving ben ik het diepe ingesprongen en daar heb ik geen moment spijt van gehad. Ik heb de vrijheid en het vertrouwen gekregen om mijn onderzoek vorm te geven op een manier die goed bij mij paste. De afgelopen tijd heb ik veel nagedacht over wat er voor heeft gezorgd dat ik mijn promotietraject tot een goed einde heb kunnen brengen en er nu daadwerkelijk een proefschrift ligt. Zoals een onderzoeker betaamt kan ik daar natuurlijk geen eenduidig antwoord op geven, want er zijn ontzettend veel factoren die daar aan bij hebben gedragen. Ook al lijk ik wellicht soms wat chaotisch, ik hou van structuur en categorieën, dus dit dankwoord heb ik dan ook gestructureerd op basis van die factoren.

\section{Vertrouwen}

Laat ik beginnen bij de drie mensen zonder wie dit boekje er niet had gelegen: Lisette, Saskia en Yvonne. Hopelijk spreekt het voor zich dat ik jullie voor een ontzettend lange lijst aan dingen wil bedanken, maar met name voor het vertrouwen dat jullie in mij hebben gehad.

Lisette, het is vanzelfsprekend dat ik mijn dankwoord start met jou, want zonder jou hadden de afgelopen zes jaar van mijn leven er heel anders uitgezien. We leerden elkaar natuurlijk kennen bij mijn masterthese, maar laten we dat maar even vergeten en gelijk doorgaan naar de MOOC. Toen ik lang, lang geleden als docent werkte, vroeg je me al snel of ik de coördinatie daarvan op me wilde nemen, volgens mij beide keren tijdens een borrel. Dat was de allereerste keer dat ik echt met je samen ging werken, en dat was nogal een ervaring. Met jou is niks saai; qua proces maar ook qua ideeën. Ik vind je ontzettend creatief, chaotisch, enthousiast en grappig. Ik vergeet nooit meer dat je voorstelde dat Robbert na zijn pensioen maar met kuikens aan de slag zou moeten gaan. Kuikens. Je hebt me ontzettend veel mooie kansen 
gegeven, waaronder natuurlijk dit promotietraject, maar ook het eHealth-boek, de MOOC en de vele cursussen en lezingen die je me al snel toevertrouwde. Je hebt me de vrijheid gegeven die ik nodig had om mezelf verder te ontwikkelen, maar tegelijkertijd wist ik ook dat als er iets aan de hand was, jij er zou zijn om op terug te vallen. Een paar jaar geleden zei je tegen een kerstdiner tegen mij: 'ja maar Hanneke, jij bent nèt zo erg als ik'! Ik weet eerlijk gezegd niet of het zo bedoeld was, maar ik vat het op als een compliment. Ik hoop dat ik mezelf kan ontwikkelen tot een onderzoeker met jouw creativiteit, vermogen om buiten de gebaande paden te denken, betrokkenheid en intense passie voor bitterballen.

Saskia, ik had me geen betere co-promotor kunnen wensen. Ik hoop natuurlijk dat je dat weet, maar ik benadruk het hier nog maar een keer. Je hebt me geleerd om altijd logisch na te blijven denken: niet een ingewikkeld onderzoeksdesign of hippe technologie als uitgangspunt nemen, maar beginnen bij de vraag, bij het doel, bij de toegevoegde waarde. Eén van de leukste dingen van mijn promotietraject vond ik het brainstormen met jou over onze ideeën en visie, of dat nou in de auto onderweg naar Deventer was, tijdens een afspraak met heel veel koekjes of Broodbodebroodjes, of tijdens een enigszins overenthousiaste bierproeverij in Glasgow. Ik ben dan ook erg blij dat we kunnen blijven samenwerken, want er is niemand met wie ik dat liever doe dan met jou. Bedankt voor het vertrouwen dat je in me hebt gehad, al vanaf het begin, en dat ik altijd bij je terecht kon (en kan). Als ik zat met vervelende reviews, twijfels over mezelf of ander gedoe: het hielp altijd om het even bij jou kwijt te kunnen. Ik kan nog wel even doorgaan, maar volgens mij is het punt wel duidelijk: je bent extraordinary!

Yvonne, wellicht is het een open deur (en ja, dat kan ik zeggen, want die heb ik inmiddels): je hebt me ontzettend veel geholpen de afgelopen jaren, misschien nog wel meer dan dat je zelf door hebt gehad. Je hebt me geïnspireerd, me geleerd om verbanden te leggen tussen verschillende velden, me wegwijs gemaakt in de forensische zorg en mijn kritische blik verder aangescherpt. Tijdens al het thuiswerken van dit afgelopen jaar heb ik vaak met heimwee teruggedacht aan de tijden waarin ik nog tegenover je zat en de tientallen, zo niet honderden associaties die zich door de jaren heen gevormd hebben. Je zorgvuldig samengestelde collectie gezonde snacks (worteltjes, radijsjes, maïswafels), enthousiaste anekdotes over je gezin, reizen of fotografie, geïrriteerd gemompel over een stuk met spelfouten, uitgebreide analyses over de beste gin en bijbehorende tonic, dropjes, desk research... Het wortelincident van 2019 zal ik hier maar niet noemen. Yvonne, bedankt voor je enorme betrokkenheid, bedankt voor je oprechtheid, bedankt voor het vertrouwen dat je in 
me hebt, en natuurlijk bedankt voor al je spellingschecks (waarschijnlijk zie je in dit dankwoord ook wel wat kromme zinnen, excuus). Mijn promotietraject was ontzettend leerzaam, maar vooral heel erg leuk, en dat komt voor een groot deel door jou!

Ik wil dit deel over vertrouwen graag afsluiten door mijn enorme dankbaarheid richting Stichting Vrienden van Oldenkotte uit te spreken. Zonder jullie was dit onderzoek niet mogelijk geweest. Hartelijk dank voor jullie interesse en steun voor mijn promotietraject en de bijbehorende onderzoekslijn!

\section{Inspiration}

Of course, inspiration is an essential ingredient for a PhD trajectory. As researchers, we build upon the work of others, and I am very grateful that my committee consists of members whose work has inspired me immensely. Prof. dr. David Mohr, prof. dr. Falko Sniehotta, prof. dr. Geke Ludden, prof. dr. Wim Veling and prof. dr. Stefan Bogaerts: thank you for taking the time and energy to read my thesis! I feel very privileged to be able to defend my thesis for a committee consisting of inspiring researchers with an impressive expertise on topics that drive my research, such as forensic psychiatry, behaviour change, human centred-design, development and evaluation of behavioural intervention technologies, and the possibilities of technology to change the way we look at health(care). I am very grateful for your time and effort.

\section{Collegialiteit}

Tijdens mijn promotieonderzoek heb ik het voorrecht gehad om in meerdere erg leuke teams te werken en van elk team weer iets te leren. Ondanks de verschillen is het overkoepelende thema bij alle teams waar ik mee heb mogen werken collegialiteit. Elkaar ondersteunen, geïnteresseerd zijn in elkaar en het ook vooral heel gezellig hebben samen.

Laat ik beginnen met het Persuasive Lab en bijbehorende eHealth overleg die continu aan het uitdijen zijn, wat volgens mij wel aantoont dat we goed bezig zijn met z'n allen. Jobke, Iris, Christian, Roberto, Britt, Annemieke, Judith, Noortje, Charlotte, Aniek, Britt, Annemarie, Manon, Rikke, Sofia, Nienke, Nadine, Saskia, Julia en Lisette: bedankt voor de gezellige borrels en etentjes, de (meestal) inspirerende overleggen, de leuke congressen en toffe projecten waar we mee bezig waren of zijn. And Roberto, since I'm not the senior PhD anymore, I presume that you'll take that title from now on? Ik kijk uit naar de komende jaren waarin we ons Lab verder op gaan 
bouwen en de hopelijk vele projecten waar we samen aan gaan werken! Daarnaast zijn er natuurlijk nog veel andere UT-collega's met wie ik de afgelopen jaren heb samengewerkt en waar ik veel van heb geleerd. Ik wil graag mijn PHT-collega's bedanken, onder andere Matthijs, Robbert, Peter, Stans, Tessa, Jorinde, Teuntje, Christina, Erik, Marcel en Gerben. Ernst, bedankt voor je vertrouwen, ik kijk er naar uit om de komende jaren het cluster verder op te bouwen, samen met Iris, (blonde) Hanneke en Nadine. Een speciaal bedankje voor Daniëlle, Talitha en Marieke: bedankt voor al jullie onmisbare hulp bij alles wat er komt kijken bij promoveren! Mijn promotieperiode bestond zeker niet alleen uit onderzoek, maar ook uit onderwijs. Daarom wil ik ook graag mijn onderwijscollega's bedanken voor alles wat ze me de afgelopen jaren hebben geleerd. Suzanne, Jenny, Janneke, Zwenny, Nienke, Nils, Manon, Joleen en Laura, bedankt! Het is niet voor niks dat ik al bijna zeven jaar (!) op de UT werk: ik voel me er thuis, kan er mezelf zijn, leer ontzettend veel en kan samenwerken met de leukste collega's!

Eén van de aller-, allerleukste aspecten van mijn promotie was zonder twijfel de samenwerking met Transfore. Niet alleen omdat ik de combinatie tussen onderzoek en praktijk ontzettend als waardevol heb ervaren, maar ook doordat ik me er ontzettend thuis voel. Mijn inmiddels 'echte' collega's van het directiebureau, Maaike, Dirk, Linda, Yvonne, Elles, Frank, Joanne, Sabine, Pascalle, Wim, Wendy, Tinie, Rian, Rita, Martin, Lisa, Tahnee en natuurlijk Hanneke Hermkens: bedankt voor de gezellige lunchpauzes, alle flauwe grappen, de (digitale) koffiepauzes en borrels, en alle interesse in en hulp bij mijn onderzoek! Dirk, ik wil jou nog even extra bedanken. We hebben veel samengewerkt: het begon allemaal met VooRuit met VR, en daarna ook meerdere KFZ-projecten, TDDU University, en natuurlijk het organiseren van het paaseieren zoeken en rondbrengen van de tulpen. Ik werk graag met je samen door je enthousiasme, je kritische blik, je doortastendheid, je deur die altijd openstaat en helaas ook je slechte grappen. Tinie en Rian, ik ben ontzettend blij dat jullie me de kans hebben gegeven om ook na mijn promotie bij Transfore te blijven werken. Ik heb er zin in!

\section{Een veilige bubbel}

Lieve werkdumpers, ik heb jullie allemaal al in andere categorieën genoemd, maar ik wil jullie ook apart bedanken omdat jullie allemaal ontzettend belangrijk voor me zijn. Mensen hebben soms het idee dat de wetenschappelijke wereld keihard en competitief is, maar uiteindelijk valt dat best mee, vooral als je het geluk hebt om een 
bubbel te kunnen vormen met een paar collega's hebt waar je altijd op kan bouwen.

Nienke, mijn recente brilbuddy, mijn 'we vinden dezelfde mensen irritant'buddy, mijn kaasbuddy, mijn 'ik verveel me, nu ga ik tegen je aanpraten'-buddy, mijn woordgrap-buddy... Je bent ook gewoon een goede buddy, want je staat altijd onvoorwaardelijk voor mensen klaar. Je wil altijd even meekijken, meedenken, meeleven, meepraten, ook al ben je stiekem eigenlijk te druk. Ik vind dat de mooiste eigenschap die een collega (en paranimf) kan hebben. Ontzettend supermegabedankt voor al je hulp, je bent awesome! (Ik weet niet waarom, maar als ik het nu teruglees klinkt het sarcastisch. Maar ik meen het echt!) En hierbij je toegezegde extra zin.

Julia Keizer. Wat was het leven toch een stuk minder leuk geweest zonder Flarco Florsato, onze chipszak, Herman de rat en natuurlijk Suzan \& Freek. Met heimwee denk ik terug aan alle vrijdagmiddagen; och, wat hebben we hard gewerkt en elkaar eindeloos geïnspireerd. Eén van de grootste nadelen van het thuiswerken het afgelopen jaar was dat ik niet even over mijn scherm kon kijken en een eye roll met je kon delen. Als kamergenoten waren we een goede match, met name door je talent om ondanks mijn geratel toch door te blijven werken. Ik vind het ontzettend tof dat we vanaf het begin van onze promoties tegenover elkaar hebben gezeten en dat je nu ook mijn paranimf bent. Bedankt dat je het met me vol hebt gehouden!

Nadine. Er zijn wel tienduizend dingen waar ik je voor kan en wil bedanken, maar ik wil vooral nogmaals benadrukken hoe ontzettend fijn, tof, leuk en inspirerend het is om samen met jou onderwijs te geven en ontwikkelen! Waar ik soms wat all over the place kan zijn, heb jij altijd de structuur in je hoofd en kun je dat ook nog eens combineren met creativiteit en het uitproberen van nieuwe dingen. Bedankt dat je de afgelopen jaren altijd voor me hebt klaargestaan: om te brainstormen over nieuwe vakken, om mijn gezeur aan te horen, om lekkere biertjes uit te zoeken, om me te helpen met de opmaak van mijn proefschrift (FLOEPJES!!!!), om krabben te vangen, of natuurlijk om Broodbode te eten.

Saskia, onze supreme leader. De verstandigste hen in ons kippenhok. Er zijn maar weinig mensen waarbij je denkt: 'oh, die bemoeit zich er mee, dan komt het wel goed'. Voor mij ben jij daar het beste voorbeeld van. Ik vind dat jij bent wat elke wetenschapper zou moeten zijn: niet alleen ontzettend goed in wat je doet, maar ook altijd behulpzaam en betrokken. Even meelezen met een tekst, mensen uitnodigen om met jouw papers mee te schrijven, meedenken over een aanvraag, vechten voor contracten, altijd een luisterend oor bieden en ook regelmatig even vragen hoe het gaat. 
Ik ben echt on-Achterhoeks trots op hoe we 't gedaan hebben met zijn allen de afgelopen jaren, ik ben trots op waar we voor staan en ik ben ook alvast trots op alle toffe dingen die we de komende jaren gaan doen. GO TEAM!

\section{Samenwerking}

Het is een cliché dat in elk dankwoord naar voren komt, maar dat is het niet voor niets: promoveren doe je niet alleen. Ik heb het voorrecht gehad om tijdens mijn promotie met veel verschillende mensen en organisaties samen te werken. Ik heb daar ontzettend veel van geleerd en heb me in de loop der jaren steeds meer gerealiseerd dat interdisciplinariteit niet alleen een voordeel, maar essentieel is om verder te komen.

Het belang van het betrekken van verschillende perspectieven is me vooral duidelijk geworden dankzij het VooRuit met VR-project. Wat ben ik ontzettend blij dat dit aan het begin van mijn promotietraject op mijn pad is gekomen! Ik ben ons VooRuit met VR-team ontzettend dankbaar voor alle inzet, enthousiasme en creativiteit: Ron, Jakob, Anne Marike, Fleur, Kirby, Kevin, Anke, Yvonne, Dirk, Marileen, Bas en Joan, samenwerken met jullie is een feestje! Bedankt voor de inspiratie, taart en gezellige overleggen. Wat een mazzel dat ik de komende tijd, samen met Marileen, door kan gaan met dit onderzoek! Ook wil ik natuurlijk CleVR bedanken, in het speciaal Guntur, Freek Jan en Yorick, voor de manier waarop jullie met ons meedenken, voor jullie flexibiliteit en geduld, en natuurlijk voor het ontzettend toffe product waar we mee bezig zijn!

Ik heb mijn onderzoek met name uitgevoerd binnen Transfore en de Dimence Groep. Ik ben zeker niet alleen gaan promoveren voor dit boekje, maar vooral om het gevoel te krijgen dat ik zo af en toe iets nuttigs bijdraag, hoe klein ook. Zonder de betrokkenheid van heel veel mensen was dat niet mogelijk geweest. Ten eerste wil ik mijn dank uitspreken naar alle medewerkers van Transfore en de Dimence Groep voor hun hulp de afgelopen jaren, bijvoorbeeld door te helpen met het organiseren van onderzoeken (Daphne, daar wil ik jou in het speciaal voor bedanken!), het invullen van vragenlijsten, het meedoen aan interviews of focusgroepen of brainstormen over zinvolle toepassingen van technologie. Ook mijn DG Connected collega's zijn onmisbaar voor zinvol onderzoek: Gillian, Sabine en Kirsten, wat zijn we met toffe dingen bezig, ik hoop dat we dat de komende jaren nog verder uit kunnen gaan bouwen! Ten slotte mijn enorme waardering voor alle patiënten van Transfore die enthousiast mee hebben gedacht en deel hebben genomen aan interviews, vragenlijsten en focusgroepen. Hoe waardevol dat was kan 
ik het beste illustreren met het antwoord van een patiënt op de vraag waar we VR in de forensische zorg voor kunnen gebruiken: "Ik heb ontwikkelingslanden opgeschreven." "Ontwikkelingslanden?" "Ja! Om te laten zien dat wij het hier zo slecht nog niet hebben!"

Ten slotte heb ik de afgelopen jaren mogen samenwerken met veel getalenteerde en enthousiaste onderzoekers. Een belangrijk 'zijspoor' van mijn promotietraject was het Crossing borders project, waarin we in een vrij omvangrijk rapport onze visie op de huidige stand van zaken en toekomst van technologie in de forensische zorg hebben mogen opschrijven. Joyce, Kira, Dirk, Bianca, Saskia en natuurlijk het $\mathrm{Ed}$ en $\mathrm{KFZ}$, dank voor dit leuke en zinvolle project! Floor, oudkamergenootje, we hebben aan veel leuke projecten gewerkt, zoals de MOOC, de log data analyse, health sciences onderwijs, en de lijst is nog een heel stuk langer. Jobke, bedankt voor je gezelligheid en de leuke samenwerking in het blended care project en natuurlijk bij Saxion! Marcia, obrigada for all of your valuable help throughout the years! Tessa, het onderzoek waar we mee bezig zijn is officieel geen onderdeel van dit boekje, maar hangt er wel nauw mee samen, dus ik ben erg blij dat we hier de komende jaren samen mee aan de slag kunnen. Daarnaast wil ik mijn FoReTech collega's van het ErasmusMC, Frank, Pascalle en Sabine, de bedanken voor de leuke brainstormsessies en prettige samenwerking. Op naar een nieuw project over prikkelverwerking en technologie! Deze lange categorie over samenwerken eindig ik met mijn studenten die in de loop der jaren ontzettend veel aan dit onderzoek hebben bijgedragen: Kirby, Ankie, Ines, Karen, Nathalie, Alper, Marcia, Niels, Dennis, een ontzettend speciaal bedankje voor jullie inzet en hulp!

\section{Afleiding}

Dan gaan we nu door naar de volgende categorie: voldoende afleiding. Onderzoek is leuk, maar ik heb de afgelopen jaren geleerd dat ik het af en toe ook even helemaal moet vergeten en los moet laten, zodat ik daarna weer met een frisse blik en een opgeladen batterij aan de slag kan. Ik heb het geluk dat ik de allerleukste vrienden heb die me daar ontzettend goed bij hebben geholpen! Tijdens dit afgelopen lockdown-jaar heb ik nog maar eens goed gemerkt hoe onmisbaar jullie zijn. Een speciale shout-out naar Kap'tein Evert (Paddy's! Hans, wat ben je aan het doen?), Sarina en Kevin (Karaoke! The Passion! Songfestival!), Anoukie (Paal! Aiaiaiaiai!), Suzanne (Mini-biertjes! Pizza Boscaiola! Hamsters!), Maud, Dennis, Karlo en Jorn (Feestjes ohne ende), Eline en Bas (Rosé! Hoepelen!), en Koen en Jip (Temptation, shhhhh!). En natuurlijk mijn allerliefste Lollipops: lieve Sil, Jojob, Arie, Myr, Jenn en 
ler, en natuurlijk onze trouwe aanhang, Pieter, Bas, Dave, Martijn, Thomas en Toinne: wat heb ik een mazzel dat jullie er zijn! Ik vind het ontzettend speciaal hoe jullie met me meeleven, en ik met jullie, al bijna 20 jaar lang. Van Terschelling naar Porto, van i’Varca naar Club Plava, van verjaardagen met El Picu naar bruiloften met goede wijn, van professor Slimmik naar een promotie. Wat mis ik alle etentjes, borrels, feestjes en weekendjes weg. Mijn leven zou echt zo ontzettend veel minder leuk zijn zonder jullie!

\section{Veerkracht}

Lieve Wietse, Anke, Kees en kleine Sammie. We hebben de afgelopen jaren veel mooie momenten gedeeld, maar ook veel te veel verdrietige. Van jullie heb ik geleerd wat veerkracht inhoudt, en dat er zelfs op de donkerste momenten lichtpuntjes zijn, ook al is het soms even zoeken. Ik ben blij dat ik onderdeel mag zijn van jullie familie. Bedankt voor jullie steun en interesse de afgelopen jaren! Jan Willem, ik koester warme herinneringen aan de vele door jou zorgvuldig uitgedachte wandelingen, waar je altijd naast me kwam lopen om te vragen hoe het ging met mijn onderzoek en natuurlijk ook het onderwijs. Dankjewel, ik wou dat je erbij was geweest.

\section{Een goede basis}

Zonder een goede basis had dit proefschrift er niet gelegen. Pap en mam, daar heb ik jullie $100 \%$ voor te danken. Al sinds ik als klein meisje schrijfster wilde worden hebben jullie me geholpen: eerst met het opschrijven mijn vrij uitgebreide verhalen in boekjes over onder andere Frety de meikever, en daarna, toen ik zelf kon schrijven, hebben jullie altijd de tijd genomen om alles te lezen. Ik kan altijd bij jullie terecht: om gewoon even te relaxen en niks te doen, om kleren te repareren, om samen (veel te) uitgebreid te eten, of om even stoom af te blazen. Jullie hebben altijd onvoorwaardelijk vertrouwen in me gehad en me ondersteund in alle keuzes die ik heb gemaakt. En kijk, het heeft gewerkt, er ligt nu een echt boek! Het is dan wel iets minder spannend dan 'Alleen in het oerwoud', maar toch. Bedankt voor alles wat jullie voor me hebben gedaan en nog steeds doen. Bedankt dat jullie nog steeds mijn thuis zijn.

Martin en Jochem, ik denk dat er maar weinig mensen die zo verbaasd (maar hopelijk ook zo trots) zijn dat dit proefschrift er ligt. Bij deze dan ook zwart op wit het verzoek om me met dr. Kip te adresseren, in plaats met één van jullie bijnamen voor me, die ik hier maar niet zal noemen. Maar zonder gein, ik vind het ontzettend tof hoe jullie met me meeleven en er altijd voor me zijn. Als ik een lijst zou moeten maken 
van de allerleukste dingen van de afgelopen jaren staan de vele bierproeverijen met jullie en natuurlijk Silke daar zonder twijfel in. Ik had me geen leukere, lompere en lievere broertjes kunnen wensen. Omdat de balans nu iets te veel naar aardig doorschiet en we daar allemaal niet zo goed mee om kunnen gaan komen hier even wat compenserende beledigingen: Martin, je had vroeger een rare hoge stem en Jochem, je bent een nerd.

Naast mijn ouders en broertjes zijn er natuurlijk nog veel meer familieleden die ik graag wil bedanken. Silke, je bent een ontzettend toffe schoonzus! Ik drink met niemand liever een fles wijn met een vogel er op. Ik wil ook mijn familie bedanken die altijd geïnteresseerd is en met me mee heeft geleefd, onder andere tante Annie, oom Henk, Lianne, Inge, Rick, oom Bert, tante Margreet, oom Gerrit en tante Gretha. We hebben elkaar helaas al lang niet kunnen zien en ik vind het erg jammer dat jullie niet in het echt bij de verdediging kunnen zijn. Hopelijk zien we elkaar snel weer! En mijn lieve oma Wiggers: ja, Hannemans studie is nu eindelijk af. Je oorbellen doe ik de $26^{e}$ in, dan ben je er ook een beetje bij.

\section{Thuisfront}

Bijna elk dankwoord eindigt met het thuisfront en dat is niet voor niks. Zonder een fijn thuis, een plek waar je je op je gemak voelt, waar je altijd jezelf kan zijn, is het niet mogelijk om de ruimte in je hoofd te maken die nodig is om na te denken en te schrijven. Een thuis is natuurlijk meer dan een huis, het bestaat uit mensen. En dieren. Ik heb even getwijfeld of ik mijn katten, Vuurdraak en Mufasa, zou noemen. Toen bedacht ik me dat iedereen die me een beetje kent me toch al een crazy cat lady vindt, dus ach, wat heb ik te verliezen? (Daarnaast zei Nienke dat het kon.) Ik heb tijdens dit thuiswerk-jaar geleerd dat het aaien van katten een uiterst effectieve manier is om mijn wespennest-hoofd wat rustiger te maken, vooral tijdens het afronden van een proefschrift tijdens een hittegolf. Ik kan iedereen aanraden om minimaal twee katten in huis te hebben! Het zijn verrassend goede gesprekspartners.

Ik ben dit dankwoord begonnen met mensen zonder wie dit boekje er niet had gelegen, en ik wil ook eindigen met iemand onmisbaar is. Bas Jan, je weet dat het lastig voor me is om zonder sarcasme uit te drukken hoe belangrijk je voor me bent, maar ik doe toch een poging. Ik heb lang nagedacht over wat ik hier neer wil zetten. lets over het engelengeduld dat je hebt moeten opbrengen om weer naar één van mijn veel te lange verhalen te luisteren. Of misschien wel iets over hoe fijn ik het vond om samen te brainstormen over wat zelfcontrole is, of hoe agile en onderzoek met elkaar te combineren zijn. Of dat je voor me kookte als het even te druk was in mijn 
hoofd. Maar ik kwam er op uit dat het eigenlijk vrij simpel is: ik ben zo geweldig ontzettend megablij dat je in mijn leven bent, je bent mijn allerbeste maatje, ik kijk uit naar alle avonturen die we samen nog gaan beleven en ik hou van je. Net zoveel als jij van blauw-wit gestreepte truien houdt (sorry, dat moest).

\section{Weet wanneer je moet stoppen}

De laatste categorie: weten wanneer je moet stoppen. Op een gegeven moment zijn er genoeg papers geschreven, is het maximaal aantal woorden gebruikt, is een idee 'klaar' genoeg, en is het tijd om af te ronden. Ik ben dan ook aangekomen bij het einde van mijn dankwoord en mijn proefschrift. Wat had ik jullie graag allemaal in het echt bedankt, om nogmaals te benadrukken hoe blij ik ben met al het vertrouwen, de inspiratie, de veilige bubbels, de samenwerking, de collegialiteit en de afleiding die ik de afgelopen jaren heb mogen ontvangen. Het was mijn grote droomwens om een enorm feest voor jullie te geven zodat ik mijn dank op de manier die het beste bij mij past uit had kunnen drukken. Helaas laat de huidige situatie dat niet toe, maar hierbij beloof ik plechtig dat, als het weer kan, ik jullie allemaal ga trakteren op een goed glas wijn, een lekker speciaalbiertje (minimaal 3.75 op Untapped) of een goede kop koffie. Voor Yvonne natuurlijk een gin tonic, voor Lisette wijn mèt bitterballen, en Saskia, wellicht nog een keer een bierproeverij?

Dan wil ik nu graag mijn proefschrift, het product van vele jaren noeste arbeid en de kroon op mijn werk, eindigen met een wijze uitspraak die erg typerend voor mij is:

MAND! 
"The most important step a man can take. It's not the first one, is it? It's the next one. Always the next step."

Brandon Sanderson, Oathbringer 
While technology is considered to have many potential benefits for forensic mental healthcare, it is not yet clear how, why and for whom eHealth interventions can be of added value in this unique context. To answer these questions, this thesis is focused on the holistic development, implementation and evaluation of different types of technologies that can be used for treatment of forensic psychiatric patients. In this thesis' first part, the current state of affairs of technology in treatment of offenders is analysed, with a specific emphasis on the implementation of existing web-based interventions. The second part focuses on a participatory development approach for a novel type of eHealth intervention. This iterative development process resulted in an interactive, personalized VR application to identify and treat triggers for delinquent behaviour. Finally, the third part of this thesis investigates the possibilities of another type of technology - a persuasive mobile app - to strengthen self-control, an important predictor of crime. This new self-control training app was evaluated by means of a mixed-methods approach. The main conclusion of this thesis is that in order for eHealth to be of added value, adaptivity is key: the technology, the people involved, and the context in which it is used, but also the development, implementation and evaluation processes all have to be adaptive and flexible. 